Dissertation zur Erlangung des Doktorgrades

der Fakultät für Chemie und Pharmazie

der Ludwig-Maximilians-Universität München

\title{
Powder Suspensions in
}

\section{Non-aqueous Vehicles for Delivery}

\section{of Therapeutic Proteins}

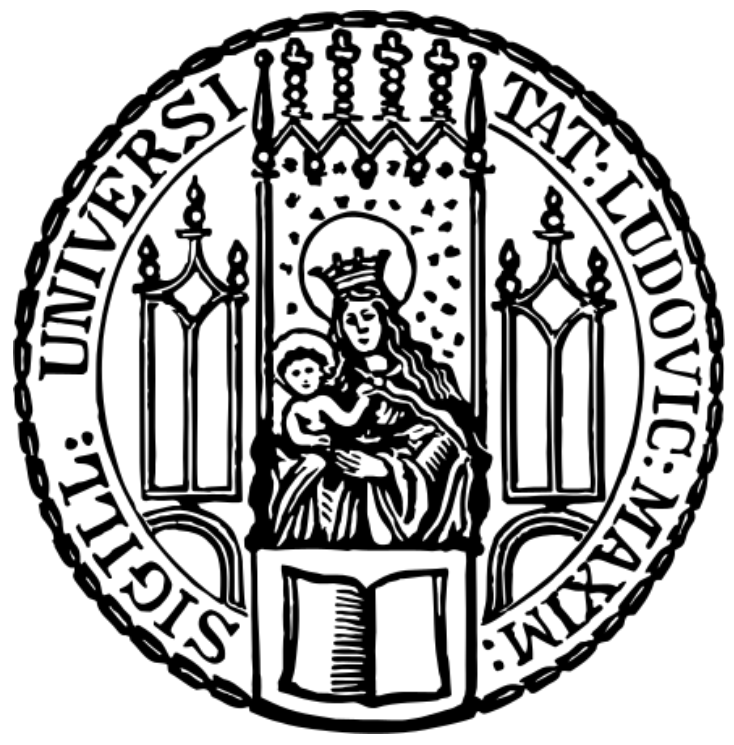

\section{Christoph Marschall}

aus Backnang, Deutschland 


\section{Erklärung}

Diese Dissertation wurde im Sinne von $\S 7$ der Promotionsordnung vom 28. November 2011 von Herrn Prof. Dr. Wolfgang Frieß von der Fakultät Chemie und Pharmazie betreut.

\section{Eidesstattliche Versicherung}

Diese Dissertation wurde eigenständig und ohne unerlaubte Hilfe erarbeitet.

Stuttgart den 27. Oktober 2019

Christoph Marschall

Dissertation eingereicht am: 8. November 2019

1. Gutachter: Prof. Dr. Wolfgang Frieß

2. Gutachter: Prof. Dr. Gerhard Winter

Mündliche Prüfung am: 4. Dezember 2019 
Für meine Eltern 


\section{Acknowledgements}

The present thesis was prepared between March 2015 and October 2018 at the LudwigMaximilians-Universität Munich in the Department of Pharmacy, Pharmaceutical Technology under the supervision of Prof. Dr. Wolfgang Frieß.

First of all, I would like to express my sincere gratitude and profound respect to Professor Wolfgang Frieß for offering me the opportunity to be part of his exceptional research group. It was an honour to experience his outstanding encouraging and challenging attitude, his mentorship, as well as his guidance and support. His broad scientific input, deep knowledge and his mentoring were of essential importance for the whole project.

Furthermore, I would like to thank Professor Gerhard Winter not only for co-referee the thesis and for his scientific input, but also for the pleasant conversations during extracurricular activities. It was always highly exciting to observe his interest and innovative approach to work on the cutting edge of pharmaceutical research.

I would also like to thank Gerhard Simon, Sabine Kohler and Professor Olivia Merkel for their continuous support regarding a broad range of different topics. It was further always a great and collaborative time in the AFL lab course together with Regine, Ayla, Susanne and Alexandra. The help of Christian Minke with the scanning electron microscopy investigations is highly appreciated.

Novaliq GmbH \& Co. KG is highly acknowledged for funding and promoting the project. In particular I want to thank Gesche, Bernhard and Madlen for their guidance and scientific input and the welcoming atmosphere during my stays in Heidelberg. Special thanks also go to Mikhail and Julia for their scientific support and to Markus for the interesting intellectual property related discussions.

Moreover, I had the chance to work together with various outstanding students, which all gave valuable input to this thesis. Anna, Kai, Magdalena and Stephanie it was a great pleasure to work with you in a team.

I want to say thanks to my awesome colleagues at the university for their support, scientific discussions and the fantastic time spend at the university, on conferences and during group excursions. Without them it would not have been possible to achieve what was achieved in this thesis. Especially the time in my lab, the "Damensauna", spent together with Kay, Yordanka, Inas, Fabian and Olli, was amazing and shaped my personal growth. I also highly 
appreciate the numerous information and inputs regarding scientific practice and methods, which I received from my colleagues who were always ready to help. Many thanks to the colleagues in the pharmaceutical technology group, including Corinna, Jacqueline, Ellen, Kerstin, Christoph, Bifeng, Stefanie, Eduard, Natalie, Robina, Ivonne, Imke, Michaela, Andreas S., Andreas T., Hristo, Laura, Julian, Teresa, Simon, Aline, Weiwei, Bernard, Dennis, Moritz, Ute, Lorenz, Natascha, Rima, Aditi and Tobias.

My infinite thanks are owed to my parents, my brother Stephan, my sister Eva, my grandparents, my family and long-standing friends for their continuous and unconditional support. Last but not least, my biggest debt of gratitude goes to Haitong for always motivate and strengthen me in difficult situations, for encouraging me, for her patience, for never letting me down and for together get through four years of long-distance relationship. 


\section{Table of content}

\section{Chapter I}

Introduction

\section{Chapter II}

Objectives and outline of the thesis.

39

\section{Chapter III}

Preparation of highly concentrated protein powder suspensions by wet media and cryogenic milling of lyophilizates.

\section{Chapter IV}

Protein powder suspensions - formulation performance at high concentration

\section{Chapter V}

Long-term stability of protein powder suspensions in non-aqueous vehicles part I - suspension physical stability

\section{Chapter VI}

Long-term stability of protein powder suspensions in non-aqueous vehicles part II monoclonal antibody stability

\section{Chapter VII}

Optimized formulations for topical ocular protein delivery based on protein powder dispersions in non-aqueous vehicles

\section{Chapter VIII}

Summary of the thesis. 


\section{Chapter I}

\section{Introduction}

\section{Abstract}

Formulating biopharmaceuticals is a challenging task due to their complex and sensitive nature. Protein drugs are typically marketed either as an aqueous solution or as a lyophilizate. Usually aqueous solutions are preferred as neither drying nor reconstitution are required. But it may be unfeasible if the protein features low stability. An interesting alternative to avoid at least reconstitution are protein powder suspensions in non-aqueous vehicles. Such formulations combine the ready-to-use approach with the high protein stability in the solid state. Additionally, protein powder suspensions offer a potentially lower viscosity compared to aqueous solutions at high protein concentrations. Besides injection, other application routes might also benefit from the protein powder approach such as topical or inhalational delivery.

Protein powders, which can be dispersed in the non-aqueous suspension vehicle, are usually prepared by spray-drying or freeze-drying with an additional milling step, but other techniques have also been described in literature. An ideal powder preparation technique results in minimum protein damage and yields particle sizes in the lower micrometre range and homogeneous particle size distribution enabling subcutaneous or intramuscular injection through hypodermic needles.

As suspension vehicles traditional non-aqueous injectable liquids, such as plant oils, may be selected. But they show an inherent high viscosity, which can lead to unacceptable glide forces during injection. Furthermore, the vehicle should provide high product stability with respect to protein integrity and suspension resuspendability.

The introduction will describe previous research on how proteins can be formulated as protein powder suspensions in non-aqueous vehicles for subcutaneous injection including potential vehicles, protein powder preparation techniques, protein and suspension physical stability, as well as the use in the field of high concentration protein formulations. 


\section{Introduction}

\subsection{Challenges and current trends in formulation of biopharmaceuticals}

An end of the extreme success of protein pharmaceuticals, which is ongoing over the last two decades, is not in sight. Over the last five years, approximately 20 products of this class gained approval by the European Medicine Agency (EMA) each year. ${ }^{1}$ Compared to small molecule drugs, biopharmaceuticals can address additional therapeutic targets and are thus a valuable addition for the treatment of severe diseases such as cancer and autoimmune disorders. ${ }^{2}$ Based on their mode of action, therapeutic proteins can be classified in different categories including the three major categories: enzymes, receptor modulators (hormones) and monoclonal antibodies (mAbs). ${ }^{2}$ MAbs are currently the largest class of protein therapeutics and consistently achieve highest sales of the whole pharmaceutical sector. ${ }^{1,3}$

Therapeutic proteins show very poor oral bioavailability, due to their high sensitivity towards an acidic environment and gastric enzymes such as peptidases and proteases, as well as their poor epithelial permeability. ${ }^{4-6}$ As a consequence, proteins are almost exclusively administered intravenously or by subcutaneous and intramuscular injections. ${ }^{6,7}$ Approved and currently marketed exceptions are intended for local therapy and consist of e.g. dornase alfa (inhalational), pancreatic enzymes (oral) and nerve growth factor (eye drops).

On a molecular level, proteins are characterized by their primary (sequence of the single amino acids), secondary (spatial arrangement of neighbouring amino acids, including alphahelices, beta-sheets and random coils), tertiary (folding of the secondary in a three dimensional structure) and in some cases quaternary structure (interaction of monomer subunits). ${ }^{7}$ The complete structure of the protein is stabilized by covalent, including peptide and disulphide bonds, as well as non-covalent bonds such as ionic interactions, hydrogen bonds, hydrophobic interactions and van der Waals forces. ${ }^{8}$

During manufacturing and storage, chemical and physical instabilities of the protein can occur. ${ }^{8,9}$ These instabilities have to be prevented, as they cannot only lead to loss of the therapeutic function of the protein, but might also lead to undesired immunogenic reactions of the patient. ${ }^{8,10,11}$ Chemical degradation pathways incorporate a wide range of different reactions such as deamidation, hydrolysis, oxidation, disulphide bond breakage/formation or racemization. ${ }^{8,11}$ Physical instability of proteins includes conformational instabilities and aggregation of protein monomers. ${ }^{8,11}$ Aggregation is a common challenge for protein therapeutics and is often induced by shear and interface stresses (air, silicone oil, tube wall, 
etc.) occurring during manufacturing, transportation and storage (freezing/thawing, pumping, filling, shaking)..$^{8,12,13}$

If a liquid aqueous formulation is not feasible, freeze-drying is the preferred option to provide stable protein formulations. ${ }^{14-16}$ Of the 264 therapeutic proteins approved by the EMA from 1995 to $2018,34 \%$ are lyophilized products. ${ }^{1}$ The protein integrity during the process and upon storage is preserved by lyo- and cryoprotectants, preferably by carbohydrates such as sucrose or trehalose. ${ }^{16,17}$ After drying the protein is embedded in an amorphous stabilizer matrix, minimizing aggregation and chemical degradation kinetics. ${ }^{17}$ An important disadvantage of lyophilizates is the necessity of an additional reconstitution step making the application more time consuming and complex and thus increasing the risk of contamination and dosing errors.

\subsection{High concentration protein formulations}

A hot topic and challenge in the field of protein formulation are high concentration formulations of more than $100 \mathrm{mg} / \mathrm{ml}$ protein. ${ }^{18-20}$ Especially for mAbs, often several milligrams per dose are needed. ${ }^{19,20}$ This gets even more challenging with the rising popularity of outpatient treatment by subcutaneous (s.c.) or intramuscular (i.m.) injections, which is the desired route for delivery of protein drugs for chronic diseases. The s.c. and i.m. route of administration exhibit a volume restriction (patient und injection time related), which, combined with high mAb doses, calls for high concentration formulations. ${ }^{19,20}$ Such formulations are usually provided in prefilled syringes and autoinjectors, as they enable administration of the drug by the patient himself. ${ }^{18,20}$ Challenges of the highly concentrated aqueous formulations are an increased viscosity and decreased protein stability. ${ }^{19,21,22}$

\subsection{Protein powder suspensions - a potential alternative to conventional formulations} Protein powder suspensions in non-aqueous vehicles offer a promising alternative to conventional formulations of biopharmaceuticals with several valuable advantages. Protein powder suspensions consist of microparticles, compromising the therapeutic protein, dispersed in a non-aqueous liquid. Figure I-1 illustrates the simplified basic ground operations to yield such formulations. 


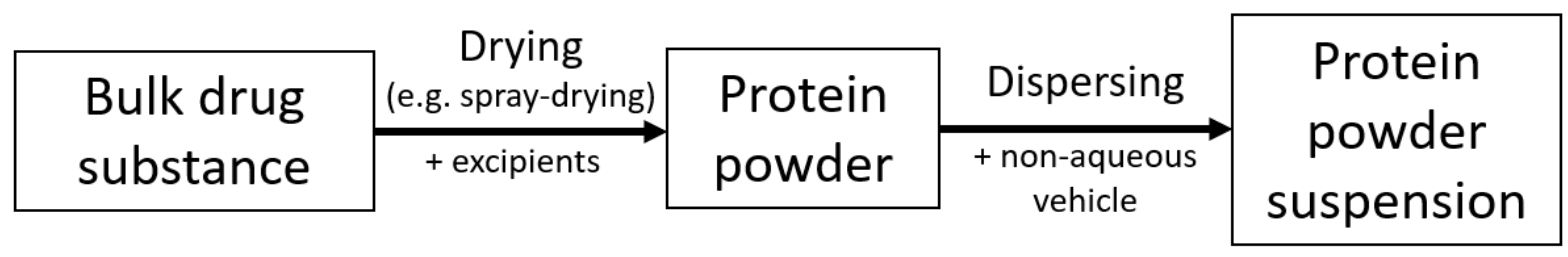

Figure I-1: Simplified basic ground operations to manufacture protein powder suspensions in non-aqueous vehicles.

A distinction must be made between protein powder suspensions in non-aqueous vehicles for sustained release versus suspensions which deliver the therapeutic protein in a comparable pharmacokinetic manner as an aqueous solution (protein powder for subcutaneous application). Chen et al. were the first who described the use of the protein powder suspension approach for mAbs and conducted pharmacokinetic studies in cynomolgus monkeys. ${ }^{23}$ No differences in the plasma profiles were detected between a protein powder suspension in benzyl benzoate and an aqueous solution of an Anti-IL-12p40 mAb after s.c. injection. ${ }^{23}$ There is no clear line separating the sustained release with non-sustained release formulation techniques, but it is clear, that existing know-how can be transferred from one to the other. In general, formulations for sustained release are prepared in highly viscous vehicles and may additionally contain release modifying excipients. ${ }^{24}$ Due to the high viscosity of the formulations, they have to be injected through needles with large diameters (e.g. 18G needle) or need to be provided through delivery devices (e.g. osmotic pumps). ${ }^{25}$ In contrast, protein powders for subcutaneous application are formulated in vehicles with low viscosity enabling injection through thin hypodermic needles such as 26 or $27 \mathrm{G}$ needles. ${ }^{26}$

The focus of the introduction mainly lies on the protein powder suspensions for subcutaneous administration which do not provide a distinct sustained release behaviour. Nonetheless sustained release formulations will be discussed in section 7 .

Another interesting approach is local topical protein delivery, which gained increased attention after the recent approval of cenegermin (nerve growth factor) eye drops for the treatment of neurotropic keratitis.

Several studies in literature show the high potential of protein powder suspensions in nonaqueous vehicles. The most fascinating features of formulating therapeutic proteins in powder suspensions in non-aqueous vehicles are their potential low viscosity at high concentrations and the high protein stability at elevated temperatures. ${ }^{26-29}$ A large variety of different 
suspension vehicles has been investigated. Freeze-drying with subsequent micronization and spray-drying are the main powder preparation techniques used (Table I-1). A variety of proteins have been formulated as protein powder suspensions in non-aqueous vehicles ranging from model proteins such as bovine serum albumin (BSA) and lysozyme to marketed biopharmaceuticals such as bevacizumab and trastuzumab (Table I-1).

Table I-1: Chronological overview on patents, articles and PhD theses on protein powder suspensions in non-aqueous vehicles for subcutaneous administration.

\begin{tabular}{|c|c|c|c|}
\hline $\begin{array}{l}\text { Literature } \\
\text { (Author, year) }\end{array}$ & Vehicle & $\begin{array}{ll}\begin{array}{l}\text { Powder } \\
\text { technique }\end{array} & \text { preparation } \\
\end{array}$ & Protein \\
\hline $\begin{array}{l}\text { Pena et } a . .^{30}, \\
1995\end{array}$ & MCT & $\begin{array}{l}\text { Milling of lyophilizates (pestle } \\
\text { and mortar) or spray-drying }\end{array}$ & $\begin{array}{l}\text { Recombinant } \quad \text { bovine } \\
\text { somatotropin }\end{array}$ \\
\hline $\begin{array}{l}\text { Knepp et al. }^{27,31} \text {, } \\
\text { 1998/2004 }\end{array}$ & $\begin{array}{l}\text { Perfluorodecalin, } \\
\text { perfluorotributylamine, } \\
\text { methoxyflurane, PEG 400, } \\
\text { soybean oil, tetradecane, } \\
\text { octanol, light mineral oil }\end{array}$ & $\begin{array}{l}\text { Lyophilizates dispersed in } \\
\text { suspension vehicle by manual } \\
\text { shaking or spray-drying }\end{array}$ & $\begin{array}{l}\text { Plasma derived Factor IX, } \\
\text { recombinant human alpha } \\
\text { interferon, chymotrypsin, } \\
\text { plasma protein, albumin, } \\
\text { lysozyme, trypsinogen }\end{array}$ \\
\hline $\begin{array}{l}\text { Chen et al. }{ }^{23}, \\
2006\end{array}$ & $\begin{array}{l}\text { Benzyl benzoate, benzyl } \\
\text { alcohol, ethyl alcohol }\end{array}$ & $\begin{array}{l}\text { Milling of lyophilizates (pestle } \\
\text { and mortar) or spray-drying }\end{array}$ & $\begin{array}{l}\text { Anti-IL-12p40 and anti TNF } \alpha \\
\text { mAbs, BSA, lysozyme }\end{array}$ \\
\hline Rutz $^{24}, 2007$ & $\begin{array}{l}\text { Medium chain triglycerides, } \\
\text { sesame oil }\end{array}$ & $\begin{array}{l}\text { Lyophilizates dispersed in } \\
\text { suspension vehicle using a } \\
\text { high shear homogenizer or by } \\
\text { wet media milling with a } \\
\text { mortar grinder }\end{array}$ & $\begin{array}{l}\text { BSA, recombinant human } \\
\text { growth hormone }\end{array}$ \\
\hline $\begin{array}{l}\text { Miller et al. }{ }^{29,32} \text {, } \\
2010 / 2012\end{array}$ & $\begin{array}{l}\text { Benzyl benzoate and } \\
\text { safflower oil }\end{array}$ & $\begin{array}{l}\text { Milling of lyophilizates (pestle } \\
\text { and mortar) }\end{array}$ & Lysozyme \\
\hline $\begin{array}{l}\text { Bowen et } \\
\text { al. }^{26,33}, 2012\end{array}$ & $\begin{array}{l}\text { Propylene glycol diesters of } \\
\text { caprylic and capric acids, } \\
\text { ethyl lactate, benzyl } \\
\text { benzoate }\end{array}$ & Spray-drying & $\begin{array}{l}\text { Bevacizumab, trastuzumab, } \\
\text { rituximab }\end{array}$ \\
\hline $\begin{array}{l}\text { Dai et al. }{ }^{28} \text {, } \\
2012\end{array}$ & $\begin{array}{l}\text { Ethyl oleate, sesame oil, } \\
\text { medium chain triglycerides }\end{array}$ & $\begin{array}{l}\text { Lyophilizates dispersed in } \\
\text { suspension vehicle or spray- } \\
\text { drying }\end{array}$ & BSA, anti-TNF $\alpha$ mAb \\
\hline $\begin{array}{l}\text { Berkenhoff }^{34}, \\
2013\end{array}$ & $\begin{array}{l}\text { Sesame oil, medium chain } \\
\text { triglycerides, benzyl } \\
\text { benzoate }\end{array}$ & 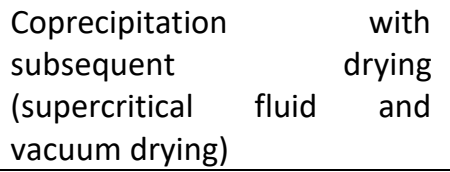 & $\mathrm{mAb}$ \\
\hline $\begin{array}{l}\text { Guenther et } \\
\text { al. }^{35}, 2013\end{array}$ & $\begin{array}{l}\text { Perfluorohexyloctane, } \\
\text { perfluorodecalin, } \\
\text { perfluorooctane, octane }\end{array}$ & $\begin{array}{l}\text { Lyophilizates dispersed in } \\
\text { suspension vehicle }\end{array}$ & Chymotrypsinogen A, BSA \\
\hline $\begin{array}{l}\text { Srinivasan et } \\
\text { al. }^{36}, 2013\end{array}$ & $\begin{array}{l}\text { Isoproply alcohol, ethyl } \\
\text { alcohol, benzyl benzoate, } \\
\text { PEG 200, propylene glycol } \\
\text { and others }\end{array}$ & $\begin{array}{l}\text { Precipitation or milling of } \\
\text { lyophilizates (pestle and } \\
\text { mortar) }\end{array}$ & p-Globulin, mAb \\
\hline $\begin{array}{l}\text { Gesche et al. }{ }^{37}, \\
2016\end{array}$ & $\begin{array}{l}\text { Perfluorobutylpentane, } \\
\text { perfluorohexyloctane }\end{array}$ & $\begin{array}{l}\text { Lyophilizates dispersed in } \\
\text { suspension vehicle }\end{array}$ & $\begin{array}{l}\text { Anti-ESCR } \begin{array}{l}\text { mAb, } \\
\text { bevacizumab and other } \\
\text { mAbs }\end{array} \\
\end{array}$ \\
\hline
\end{tabular}




\section{Obtaining the protein powder}

\subsection{Challenges during drying, the effect of stabilizers and requirements for protein powder used in non-aqueous suspensions}

Protein drug substance, which is expressed in genetically modified cell cultures (e.g. Chinese hamster ovary cells) and subsequently purified, comes as an aqueous solution, potentially frozen. To obtain protein powder suspensions, the water has to be removed and the dry form is dispersed in the non-aqueous vehicle. Removal of water commonly leads to a markedly higher protein stability compared to the respective aqueous solution. ${ }^{9,14,15}$ Still, drying of biopharmaceuticals is a challenging process step, as the removal of water leads to various stresses. ${ }^{16,17,38}$ To ensure stability, the hydrogen bonds between amino acid side chains and water, which are stabilizing the protein conformation have to be replaced for example with carbohydrates such as sucrose or trehalose. ${ }^{16,17}$ In general, trehalose is favoured, due to its higher glass transition temperature, lower hygroscopicity, as well as lower reactivity. ${ }^{16,39,40}$ After drying the protein is embedded in an amorphous stabilizer matrix, minimizing aggregation and chemical degradation kinetics. ${ }^{17}$ Important requirements for protein stabilization with carbohydrates are non-reducing properties and high glass transition temperatures. ${ }^{17}$ For stabilization, the protein has to be incorporated into an amorphous matrix. ${ }^{1}$ More information about protein stabilizing mechanisms during long term storage are discussed in 6.1.

Other excipients used for formulation of non-aqueous protein powder suspensions include buffering agents, surfactants and antioxidants. Buffering agents can be categorized in amino acid and non-amino acid buffering agents. Typical amino acid buffer systems include histidine and arginine. ${ }^{1,16}$ Sodium phosphate, sodium citrate and Tris buffer represent popular nonamino acid buffer agents. ${ }^{1,16}$ Selection of suitable $\mathrm{pH}$ and buffering agent are additionally of utmost importance for protein stability. ${ }^{1,41}$ Formulations of proteins in non-aqueous vehicles might further benefit from addition of surface-active excipients. Hydrophilic surfactants such as polysorbates or poloxamer can be incorporated into the protein powder. Surfactants can prevent proteins from undergoing instabilities at interfaces such as unfolding and subsequent aggregation. ${ }^{42-46}$ Relevant interfaces are present during manufacturing, as well as during drug release. Antioxidants, specifically, methionine can protect the protein against oxidation. ${ }^{1}$ To achieve a successful injection of protein powder suspensions in non-aqueous vehicles through thin hypodermic needles, powders with a particle size in the lower micrometre range 
are essential. ${ }^{24,26}$ The criteria for the powder used for protein powder suspensions in nonaqueous vehicles are quite comparable to protein powders used for inhalational drug delivery. Thus, one can learn from various investigations in this field. The interested reader is referred to existing reviews of such preparations. ${ }^{47,48}$ Other reviews offer an additional intensive insight in challenges during drying of biopharmaceuticals. ${ }^{16,38}$

The recommended maximum particle size to prevent needle clogging is stated to be $1 / 3$ of the needle inner diameter. ${ }^{49,50}$ Consequently, for a $27 \mathrm{G}$ needle, which is frequently used for s.c. injections, exhibiting an inner needle diameter of $210 \mu \mathrm{m}$, powders with a maximum particle size smaller than $70 \mu \mathrm{m}$ should be aimed for. Protein powder suspensions for subcutaneous (s.c.) or intramuscular (i.m.) administration are usually prepared using protein powder of about 5-30 $\mu$ m median size. ${ }^{26,29}$

In the following sections different powder preparation techniques which have been used previously to prepare protein powder suspensions in non-aqueous vehicles will be discussed with special focus on freeze- and spray-drying, which represent the most popular techniques in this field (Table I-1).

\subsection{Freeze-drying and subsequent micronization}

Lyophilization is the most widespread, because gentle, drying technology for biopharmaceuticals. ${ }^{1,16}$ The process of freeze-drying consists of the two main steps freezing and drying, while the drying step is further subdivided into a primary and a secondary drying step. ${ }^{16,51}$ In the two drying steps, a vacuum is applied and through sublimation and desorption, water is removed from the product. ${ }^{16}$ This process is driven by the temperature difference between the product and the condenser, which is usually more than $20 \mathrm{~K} \cdot{ }^{16}$ During the lengthy primary drying step the large fraction of unbound frozen water is removed. ${ }^{16,51}$ After the primary drying step, substantial amounts of water, dependant amongst others on total solid content, formulation composition and drying parameters, are still present in the lyophilizates. ${ }^{51}$ This water fraction is reduced to below $1 \%$ in the secondary drying step at increased temperature. ${ }^{14,51}$ During freezing and drying the protein is exposed to various stresses, which can be counteracted by the addition of cryo- and lyoprotectants such as carbohydrates, appropriate buffers and surfactants. ${ }^{16,41}$

For the preparation of protein powder suspensions in non-aqueous vehicles, the lyophilized powder has to be micronized. Micronization can either be performed by dry milling or by wet 
media milling directly in the vehicle. The micronization process comes with high energy input and harbours the risk of damaging the sensitive protein. Therefore, process parameters have to be carefully selected and optimized. ${ }^{52,53}$ An ideal milling process balances milling duration and energy input per time to reach sufficient micronization at minimal protein damage. Potential dry milling techniques for protein lyophilizates include ball milling ${ }^{54,55}$, jet milling52,56 or simply by hand with a pestle and mortar ${ }^{24,30}$. For high protein integrity and minimal abresion, stainless steel or zirconium dioxide mills are recommended. ${ }^{56-59}$

Milling with pestle and mortar has been used frequently (Table l-1) due to its easy handling in a lab environment, but is not feasible in a commercial manufacturing environment. Jet milling is a more frequently used alternative to process pharmaceutical powders in pharmaceutical manufacturing. Here, the material gets highly accelerated in a chamber by a tubular gas stream and due to interparticle collision and attrition the powder is micronized. ${ }^{47,52}$ As a consequence of the spherical and elliptical path of the gas stream and centrifugal forces, large particles remain in the milling chamber, while fine particles are removed. ${ }^{47,52}$ Jet milling usually results in powder particles with a size range of around $1-20 \mu \mathrm{m} .{ }^{47,48,52}$ As a consequence of the high sensitivity of proteins, jet milling is challenging. ${ }^{52}$ Ehmer jet milled lysozyme and BSA and obtained powder with D90 values below $10 \mu \mathrm{m}$, but with significant protein damage. After milling, lysozyme showed $87 \%$ remaining activity and increased surface hydrophobicity as analyzed by fluorescence spectroscopy. Milling of BSA also led to an increase in surface hydrophobicity and to formation of $14 \%$ insoluble fraction, which could be decreased to $6-9 \%$ by application of cryogenic conditions. ${ }^{52}$ Especially the number of milling cycles has a strong influence on maintaining protein integrity. ${ }^{52}$ Platz et al. successfully jet milled lyophilizates containing human growth hormone, interferon $\beta$ or granulocyte-colony stimulating factor yielding D90 particle sizes below $5 \mu \mathrm{m}$. This was possible by optimizing process and formulation parameters such as material of the mill, milling in nitrogen atmosphere and use of human serum albumin and sorbitol as stabilizers. ${ }^{56,59}$

Alternatively, micronization of protein lyophilizates can be achieved by ball milling. ${ }^{53-55,60,61}$ The lyophilizate is ground between the moving milling balls accelerated by shaking or rotation, or between the balls and the container wall. Etzl et al. showed, that integrity of ovalbumin and recombinant granulocyte-colony stimulating factor is preserved during cryogenic ball milling. ${ }^{54,60}$ Nevertheless, their obtained particle size of 20 to $70 \mu \mathrm{m}$, as well as D90 values above $115 \mu \mathrm{m}$, makes this powder unsuitable for the use in protein powder suspensions 
injectable through thin needles. Lysozyme, glucose oxidase, bovine serum albumin and influenza vaccine were also successfully ball milled. ${ }^{53,55}$ Anamur et al. prepared similar particles with a similar cryogenic ball milling process as described by Etzl. ${ }^{55,62}$ Powders prepared by Lee et al., who used a non-cryogenic ball milling approach, were slightly smaller and featured a particle size of 10 to $60 \mu \mathrm{m} .{ }^{53}$ Overall, the ball milling process parameters have to be carefully optimized to preserve protein stability. Lee et al. showed, that decreasing the milling frequency in a ball mill can minimize protein damage. ${ }^{53}$ As with jet milling, cooling enables a process with minimum protein damage. ${ }^{60}$

Micronization of the lyophilizate in the vehicle, also known as wet media milling, represents an alternative. Here, the suspension vehicle separates the particles and thus improves the milling process by hindering reagglomeration phenomena. Another option is dispersing the lyophilizate by the use of an ultrasound or a high shear homogenizer. Rutz prepared a suspension of BSA lyophilizates in sesame oil employing a high shear homogenizer and achieved median particle sizes between 30 and $40 \mu \mathrm{m} .{ }^{24}$ Nevertheless, still particles larger than $80-120 \mu \mathrm{m}$ were present in the suspension, harboring a risk for needle clogging with thin needles.

\subsection{Spray-drying}

The standard alternative to lyophilization and milling for generation of the protein powder is spray-drying as it combines drying and particle formation (Table I-1). In spray-drying the protein solution is finely dispersed by a nozzle into a drying chamber. The generated droplets are dried in a heated drying gas flow. The powder product is finally collected by a cyclone or a filter. Particle properties such as shape and size can be engineered by the process and the formulation parameters. By varying the atomization procedure, for example with different nozzles, atomization pressure in two fluid nozzles or the feed rate, the initial droplet size and thus the final powder particle size can be adjusted. ${ }^{63,64}$ Two fluid nozzles are the most frequently used nozzles in spray-drying of proteins, but other nozzles are available such as rotary atomizers, single fluid nozzles, multi fluid nozzles and ultrasonic nozzles. ${ }^{63,65,66}$ Varying the total solid content in the feed solution offers an additional way to influence the particle morphology and size.9,67 Furthermore, the type of excipient influences the powder morphology. ${ }^{68}$ Powder particle sizes of spray-dried proteins are usually in the lower micrometre range, ranging from 1-10 $\mu \mathrm{m}$. 
During droplet formation, the protein is exposed to shear and interface stresses. ${ }^{48,69,70}$ The shear rates of $10^{4}$ to $10^{5} 1 / \mathrm{s}$ during atomization are considered tolerable for proteins. ${ }^{70} \mathrm{In}$ contrast, the interface stress is critical. ${ }^{70,71}$ Proteins have high affinity to the air-water interface at which they may unfold and aggregate. ${ }^{13,72}$ Consequently, surfactants, such as polysorbates, should be added to the feed solution. ${ }^{44,71}$ Whereas the inlet temperature of the drying gas is usually from 70 to $150^{\circ} \mathrm{C}$, the droplet temperature is much lower due to water evaporation. ${ }^{64,70}$ The outlet temperature plays a more critical role compared to the inlet temperature, but at this stage the proteins are better preserved due to the dry state of the particles. ${ }^{64,70,73}$ Formation of oxidized protein species upon spray-drying can be counteracted by the addition of methionine. ${ }^{74}$

Spray-dried powders commonly show a high residual moisture content of about $3-5 \%{ }^{26,75}$ Remaining water acts as a plasticizer enhancing particle fusion and risk of excipient crystallization. ${ }^{76-80}$ Further, remaining water may lead to reduced protein stability due to enhanced mobility and chemical instability, with water molecules as part of the degradation reaction. ${ }^{81,82} \mathrm{~A}$ potential technique to counteract this challenge is an additional drying step for example vacuum drying. ${ }^{73,83}$
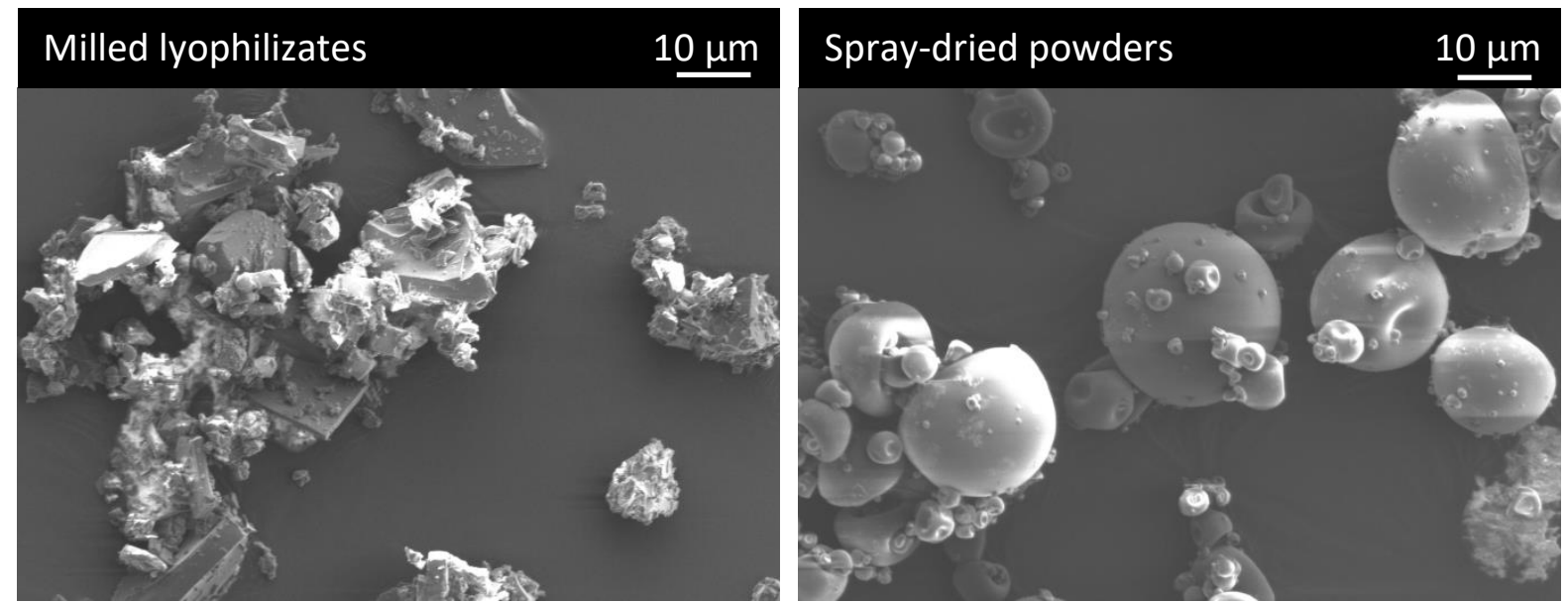

Figure I-2: SEM images of powders containing lysozyme and trehalose at a ratio of 70:30.

Spray-drying usually results in spherical particles (Figure I-2), which are superior to shed-like milled particles as these show an increased tendency to needle clogging due to a bridging effect. Knepp et al. demonstrated, that suspensions of different spray-dried proteins with powder concentrations of $700 \mathrm{mg} / \mathrm{ml}$ are injectable through a $30 \mathrm{G}$ needle. ${ }^{31}$ 


\subsection{Other powder preparation techniques}

A related alternative to spray-drying and freeze-drying is spray-freeze drying. In this technique, the feed solution is sprayed into a cryogenic liquid leading to freezing of the sprayed droplets. The obtained intermediate product is then transferred into a freeze-drier and lyophilized. ${ }^{84}$ Powders obtained from spray-freeze drying are usually spherical and compared to spray-dried powders larger in size and more porous. ${ }^{47,65} \mathrm{~A}$ potential advantage compared to spray-drying is its higher yield and possibility to spray highly heat sensitive proteins. ${ }^{38,65}$ Nevertheless, its commercial use is limited due to its time and resource intensive nature. ${ }^{47}$ An interesting approach was described by Gombotz et al. who further processed a suspension containing spray-freeze dried protein powder in different organic liquids with an ultrasound probe. ${ }^{85}$ This technique was able to further decrease the particle size of the powder. It would be of high interest to learn whether a similar procedure can work with a freeze-dried product.

Another potential alternative to freeze-drying and spray-drying is supercritical fluid drying. ${ }^{86-}$ 88 Here a solution or suspension is dried by the use of a supercritical fluid, usually carbon dioxide, which is in the supercritical state at mild conditions above $31^{\circ} \mathrm{C}$ and 73 bar..$^{38}$ Jovanović et al. successfully prepared lysozyme powders by spraying a feed solution into a critical fluid, yielding in particles with a size range of 1 to $25 \mu \mathrm{m} .{ }^{87}$ Such particles would be suitable for the use in non-aqueous protein powder suspensions.

Furthermore, other particle engineering techniques such as microcrystals or precipitation can be combined with an additional drying step to yield appropriate protein powder. ${ }^{36,89-91} \mathrm{An}$ interesting approach was described by Berkenhoff, who coprecipitated a mAb into protein coated microcrystals, which were subsequently dried using a combination of supercritical fluid drying and subsequent vacuum drying. ${ }^{34}$ 


\section{The suspension vehicles and suspension preparation}

\subsection{Suspension vehicles for parenteral administration}

It is understood, that the suspension vehicle is of high importance, as it directly influences the suspension's physical performance and stability as well as the protein stability. As nearly all of the marketed protein formulations are intended for parenteral use, the introduction focusses on vehicles suitable for subcutaneous or intramuscular administration. Table I-2 gives an overview on the most promising candidates for vehicles used in protein powder suspensions.

Table I-2: Overview of important potential vehicles for the use in protein powder suspensions.

\begin{tabular}{|c|c|c|c|}
\hline Group & Example & $\begin{array}{l}\text { Viscosity } \quad[\mathrm{mPa} \cdot \mathrm{s}] \\
\text { (Temp.) }\end{array}$ & $\begin{array}{l}\text { Parenterally } \\
\text { approved }^{92}\end{array}$ \\
\hline \multirow[t]{3}{*}{ Plant oils } & - $\quad$ Sesame oil & $51-61\left(25^{\circ} \mathrm{C}\right)^{24,28}$ & Yes \\
\hline & - Safflower oil & $52\left(26^{\circ} \mathrm{C}\right)^{93}$ & Yes \\
\hline & - $\quad$ Soybean oil & $56\left(25^{\circ} \mathrm{C}\right)^{24}$ & Yes \\
\hline Medium chain triglycerides & $\begin{array}{l}\text { - Triglycerides of caprylic and } \\
\text { capric acid }\end{array}$ & $23-27\left(25^{\circ} \mathrm{C}\right)^{24,28}$ & Yes \\
\hline $\begin{array}{l}\text { Propylene glycol diesters of } \\
\text { medium chain fatty acids }\end{array}$ & $\begin{array}{l}\text { Propylene glycol diesters of } \\
\text { caprylic and capric acids }\end{array}$ & $9\left(20^{\circ} \mathrm{C}\right)^{26}$ & No \\
\hline \multirow[t]{2}{*}{ Fatty acid esters } & - $\quad$ Ethyl oleate & $6\left(25^{\circ} \mathrm{C}\right)^{28}$ & No \\
\hline & - Isopropyl myristate & $5\left(25^{\circ} \mathrm{C}\right)^{28}$ & No \\
\hline Polyethylene glycol & - $\quad$ PEG 200 & $48\left(25^{\circ} \mathrm{C}\right)^{36}$ & Yes \\
\hline \multirow[t]{2}{*}{ Esters } & - $\quad$ Benzyl benzoate & $8-9\left(25^{\circ} \mathrm{C}\right)^{24,36}$ & Yes \\
\hline & - Ethyl lactate & $2\left(20^{\circ} \mathrm{C}\right)^{26}$ & No \\
\hline \multirow[t]{4}{*}{ Alcohols } & - Benzyl alcohol & $5\left(25^{\circ} \mathrm{C}\right)^{94}$ & Yes \\
\hline & - Isopropyl alcohol & $2.4\left(25^{\circ} \mathrm{C}\right)^{28}$ & No \\
\hline & - Ethyl alcohol & $1.2\left(25^{\circ} \mathrm{C}\right)^{28}$ & Yes \\
\hline & - $\quad$ Propylene glycol & $39\left(25^{\circ} \mathrm{C}\right)^{95}$ & Yes \\
\hline Perfluorinated carbons & - $\quad$ Perfluorodecalin & $6\left(25^{\circ} \mathrm{C}\right)^{96}$ & No \\
\hline \multirow[t]{2}{*}{ Semifluorinated alkanes } & - Perfluorohexyloctane & $3.44\left(25^{\circ} \mathrm{C}\right)^{97,98}$ & No \\
\hline & - Perfluorobutylpentane & $1.05\left(25^{\circ} \mathrm{C}\right)^{98}$ & No \\
\hline
\end{tabular}

Important requirements of organic liquids for the use in parenteral applications include low water content, free of reactive species, easy to sterilize, non-toxic, no pharmacological effect, non-allergenic, metabolizes to non-toxic species and acceptable viscosity. ${ }^{24,26,99}$ Thus, the vehicle should be highly purified. Additional procedures to improve product stability with regard to oxidation, could be degassing the vehicle with nitrogen or vacuum methods, the addition of an antioxidant or treatment of the vehicle with activated aluminium oxide to remove peroxides. ${ }^{28,100-102}$

Vegetable oils, such as sesame oil, safflower oil and soybean oil, have a long history in parenteral formulations of small molecules due to their good tolerability. ${ }^{99}$ Marketed 
examples include fluphenazine decanoate injection USP, a solution in sesame oil containing $12 \mathrm{mg} / \mathrm{ml}$ benzyl alcohol as preservative, and Posilac ${ }^{\circledR}$, which is a suspension of zinc bovine recombinant somatotropin in sesame oil gelled with aluminium stearate for veterinary use. Vegetable oils feature two major drawbacks, which are their high viscosity (see Table I-2) and the presence of unsaturated fatty acids. ${ }^{24,27}$ The carbon-carbon double bond of the unsaturated fatty acids can lead to the formation reactive oxygen species and thus affect protein stability (see 6.1). ${ }^{27,103,104}$

An alternative are medium chain triglycerides containing only saturated fatty acids with a shorter chain length and hence lower viscosity. Medium chain triglycerides (MCT) are parenterally approved. ${ }^{92}$ An interesting marketed formulation containing MCT is Bydureon BCise $^{\circledR}$, consisting of extended release polylactic-co-glycolic acid (PLGA) microparticles of exenatide, suspended in MCT and provided in a single-dose, pre-filled pen device. The use of MCT in parenteral nutrition is another popular application. MCT-related, lower viscosity vehicles are propylene glycol diesters of caprylic and capric acids featuring a viscosity of approximately $9 \mathrm{mPa} \cdot \mathrm{s}$ compared to $23-27 \mathrm{mPa} \cdot \mathrm{s}$ of MCT. ${ }^{24,26,28}$

Another suspension vehicle used for protein powder suspensions is ethyl oleate, due to its low viscosity of $6 \mathrm{mPa} \cdot \mathrm{s} .{ }^{28}$ Ethyl oleate is not approved for parenteral use by the FDA. ${ }^{92}$ It has been used for preparation of progesterone injections and other steroids by compounding pharmacies in the US, as it is much easier to inject than standard USP progesterone formulations in sesame oil. ${ }^{105,106}$ An alternative potential fatty acid ester suitable as a suspension vehicle with low viscosity is isopropyl myristate, which is also not approved for parenteral use by the FDA and features a viscosity of $5 \mathrm{mPa} \cdot \mathrm{s}^{49,100,104}$

Polyethylene glycols have been considered as vehicles for protein powder suspensions by Knepp et al. and Srinivasan et al. ${ }^{27,36}$ Polyethylene glycols (PEG) are approved in parenteral applications up to concentrations of $55 \%(\mathrm{~m} / \mathrm{V}) .{ }^{92}$ Due to their high viscosity (Table I-2), they are not suitable for high concentration protein formulations. Another drawback of PEG is its susceptibility to oxidation. ${ }^{107,108}$

Bowen et al. prepared mAb suspensions in benzyl benzoate and ethyl lactate with low viscosities and glide forces during injection at high concentrations. ${ }^{26}$ Especially ethyl lactate formulations showed remarkably low glide forces due to the low inherent viscosity of $2 \mathrm{mPa} \cdot \mathrm{s}^{26} \mathrm{~A}$ drawback of ethyl lactate is its pronounced irritative and toxic character. ${ }^{109,110}$ Benzyl benzoate, which features a viscosity of $9 \mathrm{mPa} \cdot \mathrm{s}$ is parenterally approved up to 
concentrations of $50 \%(\mathrm{~m} / \mathrm{V})$ and usually added as a cosolvent. ${ }^{26,92}$ It has been used in several studies as a potential vehicle for protein powder suspensions. ${ }^{23,26,29}$ Benzyl alcohol has been proposed as a vehicle for protein powder suspensions by Chen et al. ${ }^{23}$ Benzyl alcohol is approved by the EMA and FDA as preservative and solubilizing agent up to concentrations of $5 \%(\mathrm{~m} / \mathrm{V}) .{ }^{92,111}$

Srinivasan et al. used different alcohols as vehicles for protein powder suspensions, such as ethyl alcohol, isopropyl alcohol and propylene glycol. ${ }^{36}$ Ethyl alcohol and propylene glycol are parenterally approved. ${ }^{92}$ Especially ethyl alcohol and isopropyl alcohol offer very low inherent viscosities (Table I-2). Nevertheless, an increasing hydrophilicity of the vehicle comes with an increased solubilizing capacity for sugars and thus potentially decreased stability of the protein. For example, the solubility of sucrose at $25^{\circ} \mathrm{C}$ is stated with 0.5 and $20 \mathrm{mg} / \mathrm{ml}$ in ethyl alcohol and propylene glycol, respectively. ${ }^{112,113}$ Additionally, it is important to note, that the use of water miscible solvents might lead to unfolding of the protein when forming mixtures with water after injection into the tissue. ${ }^{114,115}$

Perfluorocarbons and semifluorinated alkanes (SFAs) represent interesting classes for protein formulation and have been investigated in several studies. ${ }^{27,35,37}$ Both offer high compatibility with proteins due to their inert character, which limits unwanted reactions during storage. $27,35,37$ Perfluorocarbons, such as perfluorodecalin (PFD), have been studied intensively as blood substitutes and in the field of liquid breathing due to their high oxygen solubilizing capacity. ${ }^{116-118}$ They do not undergo metabolism and are exhaled via the lung. ${ }^{116-}$ 118 SFAs are diblock molecules, which consist of a linear perfluorinated hydrocarbon segment and a linear alkyl group. ${ }^{119,120}$ In the case of SFAs, especially perfluorobutylpentane (F4H5) and perfluorohexyloctane $(\mathrm{F} 6 \mathrm{H} 8$ ) have been investigated due to their low viscosity, low reactivity as well as good biocompatibility. ${ }^{35,97,98}$ Tsagogiorgas et al. reported, that no toxic effects could be detected after intravenous application of a propofol formulation in $\mathrm{F} 6 \mathrm{H} 8$ in rats. ${ }^{97}$ SFAs come with very good spreading properties and low viscosity, which makes them also highly suitable for topical eye delivery. They have been extensively tested for delivery of small molecules to the front of the eye but might also be suitable for topical eye delivery of suspended proteins. ${ }^{121,122}$

Additionally, stabilizing excipients might be added directly to the vehicle. Surface active flocculating or gelling agents, such as sorbitan fatty acid esters potentially increase the physical suspension stability including resuspendability. ${ }^{104}$ Oil soluble antioxidants such as 
ascorbic acid esters and tocopherols offer another possibility to improve long term stability. ${ }^{1,123}$

\subsection{Suspension preparation and further manufacturing considerations}

In order to obtain the protein powder suspension a dispersion step is necessary. Potential methods include high-shear homogenizers, wet media milling, ultrasound probes or by the use of an ultrasound bath. ${ }^{26,124}$ An optimum dispersion technique is able to finely disperse the powder in the suspension vehicle to yield injectable formulations, without damaging the biopharmaceutical. Akers et al. recommend still sieving of the bulk suspension before filling to remove potential incomplete micronized or dispersed particles/agglomerates which would risk needle clogging in parenteral formulations. ${ }^{101}$

For dispensing the final suspension into the primary packaging material different pumps are available such as diaphragm pump, rotary peristaltic pump, rotating piston pump and time/pressure fillers. ${ }^{125,126}$ Each of the pumps offers different advantages and disadvantages. Thus, factors influencing the selection of a suitable pump, such as settling rates of the powder in the vehicle, viscosity and powder concentration, have to be considered. Especially prevention of particle settling is important to achieve content uniformity of the drug product.

As a final filtration step is not possible, working under particle-free and sterile conditions is crucial. Additionally, for protein powder handling, an inert environment with low humidity to minimize oxygen and moisture contact is imperative, for example in a nitrogen environment. ${ }^{127}$ 


\section{Rheology and injectability of protein powder suspensions}

\subsection{Rheology}

The rheological behaviour of liquid parenterals has a strong influence on both the manufacturing process and the syringeability and injectability upon application. Besides shape, size and total solid concentration of the suspended powders, the vehicle's inherent viscosity also determines the suspension's rheological behaviour. ${ }^{26,128,129}$ The type of protein does not affect the suspension viscosity. ${ }^{26}$ The suspension viscosity is strongly dependent on the applied shear rate. Low shear rates exist during drawing a suspension into a syringe through a thick needle. During injection high shear rates $\left(>10^{4} 1 / \mathrm{s}\right)$ occur as the suspension flows through a thin hypodermic needle (see 5.2). ${ }^{29,130}$ With increasing concentration protein powder suspensions show a pronounced shear thinning behaviour. ${ }^{30,34}$ Thus, suspension viscosity of highly concentrated formulations can be remarkably low at high shear rates.

Previous work in the field of protein powder suspensions indicated, that particle morphology and size affect the suspension rheology depending on the shear rate. ${ }^{28,30}$ At low shear rates the effect of particle-particle interactions on viscosity is increased. Pena et al. reported lower viscosities at low shear rates of rbSt powder suspensions containing milled or shattered spraydried particles compared to suspensions containing smaller spherical spray-dried particles. ${ }^{30}$ This was explained by more dense packing and thus increased particle-particle interactions in suspension containing the spray-dried powder. Nevertheless, when the suspensions containing the powders with different morphologies were exposed to high shear rates upon injection through a $20 \mathrm{G}$ needle, no influence of the morphology was detected.

At high concentrations, the effect of particle-particle interactions on suspension viscosity is negligible. According to Krieger and Dougherty, in concentrated suspensions, the influence of the viscosity of the pure vehicle $\eta_{0}$ on the resulting composition viscosity $\eta$ can be described by equation 1 using the volume fraction of the suspended material $\varphi$, the maximum volume fraction $\varphi_{\max }$, as well as the intrinsic viscosity [n] (equation 1). ${ }^{128}$

$$
\eta=\eta_{0}\left[1-\frac{(\varphi)}{\left(\varphi_{\max }\right)}\right]^{-[\eta] \varphi_{\max }}
$$

Powder properties influencing suspension viscosity include $\varphi_{\max }$ and [n]. Both are not influenced by the particle size, but $\varphi_{\max }$ can be influenced by the particle size distribution. ${ }^{131}$ 
In suspensions containing a broad particle size distribution, the smaller particles are able to occupy the space between the larger particles leading to an increase of the maximum volume fraction. Additionally, smaller particles are able to act as a lubricant for larger particles. ${ }^{131}$ Contrarily to these considerations, Dai et al. reported lower viscosities of suspensions containing spray-dried BSA powder with a particle size of $2 \mu \mathrm{m}$ compared to powders of $13 \mu \mathrm{m} .^{28}$

The particle shape has a strong influence on the intrinsic viscosity [ $\eta$, with the lowest possible value of 2.5 for rigid spheres. Deviations from the perfect sphere usually result in an increase of $[\eta]$ as a consequence of an extra energy dissipation, hence, in an increased viscosity. ${ }^{131}$ As a consequence, suspensions containing milled particles, with a non-spherical shed-like morphology, should show higher viscosity, than suspensions containing spray-dried particles, at high shear rates with an identical particle size distribution. Overall, investigations on the influence of particle size and morphology of protein powders on suspension rheology are of high importance.

To minimize $\varphi$, the amount of non-protein constituents in the powder should be kept as low as possible (see 6.1). For example, Berkenhoff prepared suspensions of protein coated microcrystals in MCT or mixtures of sesame oil and benzyl benzoate. The viscosities of the obtained suspensions were significantly higher compared to the respective aqueous solutions, which could be explained by the high inherent viscosities of the tested vehicles (see Table I-2), as well as the limited mAb concentrations in the powder $(44 \% \mathrm{~m} / \mathrm{m})$.

Due to the importance of the vehicles inherent viscosity, traditional parenterally approved vegetable oils for s.c. or i.m. injection, with high viscosities, are of limited use for highly concentrated protein formulations. ${ }^{26}$ Thus, suspension vehicles for highly concentrated protein powder suspensions should show a viscosity below $10 \mathrm{mPa} \cdot \mathrm{s}^{26}$ Bowen et al. reported a viscosity of less than $10 \mathrm{mPa} \cdot \mathrm{s}$ for a powder suspension containing $200 \mathrm{mg} / \mathrm{ml} \mathrm{mAb}$ in ethyl lactate. Aqueous formulations may exhibit much higher viscosities, depending on the proteinprotein interaction in water. ${ }^{132}$ Exemplarily, Shire et al. reported a viscosity above $120 \mathrm{mPa} \cdot \mathrm{s}$ for a $140 \mathrm{mg} / \mathrm{ml}$ mAb solution. ${ }^{19}$ 


\subsection{Syringeability and injectability}

The outpatient treatment by subcutaneous (s.c.) injection is the desired application route for protein drugs administered for chronic diseases such as rheumatic arthritis. Prefilled syringes and autoinjectors simplify therapeutic management at the patient's home or by the patient himself. ${ }^{18,20}$ Important parameters regarding applicability are syringeability and injectability. Syringeability describes the ability to transfer a formulation through a needle from a vial into a syringe, while injectability describes the injection from the syringe into the patient. ${ }^{101,133,134}$ To ensure syringeability and injectability of a suspension, the powder particle size has to be small enough to prevent needle clogging and particle agglomeration during storage has to be minimized.

The withdrawal of the suspension from a vial should not take too long and not affect the protein concentration. During syringing a suction force by drawing back the plunger is created. At this point, the suspension has to overcome the yield point to guarantee a suspension flow. The protein powder suspension gets sucked into the needle and then flows into the syringe. Additionally, the suspension has to flow down along the vial wall adequately. Thus, an important characteristic for the suspension formulation is its yield point, which describes the minimum force required to initiate flow of a system. In case of a high yield point, the suspension does not flow adequately and only vehicle may be drawn into the syringe leading to inexact dosing.

During syringing the formulation is subjected to different shear rates $\dot{\gamma}(1 / \mathrm{s})$. These shear rates can be calculated according to equation 2 using the needle or vial inner radius ( $\left.r_{\text {needle/vial }}\right)$ and the volume flow $\left(\frac{d V}{d t}\right){ }^{29,124}$

$$
\dot{\gamma}=\frac{4 \frac{d V}{d t}}{\pi r_{\text {needle } / \text { vial }}^{3}}
$$

The passage through the needle into the syringe is less difficult due to the high volume flow and therefore high shear rates. The flow of the suspension down the vial wall is more critical, regarding dosing accuracy, due to low shear rates leading to high viscosities. As an alternative, protein powder suspensions could be provided in a prefillable syringe. 
The glide force during injection can be calculated according to equation 3 which is a modification of Hagen-Poiseuille law considering the geometrical dimensions of the injection device and the formulation viscosity $\eta(\mathrm{mPa} \cdot \mathrm{s}) .{ }^{130}$

$$
\left.\mathrm{F}=\frac{8 \frac{\mathrm{dV}}{\mathrm{dt}} \cdot \mathrm{l} \cdot r_{\text {syringe }}^{2}}{\mathrm{r}_{\text {needle }}^{4}} \cdot \eta+\mathrm{F}_{\text {friction; } ;(\mathrm{dv}} \mathrm{dt}\right)
$$

The resulting glide force $F(N)$ is hereby described by the volume flow $d V / d t\left(m^{3} / s\right)$, the length of the needle $(\mathrm{m})$, the inner radius of the syringe $r_{\text {syringe }}$ and the needle $r_{\text {needle }}(\mathrm{m})$, the dynamic viscosity $\eta(\mathrm{mPa} \cdot \mathrm{s})$, as well as the frictional forces between stopper and barrel of the syringe $\mathrm{F}_{\text {friction }}(\mathrm{N}) .{ }^{130}$ The equation shows, that the formulation's viscosity has a strong effect on the glide force needed for injection. In order to yield information about glide forces during injection the viscosity should be investigated at the relevant shear rate.

Maximum acceptable glide forces between 15 and $30 \mathrm{~N}$, depending on the patient group, syringe design and injection volume, are given in literature. ${ }^{26,135-137}$ Bowen and co-workers prepared a suspension of spray-dried rituximab in ethyl lactate containing $333 \mathrm{mg} / \mathrm{ml}$ protein ( $500 \mathrm{mg} / \mathrm{ml}$ total solid content) which yielded a glide force of approximately $15 \mathrm{~N}$ using a $27 \mathrm{G}$ needle. ${ }^{26,33}$ Knepp et al. described formulations containing $350 \mathrm{mg} / \mathrm{ml}$ of either albumin, lysozyme or trypsinogen $(700 \mathrm{mg} / \mathrm{ml}$ total solid content) in perfluorodecalin injectable through a 306 needle. ${ }^{31}$ 


\section{Long-term stability of protein powder suspensions in non-aqueous vehicles}

Formulation stability over the shelf-life is essential. In the case of protein powder suspensions protein stability as well as the suspension's physical stability are the key challenges. Table I-3 gives an overview of relevant factors influencing protein and suspension physical stability.

Table I-3 Factors for long-term protein (P) and suspension physical (S) stability of protein powder suspensions in non-aqueous vehicles. *not described in literature

\begin{tabular}{|c|c|}
\hline Powder & $\begin{array}{ll}\text { - } & \text { Protein to stabilizer ratio }(\mathrm{P}) \\
\text { - } & \text { Type of stabilizer/carbohydrate }\left(\mathrm{P}, \mathrm{S}^{*}\right) \\
\text { - } & \text { Residual moisture }(\mathrm{P}, \mathrm{S}) \\
\text { - } & \text { Antioxidant }\left(\mathrm{P}^{*}\right) \\
\text { - } & \text { Particle size/surface }\left(\mathrm{P}^{*}, \mathrm{~S}^{*}\right) \\
\end{array}$ \\
\hline Vehicle & $\begin{array}{ll}\text { - } & \text { Type of vehicle }(\mathrm{P}, \mathrm{S}) \\
\text { - } & \text { Water content }\left(\mathrm{P}, \mathrm{S}^{*}\right) \\
\text { - } & \text { Oxygen content }\left(\mathrm{P}^{*}\right) \\
\text { - } & \text { Reactive species }(\mathrm{P}) \\
\text { - } & \text { Stabilizers }\left(\mathrm{S}^{*}\right) \\
\end{array}$ \\
\hline
\end{tabular}

\subsection{Protein stability}

As described in 2.1, the therapeutic protein can undergo various chemical and physical instabilities in aqueous solutions during storage, which need to be minimized. An approach to enhance protein stability is the removal of water. ${ }^{9,14,15}$ The mechanisms behind the increased protein stability in the solid state can be described by the vitrification and water replacement theories. ${ }^{1}$ The vitrification theory is a kinetic consideration based on the concept, that the protein is immobilized in an amorphous matrix. ${ }^{17}$ This slows down unfolding and reduces chemical instabilities, as they require protein mobility. ${ }^{15,17,138}$ The water replacement theory is based on thermodynamic assumptions that excipients such as sugars form hydrogen bonds with the protein, hence replacing water molecules and maintaining the protein molecules' native conformation. ${ }^{17,139,140}$ If solid protein formulations are stored in hydrophobic nonaqueous liquids, protein molecules keep their native state as a result of kinetic trapping. ${ }^{141}$ The hydrogen bond interactions between protein and excipients strongly exceed hydrophobic interactions between the non-aqueous liquid and hydrophobic parts of the protein. ${ }^{141}$ Thus, protein stability in protein powder suspensions during storage is considered to be comparable to that of freeze-dried formulations when suitable non-aqueous liquids are used. In a study by Knepp et al., $\alpha$-interferon and factor IX lyophilizates suspended in 
perfluorodecalin showed high protein stability at elevated temperatures for up to a year. ${ }^{27}$ Stored in soybean oil, poorer stability was observed which was attributed to reactive species like peroxides and aldehydes as well as a higher water content in the vehicle. Additionally, high stability of several peptides and small proteins such as lysozyme, calcitonin, insulin and human growth hormone in protein powder suspensions has been reported. ${ }^{24,29,35}$ Antibody activity, monomer content and secondary structure of spray-dried golilumab in mixtures of ethyl oleate and sesame oil were preserved over six months of storage at $40^{\circ} \mathrm{C}$ and were superior compared to the aqueous reference formulation. ${ }^{28}$

Table 1-3 gives an overview on factors affecting long term protein stability in non-aqueous powder suspensions. First the inherent protein stability of the non-suspended powder and second, the influence of the suspension vehicle has to be considered. The protein to stabilizer ratio is an important feature of the powder. A minimum protein stabilizer concentration is crucial to ensure the integrity of the active biopharmaceutical drug during storage. ${ }^{26,73}$ Nevertheless, in the case of highly concentrated powder suspensions a low stabilizer content is desired to minimize the volume contribution and thus the viscosity of the system. ${ }^{26}$ Previous studies indicated sufficient stabilization of mAbs in spray-dried powders at a protein to stabilizer molar ratio of $1: 220$ to $1: 110$ during storage at elevated temperatures. ${ }^{26,73}$ This equals protein to stabilizer mass ratios of $80: 20$ and $66: 33$, respectively. The type of stabilizer also plays an important role. Sucrose or trehalose are usually favoured (see 3.1). The residual moisture in the powder has to be optimized, as remaining water may act as a plasticizer, enhancing the risk of excipient crystallization. ${ }^{76-80}$ Furthermore, water can lead to enhanced mobility and chemical instability, with water molecules as part of the degradation reaction. ${ }^{81,82}$ Oxidation is a common instability reaction of proteins and can be minimized by addition of antioxidants to the powder such as methionine. ${ }^{74,142,143}$ Additionally, protein stability may be reduced with higher specific surface area thus, smaller powder particle size. $^{144,145}$

The type of vehicle plays an important role regarding protein stability (Table I-3). ${ }^{27}$ The vehicle should not interact with the protein or stabilizer or interfere with the protein conformation. The vehicle should be highly inert to avoid reactions with the protein. Additionally, the water content, the amount of reactive species/impurities and the oxygen content needs to be minimal (see 4.1). Furthermore, oil soluble stabilizers such as antioxidants might be added. It has been shown, that (poly-)unsaturated fatty acids, which are an essential part in many 
vegetable oils, can negatively impact protein stability. ${ }^{27}$ Plasma derived factor IX powder stored in soybean oil resulted in the formation of an insoluble protein gel after 4 weeks at $37^{\circ} \mathrm{C}$, which did not occur in perfluorodecalin. ${ }^{27}$ The carbon-carbon double bond can react with oxygen, which then leads to the formation of hydroperoxides which are able to oxidize amino acid side chains of proteins. ${ }^{27,103,104}$ Additionally, as a consequence of the oxygen attack at the carbon-carbon double bond, aldehyde functional groups functions are formed, which can undergo further reactions with the amino acid side chains of the protein forming Schiff base adducts. ${ }^{27}$ These then can undergo the Amadori rearrangement leading to additional carbonyl functional groups and may crosslink protein molecules via further formation of Schiff base adducts. ${ }^{27}$

\subsection{Suspension stability}

While several articles investigated protein stability in non-aqueous protein powder suspensions, only little is known regarding the suspensions' physical stability, although it is of key importance for applicability. Only Miller et al. reported, that a suspension of milled lysozyme in benzyl benzoate at room temperature did not change in particle size after two months and was visually resuspendable after 1 year of storage. ${ }^{29}$ Yordanova showed, that a suspension of milled decapeptide in various non-aqueous vehicles was injectable after 12 months of storage at elevated temperatures. ${ }^{104}$

Development of a stable suspension is a challenging task, as the coexistence of the solid and liquid phase is prone to physical instabilities. ${ }^{124}$ Preserving consistent powder particle size and thus injectability is crucial, as needle clogging presents a serious challenge for parenteral suspensions. ${ }^{49}$ Additionally, resuspendability is mandatory to ensure dose uniformity. Due to the difference in density between the powder and the vehicle the dispersed particles show sedimentation or flotation. In the case of non-aqueous protein powder suspensions, usually sedimentation is observed due to the higher density of the powder particles compared to the vehicle. The sedimentation behaviour can be described by the Stokes law. At high powder concentrations this equation has to be modified as a consequence of particle crowding. ${ }^{29}$ Overall, the sedimentation speed can be decreased by decreasing the particle size, increasing the viscosity of the vehicle, aligning the densities or increasing the powder concentration.

It should be further distinguished whether the suspension shows flocculated or deflocculated sedimentation behaviour (Figure I-3). While particles exist as separate entities in deflocculated 
suspensions, particles form loose aggregates in flocculated suspensions. ${ }^{101}$ Flocculated suspensions are usually favoured, because of the scaffold-like structure, they form a less dense sediment, leading to easier resuspension. ${ }^{49,101}$ Deflocculated suspensions form a rather dense sediment which is harder to redisperse. ${ }^{101}$ In case of aqueous suspensions, the particleparticle interactions and thus the resuspendability can be modified by addition of electrolytes as described by the Derjaguen-Landau-Verwey and Overbeek theory (DLVO theory). In case of suspensions in non-aqueous vehicles, this approach is not feasible. ${ }^{101,146}$ Addition of surfactants or polymers are a potential alternative to induce flocculation. ${ }^{49,104}$ Especially in prefilled syringes resuspending might be challenging due to the decreased headspace. Addition of beads might further improve resuspendability. ${ }^{147}$

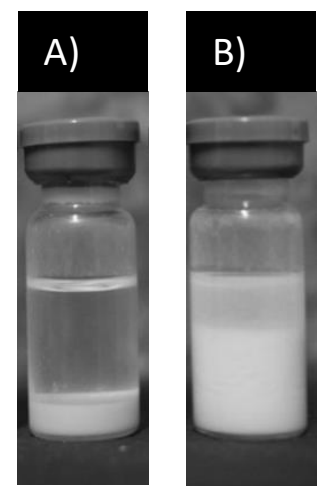

Figure 1-3: Suspension of $100 \mathrm{mg} / \mathrm{ml}$ (total solid content) spray-dried 70:30 lysozyme:trehalose powder in A) ethyl oleate (deflocculated) and B) F6H8 (flocculated) after 1 month of storage at $25^{\circ} \mathrm{C}$.

Crystal growth displays another typical physical instability of suspensions, also known as Ostwald ripening. The solubility $c_{1}$ of a smaller particle with the radius $r_{p 1}$ is higher as a consequence of higher surface free energy compared to the solubility of larger particles $c_{2}$ with the radius $r_{p 2}$. This can be explained by the Ostwald-Freundlich equation (equation 4), using the molecular weight $M$, the interface tension $\gamma$, the gas constant $R$ and the absolute temperature T. ${ }^{49,101}$

$$
\ln \frac{c_{1}}{c_{2}}=\frac{2 M \gamma}{\rho R T} \frac{1}{r_{\mathrm{p} 1}}-\frac{1}{r_{\mathrm{p} 2}}
$$


Due to a gradient of concentration, dissolved molecules will diffuse from the smaller to the larger particles, where they precipitate as a consequence of supersaturation. Thus, formulation strategies to control crystal growth include low solubility of the suspended particles in the vehicle, as well as optimized particle sizes with a narrow size distribution. The use of lipophilic excipients, soluble in the vehicle, should be prevented. In general, the rate of crystal growth can be decreased by increasing the viscosity. ${ }^{101}$ Considering protein and sugars as the main components of the suspended particles, Ostwald ripening based on growth of particles is less likely to occur in non-aqueous protein powder suspensions. Another important factor regarding suspension stability is the residual moisture. Residual water shows plasticizing effects, reduces the glass transition temperature and thus enhances particle fusion. ${ }^{76-80,148}$

\subsection{Further considerations}

Besides protein and suspension stability additional factors, with regard to long-term stability, have to be considered. These include sterility, leachables as well as container functionality. Sterility of the drug has to be assured by initial sterility using an appropriate aseptic manufacturing process, addition of preservatives in case of multidose systems as well as ensuring container closure integrity. Overall, microbial growth in non-aqueous vehicles is limited due to the absence of water, but assuring an aseptic manufacturing process is highly challenging. More relevant for non-aqueous protein powder suspensions is the aspect of leachables. Due to their higher lipophilicity, the non-aqueous vehicles might extract higher levels of organic leachables which are potentially harmful to patients. ${ }^{149}$ Additionally, interaction with the packaging material should be considered. The vehicles might interact with the container closure system. Oils can diffuse into rubber stoppers leading to swelling of the rubber matrix. ${ }^{34,150}$ Berkenhoff tested the influence of $\mathrm{MCT}$, benzyl benzoate and sesame oil on the swelling of bromobutyl rubber tip caps and fluorocarbon coated bromobutyl rubber stoppers. While no swelling of the fluorocarbon coated stoppers was detected, swelling was detected for the tip caps which did not feature such coating. ${ }^{34}$ Swelling of parts of the container closure system can lead to increased diffusion of leachables into the vehicle and may also lead to loss of function of the container closure system, such as loss of container closure integrity, an increase in the glide force needed for injection or even loss of injectability. Furthermore, interaction of surfactants, preservatives or antioxidants with the primary 
packaging material should be considered as these could lead to protein or suspension instabilities. ${ }^{101}$ 


\section{Applications and drug delivery}

Protein powder suspensions in non-aqueous vehicles are suitable for subcutaneous or intramuscular administration. Protein powder suspensions are of high value in case of high protein concentration, insufficient protein stability in an aqueous environment, for proteins with low solubility or coformulations of two or more proteins with different formulation requirements.

Commonly, protein powder suspensions do not offer a distinct sustained release as the dispersed hydrophilic protein powders quickly participate into an aqueous acceptor phase. This was shown both in vitro as well as in vivo. ${ }^{23,24}$ After subcutaneous injection to cynomolgus monkeys, similar pharmacokinetics were detected after subcutaneous injection of an aqueous antibody solution and a non-aqueous antibody powder suspension. ${ }^{23}$ If a sustained release is required, additional excipients are necessary such as polylactic-co-glycolic acid (PLGA) or aluminium stearate. One of the most successful drug products for veterinary use, Posilac ${ }^{\circledR}$, contains recombinant bovine somatotropin (rbSt) and is formulated in a sustained release formulation consisting of lyophilized rbSt powder dispersed in either MCT or sesame oil gelled with aluminium stearate. ${ }^{24,151}$ Another promising option for sustained release are formulations comprising PLGA. Nutropin Depot ${ }^{\circledR}$, a marketed sustained release human growth hormone $(\mathrm{hGH})$ formulation for human use is provided with the protein incorporated in PLGA microparticles. These microparticles are suspended in water before use. An interesting idea would be a non-aqueous suspension of therapeutic protein (e.g. hGh) containing PLGA microparticles as realized for Bydureon $\mathrm{BCise}^{\circledR}$, which is an exenatide formulation consisting of PLGA microparticles of the peptide suspended in MCT.

Furthermore, local delivery of drugs to the lung, skin or to the cornea are potential applications for non-aqueous protein powder suspensions. ${ }^{152-155}$ Just recently the FDA and EMA approved Oxervate ${ }^{\circledR}$ a topical ophthalmic solution containing recombinant human nerve growth factor (cenegermin) for the treatment of neurotrophic keratitis. This aqueous formulation has to be stored frozen due to limited protein stability and a protein powder suspension could be a highly valuable alternative formulation. 


\section{Conclusion}

Protein powder suspensions in non-aqueous vehicles represent a promising formulation technique. They combine the ready-to-use approach of an aqueous solution with the increased protein stability of lyophilizates. The high protein stability is a consequence of the solid state of the proteins, which decreases physical and chemical instabilities. Thus, protein powder formulations offer a valuable approach for proteins with low stability in an aqueous solution. This might be the case for protein with intrinsic low stability, poorly soluble proteins, highly concentrated protein formulations as well as if a coformulation of two or more proteins with different formulation optimums is desired. Another interesting approach could be the use of protein powder suspensions in the field of vaccination to overcome the challenge of cold-chain transportation and storage in countries with less developed infrastructure.

Preparation of proteins in powder suspensions comes with challenges regarding formulation, manufacturing and stability. The protein powder can be prepared by different techniques but spray-drying and freeze-drying represent the most promising methods. For both drying techniques, the important stabilizing factors such as $\mathrm{pH}$, buffers, sugars, surfactants or antioxidants have to be optimized with focus on protein integrity.

A promising feature of protein powder suspensions in non-aqueous vehicles is the potential low viscosity at high concentrations, which is currently a hot topic in pharmaceutical industry. For this purpose, the vehicles should feature an inherent viscosity of less than $10 \mathrm{mPa} \cdot \mathrm{s}$. Besides viscosity many other factors including low water content, absence of reactive species, easiness to sterilize and no toxic, pharmacological, immunogenic or local incompatibility effects. Furthermore, the vehicle shall not interfere with protein or suspension physical stability.

While several studies described high protein stability in non-aqueous protein powder suspensions, only little is known about the physical stability of the suspensions including resuspendability, particle size stability and injectability after storage. Previous successes with marketed related formulations such as Bydureon $\mathrm{BCise}^{\circledR}$ an exenatide PLGA microparticle formulation in $\mathrm{MCT}$, and Posilac ${ }^{\circledR}$, a rbSt formulation in $\mathrm{MCT}$ or sesame oil for veterinary use, indicate that such formulations may play a role in commercial protein formulations in the future. 


\section{Literature}

1. Gervasi, V. et al. Parenteral protein formulations: An overview of approved products within the European Union. Eur. J. Pharm. Biopharm. 131, 8-24 (2018).

2. Kinch, M. S. An overview of FDA-approved biologics medicines. Drug Discov. Today 20, 393-398 (2015).

3. Yanan, C., Ping, C., Binlong, C., Suxin, L. \& Hua, G. Monoclonal antibodies: formulations of marketed products and recent advances in novel delivery systems. Drug Dev. Ind. Pharm. 43, 519-530 (2017).

4. Bruno, B. J., Miller, G. D. \& Lim, C. S. Basics and recent advances in peptide and protein drug delivery. Ther. Deliv. 4, 1443-1467 (2014).

5. Choonara, B. F. et al. A review of advanced oral drug delivery technologies facilitating the protection and absorption of protein and peptide molecules. Biotechnol. Adv. 32, 1269-1282 (2014).

6. Usmani, S. S. et al. THPdb: Database of FDA-approved peptide and protein therapeutics. PLoS One 12, 1-12 (2017).

7. Crommelin, D. J. A. et al. Shifting paradigms: biopharmaceuticals versus low molecular weight drugs. Int. J. Pharm. 266, 3-16 (2003).

8. Wang, W. Instability, stabilization, and formulation of liquid protein pharmaceuticals. Int. J. Pharm. 185, 129-188 (1999).

9. Manning, M. C., Patel, K. \& Borchardt, R. T. Stability of Protein Pharmaceuticals. Pharm. Res. 6, 903-918 (1989).

10. Kraus, T., Winter, G. \& Engert, J. Test models for the evaluation of immunogenicity of protein aggregates. Int. J. Pharm. 559, 192-200 (2019).

11. Wang, W., Singh, S., Zeng, D. L., King, K. \& Nema, S. Antibody Structure, Instability, and Formulation. J. Pharm. Sci. 96, 1-26 (2007).

12. Mahler, H.-C., Friess, W., Grauschopf, U. \& Kiese, S. Protein Aggregation: Pathways, Induction Factors and Analysis. J. Pharm. Sci. 98, 2909-2934 (2009).

13. Koepf, E., Eisele, S., Schroeder, R., Brezesinski, G. \& Friess, W. Notorious but not understood: How liquid-air interfacial stress triggers protein aggregation. Int. J. Pharm. 537, 202-212 (2018).

14. Arakawa, T., Prestrelski, S. J., Kenney, W. C. \& Carpenter, J. F. Factors affecting shortterm and long-term stabilities of proteins. Adv. Drug Deliv. Rev. 46, 307-326 (2001).

15. Chang, L. L. \& Pikal, M. J. Mechanisms of protein stabilization in the solid state. J. Pharm. Sci. 98, 2886-2908 (2009).

16. Wang, W. Lyophilization and development of solid protein pharmaceuticals. Int. J. Pharm. 203, 1-60 (2000). 
17. Mensink, M. A., Frijlink, H. W., Maarschalk, K. van der V. \& Hinrichs, W. L. J. How sugars protect proteins in the solid state and during drying (review): Mechanisms of stabilization in relation to stress conditions. Eur. J. Pharm. Biopharm. 114, 288-295 (2017).

18. Jezek, J., Darton, N. J., Derham, B. K., Royle, N. \& Simpson, I. Biopharmaceutical formulations for pre-filled delivery devices. Expert Opin. Drug Deliv. 10, 811-828 (2013).

19. Shire, S. J., Shahrokh, Z. \& Liu, J. Challenges in the Development of High Protein Concentration Formulations. J. Pharm. Sci. 93, 1390-1402 (2004).

20. Mathaes, R., Koulov, A., Joerg, S. \& Mahler, H. C. Subcutaneous Injection Volume of Biopharmaceuticals - Pushing the Boundaries. J. Pharm. Sci. 105, 2255-2259 (2016).

21. Alford, J. R., Kendrick, B. S., Carpenter, J. F. \& Randolph, T. W. High Concentration Formulations of Recombinant Human Interleukin-1 Receptor Antagonist: II. Aggregation Kinetics. Int. J. Drug Dev. Res. 3, 26-33 (2011).

22. Saluja, A. \& Kalonia, D. S. Nature and consequences of protein-protein interactions in high protein concentration solutions. Int. J. Pharm. 358, 1-15 (2008).

23. Chen, G., Houston, P. \& Luk, A. S.-K. WO2006071613A2 - Injectable non-aqueous suspension. (2006).

24. Rutz, A. Oily suspensions as parenteral depot systems of recombinant proteins. (LMU Munich, 2007).

25. Liu, K., DesJardin, M. A., Hill, B. L. \& Li, Z. US7772182B2 - Stable suspension formulations of erythropoietin receptor agonists. (2005).

26. Bowen, M., Armstrong, N. \& Maa, Y.-F. Investigating High-Concentration Monoclonal Antibody Powder Suspension in Nonaqueous Suspension Vehicles for Subcutaneous Injection. J. Pharm. Sci. 101, 4433-4443 (2012).

27. Knepp, V. M., Muchnik, A., Oldmark, S. \& Kalashnikova, L. Stability of nonaqueous suspension formulations of plasma derived factor IX and recombinant human alpha interferon at elevated temperatures. Pharm. Res. 15, 1090-1095 (1998).

28. Weiguo Dai, Beth Hill, Kui Liu, C. M. US 20120076800 - Non-aqueous high concentration reduced viscosity suspension formulations of antibodies. (2012).

29. Miller, M. A., Engstrom, J. D., Ludher, B. S. \& Johnston, K. P. Low viscosity highly concentrated injectable nonaqueous suspensions of lysozyme microparticles. Langmuir 26, 1067-1074 (2011).

30. Pena, L. E., Possert, P. L., Stearns, J. F., Lee, B. L. \& Hageman, M. J. Rheological characterization of rbSt oil suspensions. Int. J. Pharm. 113, 89-96 (1995).

31. Knepp, V. M., Prestrelski, S., Smith, J. \& Huang, M. US20040151779A1 - Stable flowable protein and nucleic acid formulations using non-aqueous, anhydrous, aprotic, hydrophobic, non-polar vehicles with low reactivity. (2004). 
32. Johnston, K. P., Mazuski, M. A., Engstrom, J. \& Rodrigues, M. A. J. WO2010056657A2 Low viscosity highly concentrated suspensions. (2010).

33. Armstrong, N. J., Bowen, M. N. \& Maa, Y.-F. EP2849723A1 - High-concentration monoclonal antibody formulations. (2012).

34. Berkenhoff, K. Subcutaneous suspensions of therapeutic proteins formulated as protein-coated microcrystals. (LMU Munich, 2013).

35. Guenther, B. et al. EP2806886B1 - Stabilised protein compositions based on semifluorinated alkanes. (2013).

36. Srinivasan, C., Weight, A. K., Bussemer, T. \& Klibanov, A. M. Non-aqueous suspensions of antibodies are much less viscous than equally concentrated aqueous solutions. Pharm. Res. 30, 1749-1757 (2013).

37. Gesche, G., Bernhard, G., Dieter, S. \& Anthony, P. EP3024484A1 - Stabilized antibody compositions. (2016).

38. Emami, F., Vatanara, A., Park, E. J. \& Na, D. H. Drying technologies for the stability and bioavailability of biopharmaceuticals. Pharmaceutics 10, 1-22 (2018).

39. Pramanick, S., Singodia, D. \& Chandel, V. Excipient Selection In Parenteral Formulation Development. Pharma Times 45, 65-77 (2013).

40. Roser, B. Trehalose Drying: A Novel Replacement for Freeze-Drying. Biopharm 4, 47-53 (1991).

41. Carpenter, J. F., Pikal, M. J., Chang, B. S. \& Randolph, T. W. Rational Design of Stable Lyophilized Protein Formulations: Some Practical Advice. Pharm. Res. 14, 969-975 (1997).

42. Serno, T., Härtl, E., Besheer, A., Miller, R. \& Winter, G. The Role of Polysorbate 80 and HPBCD at the Air-Water Interface of IgG Solutions. Pharm. Res. 30, 117-130 (2013).

43. Maa, Y.-F., Nguyen, P.-A. T. \& Hsu, S. W. Spray-Drying of Air-Liquid Interface Sensitive Recombinant Human Growth Hormone. J. Pharm. Sci. 87, 152-159 (1998).

44. Adler, M. \& Lee, G. Stability and surface activity of lactate dehydrogenase in spray dried trehalose. J. Pharm. Sci. 88, 199-208 (1999).

45. Thirumangalathu, R. et al. Silicone Oil- and Agitation-Induced Aggregation of a Monoclonal Antibody in Aqueous Solution. J. Pharm. Sci. 98, 3167-3181 (2010).

46. Moreno, M. R. et al. Study of stability and biophysical characterization of ranibizumab and aflibercept. Eur. J. Pharm. Biopharm. 108, 156-167 (2016).

47. Shoyele, S. A. \& Cawthorne, S. Particle engineering techniques for inhaled biopharmaceuticals. Adv. Drug Deliv. Rev. 58, 1009-1029 (2006).

48. Johnson, K. A. Preparation of peptide and protein powders for inhalation. Adv. Drug Deliv. Rev. 26, 3-15 (1997).

49. Patel, R. Parenteral suspension: an overview. Int. J. Curr. Pharm. Res. 2, 4-13 (2010). 
50. Floyd, A. G. Injectable Emulsions and Suspensions, in Pharmaceutical Dosage Forms: Disperse Systems. (Taylor \& Francis Inc, 1996).

51. Tang, X. C. \& Pikal, M. J. Design of Freeze-Drying Processes for Pharmaceuticals: Practical Advice. Pharm. Res. 21, 191-200 (2004).

52. Ehmer, A. Micronization of proteins by Jet Milling. (University of Regensburg, 2009).

53. Lee, P. W., Maia, J. \& Pokorski, J. K. Milling solid proteins to enhance activity after meltencapsulation. Int. J. Pharm. 533, 254-265 (2017).

54. Etzl, E. E., Winter, G. \& Engert, J. Toward intradermal vaccination: preparation of powder formulations by collapse freeze-drying. Pharm. Dev. Technol. 19, 213-222 (2014).

55. Anamur, C., Winter, G. \& Engert, J. Stability of collapse lyophilized influenza vaccine formulations. Int. J. Pharm. 483, 131-141 (2015).

56. Platz, R. M., IpC, A. \& Witham, lyde L. WO1993013752A1 - Improved process for preparing micronized polypeptide drugs. (1993).

57. Stein, J., Fuchs, T. \& Mattern, C. Advanced Milling and Containment Technologies for Superfine Active Pharmaceutical Ingredients. Chem. Eng. Technol. 1464-1470 (2010).

58. Irngartinger, M., Camuglia, V., Damm, M., Goede, J. \& Frijlink, H. W. Pulmonary delivery of therapeutic peptides via dry powder inhalation: effects of micronisation and manufacturing. Eur. J. Pharm. Biopharm. 58, 7-14 (2004).

59. Platz, R. M., Utsumi, J., Satoh, Y. \& Naruse, N. W01991016038A1 - Pharmaceutical aerosol formulation of solid polypeptide microparticles and method for the preparation thereof. (1990).

60. Etzl, E. Collapse dried protein powders for needle-free ballistic injection. (LMU Munich, 2016).

61. Engert, J. et al. A pilot study using a novel pyrotechnically driven prototype applicator for epidermal powder immunization in piglets. Int. J. Pharm. 545, 215-228 (2018).

62. Anamur, C. Novel formulation approaches for ballistic intradermal vaccination. (LMU Munich, 2015).

63. Ziaee, A. et al. Spray drying of pharmaceuticals and biopharmaceuticals: Critical parameters and experimental process optimization approaches. Eur. J. Pharm. Sci. 127, 300-318 (2019).

64. Lee, G. in Rational Desing of Stable Protein Formulations 135-158 (2002).

65. Maa, Y. F., Nguyen, P.-A., Sweeney, T., Shire, S. J. \& Hsu, C. C. Protein inhalation powders: spray drying vs spray freeze drying. Pharm. Res. 16, 249-254 (1999).

66. Schaefer, J. \& Lee, G. Arrhenius activation energy of damage to catalase during spraydrying. Int. J. Pharm. 489, 124-130 (2015). 
67. Maa, Y. F., Nguyen, P. A., Sit, K. \& Hsu, C. C. Spray-drying performance of a bench-top spray dryer for protein aerosol powder preparation. Biotechnol. Bioeng. 60, 301-309 (1998).

68. Keil, T. W. M. et al. Characterization of spray dried powders with nucleic acid-containing PEI nanoparticles. Eur. J. Pharm. Biopharm. (2019).

69. Mumenthaler, M., Hsu, C. C. \& Pearlman, R. Feasibility Study on Spray-Drying Protein Pharmaceuticals: Recombinant Human Growth Hormone and Tissue-Type Plasminogen Activator. Pharm. Res. 11, 12-20 (1994).

70. Ameri, M. \& Maa, Y. Spray Drying of Biopharmaceuticals: Stability and Process considerations. Dry. Technol. 24, 763-768 (2007).

71. Maa, Y. F., Nguyen, P. A. T. \& Hsu, S. W. Spray-drying of air-liquid interface sensitive recombinant human growth hormone. J. Pharm. Sci. 87, 152-159 (1998).

72. Maa, Y. \& Hsu, C. C. Protein Denaturation by Combined Effect of Shear and Air-Liquid Interface. Biotechnol. Bioeng. 54, 503-512 (1997).

73. Schuele, S. Stabilization of Antibodies in Spray-dried Powders for Inhalation. (LMU Munich, 2005).

74. Fitzner, M. Chemical and physicochemical stability of spray-dried rhIL-11 formulations. (Friedrich-Alexander University Erlangen-Nürnberg, 2003).

75. Gikanga, B. et al. Manufacturing of High-Concentration Monoclonal Antibody Formulations via Spray Drying--the Road to Manufacturing Scale. PDA J. Pharm. Sci. Technol. 69, 59-73 (2015).

76. Zhou, P., Liu, D., Chen, X., Chen, Y. \& Labuza, T. P. Stability of whey protein hydrolysate powders: Effects of relative humidity and temperature. Food Chem. 150, 457-462 (2014).

77. Ahlneck, C. \& Zografi, G. The molecular basis of moisture effects on the physical and chemical stability of drugs in the solid state. Int. J. Pharm. 62, 87-95 (1990).

78. Carstensen, J. T. \& Van Scoik, C. Amorphous-to-Crystalline Transformation of Sucrose. Pharm. Res. 7, 1278-1281 (1990).

79. Hageman, M. J. The role of moisture in protein stability. Drug Dev. Ind. Pharm. 14, 2047-2070 (1988).

80. Heljo, V. P. et al. The effect of water plasticization on the molecular mobility and crystallization tendency of amorphous disaccharides. Pharm. Res. 29, 2684-2697 (2012).

81. Lai, M. C. \& Topp, E. M. Solid-state chemical stability of proteins and peptides. J. Pharm. Sci. 88, 489-500 (1999).

82. Liu, W. R., Langer, R. \& Klibanov, A. M. Moisture-induced aggregation of lyophilized proteins in the solid state. Biotechnol. Bioeng. 37, 177-184 (1991). 
83. Maa, Y. F. et al. Effect of spray drying and subsequent processing conditions on residual moisture content and physical/biochemical stability of protein inhalation powders. Pharm. Res. 15, 768-775 (1998).

84. Costantino, H. R. et al. Protein Spray-Freeze Drying . Effect of Atomization Conditions on Particle Size and Stability. Pharm. Res. 17, 1374-1383 (2000).

85. Gombotz, W. R., Healy, M. S., Brown, L. R. \& Auer, H. E. WO1990013285A1 - Process for producing small particles of biologically active molecules. (1990).

86. Jovanović, N. et al. Stabilization of IgG by supercritical fluid drying: Optimization of formulation and process parameters. Eur. J. Pharm. Biopharm. 68, 183-190 (2008).

87. Jovanović, N. et al. Stable sugar-based protein formulations by supercritical fluid drying. Int. J. Pharm. 346, 102-108 (2008).

88. Moshashaée, S., Bisrat, M., Forbes, R. T., Nyqvist, H. \& York, P. Supercritical fluid processing of proteins: Lysozyme precipitation from organic solution. Jounral Pharm. Pharmacol. 11, 239-245 (2000).

89. Matheus, S., Friess, W., Schwartz, D. \& Mahler, H. C. Liquid high concentration IgG1 antibody formulations by precipitation. J. Pharm. Sci. 98, 3043-3057 (2009).

90. Gottschalk, S. Crystalline monoclonal antibodies: process development for large scale production, stability and pharmaceutical applications. (LMU Munich, 2008).

91. Borhani, D. W. et al. WO2008057240A9 - Crystalline anti-htnfalpha antibodies. (2008).

92. FDA Inactive Ingredient List https://www.accessdata.fda.gov/scripts/cder/iig/index.Cfm - accessed on 13.01.2019.

93. Steffe, J. F. Rheological Methods in Food Process Engineering. (1992).

94. Wohlfarth, C. Viscosity of Pure Organic Liquids and Binary Liquid Mixtures. (Springer, 2017).

95. Khattab, I. S., Bandarkar, F., Khoubnasabjafari, M. \& Jouyban, A. Density, viscosity, surface tension, and molar volume of propylene glycol + water mixtures from 293 to $323 \mathrm{~K}$ and correlations by the Jouyban - Acree model. Arab. J. Chem. 10, S71-S75 (2017).

96. Mackiewicz, J. et al. Effect of gravity in long-term vitreous tamponade: in vivo investigation using perfluorocarbon liquids and semi-fluorinated alkanes. Graefe's Arch. Clin. Exp. Ophthalmol. 245, 665-675 (2007).

97. Tsagogiorgas, C. et al. Evaluation of pharmacokinetic properties and anaesthetic effects of propofol in a new perfluorohexyloctane $(\mathrm{F} 6 \mathrm{H} 8)$ emulsion in rats - A comparative study. Int. J. Pharm. 486, 69-76 (2015).

98. Tsagogiorgas, C. et al. Semifluorinated alkanes - A new class of excipients suitable for pulmonary drug delivery. Eur. J. Pharm. Biopharm. 76, 75-82 (2010).

99. Spiegel, A. J. \& Noseworthy, M. N. Use of Nonaqueous solvents in Parenteral Products. J. Pharm. Sci. 52, 917-927 (1963). 
100. Fahr, A. Voigt's Pharmaceutical Technology. (Wiley, 2018).

101. Akers, M. J., Fites, A. L. \& Robison, R. L. Formulation Design and Development of Parenteral Suspensions. J. Parenter. Sci. Technol. 41, 88-96 (1987).

102. Dasler, W. \& Bauer, C. D. Removal of Peroxides from Organic Solvents. Ind. Eng. Chem. Anal. Ed. 18, 52-54 (1946).

103. Pratt, D. A., Tallman, K. A. \& Porter, N. A. Free Radical Oxidation of Polyunsaturated Lipids: New Mechanistic Insights and the Development of Peroxyl Radical Clocks. Acc. Chem. Res. 44, 458-467 (2012).

104. Yordanova, Y. Oil-Based Parenteral Depot Formulation for Veterinary Peptide Delivery. (LMU Munich, 2018).

105. Simon, A. L. et al. Pregnancy outcomes from more than 1,800 in vitro fertilization cycles with the use of 24-chromosome single-nucleotide polymorphism - based preimplantation genetic testing for aneuploidy. Fertil. Steril. 110, 113-121 (2018).

106. Eremin, A. V. \& Vakushin, B. I. Study of the possibility of replacing vegetable oils by ethyl oleate in the production of solutions for injection. Pharm. Chem. J. 11, 1413-1415 (1977).

107. Hemenway, J. N. et al. Formation of Reactive Impurities in Aqueous and Neat Polyethylene Glycol 400 and Effects of Antioxidants and Oxidation Inducers. J. Pharm. Sci. 101, 17-20 (2012).

108. McGinity, J. W., Hill, J. A. \& La Via, A. L. Influence of Peroxide Impurities in Polyethylene Glycols on Drug stability. J. Pharm. Sci. 64, 356-357 (1975).

109. Latven, A. R. \& Molitor, H. Comparison of the toxic, hypnotic, and irritating properties of eight organic solvents. J. Pharmacol. Exp. Ther. 65, 89-94 (1938).

110. Mottu, F., Laurent, A., Rüfenacht, D. A. \& Doelker, E. Organic Solvents for Pharmaceutical Parenterals and Embolic Liquids: A Review of Toxicity Data. PDA J. Pharm. Sci. Technol. 54, 456-469 (2000).

111. CHMP. Benzyl alcohol and benzoic acid group used as excipients - Report published in support of the 'Questions and answers on benzyl alcohol used as an excipient in medicinal products for human use' (EMA/CHMP/508188/2013). (2017).

112. Fey, M. W., Weil, M. \& Segur, J. B. Solubility of Sucrose in Aqueous Glycerol and Propylene Glycol. Ind. Eng. Chem. 43, 1435-1436 (1951).

113. Reber, L. A. The solubility of sucrose in hydroalcoholic solutions. J. Pharm. Sci. 42, 192193 (1953).

114. Griebenow, K. \& Klibanov, A. M. On Protein Denaturation in Aqueous - Organic Mixtures but Not in Pure Organic Solvents. J. Am. Chem. Soc. 7863, 141-144 (1996).

115. Brandts, J. F. \& Hunt, L. Thermodynamics of protein denaturation. III. Denaturation of ribonuclease in water and in aqueous urea and aqueous ethanol mixtures. J. Am. Chem. Soc. 89, 4826-4838 (1976). 
116. Riess, J. G. Criteria for the Selection of Perfluorochemicals for Second-Generation Blood Substitutes : Analysis of Structure/Property Relationships. Artif. Organs 8, 44-56 (1984).

117. Audran, M., Pierre, M., Ceaurriz, J. De \& Maturin, J. Determination of perfluorodecalin and perfluoro-N-methylcyclohexylpiperidine in rat blood by gas chromatography mass spectrometry. J. Chromatogr. B 745, 333-343 (2000).

118. Riess, J. G. \& Krafft, M. P. Advanced Fluorocarbon-Based Systems for Oxygen and Drug Delivery, and Diagnosis. Artifical Cells, Nanomedicine Biotechnol. 25, 43-52 (1997).

119. Krafft, M. P. \& Riess, J. G. Chemistry, physical chemistry, and uses of molecular fluorocarbon- hydrocarbon diblocks, triblocks, and related compounds-unique 'apolar' components for self-assembled colloid and interface engineering. Chem. Rev. 109, 1714-1792 (2009).

120. Napoli, M. Diblock and triblock semifluorinated n-alkanes: Preparations, structural aspects and applications. J. Fluor. Chem. 79, 59-69 (1996).

121. Dutescu, R. M., Panfil, C., Merkel, O. M. \& Schrage, N. Semifluorinated alkanes as a liquid drug carrier system for topical ocular drug delivery. Eur. J. Pharm. Biopharm. 88, 123-128 (2014).

122. Meinert, H. \& Roy, T. Semifluorinated alkanes - A new class of compounds with outstanding properties for use in ophthalmology. Eur. J. Ophthalmol. 10, 189-197 (2000).

123. Mehmood, Y. \& Farooq, U. Excipients Use in Parenteral and Lyophilized Formulation Development. Open Sci. J. Pharm. Pharmacol. 3, 19-27 (2015).

124. Birk, G. Formulation development of a highly concentrated suspension of Cilengitide. (LMU Munich, 2015).

125. Sacha, G., Rogers, J. A. \& Miller, R. L. Pre-filled syringes : a review of the history, manufacturing and challenges. Pharm. Dev. Technol. 7450, 1-11 (2015).

126. Nayak, A., Colandene, J., Bradford, V. \& Perkins, M. Characterization of Subvisible Particle Formation During the Filling Pump Operation of a Monoclonal Antibody Solution. 100, 4198-4204 (2011).

127. Towns, J. K. Moisture content in proteins : its effects and measurement. J. Chromatogr. A 705, 115-127 (1995).

128. Krieger, I. M. \& Dougherty, T. J. A Mechanism for Non-Newtonian Flow in Suspensions of Rigid Spheres. Trans. Soc. Rheol. 3, 137-152 (1959).

129. Toda, K. \& Furuse, H. Extension of Einstein's viscosity equation to that for concentrated dispersions of solutes and particles. J. Biosci. Bioeng. 102, 524-528 (2006).

130. Allmendinger, A. et al. Rheological characterization and injection forces of concentrated protein formulations: An alternative predictive model for non-Newtonian solutions. Eur. J. Pharm. Biopharm. 87, 318-328 (2014). 
131. Genovese, D. B. Shear rheology of hard-sphere, dispersed, and aggregated suspensions, and filler-matrix composites. Adv. Colloid Interface Sci. 171-172, 1-16 (2012).

132. Kanai, S., Liu, J., Patapoff, T. W. \& Shire, S. J. Reversible Self-Association of a Concentrated Monoclonal Antibody Solution Mediated by Fab-Fab Interaction That Impacts Solution Viscosity. J. Pharm. Sci. 97, 4219-4227 (2008).

133. Cilurzo, F. et al. Injectability Evaluation: An Open Issue. AAPS PharmSciTech 12, 604609 (2011).

134. Groves, M. J. Parenteral technology manual: an introduction to formulation, production and quality aspects of parenteral products. (Interpharm Press, 1989).

135. Sheikhzadeh, A., Sheikhzadeh, A., Yoon, J., Formosa, D. \& Domanska, B. The effect of a new syringe design on the ability of rheumatoid arthritis patients to inject a biological medication. Appl. Ergon. 43, 368-375 (2011).

136. Rungseevijitprapa, W. \& Bodmeier, R. Injectability of biodegradable in situ forming microparticle systems (ISM ). Eur. J. Pharm. Sci. 36, 524-531 (2008).

137. Burckbuchler, V. et al. Rheological and syringeability properties of highly concentrated human polyclonal immunoglobulin solutions. Eur. J. Pharm. Biopharm. 76, 351-356 (2010).

138. Chang, L. L. et al. Mechanism of Protein Stabilization by Sugars During Freeze-Drying and Storage: Native Structure Preservation, Specific Interaction, and/ or Immobilization in a Glassy Matrix ? J. Pharm. Sci. 94, 1427-1444 (2005).

139. Prestrelski, S. J., Tedeschi, N., Arakawa, T. \& Carpenter, J. F. Dehydration-induced Conformational Transitions in Proteins and Their Inhibition by Stabilizers. Biophys. J. 65, 661-671 (1993).

140. Allison, S. D., Chang, B., Randolph, T. W. \& Carpenter, J. F. Hydrogen Bonding between Sugar and Protein Is Responsible for Inhibition of Dehydration-Induced Protein Unfolding. Arch. Biochem. Biophys. 365, 289-298 (1999).

141. Mattos, C. \& Ringe, D. Proteins in organic solvents. Curr. Opin. Struct. Biol. 11, 761-764 (2001).

142. Pikal, M. J., Dellerman, K. M., Roy, M. L. \& Riggin, R. M. The effects of Formulation Variables on the Stability of Freeze-Dried Human Growth Hormone. Pharm. Res. 8, 427436 (1991).

143. Pikal, M. J., Dellerman, K. M. \& Roy, M. L. Formulation and stability of freeze-dried proteins: effects of moisture and oxygen on the stability of freeze-dried formulations of human growth hormone. Dev. Biol. Stand. 74, 21-37 (1992).

144. Hsu, C. C. et al. Surface Denaturation at Solid-Void Interface - A Possible Pathway by Which Opalescent Participates Form During the Storage of Lyophilized Tissue-Type Plasminogen Activator at High Temperatures. Pharm. Res. 12, 69-77 (1995).

145. Schersch, K. et al. Systematic Investigation of the Effect of Lyophilizate Collapse on Pharmaceutically Relevant Proteins, Part 2: Stability During Storage at Elevated 
Temperatures. J. Pharm. Sci. 101, 1-19 (2012).

146. Falkiewicz, M. J. Theory of suspensions. In Liebermann Pharmaceutical Dosage forms, Disperse Systems. (Dekker, 1988).

147. Grau, U. \& Pohler, W. EP19870102367 - Device for dispensing medicinal suspensions. (1987).

148. Naini, V., Byron, I. P. R. \& Phillips, E. M. Physicochemical Stability of Crystalline Sugars and Their Spray-Dried Forms : Dependence upon Relative Humidity and Suitability for Use in Powder Inhalers. Drug Dev. Ind. Pharm. 24, 895-909 (1998).

149. Markovic, I. Evaluation of safety and quality impact of extractable and leachable substances in therapeutic biologic protein products: a risk-based perspective. Expert Opin. Drug Saf. 6, 487-491 (2007).

150. Dexter, M. B. \& Shott, M. J. The evaluation of the force to expel oily injection vehicles from syringes. J. Pharm. Pharmacol. 31, 497-500 (1979).

151. Rathbone, M. J. \& McDowell, A. Long Acting Animal Health Drug Products: Fundamentals and Applications. (Springer Science \& Business Media, 2012).

152. Streit, M., Beleznay, Z. \& Braathen, L. R. Topical application of the tumour necrosis factor- $\alpha$ antibody infliximab improves healing of chronic wounds. Int. Wound J. 3, 171179 (2006).

153. Bock, F., König, Y., Kruse, F., Baier, M. \& Cursiefen, C. Bevacizumab (Avastin) eye drops inhibit corneal neovascularization. Graefe's Arch. Clin. Exp. Ophthalmol. 246, 281-284 (2008).

154. Lambiase, A. et al. Nerve growth factor promotes corneal healing: Structural, biochemical, and molecular analyses of rat and human corneas. Investig. Ophthalmol. Vis. Sci. 41, 1063-1069 (2000).

155. Lambiase, A., Rama, P., Bonini, S., Caprioglio, G. \& Aloe, L. Topical Treatment with Nerve Growth Factor for Corneal Neurotrophic Ulcers. N. Engl. J. Med. 338, 1174-1180 (1998). 


\section{Chapter II}

\section{Objectives and outline of the thesis}

Protein powder suspensions in non-aqueous vehicles provide an interesting alternative to conventional formulations such as aqueous solutions and lyophilizates and potentially feature a variety of advantages for different applications. Besides powder manufacturing, vehicle selection is key for such preparations. Powders for the use in such formulations can be prepared in several ways including milling of lyophilizates and spray-drying.

Chapter III aimed to get a deeper understanding on how milling of model monoclonal antibody (mAb) lyophilizates can be used as a technique to generate protein powders for suspensions in non-aqueous vehicles. It was of interest, if wet media milling can yield protein powder suspensions without damage to the protein. An alternative is dry milling in absence of a suspension vehicle. The chapter aimed to identify critical process parameters and to optimize the milling process. Studied process parameters included the milling ball size, milling frequency, ball to powder mass ratio, milling duration as well as application of cooling. Furthermore, it was tested whether excipients or the protein to stabilizer ratio influence protein stability during milling. With the obtained powder, suspensions were prepared and their viscosities and glide forces were tested.

Highly concentrated protein formulations currently play an important role in the pharmaceutical industry, but face different challenges such as decreased protein stability and increased glide forces needed for injection. Protein powder suspensions in non-aqueous vehicles may represent a beneficial alternative and can yield low viscosity formulations depending on the selected suspension vehicle. Traditionally used non-aqueous liquids for injection, such as vegetable oils, are not suitable for high concentration suspension formulations due to their high inherent viscosity. Consequently, low viscosity alternatives are of particular interest. Thus, the goal of Chapter IV was to test various potential vehicles regarding their ability to yield high concentration low viscosity formulations. Promising candidates included semifluorinated alkanes (SFAs), due to their low viscosity, good biocompatibility and inertness towards biopharmaceuticals. In contrary to the previous chapter, spray-drying was used to prepare the protein powder. It was of interest how SFA 
based suspensions perform with regard to rheology and injection characteristics compared to aqueous solutions. In order to select a suitable syringe design, prediction of glide forces using mathematical models and equations was evaluated. Finally, with commercial manufacturability in mind, the feasibility of the vial filling process of the developed suspensions, using a peristaltic pump, was tested and evaluated.

Chapter $\mathbf{V}$ provides more detailed insight into long term physical suspension stability of lysozyme, mAb and bevacizumab powder suspensions in different suspension vehicles including SFAs, medium chain triglycerides (MCT) and ethyl oleate (EO). Physical suspension stability includes resuspendability, particle size constancy and injectability. Both excipients and the protein to stabilizer ratio might influence the stability. Furthermore, the application of an additional drying step was tested to improve the physical suspension stability. Suspensions were stored in vials, as well as in prefillable syringes, which provide easier administration.

Not only suspension physical stability, but also protein stability has to be maintained over storage time. In the case of protein powder suspensions in non-aqueous vehicles, protein instabilities can have two different causes. First the inherent stability of the powder has to be considered. Secondly, the influence of the suspension vehicle on protein stability might play a role. The focus of Chapter VI lied on the influence of different potential vehicles and powder compositions on protein stability in non-aqueous powder suspensions. For this purpose, stability of a mAb and bevacizumab in SFAs, MCT and EO were studied. Combined with investigations on suspension physical stability this chapter should give valuable information on the applicability of the non-aqueous powder suspension approach for protein formulations.

Besides subcutaneous injection, topical ocular protein delivery to the cornea is of interest, especially after the recent approval of a protein drug for the treatment of neurotrophic keratitis. This application route faces poor drug penetration and short residence time as important challenges. In Chapter VII formulations for improved corneal protein delivery based on protein powder suspensions in non-aqueous vehicles, considering the addition of penetration enhancers, were investigated. A main focus lied on the performance of protein powder suspension in SFAs, as previous investigations on topical ocular delivery of small molecule drugs in SFAs showed promising results. 
The overall goal of the thesis was to study the various opportunities of powder suspensions in non-aqueous vehicles for protein formulation with a focus on SFAs. The various chapters present pathways for successfully developing, characterizing and manufacturing such preparations, which may provide superior suspension and protein stability also at high protein concentration. 



\section{Chapter III}

\section{Preparation of highly concentrated protein powder suspensions by wet media and cryogenic milling of lyophilizates}

\section{Abstract}

Pharmaceutical formulations utilizing protein drugs as powders can be used as drug delivery systems in various ways. Besides powders for inhalation, another promising approach is their use as suspensions in non-aqueous liquids for subcutaneous administration providing high protein stability and good injectability. In this study protein powder suspensions were prepared using a swing-mill. Milling of lyophilizates containing a model monoclonal antibody in presence of the suspension vehicle was compared to cryogenic dry milling. Wet media milling was conducted in perfluorohexyloctane and led to injectable suspensions, but marketed protein aggregation and monomer loss. When the lyophilizates were cryogenic dry ball milled less aggregation and monomer loss was detected. Differences related to protein integrity were found for different process parameters in cryogenic dry milling. Decreasing the size of the milling balls as well as the frequency led to a lower mAb monomer loss and a lower amount of aggregated protein. If not cooled with liquid nitrogen, dry milling resulted in increased damage to the mAb. The type of polyol stabilizer, as well as the protein to stabilizer ratio, did not affect the preservation of protein integrity.

As finding the right milling duration is time and resource intensive, a correlation between lyophilizate cake rigidity and milling duration was established. Based on this approach high concentration lyophilizates were successfully micronized. Suspensions of cryogenic milled powders lead to clogging of $25 \mathrm{G}$ needles, which could be prevented by an additional sieving step to remove particle agglomerates larger than $40 \mu \mathrm{m}$. Depending on the suspension vehicle, low viscosity formulations ( $<10 \mathrm{mPa} \cdot \mathrm{s}$ ) even at high concentrations ( $\geq 100 \mathrm{mg} / \mathrm{ml}$ protein concentration) were obtained featuring good injectability. Thus, we could show that protein powder suspensions with high protein stability and good handling qualities can be prepared via cryogenic milling of lyophilizates. 


\section{Introduction}

Protein powders can be used in a variety of different dosage forms, including pulmonary drug delivery ${ }^{1-3}$, embedded in matrices for sustained parenteral release $\mathrm{e}^{4,5}$ and for intradermal vaccination $^{6-8}$. Another promising approach is their use as suspensions in non-aqueous liquids for subcutaneous administration. ${ }^{9,10}$ Potential suspension vehicles include lipophilic liquids such as ethyl lactate ${ }^{9}$, medium-chain triglycerides $(\mathrm{MCT})^{9,10}$, benzyl benzoate ${ }^{9,11}$, ethyl oleate ${ }^{11}$ and vegetable oils ${ }^{11,12}$. Perfluorinated liquids such as perfluorodecalin ${ }^{12}$ as well as semifluorinated alkanes (SFAs) $)^{13,14}$ provide another option. Protein powder suspensions combine the ready to use approach of aqueous solutions with the high protein stability in the solid state. ${ }^{12}$ Another advantage of these formulations is their potentially lower viscosity compared to the respective aqueous solution at high protein concentration. ${ }^{9,11}$

Powders of biopharmaceuticals can be prepared in different ways. The two main techniques for powder preparation are lyophilization with an additional milling step ${ }^{3,6}$ and spray-drying with its variant spray-freeze drying ${ }^{1,9,15}$. Additionally, crystallization and protein coated microcrystals have been used. ${ }^{16,17}$ In this study milling of lyophilizates using a ball mill was studied. Milling of proteins is a challenging process step, as high local temperatures can occur at the breaking spots, resulting in potential protein damage. ${ }^{18}$ Recently it has been shown, that the use of a ball mill cooled with liquid nitrogen can render protein powder formulations with good process stability. ${ }^{6,7}$ Other potential milling techniques include jet milling ${ }^{18}$ or simply by hand with a pestle and a mortar ${ }^{19,10}$. When it comes to milling of mAb lyophilizates, the goal is to obtain formulations with high protein stability and homogeneous particle size distribution of the powder. As the powder prepared in this work is intended for injectable suspensions, particle size should be reduced sufficiently in order to prevent clogging of thin needles. Protein powder suspensions for subcutaneous (s.c.) or intramuscular (i.m.) administration are usually prepared using protein powder of about 5-30 $\mu \mathrm{m} \cdot{ }^{9,11}$ In literature it is usually recommended to aim for a powder particle size of $1 / 3$ of the needle inner diameter to prevent needle clogging. ${ }^{20,21}$ The achieved particle size mainly depends on the preparation technique. Spray-drying and jet-milling usually result in particle sizes of around 2-10 $\mu \mathrm{m}$, while ball milling of lyophilizates results in larger particle sizes with D50 values up to $50 \mu \mathrm{m} .{ }^{6,9,18}$ Milling in general is a difficult and hard-to-predict process step, which makes it time and resource intensive to optimize process parameters. ${ }^{18}$ An ideal milling process should balance milling duration and energy input per time to lead to sufficient micronization at 
minimal protein damage. Wet media milling is an alternative to conventional dry milling. Here the lyophilizate is milled in the presence of the suspension vehicle leading to the final product. This makes an additional dispersing step unnecessary. Interestingly we did not find any investigations in literature dealing with wet media milling of therapeutic proteins. In contrast to that, suspensions of peptides were successfully prepared by wet media milling before. 22,23 Dry milling of lyophilizates provides another interesting approach. In a previous study protein and vaccine lyophilizates were successfully cryogenic dry ball milled to $20-70 \mu \mathrm{m}$ for ballistic intradermal applications. ${ }^{7,8,24}$ These particles would be too large for use in suspensions intended for injection through thin needles.

Non-aqueous protein powder suspensions are an interesting technique for highly concentrated protein formulations. ${ }^{9,11}$ Especially monoclonal antibodies (mAbs) are often applied subcutaneously or intramuscularly in high doses to above $100 \mathrm{mg} .{ }^{25-27}$ With high protein concentrations challenges such as high solution viscosity and increased aggregation rate can arise..$^{25,28,29}$ These could potentially be prevented by using the non-aqueous protein powder approach. ${ }^{9,11}$ Due to the dry solid state, the protein is less prone to physicochemical degradation. ${ }^{30,31}$

The suspension viscosity is directly affected by the volume fraction of the powder. ${ }^{9,11}$ As a consequence, in order to obtain high-concentration protein formulations, powders should contain little stabilizer such as trehalose or sucrose, but provide sufficient protein stability. ${ }^{32}$ The powder preparation technique of lyophilizate milling was selected, as lyophilizates are the most common powder form for biopharmaceuticals with several marketed products. ${ }^{33}$ But the micronization process, which comes with a high energy input, harbours the risk of damaging the sensitive protein. In this study we investigated, whether protein powder suspensions can be prepared via wet media milling in the non-aqueous vehicle or cryogenic dry ball milling. Results of milling lyophilizates with a low stabilizer content, which are needed for the preparation of highly concentrated protein powder suspensions were of special interest. Further suspension quality and handling properties, specifically injectability were studied. Selected suspension vehicles included perfluorohexyloctane and medium chain triglycerides. 


\section{Materials and Methods}

\subsection{Materials}

A monoclonal IgG1 antibody (mAb) produced in Chinese hamster ovary cells in $25 \mathrm{mM}$ histidine $1.6 \mathrm{mM}$ glycine buffer $\mathrm{pH} 6.0$ at $57 \mathrm{mg} / \mathrm{ml}$ was used $\left(\varepsilon_{280 \mathrm{~nm}}: 1.49 \mathrm{ml} \mathrm{g}^{-1} \mathrm{~cm}^{-1}\right)$. Lysozyme (Lys) bulk solutions were prepared by dissolution of pure lysozyme (white lysozyme 22300 units/g hen egg white, Dalian Greensnow Egg Products Development, Liaoning, China) in $10 \mathrm{mM}$ histidine buffer at $\mathrm{pH}$ 6.0. Formulations were prepared in highly purified water (HPW) obtained via an ELGA Purelab system (ELGA LabWater, Celle, Germany) using trehalose (Hayashibara, Okayama, Japan), mannitol, sucrose, L-histidine and L-histidinemonohydrochloride monohydrate (Sigma-Aldrich, St. Louis, USA). Perfluorohexyloctane (F6H8) (provided by Novaliq, Heidelberg, Germany) and Miglyol ${ }^{\circledR} 812$ (MCT) (Caesar \& Loretz, Hilden, Germany) were used as suspension vehicles. Dispersion medium for laser diffraction measurement contained isooctane and Span 80 (Merck, Darmstadt, Germany). Running buffer for high pressure size exclusion chromatography (HP-SEC) contained HPW, sodium sulphate, monosodium phosphate dihydrate (Grüssing, Filsum, Germany) and disodium phosphate dihydrate (Bernd Kraft, Duisburg, Germany).

\subsection{Formulations for freeze-drying}

Solutions for freeze-drying contained the respective protein and sugars as stabilizers. Protein buffers were exchanged to the respective buffer using a SpectraPor RC dialysis membrane with a molecular weight cut off of 6-8 kDa (Spectrum Laboratories, Los Angeles, USA). All formulations were prepared in a $10 \mathrm{mM}$ histidine buffer at pH 6.0 and were filtered using a VWR $0.2 \mu \mathrm{m}$ polyethersulfone syringe filter (VWR, Radnor, USA). For freeze-drying, $4 \mathrm{ml}$ of the prepared solution was transferred in 10R type 1 glass vials (MGlas, Muennerstadt, Germany) and a lyophilization stopper was attached (Helvoet Pharma, Tilburg, Netherlands). Vials and stoppers were washed with HPW and dried for $8 \mathrm{~h}$ at 100 and $80^{\circ} \mathrm{C}$, respectively. Formulations are described in Table III-1. 
Table III-1: Formulations for freeze-drying.

\begin{tabular}{|c|c|c|}
\hline Formulation & Protein, stabilizer ( $\mathrm{m} / \mathrm{m}$ ratio) & Total solid content \\
\hline $\mathrm{mAb} / \mathrm{Suc} / 1: 1 / 5 \%$ & mAb, sucrose (1:1) & $50 \mathrm{mg} / \mathrm{ml}$ \\
\hline $\mathrm{mAb} / \mathrm{Suc} / 1: 1 / 2.5 \%$ & mAb, sucrose $(1: 1)$ & $25 \mathrm{mg} / \mathrm{ml}$ \\
\hline $\mathrm{mAb} /$ Suc/1:1/10\% & mAb, sucrose $(1: 1)$ & $100 \mathrm{mg} / \mathrm{ml}$ \\
\hline $\mathrm{mAb} / \mathrm{Suc} / 1: 6 / 5 \%$ & mAb, sucrose (1:6) & $50 \mathrm{mg} / \mathrm{ml}$ \\
\hline mAb/Man/Suc/1:5:1/5\% & mAb, mannitol, sucrose $(1: 5: 1)$ & $50 \mathrm{mg} / \mathrm{ml}$ \\
\hline $\mathrm{mAb} / \mathrm{Suc} / 7: 3 / 5 \%$ & mAb, sucrose $(7: 3)$ & $50 \mathrm{mg} / \mathrm{ml}$ \\
\hline $\mathrm{mAb} /$ Tre/7:3/5\% & mAb, trehalose $(7: 3)$ & $50 \mathrm{mg} / \mathrm{ml}$ \\
\hline Lys/Suc/1:1/5\% & Lys, sucrose $(1: 1)$ & $50 \mathrm{mg} / \mathrm{ml}$ \\
\hline Lys/Suc/1:1/10\% & Lys, sucrose $(1: 1)$ & $100 \mathrm{mg} / \mathrm{ml}$ \\
\hline Placebo/5\% & sucrose & $50 \mathrm{mg} / \mathrm{ml}$ \\
\hline Placebo/7.5\% & sucrose & $75 \mathrm{mg} / \mathrm{ml}$ \\
\hline Placebo/10\% & sucrose & $100 \mathrm{mg} / \mathrm{ml}$ \\
\hline
\end{tabular}

\subsection{UV-Vis}

Protein concentrations were measured with a NanoDrop 2000 spectrophotometer (Thermo Scientific, Waltham, USA) at a wavelength of $280 \mathrm{~nm}$.

\subsection{Freeze-drying}

Freeze-drying was conducted using a pilot scale Christ 2D-6 LSCplus freeze-drier (Martin Christ Gefriertrocknungsanlagen, Osterode, Germany). The freezing step was conducted with a ramp of $1 \mathrm{~K} / \mathrm{min}$ to $-50^{\circ} \mathrm{C}$ followed by a $2 \mathrm{~h}$ hold. For primary drying a vacuum of $0.133 \mathrm{mbar}$ was applied. The shelf temperature was increased by $0.33 \mathrm{~K} / \mathrm{min}$ to $-25^{\circ} \mathrm{C}$ and held for $60 \mathrm{~h}$. Secondary drying was performed at $35^{\circ} \mathrm{C}$ and $0.133 \mathrm{mbar}$ for $12 \mathrm{~h}$ after increasing the temperature by $0.1 \mathrm{~K} / \mathrm{min}$. Lyophilizates were closed under slight vacuum of $800 \mathrm{mbar}$ in the freeze-drier, removed, manually capped using 10R caps (Westpharma, Exton, USA) and stored at $5^{\circ} \mathrm{C}$ in a desiccator until further use. 


\subsection{Powder handling}

Powder handling was conducted under nitrogen environment in a custom-made glove box to prevent water uptake.

\subsection{Wet media milling}

Wet media milling was conducted using a Retsch MM 301 swing mill (Retsch, Haan, Germany). A $25 \mathrm{ml}$ stainless steel milling jar was filled with $407 \mathrm{~mm}$ stainless steel milling balls and $600 \mathrm{mg}$ of $\mathrm{mAb} / \mathrm{Suc} / 1: 1 / 5 \%$ lyophilizates. The suspension vehicle was added to a final powder concentration in suspension of $100 \mathrm{mg} / \mathrm{ml}\left(c_{\text {protein }}=50 \mathrm{mg} / \mathrm{ml}\right)$. Milling was conducted at different frequencies $(10,15$ and $25 \mathrm{~Hz})$. In order to reconstitute the milled formulations, the suspension vehicle was removed using a washing step. For this purpose, $1.5 \mathrm{ml}$ of the formulations were filled in $15 \mathrm{ml}$ centrifuge tubes (Greiner Bio-One, Kremsmuenster, Austria). Filtered isooctane (PTFE syringe filter $0.22 \mu \mathrm{m}$, VWR, Radnor, USA) was added to a final volume of $14 \mathrm{ml}$, the tubes were vortexed and were then centrifuged at $1000 \mathrm{rpm}$ for $3 \mathrm{~min}$. The supernatant was then removed. This procedure was repeated 5 times. The tubes were then placed in a VTS-2 vacuum drier (Memmert, Schwabach, Germany) for 2 days at 100 mbar in order to remove remaining isooctane. As a control, the same procedure was also performed with unprocessed lyophilizates.

\subsection{Cryogenic dry-milling}

Cryogenic dry milling was conducted using a Retsch CryoMill (Retsch, Haan, Germany). A quantity of $1 \mathrm{~g}$ of lyophilizates and the stainless-steel milling balls were filled into a $25 \mathrm{ml}$ stainless steel milling jar. Before milling, the milling jar was precooled with liquid nitrogen for $10 \mathrm{~min}$. Milling was conducted at different frequencies and ball to powder mass ratios (BPM) with 7 or $15 \mathrm{~mm}$ stainless steel milling balls. If not otherwise mentioned lyophilizates were cryogenic ball milled using the established settings of $25 \mathrm{~Hz} / 7 \mathrm{~mm} / \mathrm{BPM}$ 1:14 (see 4.2.1).

\subsection{Karl-Fischer}

The amount of residual water in the lyophilizates was analyzed using a Karl-Fischer-Titrator Aqua 40.00 (Analytik Jena, Jena, Germany) equipped with a head space module at a chamber temperature of $100^{\circ} \mathrm{C}$. 


\subsection{Powder true density}

Powder true density was analysed using an AccuPyc 1330 helium pycnometer (Micrometrics, Aachen, Germany). Prior to analysis 10 cleaning cycles were conducted. About $200-300 \mathrm{mg}$ of the powder was filled into the sample container. Powder true density results are based on the average of 6 measurements.

\subsection{Scanning electron microscopy}

Powders were investigated on self-adhesive carbon tapes stuck on aluminium stubs using a FEI Helios G3 UC (Thermo Fisher Scientific, Waltham, USA). Wet media milled powders (in F6H8) were pipetted directly on the carbon tape and dried in the VTS-2 vacuum drier for $24 \mathrm{~h}$ at 10 mbar.

\subsection{Laser diffraction}

Volume based powder particle size distribution was analyzed in isooctane containing $1 \%$ Span 80 using a Laser Diffraction Particle Size Analyzer LA-960 (Horiba, Kyoto, Japan). The dispersion medium was filtered through a $0.22 \mu \mathrm{m}$ PTFE syringe filter (VWR, Radnor, USA) before use. Dispersions containing the milled powder were additionally homogenized using a Sonopuls ultrasonic homogenizer equipped with a MS72 probe (Bandelin, Berlin, Germany) for $30 \mathrm{~s}$ at $10 \%$ intensity.

\subsection{X-Ray Powder diffraction}

Powder physical state was analyzed using an X-ray diffractometer (XRD) 3000 TT (Seifert, Ahrenburg, Germany) equipped with a copper anode (40 kV, $30 \mathrm{~mA}, 0.15418 \mathrm{~nm}$ ). The sample was placed on a copper sample holder and measured from 5 to $40^{\circ} 2-\Theta$ with $0.5^{\circ} 2-\Theta$ steps for 2 s per step.

\subsection{Cake rigidity}

Lyophilizate cake rigidities were examined using a Texture Analyzer XT plus (Stable Micro Systems, Godalming, UK). Lyophilizates were frozen for $1 \mathrm{~min}$ in liquid nitrogen and were subsequently tested by measuring the force a $6 \mathrm{~mm}$ diameter cylinder needed to penetrate $8 \mathrm{~mm}$ into the cake at a speed of $10 \mathrm{~mm} / \mathrm{s}$. 


\subsection{HPLC-SEC}

Protein stability was analyzed after reconstitution by HP-SEC using an Agilent 1100 with UV detection at $280 \mathrm{~nm}$ (Agilent Technologies, Santa Clara, USA) equipped with a TSKgel G3000SWXL column (Tosoh, Tokyo, Japan). As an eluent a $100 \mathrm{mM}$ phosphate, $100 \mathrm{mM}$ sulfate buffer at pH 6.8 was used at a flow rate of $0.5 \mathrm{ml} / \mathrm{min}$. The buffer was filtered before use by using a Sartorius pressure vessel equipped with a Sartorius $0.2 \mu \mathrm{m}$ cellulose acetate membrane filter (Sartorius, Goettingen, Germany). The monomer recovery of milled powders is stated in relation to the monomer concentration in the lyophilizate.

\subsection{Light obscuration}

The amount of subvisible particles was examined by light obscuration (LO) using a particle counter SVSS-C (PAMAS, Partikelmess- und Analysesysteme GmbH, Rutesheim, Germany). Powder was reconstituted in HPW based on the powder mass to yield the same protein concentration as the solution showed before freeze-drying. After reconstitution, the vials were transferred into a vacuum chamber at $100 \mathrm{mbar}$ for $30 \mathrm{~min}$ to remove air bubbles which were formed during the powder reconstitution step. The system was rinsed with $10 \mathrm{ml} \mathrm{HPW}$ after each run. The pre-run volume, as well as the measurement volume were $0.3 \mathrm{ml}$ (number of measurements per sample: 3 ).

\subsection{Fourier Transform Infrared spectroscopy}

Fourier Transform Infrared spectroscopy (FTIR) of reconstituted samples was conducted using a Bruker Tensor 27 FTIR Spectrometer (Bruker, Billerica, USA) equipped with a Bruker BIO-ATR unit. For each transmission spectrum a 100 - scan interferogram was created at a single beam mode with a $4 \mathrm{~cm}^{-1}$ resolution. The spectrum was then processed using the protein dynamics software Opus 6.5 in order to create a vector-normalized second derivative amide I-spectrum.

\subsection{Suspension preparation with cryogenic milled powder}

Suspensions were prepared at different concentrations by addition of the non-aqueous vehicle to the cryogenic milled powder, which had been sieved through a stainless steel sieve with a mesh size of $40 \mu \mathrm{m}$ (50 mm sieve diameter) (A-Technik, Leinburg, Germany). The amount of suspension vehicle was calculated based on the true densities of the powders. Suspensions were then homogenized using an VWR Ultrasonic cleaner (VWR, Radnor, USA) 
for 20 min with additional shaking by hand after 5, 10 and $15 \mathrm{~min}$. For a better understanding, concentrations are hereinafter referred to as the protein concentration in suspension.

\subsection{Rheology}

Suspension viscosity was analyzed using an Anton Paar Physica MCR 100 (Anton Paar, Graz, Austria) cone plate rheometer (cone diameter $50 \mathrm{~mm}$ ) at a temperature of $25^{\circ} \mathrm{C}$. After performing a logarithmic ramp from 100 1/s to 5000 1/s over $30 \mathrm{~s}$, the viscosity was analyzed at the final shear rate of 5000 1/s for 5 measurements over $5 \mathrm{~s}$.

\subsection{Injectability}

Syringe glide force measurements were performed using a Texture Analyzer XT plus. Suspensions were drawn into a $1 \mathrm{ml} \mathrm{B}$. Braun Inject F syringe (B. Braun, Melsungen, Germany) and a 25 or $26 \mathrm{G}$ Terumo Agani needle (Terumo, Tokyo, Japan) was then attached. Glide forces needed for injection, were determined at a volume flow of $0.1 \mathrm{ml} / \mathrm{s}$.

\subsection{Light microscopy}

Needle inner diameters were determined using a Keyence VHX $500 \mathrm{~F}$ digital microscope (Keyence, Osaka, Japan) equipped with a VH-Z2OR lens. 


\section{Results and discussion}

\subsection{Wet media milling}

\subsubsection{Effect of process parameters on milling duration}

In contrast to proteins, wet media milling of therapeutically used peptides, such as cetrorelix, has been described in literature. ${ }^{22,23}$ Wet media milling provides the advantage of combined milling and dispersing in one step. In addition, the suspension vehicle separates the particles and by this improves the milling process. Since proteins may be damaged during powder milling, the process parameters frequency and milling duration were to be optimized to yield injectable formulations with minimal protein damage. ${ }^{5,18}$ Milling was conducted in a $25 \mathrm{ml}$ jar filled with $407 \mathrm{~mm}$ stainless steel milling balls and $600 \mathrm{mg}$ of mAb/Suc/1:1/5\% lyophilizates. Injectability was considered adequate, if upon injection testing through a 25 or $26 \mathrm{G}$ needle a glide force profile without the presence of peaks, representing needle clogging, was achieved (exemplary shown for a $50 \mathrm{mg} / \mathrm{ml}$ mAb suspension in $\mathrm{F} 6 \mathrm{H} 8$ milled at a frequency of $15 \mathrm{~Hz}$ in Figure III-1).

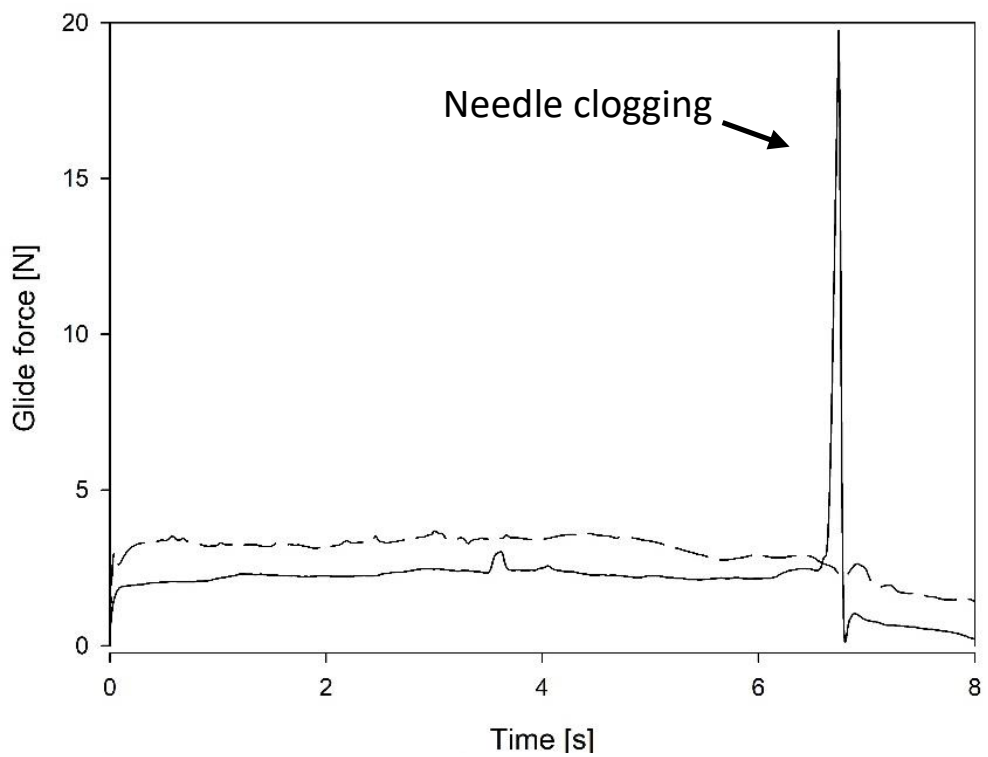

Figure III-1: Injection profile through a 25G needle of a protein powder suspension prepared by wet media milling $\left(c_{m A b}=50 \mathrm{mg} / \mathrm{ml}\right)$. Suspensions contained $\mathrm{mAb} / \mathrm{Suc} / 1: 1 / 5 \%$ lyophilizates in $\mathrm{F} 6 \mathrm{H} 8$ and were milled at $15 \mathrm{~Hz}$ for $3 \mathrm{~min}(-)$ or $5 \mathrm{~min}(--)$. 
Table III-2 Effect of milling frequency and duration on particle size and injectability of wet media milling mAb/Suc/1:1/5\% lyophilizates in $\mathrm{F} 6 \mathrm{H} 8$ or $\mathrm{MCT}$ at a mAb concentration of $50 \mathrm{mg} / \mathrm{ml}$ (cl = needle clogging).

\begin{tabular}{|c|c|c|c|c|c|}
\hline $\begin{array}{l}\text { Vehicle/ } \\
\text { frequency }\end{array}$ & $\begin{array}{l}\text { Milling } \\
\text { duration }\end{array}$ & \multicolumn{3}{|c|}{$\begin{array}{c}\text { Powder particle size }[\mu \mathrm{m}] \\
\text { D5/D50/D95 }\end{array}$} & \multirow{2}{*}{$\begin{array}{l}\text { Inject- } \\
\text { ability } \\
\mathrm{cl}\end{array}$} \\
\hline F6H8/ & 5 & $7.6 \pm 0.4$ & $26.5 \pm 1.3$ & $75.4 \pm 2.9$ & \\
\hline \multirow[t]{4}{*}{$10 \mathrm{~Hz}$} & 8 & $6.5 \pm 0.3$ & $21.2 \pm 0.9$ & $64.4 \pm 15.6$ & $25 G$ \\
\hline & 10 & $6.0 \pm 0.2$ & $19.5 \pm 1.3$ & $53.8 \pm 2.6$ & $25 G$ \\
\hline & 15 & $5.2 \pm 0.2$ & $16.6 \pm 0.6$ & $40.2 \pm 8.2$ & $25 G$ \\
\hline & 20 & $4.6 \pm 0.1$ & $15.4 \pm 0.3$ & $36.0 \pm 1.4$ & $25 G / 26 G$ \\
\hline F6H8/ & 3 & $5.8 \pm 0.1$ & $20.7 \pm 0.3$ & $45.8 \pm 3.0$ & $\mathrm{cl}$ \\
\hline $15 \mathrm{~Hz}$ & 5 & $5.5 \pm 0.4$ & $18.1 \pm 0.6$ & $37.4 \pm 3.4$ & $25 G$ \\
\hline F6H8/ & 2 & $6.4 \pm 0.1$ & $22.1 \pm 0.4$ & $46.8 \pm 3.4$ & $\mathrm{cl}$ \\
\hline $25 \mathrm{~Hz}$ & 3 & $5.6 \pm 0.3$ & $17.3 \pm 0.4$ & $37.6 \pm 2.3$ & $25 G$ \\
\hline MCT/ & 8 & $6.7 \pm 0.3$ & $29.3 \pm 7.0$ & $658.9 \pm 495.6$ & cl. \\
\hline $10 \mathrm{~Hz}$ & 10 & $5.1 \pm 0.2$ & $16.8 \pm 0.8$ & $73.3 \pm 19.6$ & $25 G$ \\
\hline
\end{tabular}

Milling of a $100 \mathrm{mg} / \mathrm{ml}$ suspension in $\mathrm{F} 6 \mathrm{H} 8$ was conducted at 10,15 and $25 \mathrm{~Hz}$ and in MCT at $10 \mathrm{~Hz}$. The time needed to achieve sufficient micronization was frequency and suspension vehicle dependant (Table III-2). Increasing the frequency led to a shorter milling duration, while only minimal differences in the final powder particle size were found (Table III-2). Adequate micronization in MCT took longer compared to F6H8, which can be explained by the higher viscosity of MCT (25 vs $3.4 \mathrm{mPa} \cdot \mathrm{s}$ ) slowing down the milling balls. Similar particle sizes were found for powders milled in either $\mathrm{F} 6 \mathrm{H} 8$ or MCT at a frequency of $10 \mathrm{~Hz}$, with slightly higher D95 values for powder milled in MCT. Particle sizes were confirmed by SEM, showing the typical shed like morphology of milled lyophilizates (Figure III-2). ${ }^{6}$ The D95 powder values of the injectable suspensions were about $1 / 8$ to $1 / 4$ the inner needle diameter ( $25 \mathrm{G}=306 \pm$ $6 \mu \mathrm{m}$ and $26 \mathrm{G}=263 \pm 4 \mu \mathrm{m}$ ). This is below the recommended maximum particle size needed to prevent needle clogging of $1 / 3$ of the needle inner diameter..$^{20,21}$ The suspensions in $\mathrm{F} 6 \mathrm{H} 8$, at a mAb concentration of $50 \mathrm{mg} / \mathrm{ml}$, prepared with different process parameters all required 
an injection force of $3 \mathrm{~N}$, while for MCT suspensions a higher force of $9 \mathrm{~N}$ was needed (25G needle).

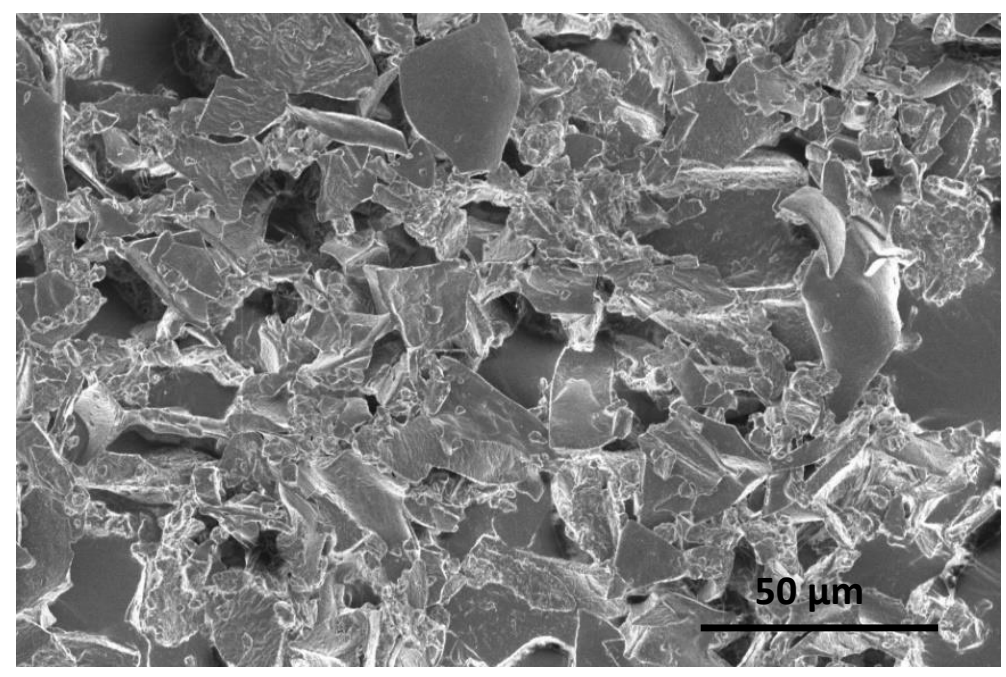

Figure III-2: SEM image of wet media milled powder. MAb/Suc/1:1/5\% lyophilizates were milled in $\mathrm{F} 6 \mathrm{H} 8$ for $3 \mathrm{~min}$ at $25 \mathrm{~Hz}$ at a mAb concentration of $50 \mathrm{mg} / \mathrm{ml}$.

\subsubsection{Protein integrity after wet media milling}

MAb integrity after wet media milling of $\mathrm{mAb} / \mathrm{Suc} / 1: 1 / 5 \%$ lyophilizates was studied by LO, HPSEC and FTIR. For reconstitution the suspensions were washed with isooctane and subsequently dried in a vacuum chamber. The same procedure was conducted with the unprocessed lyophilizate, where the mAb could be recovered without any loss or damage. LO and HP-SEC showed similar trends for damage to the protein. All milling parameters led to subvisible particle counts above European pharmacopeia (Ph. Eur. 9.0) limits (6000 particles $\geq 10 \mu \mathrm{m}$ and 600 particles $\geq 25 \mu \mathrm{m}$ ) (Figure III-3). ${ }^{34}$ SEC indicated a drastic decrease in monomer recovery, an increase in soluble aggregates by approximately 1 to $2 \%$ and no change in fragment content ( 3.2\%) (Figure III-3). Protein aggregation was similar for suspensions prepared to be injectable through a $25 \mathrm{G}$ needle, regardless of the applied milling frequency. A longer milling duration of $20 \mathrm{~min}$ at $10 \mathrm{~Hz}$, which was needed to inject the suspension through a $26 \mathrm{G}$ needle, caused more protein damage. 

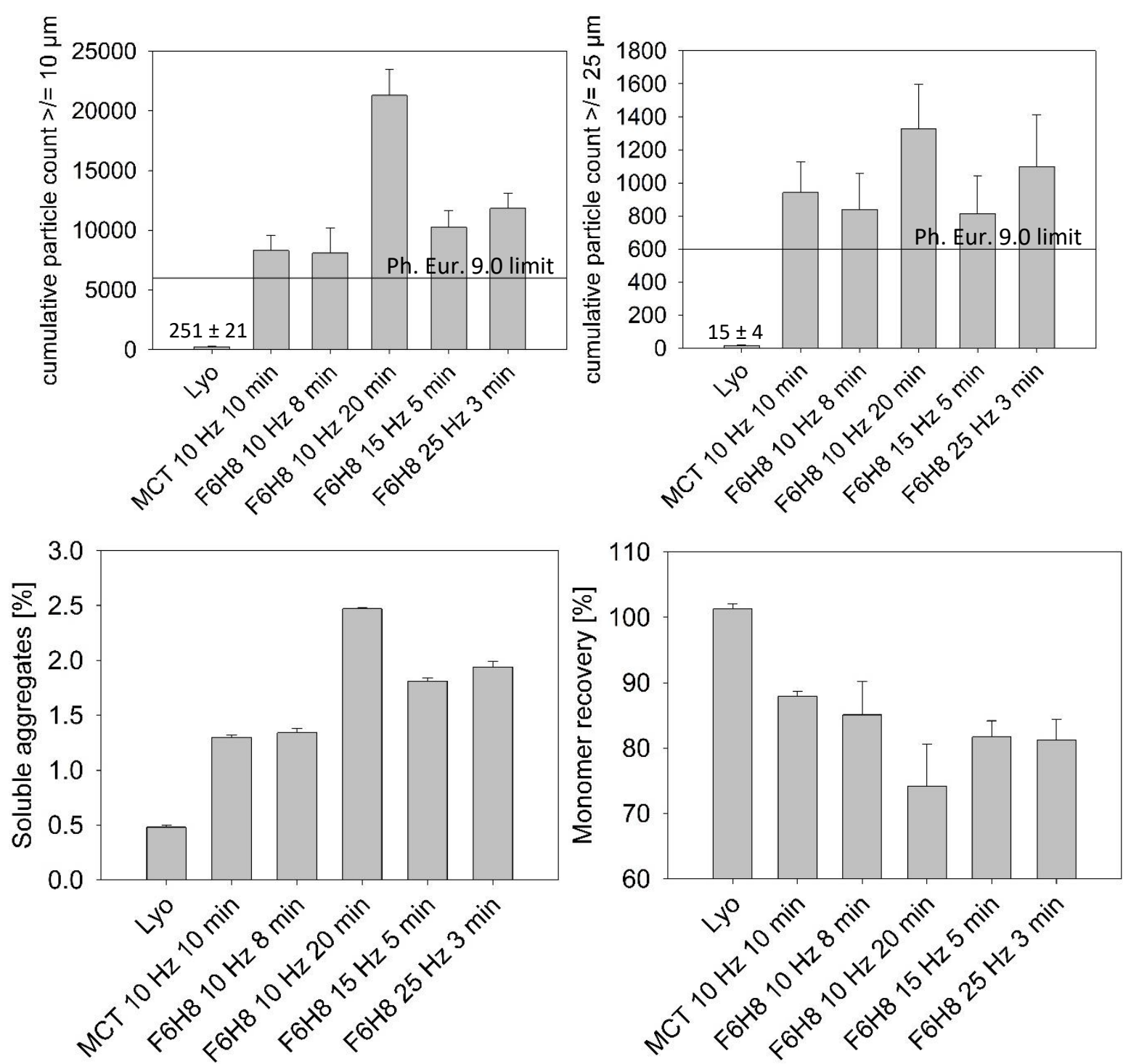

Figure III-3: Subvisible particle counts, soluble aggregates and monomer recovery after wet media milling of $\mathrm{mAb} / \mathrm{Suc} / 1: 1 / 5 \%$ lyophilizates in $\mathrm{F} 6 \mathrm{H} 8$ at a $\mathrm{mAb}$ concentration of $50 \mathrm{mg} / \mathrm{ml}$. The powder, which was obtained after the isooctane washing step, was reconstituted in HPW based on the powder mass, in order to yield the same protein concentration as the solution showed before freeze-drying. 


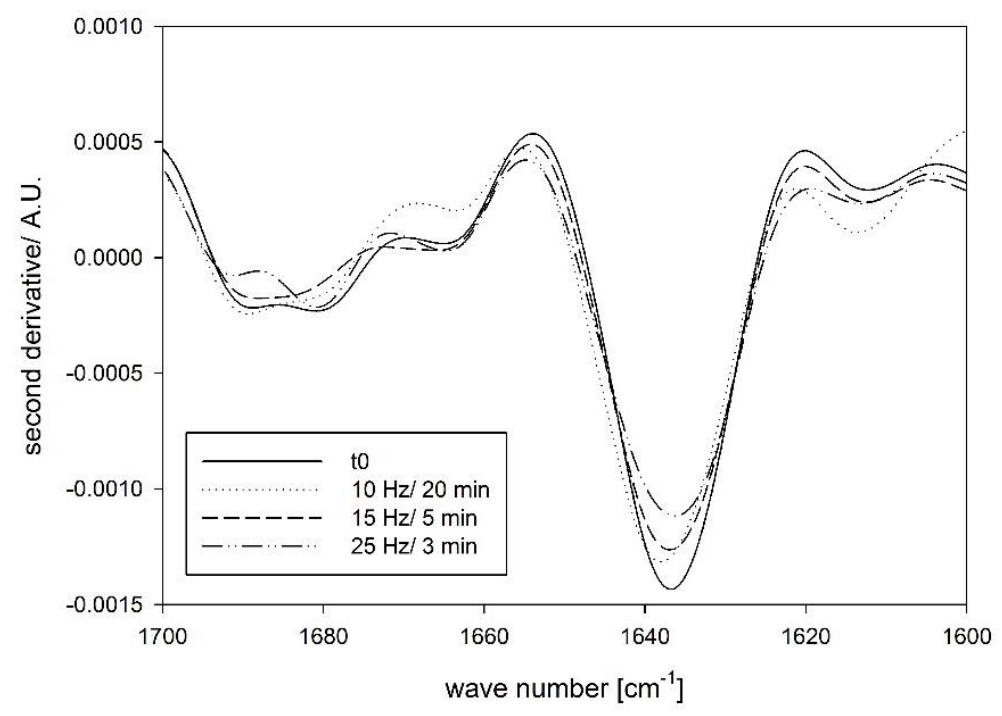

Figure III-4: Effect of wet media milling of $\mathrm{mAb} / \mathrm{Suc} / 1: 1 / 5 \%$ lyophilizates in $\mathrm{F} 6 \mathrm{H} 8$ $\left(c_{\mathrm{mAb}}=50 \mathrm{mg} / \mathrm{ml}\right)$ on mAb secondary structure.

Additionally, FTIR spectroscopy was used to detect changes in the secondary structure of the wet media milled mAb. No marked changes of the amide-I-band were detectable (Figure III4). Overall, SEC and LO indicated substantial mAb aggregation upon wet media milling rendering the process unsuitable for the preparation of protein powder suspensions.

\subsection{Cryogenic ball milling}

\subsubsection{Effect of process parameters on particle size and mAb stability}

Since wet media milling resulted in substantial mAb damage, cryogenic ball milling of lyophilized mAb powders was evaluated as an alternative processing technique. Previously Etzl et al. showed, that stability of ovalbumin and recombinant granulocyte-colony stimulating factor can be preserved during cryogenic milling. ${ }^{6,24}$ Their targeted particle size of 20 to $70 \mu \mathrm{m}$, as well as their D90 values of $>115 \mu \mathrm{m}$ make them appropriate for the aimed ballistic intradermal application, but unsuitable for the use in protein powder suspensions intended for injection through thin needles. Based on experiments conducted with wet media milling a D95 of less than $40 \mu \mathrm{m}$ was targeted to provide injectability with a $25 \mathrm{G}$ needle. Cryogenic ball milling of $\mathrm{mAb} / \mathrm{Suc} / 1: 1 / 5 \%$ lyophilizates was used to gain an understanding of the impact of the process parameters. $A$ ball to powder mass ratio (BPM) of $1: 28$ and 1:14, ball size frequency combinations of $7 \mathrm{~mm} / 25 \mathrm{~Hz}, 15 \mathrm{~mm} / 15 \mathrm{~Hz}$ and $15 \mathrm{~mm} / 25 \mathrm{~Hz}$ as well as milling durations up to 5 min were tested (Table III-3). 
Table III-3: Effect of process parameters on particle size of milled mAb/Suc/1:1/5\% lyophilizates. Bold: D95 below $40 \mu \mathrm{m}$ target value. Standard deviations from $\mathrm{n}=3$.

\begin{tabular}{|c|c|c|c|c|c|}
\hline \multirow[t]{2}{*}{ BPM } & \multirow{2}{*}{$\begin{array}{c}\text { Process } \\
\text { parameters }\end{array}$} & \multirow{2}{*}{$\begin{array}{c}\text { Milling } \\
\text { duration } \\
\text { [min] }\end{array}$} & \multicolumn{3}{|c|}{ Size $[\mu \mathrm{m}]$} \\
\hline & & & D5 & D50 & D95 \\
\hline \multirow[t]{9}{*}{$1: 28$} & \multirow{3}{*}{$\begin{array}{l}15 \mathrm{~Hz} / \\
15 \mathrm{~mm}\end{array}$} & 0.5 & $3.1 \pm 0.3$ & $11.0 \pm 0.7$ & $261.6 \pm 69.4$ \\
\hline & & 1 & $2.6 \pm 0.4$ & $10.8 \pm 2.0$ & $157.8 \pm 68.9$ \\
\hline & & 2 & $2.0 \pm 0.0$ & $6.9 \pm 0.6$ & $15.0 \pm 2.3$ \\
\hline & \multirow{3}{*}{$\begin{array}{l}25 \mathrm{~Hz} / \\
15 \mathrm{~mm}\end{array}$} & 0.25 & $4.1 \pm 0.2$ & $14.3 \pm 0.5$ & $206.5 \pm 171.1$ \\
\hline & & 0.5 & $2.2 \pm 0.0$ & $6.5 \pm 0.7$ & $69.7 \pm 99.0$ \\
\hline & & 1 & $1.7 \pm 0.0$ & $6.1 \pm 0.4$ & $16.5 \pm 3.8$ \\
\hline & \multirow{3}{*}{$\begin{array}{l}25 \mathrm{~Hz} / \\
7 \mathrm{~mm}\end{array}$} & 3 & $5.0 \pm 0.3$ & $11.1 \pm 0.6$ & $108.6 \pm 131.7$ \\
\hline & & 4 & $2.3 \pm 0.1$ & $7.8 \pm 0.6$ & $19.4 \pm 5.5$ \\
\hline & & 5 & $2.2 \pm 0.4$ & $6.9 \pm 0.6$ & $15.0 \pm 2.3$ \\
\hline \multirow[t]{3}{*}{$1: 14$} & \multirow{3}{*}{$\begin{array}{l}25 \mathrm{~Hz} / \\
7 \mathrm{~mm}\end{array}$} & 3 & $3.9 \pm 0.1$ & $12.8 \pm 1.1$ & $50.9 \pm 9.9$ \\
\hline & & 4 & $3.2 \pm 0.4$ & $11.7 \pm 0.8$ & $35.8 \pm 7.8$ \\
\hline & & 5 & $3.1 \pm 0.4$ & $9.5 \pm 0.8$ & $18.8 \pm 0.6$ \\
\hline
\end{tabular}

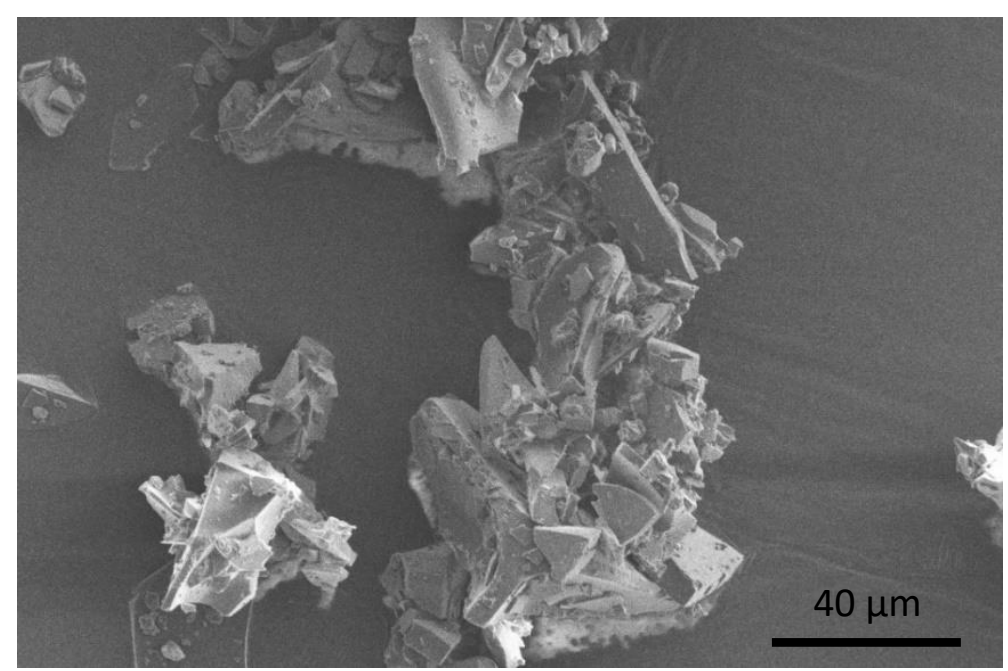

Figure III-5: SEM image of milled mAb/Suc/1:1/5\%; 5 min; 25 Hz; 7 mm; BPM 1:14. 
All process parameters led to the desired particle size in the lower micrometre range over process time. SEM confirmed the laser diffraction results (Figure III-5). Powders showed the typical shed like morphology of milled lyophilizates. ${ }^{24}$ With decreasing the frequency $(25 \rightarrow$ $15 \mathrm{~Hz})$, the BPM $(1: 28 \rightarrow 1: 14)$ or the milling ball diameter $(15 \rightarrow 7 \mathrm{~mm})$ a longer milling time was needed for sufficient micronization. The final powder particle size was independent of the frequency/ball diameter combination, if the BPM was kept at 1:28. Slightly larger particles were obtained at a BPM of 1:14. Obtained particles were smaller after cryogenic milling (D5/D50/D95 - $3.6 \pm 0.1 / 9.5 \pm 0.8 / 18.8 \pm 0.6 \mu \mathrm{m}$ ) compared to particles obtained by milling at room temperature (D5/D50/D95 - $3.1 \pm 0.4 / 13.0 \pm 0.5 / 136.4 \pm 114.7 \mu \mathrm{m}$ ) (process parameters: $5 \mathrm{~min}, 25 \mathrm{~Hz}, 7 \mathrm{~mm}$, BPM 1:14). This finding can be explained by the more brittle character of the lyophilizate at low temperature enhancing breakage as well as minimizing reagglomeration phenomena. Similar findings were previously described by Etzl. ${ }^{24}$

Table III-4: Subvisible particles in Placebo/5\% formulations.

\begin{tabular}{|c|c|c|}
\hline Milling duration & $\geq 10 \mu \mathrm{m}$ & $\geq 25 \mu \mathrm{m}$ \\
\hline Lyophilizate & $9 \pm 12$ & $0 \pm 0$ \\
\hline $3 \mathrm{~min}$ & $114 \pm 24$ & $4 \pm 1$ \\
\hline $4 \mathrm{~min}$ & $108 \pm 36$ & $8 \pm 6$ \\
\hline $5 \mathrm{~min}$ & $88 \pm 35$ & $3 \pm 3$ \\
\hline
\end{tabular}

Micronization of placebo lyophilizates was achieved after 5 min of milling (D5/D50/D95 = 2.9 $\pm 0.1 / 6.3 \pm 0.8 / 13.3 \pm 1.6 \mu \mathrm{m})$. The final powder particle size was slightly smaller compared to the respective $\mathrm{mAb}$ formulation at a sucrose to stabilizer ratio of 1:1 (mAb/Suc/1:1/5\%; D50 $=9.5 \pm 0.8 \mu \mathrm{m})$. Only minimal particle levels were seen when placebo lyophilizates were cryogenic milled for up to $5 \mathrm{~min}$ (Placebo/5\%) $(25 \mathrm{~Hz} / 7 \mathrm{~mm} /$ BPM 1:14) (Table III-4). The fact that the particle count was the same after 3, 4 and 5 min of milling indicates, that particles rather originate from powder handling in a non-particle-controlled environment than from abrasion of the milling jar and the balls, as also seen previously by Etzl. ${ }^{6}$ Potential abrasion could be counteracted by the use of milling equipment made of zirconium dioxide. ${ }^{23,35}$ 

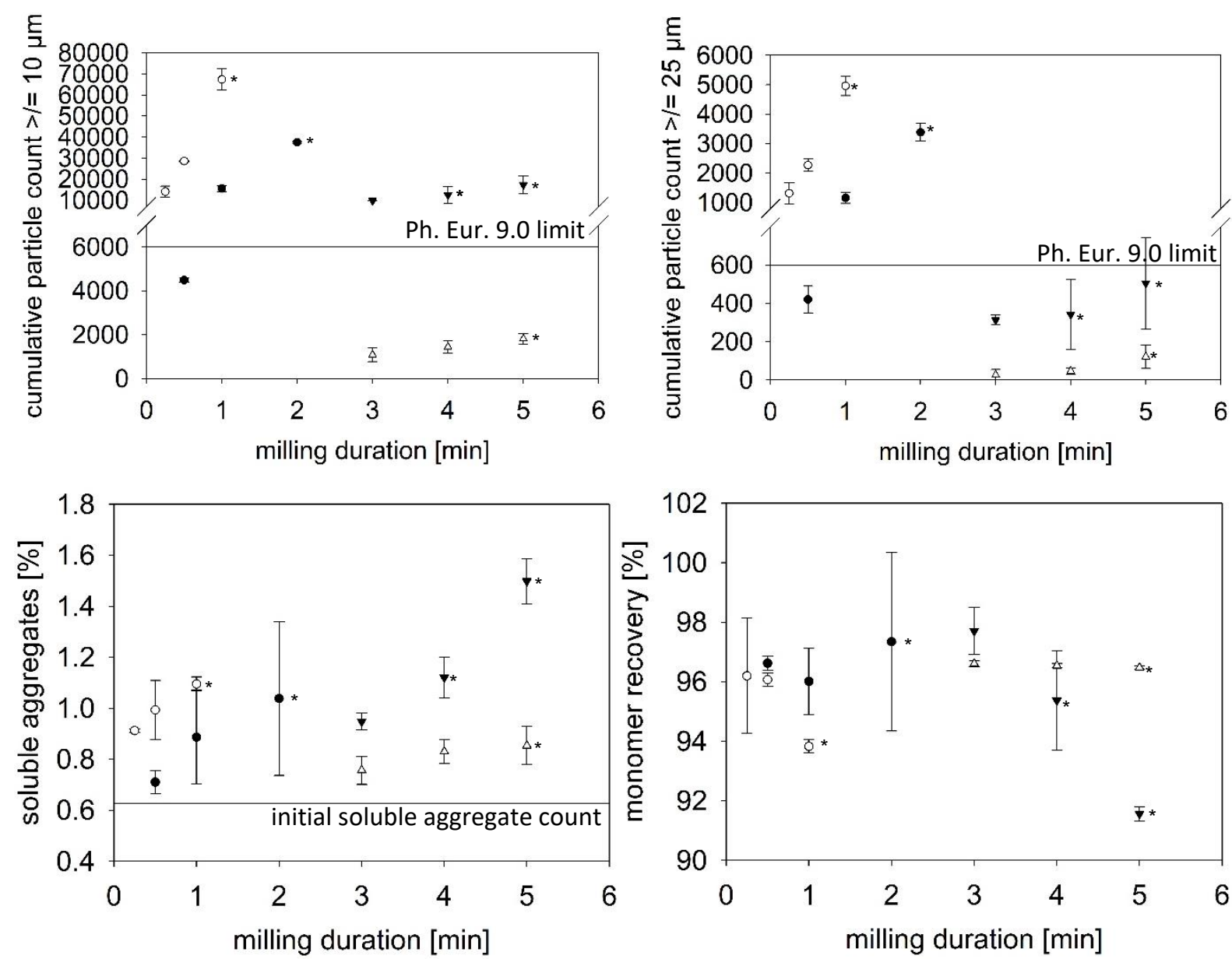

Figure III-6: Effect of cryogenic ball milling of mAb/Suc/1:1/5\% lyophilizates with a BPM of 28:1 at (frequency/ milling ball diameter) $15 \mathrm{~Hz} / 15 \mathrm{~mm}(\bullet), 25 \mathrm{~Hz} / 15 \mathrm{~mm}(0), 25 \mathrm{~Hz} / 7 \mathrm{~mm}$ $(\nabla)$ or with a BPM of $14: 1$ at $25 \mathrm{~Hz} / 7 \mathrm{~mm}(\triangle)$ on subvisible particle counts, soluble aggregates and monomer recovery. Sufficiently milled powders are marked*. The powder was reconstituted in HPW, based on the powder mass, in order to yield the same protein concentration as the solution showed before freeze-drying. 


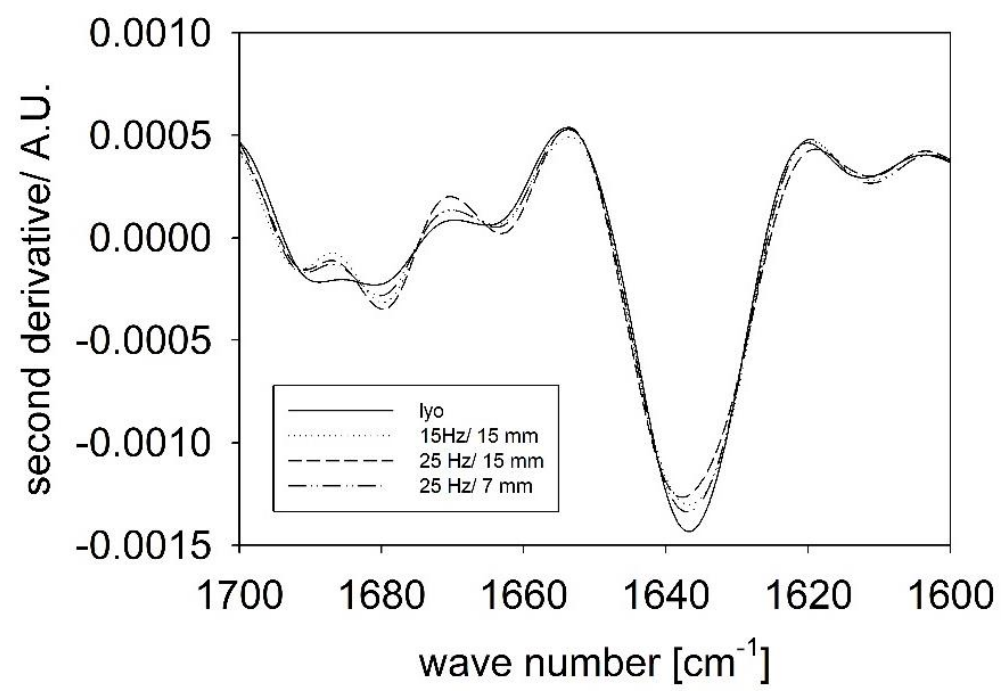

Figure III-7: Effect of milling parameters (BPM 1:28) on mAb secondary structure in mAb/Suc/1:1/5\% lyophilizates.

Cryogenic ball milling led to subvisible particle formation, a decrease in monomer content, as well as an increase in soluble aggregate content (Figure III-6). In accordance to literature the effect became more pronounced with longer milling duration. ${ }^{18}$ No shift of the amide-I-band was detected by FTIR (Figure III-7). Cryogenic milling at a BPM of 1:28 and $15 \mathrm{~mm}$ balls, indicated, that a lower milling frequency of $15 \mathrm{~Hz}$ led to a more controllable process and resulted in less protein damage compared to $25 \mathrm{~Hz}$. This finding is in accordance with results by Lee et al., who showed, that less lysozyme or glucose-oxidase is damaged when a lower milling frequency is applied. ${ }^{5}$ At a BPM of 1:28, less mAb damage occurred, if smaller milling balls were used. This can be explained by lower speed or weight resulting in less impact and local energy input, hence less stress for the protein. Cryogenic milling benefitted from decreasing the BPM from 1:28 to 1:14, which led to less protein damage, when the small milling balls were deployed (Figure III-6). By the use of optimized process parameters, it was possible to obtain subvisible particle levels below Ph. Eur. 9.0 limits.

Compared to cryogenic milling, milling at room temperature (25 Hz/7 mm/BPM 1:14 for 5 min) resulted in higher subvisible particle counts (16927 $\geq 10 \mu \mathrm{m}$ and 974 particles $\geq 25 \mu \mathrm{m})$ and a drastically lower monomer recovery (56.5\%), whereas the amount of soluble aggregates was similar. Cooling is key in milling of proteins. ${ }^{18,24}$ It is assumed, that cooling counteracts the extremely high local heat generated at the breaking area. ${ }^{36}$ The local heat dissipates fast and results in a general temperature increase of the whole milling container. ${ }^{5}$ 
Compared to we media milling, cryogenic milling resulted in less protein damage, which may be ascribed to the protective effect of the low temperature during the milling process. This hypothesis is supported by findings from Asmus et al., who milled a frozen suspension containing a single-chain antibody fragment without loss of protein activity. ${ }^{37}$ Based on the observed results, lyophilizates were cryogenic ball milled at $25 \mathrm{~Hz} / 7 \mathrm{~mm} / \mathrm{BPM}$ 1:14 for studying the impact of the formulation composition.

\subsubsection{Effect of formulation parameters}

Subsequently, the effect of the lyophilizates formulation on protein stability during cryogenic milling was studied. The total solid content in solution, the protein to stabilizer ratio, as well as the type of stabilizer were varied. Table III-5 shows the effect of formulation parameters on the milling duration needed for sufficient micronization, as well as the resulting powder particle size distribution. With higher total solid content in solution more time was needed for micronization, whereas the final powder particle size was not affected. A lower protein:sucrose ratio of 1:6 as well as exchanging mannitol for sucrose (mannitol: sucrose ratio of $5: 1)$ did not affect the required milling duration and the resulting powder particle size. No difference in powder particle morphology and the amorphous or crystalline state of the milled Iyophilizates were observed (Figure III-8/-9), despite the high energy input, which may result in amorphization or changes in crystal polymorphic varieties. ${ }^{38,39}$ Similar observations were described by Etzl. ${ }^{6}$

Table III-5: Effect of formulation parameters on milling duration needed for sufficient micronization and resulting powder particle size. Lyophilizates were milled at $25 \mathrm{~Hz}$ with $7 \mathrm{~mm}$ milling balls and a BPM of 1:14.

\begin{tabular}{|c|c|c|c|c|}
\hline Formulation & $\begin{array}{c}\text { Milling } \\
\text { duration } \\
{[\mathrm{min}]}\end{array}$ & \multicolumn{3}{|c|}{ D5/D50/D95 $[\mu \mathrm{m}]$} \\
\hline $\mathrm{mAb} /$ Suc/1:1/2.5\% & 4 & $3.1 \pm 0.3$ & $9.1 \pm 0.8$ & $18.0 \pm 2.9$ \\
\hline $\mathrm{mAb} /$ Suc/1:1/10\% & 7 & $2.4 \pm 0.1$ & $7.3 \pm 1.8$ & $15.0 \pm 5.7$ \\
\hline $\mathrm{mAb} / \mathrm{Suc} / 1: 6 / 5 \%$ & 5 & $2.1 \pm 0.1$ & $9.0 \pm 1.1$ & $20.2 \pm 3.3$ \\
\hline $\mathrm{mAb} /$ Man/Suc/1:5:1/5\% & 5 & $2.7 \pm 0.1$ & $8.0 \pm 0.5$ & $14.8 \pm 1.6$ \\
\hline
\end{tabular}



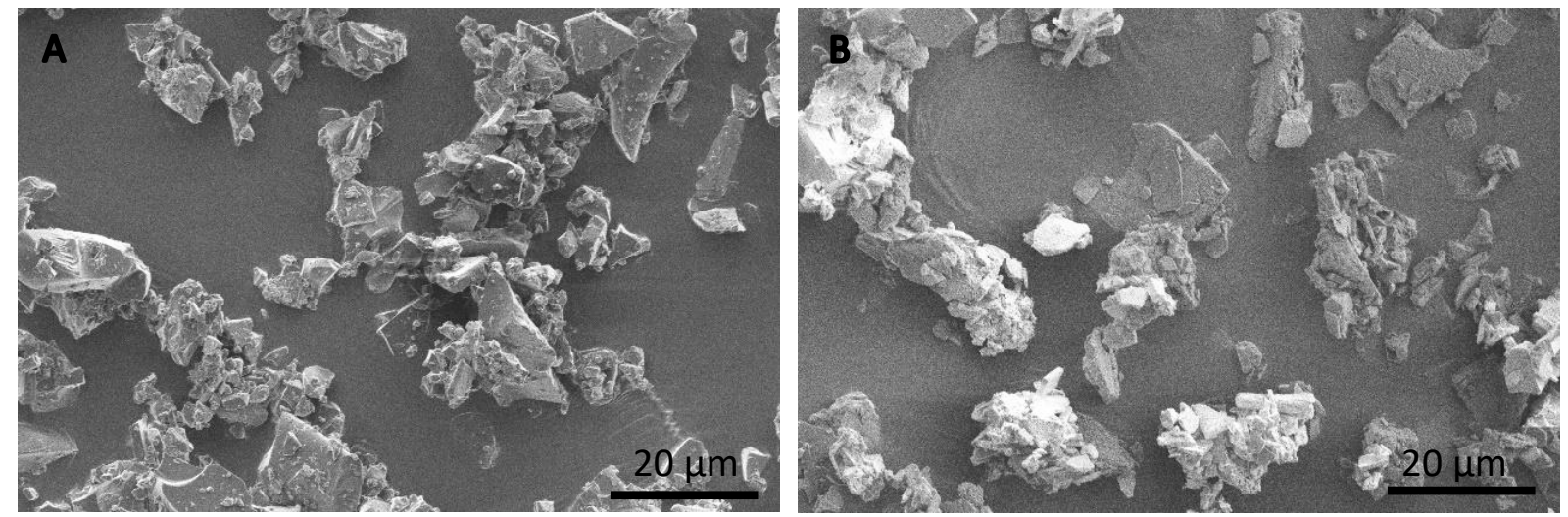

Figure III-8: SEM images of milled mAb/Suc/1:6/5\% (A) and mAb/Man/Suc/1:5:1/5\% (B) lyophilizates. Lyophilizates were milled for $5 \mathrm{~min}$ at $25 \mathrm{~Hz}$ with $7 \mathrm{~mm}$ milling balls and a BPM of 1:14.
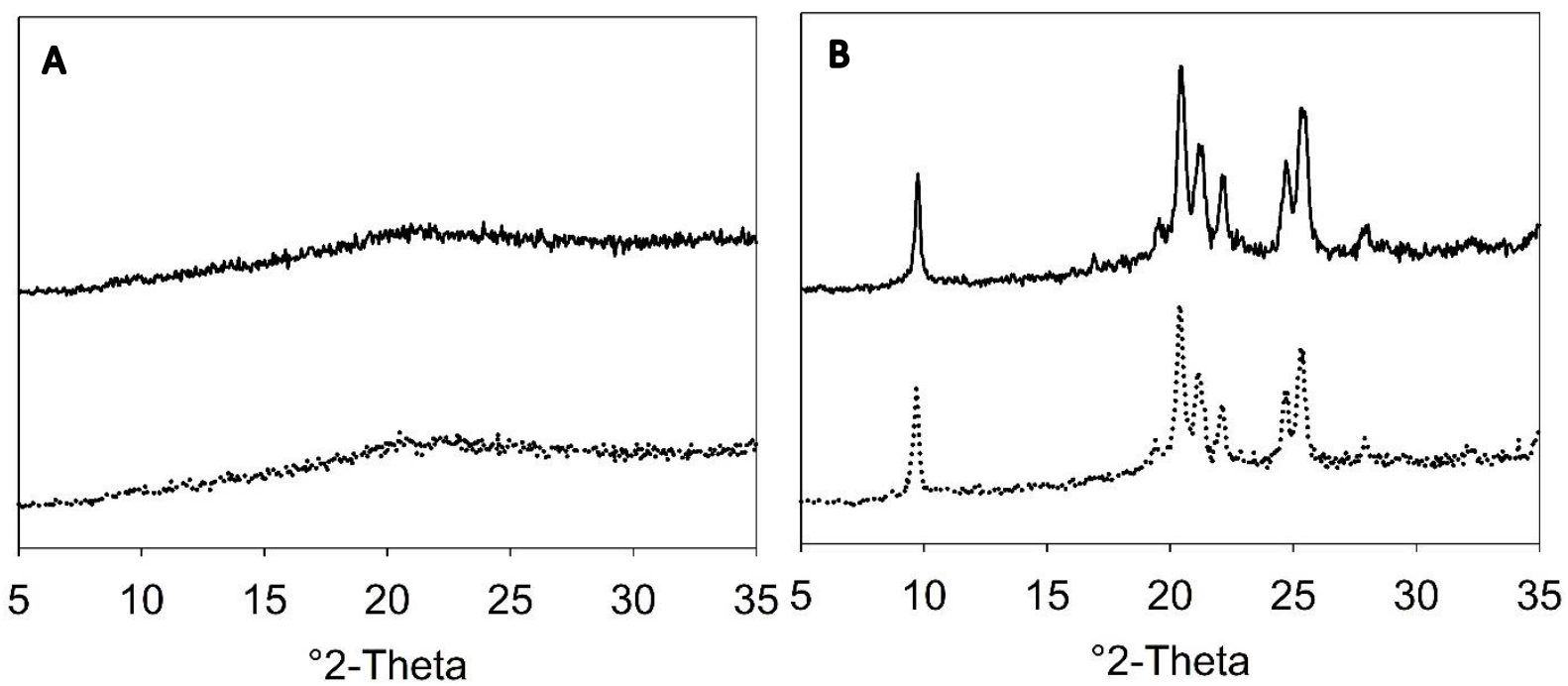

Figure III-9: XRPD patterns of lyophilizates $(\cdots)$ and milled powders $(-)$ of $m A b / S u c / 1: 6 / 5 \%$ (A) and mAb/Man/Suc/1:5:1/5\% (B) formulations. Lyophilizates were milled for 5 min at $25 \mathrm{~Hz}$ with $7 \mathrm{~mm}$ milling balls and a BPM of 1:14.

Milled powders obtained from lyophilizates with a solid content of 2.5 and $5 \%(\mathrm{~m} / \mathrm{V})$ did not differ in protein integrity, whereas a slightly higher subvisible particle level was found in milled lyophilizates of $10 \%$ total solid content (Table III-6). This finding can be explained by the longer milling duration required for micronization. The mAb to sucrose ratio did not affect the mAb integrity during milling (Table III-6/-7). A slight increase in the amount of soluble aggregates was detected in mannitol containing milled powders, while no effect of the formulation 
composition on the amount of subvisible particles, fragments or monomer recovery was found.

Table III-6: Effect of formulation parameters on subvisible particle counts. Lyophilizates were milled at $25 \mathrm{~Hz}$ with $7 \mathrm{~mm}$ milling balls and a BPM of 1:14. In order to enable comparison of lyophilizates with a different total solid content in solution, measured particle counts related to $1 \mathrm{mg}$ mAb were calculated based on the measured values.

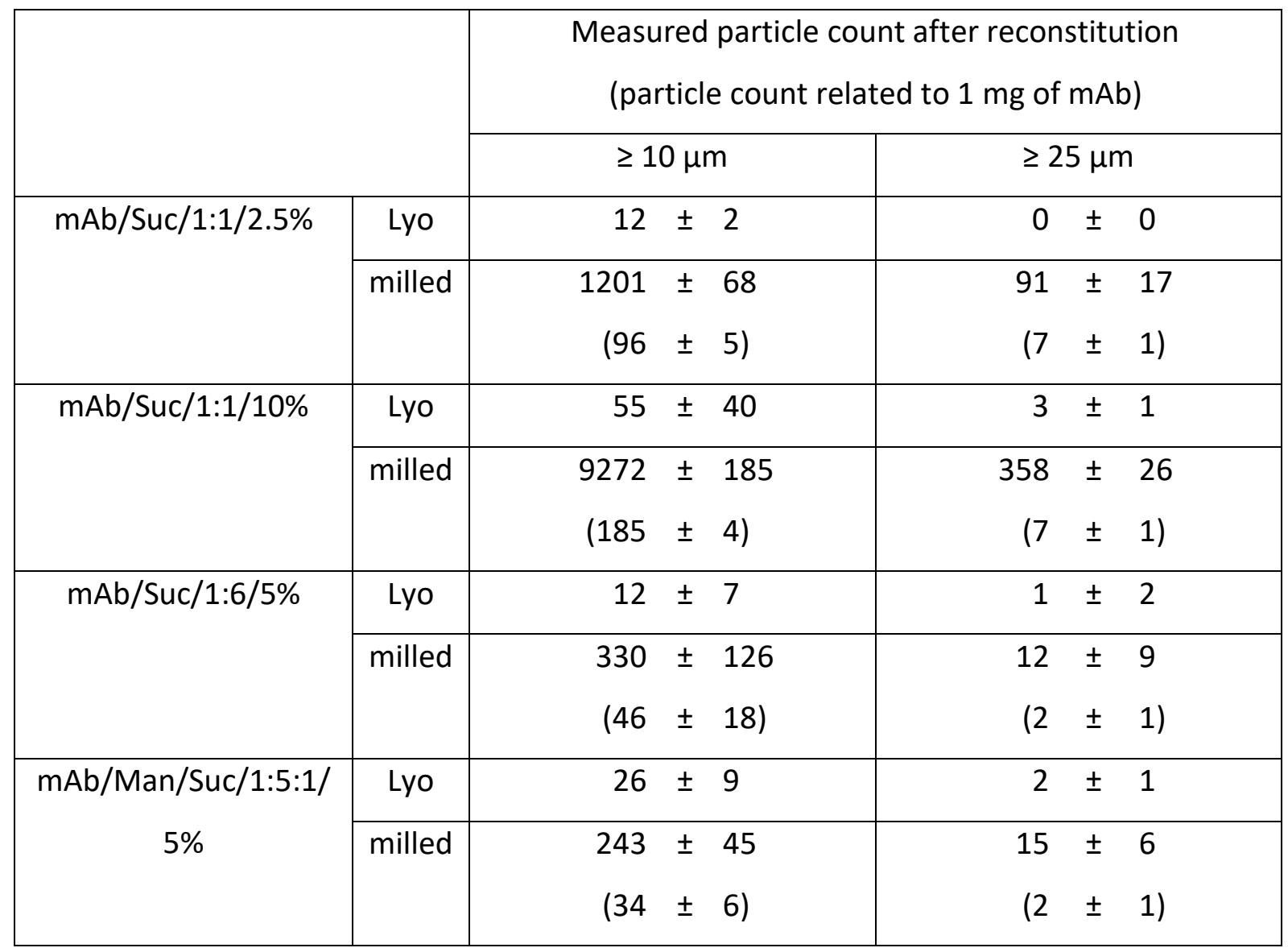


Table III-7: Effect of formulation parameters on soluble aggregates, fragments and monomer recovery. Lyophilizates were milled at $25 \mathrm{~Hz}$ with $7 \mathrm{~mm}$ milling balls and a BPM of 1:14.

\begin{tabular}{|c|c|c|c|c|}
\hline \multicolumn{2}{|c|}{} & Aggregates [\%] & Fragments [\%] & $\begin{array}{c}\text { Monomer } \\
\text { recovery [\%] }\end{array}$ \\
\hline \multirow{2}{*}{$\mathrm{mAb} /$ Suc/1:1/2.5\% } & Lyo & $0.6 \pm 0.0$ & $2.7 \pm 0.0$ & - \\
\cline { 2 - 5 } & milled & $0.6 \pm 0.0$ & $2.7 \pm 0.0$ & $98.6 \pm 0.8$ \\
\hline \multirow{2}{*}{$\mathrm{mAb} /$ Suc/1:1/10\% } & Lyo & $0.6 \pm 0.0$ & $2.6 \pm 0.0$ & - \\
\cline { 2 - 5 } & milled & $0.7 \pm 0.0$ & $2.7 \pm 0.0$ & $97.3 \pm 2.1$ \\
\hline \multirow{2}{*}{$\mathrm{mAb} /$ Suc/1:6/5\% } & Lyo & $0.6 \pm 0.0$ & $2.8 \pm 0.1$ & - \\
\cline { 2 - 5 } & milled & $0.6 \pm 0.0$ & $3.0 \pm 0.0$ & $98.4 \pm 0.4$ \\
\hline \multirow{2}{*}{$\mathrm{mAb} / \mathrm{Man} /$ Suc/1:5:1/5\% } & Lyo & $0.7 \pm 0.1$ & $2.8 \pm 0.0$ & - \\
\cline { 2 - 5 } & milled & $1.0 \pm 0.0$ & $3.1 \pm 0.1$ & $97.3 \pm 0.6$ \\
\hline
\end{tabular}

\subsubsection{Effect of cake rigidity on milling duration needed for sufficient micronization}

In order to avoid undesired protein damage, the milling duration should be kept as short as possible. An optimum milling duration is usually found by trial and error. ${ }^{18}$ Since the mechanical properties of the lyophilizate to be milled correlate with the time and energy needed for micronization, cake rigidity was tested. Overall the type of protein showed a substantial influence on cake rigidity (Figure III-10). The empirical fit based on different placebo and protein formulations indicates the potential to predict the time needed for milling by utilizing the cake properties. 

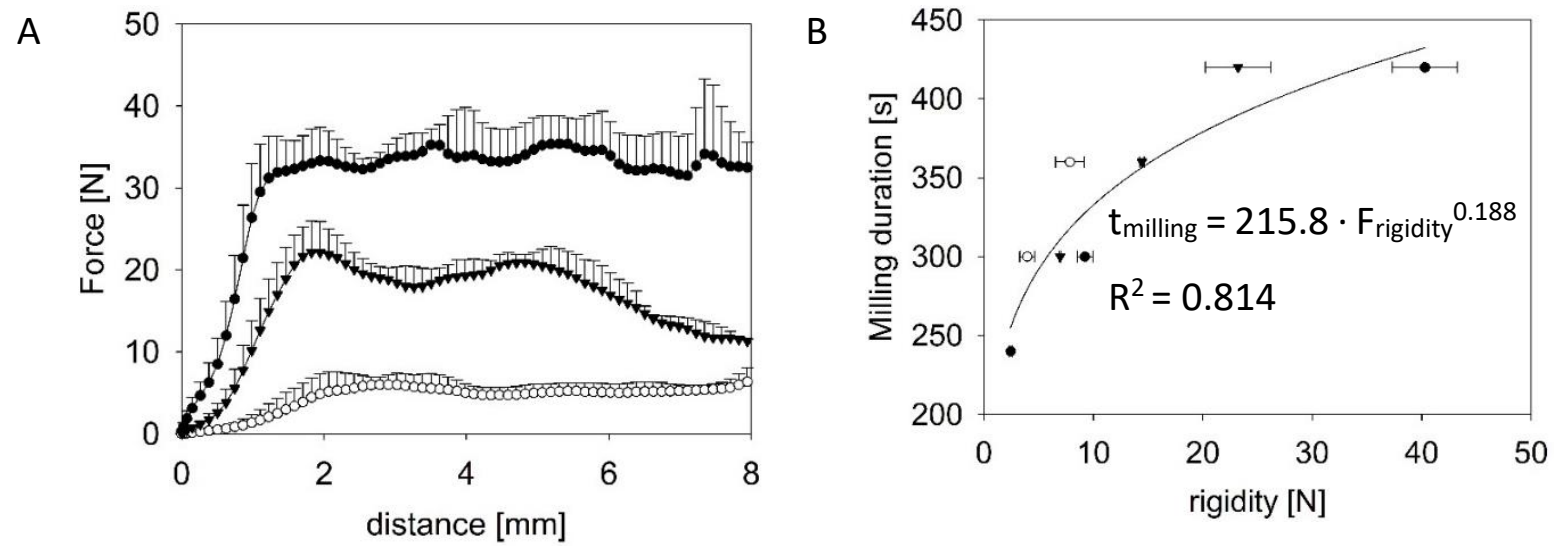

Figure III-10: Rigidity of lyophilizates with a total solid content of $10 \%(\mathrm{~m} / \mathrm{V})(\mathrm{A})$ and relation of cake rigidity with the milling duration needed for sufficient micronization (B) for mAb:sucrose $(\bullet)$, Lys:sucrose (0) (1:1) or placebo formulations( $\mathbf{v})$. Lyophilizates were milled at a frequency of $25 \mathrm{~Hz}, 7 \mathrm{~mm}$ milling balls and a BPM of 1:14.

\subsubsection{Milling of lyophilizates with a 70:30 protein to stabilizer ratio}

The volume fraction of suspended material has a strong influence on suspension viscosity. ${ }^{40,41}$ In order to provide highly concentrated protein suspension formulations, the volume contribution of the stabilizing excipients in the powder should be kept low for easy injection, but high enough to ensure protein stability. ${ }^{9}$ Molar ratios of mAb:stabilizer up to $1: 110 \mathrm{~m} / \mathrm{m}$ $=80 / 20$ ) are considered sufficient. ${ }^{42}$ In contrast to that, previous studies focussed on milling of lyophilizates with a low protein to stabilizer ratio., ${ }^{7,24}$ In other literature examples no stabilizer was used. ${ }^{5,18}$ This might work with rather stable proteins such as lysozyme, but could be problematic for more complex proteins such as mAbs. ${ }^{32}$

Based on the developed empirical fit (Figure III-10) we calculated the time needed for sufficient micronization. Due to cake rigidities of $10.3 \pm 1.2 \mathrm{~N}$ (mAb/Suc/7:3/5\%) and $10.0 \pm$ $1.8 \mathrm{~N} \mathrm{(mAb/Tre/7:3/5 \% ),} \mathrm{lyophilizates} \mathrm{were} \mathrm{cryogenic} \mathrm{ball} \mathrm{milled} \mathrm{for} 334 \mathrm{~s}$ and $333 \mathrm{~s}$ respectively. Both lyophilizates were sufficiently micronized confirming the established empirical model. No differences in the final particle size were found by laser diffraction (Figure III-11). 


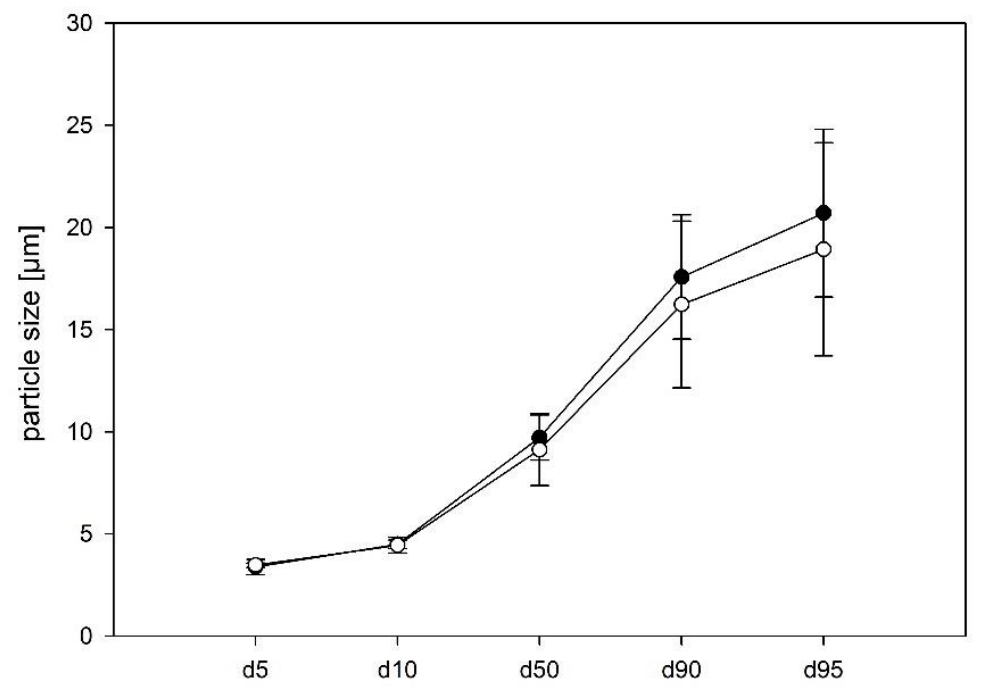

Figure III-11: Powder particle size of cryogenic milled $\mathrm{mAb} / \mathrm{Suc} / 7: 3 / 5 \%(\bullet)$ and $\mathrm{mAb} / \mathrm{Tre} / 7: 3 / 5 \%$ (o) lyophilizates milled at a frequency of $25 \mathrm{~Hz}, 7 \mathrm{~mm}$ milling balls and a BPM of 1:14.
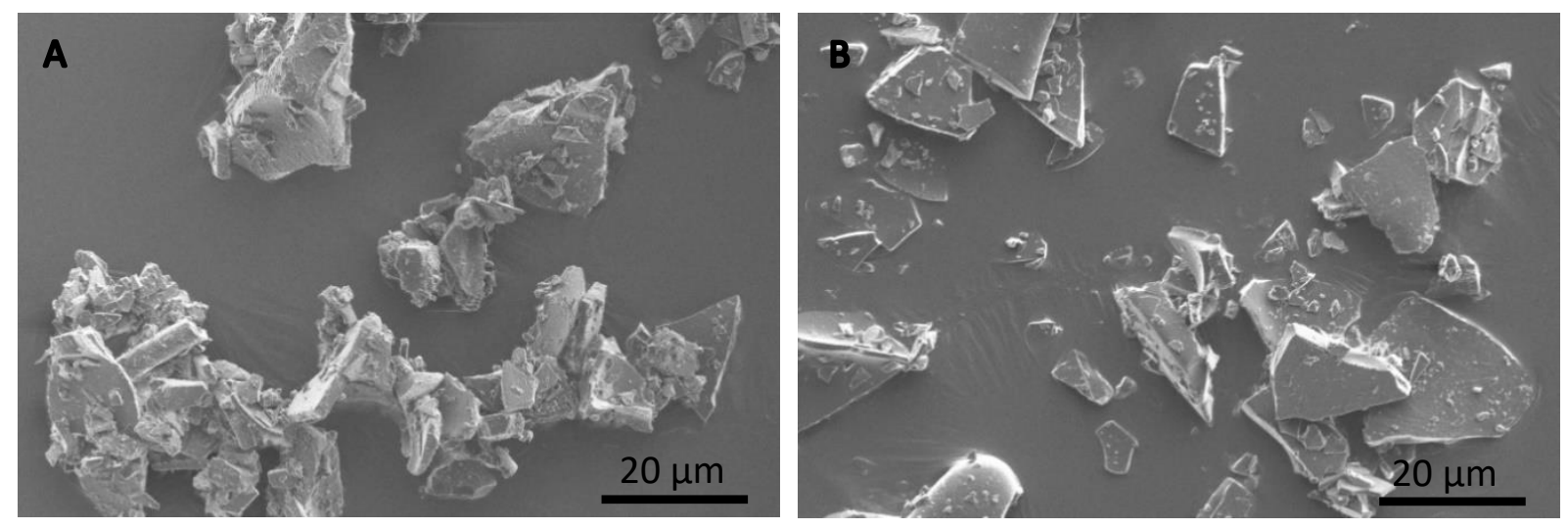

Figure III-12: SEM images of cryogenic milled mAb/Suc/7:3/5\% (A) and mAb/Tre/7:3/5\% (B) lyophilizates cryogenic milled at a frequency of $25 \mathrm{~Hz}, 7 \mathrm{~mm}$ milling balls and a BPM of 1:14. 
Table III-8: Subvisible particles before and after cryogenic milling at a frequency of $25 \mathrm{~Hz}$, $7 \mathrm{~mm}$ milling balls and a BPM of 1:14 for mAb/Suc/7:3/5\% and mAb/Tre/7:3/5\% lyophilizates. In order to enable comparison, measured particle counts related to $1 \mathrm{mg}$ mAb were calculated based on the measured values.

\begin{tabular}{|l|l|r|r|}
\hline \multirow{2}{*}{} & \multicolumn{2}{|c|}{ Particle count related to $1 \mathrm{mg}$ of mAb } \\
\cline { 2 - 4 } \multicolumn{2}{|c|}{} & $\geq 10 \mu \mathrm{m}$ & $\geq 25 \mu \mathrm{m}$ \\
\hline mAb/Suc/7:3/5\% & Lyo & $5 \pm 1$ & $0 \pm 0$ \\
\cline { 2 - 4 } & milled & $187 \pm 21$ & $6 \pm 2$ \\
\hline mAb/Tre/7:3/5\% & Lyo & $4 \pm 1$ & $0 \pm 0$ \\
\cline { 2 - 4 } & milled & $171 \pm 3$ & $6 \pm 2$ \\
\hline
\end{tabular}

Table III-9: Soluble aggregates, fragments and monomer recovery before and after cryogenic milling at a frequency of $25 \mathrm{~Hz}, 7 \mathrm{~mm}$ milling balls and a BPM of $1: 14$ for mAb/Suc/7:3/5\% and mAb/Tre/7:3/5\% lyophilizates.

\begin{tabular}{|c|l|c|c|c|}
\hline \multicolumn{2}{|l|}{} & Aggregates [\%] & Fragments [\%] & $\begin{array}{c}\text { Monomer } \\
\text { recovery [\%] }\end{array}$ \\
\hline \multirow{2}{*}{ mAb/Suc/7:3/5\% } & Lyo & $0.5 \pm 0.0$ & $2.8 \pm 0.0$ & - \\
\cline { 2 - 5 } & milled & $0.8 \pm 0.0$ & $2.9 \pm 0.0$ & $97.4 \pm 1.8$ \\
\hline mAb/Tre/7:3/5\% & Lyo & $0.5 \pm 0.0$ & $2.9 \pm 0.0$ & - \\
\cline { 2 - 5 } & milled & $0.7 \pm 0.0$ & $2.9 \pm 0.1$ & $101.3 \pm 2.1$ \\
\hline
\end{tabular}




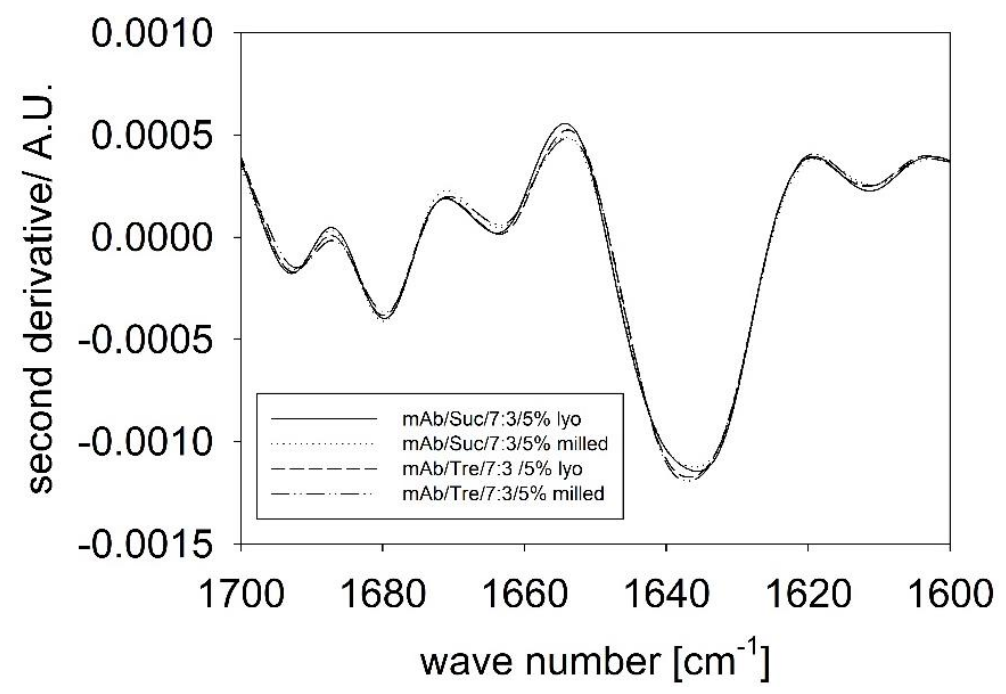

Figure III-13: FTIR spectra of cryogenic ball milled lyophilizates with a low stabilizer content. Lyophilizates were cryogenic milled at $25 \mathrm{~Hz}$ with $7 \mathrm{~mm}$ milling balls and a BPM of 1:14.

Milling of lyophilizates with a low stabilizer content did not result in significant mAb damage independent of the stabilizing sugar (Table III-8/-9). Compared to lyophilizates with a higher stabilizer content (mAb:sucrose of 1:6 or 1:1) minimally higher amounts of subvisible particles $\geq 10 \mu \mathrm{m}$ per mg mAb were found (Table III-6/-8). No shift of the amide-I band after milling was found by FTIR (Figure III-13). Thus, lower amounts of sugar are sufficient for stabilizing the $m A b$ during freeze-drying and cryogenic milling. Additionally, long term stability during storage has to be studied.

\subsection{Suspension characterization}

In order to provide an easy manual injection procedure, the glide force of the syringe system should not exceed $25-30 \mathrm{~N} .{ }^{43,44}$ The injection force is a function of the formulation's viscosity as well as syringe/needle geometries and injection speed. ${ }^{43,44}$ The ultimate goal is to provide low viscosities at high protein concentration to allow a comfortable application. ${ }^{25,27}$

Suspensions prepared by dispersing the cryogenic milled powder in the non-aqueous vehicle in the ultrasound bath, were not injectable and led to needle clogging of $25 \mathrm{G}$ needles. In contrast, suspensions prepared by wet media milling, could be injected through 25 and $26 \mathrm{G}$ needles (Table III-2).

An additional sieving step using a stainless steel sieve with a $40 \mu \mathrm{m}$ mesh size was necessary to obtain suspensions of cryogenic milled powder, which were injectable through a $25 \mathrm{G}$ needle (Figure III-14). After milling a small fraction of larger particles is present, which is not 
detected by laser diffraction and can be attributed to either insufficiently milled material or powder agglomerates.

Obtained suspensions showed shear thinning behaviour, which was especially pronounced at concentrations above $100 \mathrm{mg} / \mathrm{ml}$ (Figure III-14). The volume contribution of the dispersed powder directly affects the resulting viscosity, leading to the necessity of powders with a low stabilizer content. ${ }^{40,41}$ Exemplarily, to obtain a protein concentration of $100 \mathrm{mg} / \mathrm{ml}$, $700 \mathrm{mg} / \mathrm{ml}$ of a lyophilizate with a protein to sucrose ratio of $1: 6$ are needed. This is not feasible, as this concentration is above the possible maximum volume fraction in suspension of $50 \%(\mathrm{~V} / \mathrm{V}) .{ }^{11}$
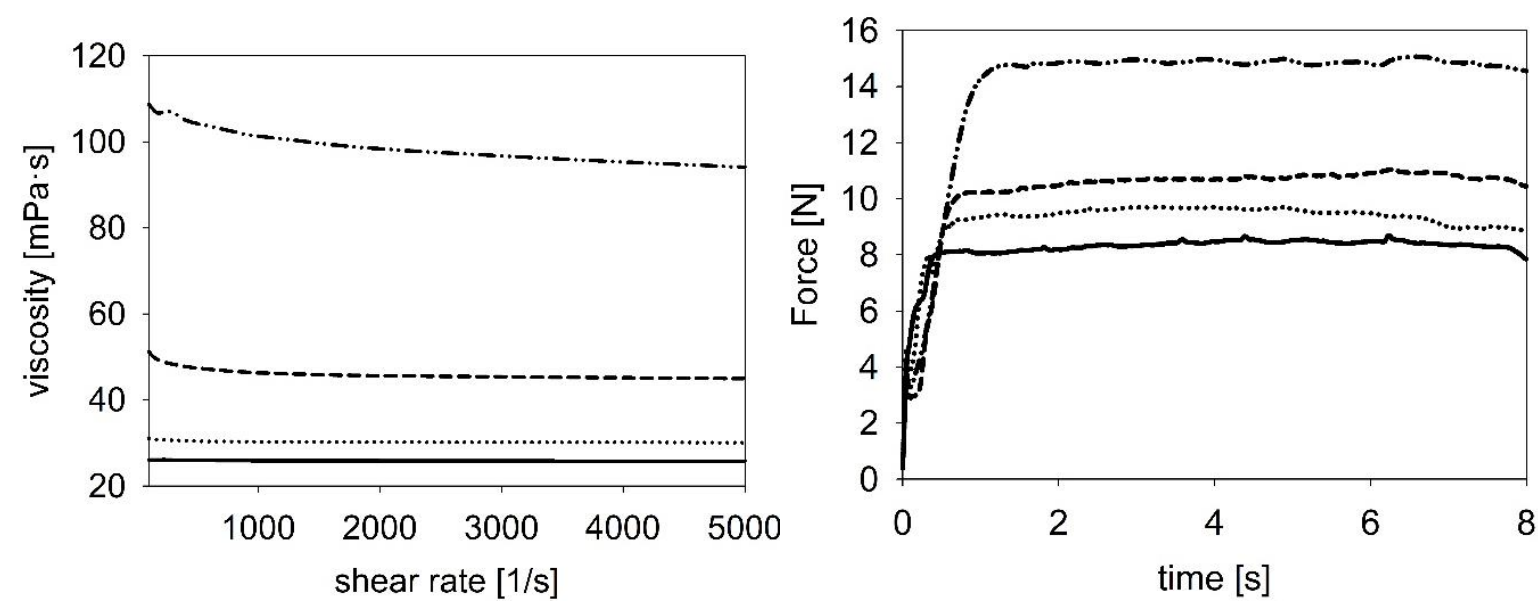

Figure III-14: Exemplary dynamic viscosities and glide force profiles for MCT mAb suspensions (mAb:Suc ratio $=1: 1) . c_{m A b}=25(-), 50(\cdots), 100(--)$ and $150 \mathrm{mg} / \mathrm{ml}(-\cdot-)$. Lyophilizates were cryogenic milled at $25 \mathrm{~Hz}$ with $7 \mathrm{~mm}$ milling balls and a BPM of 1:14. 

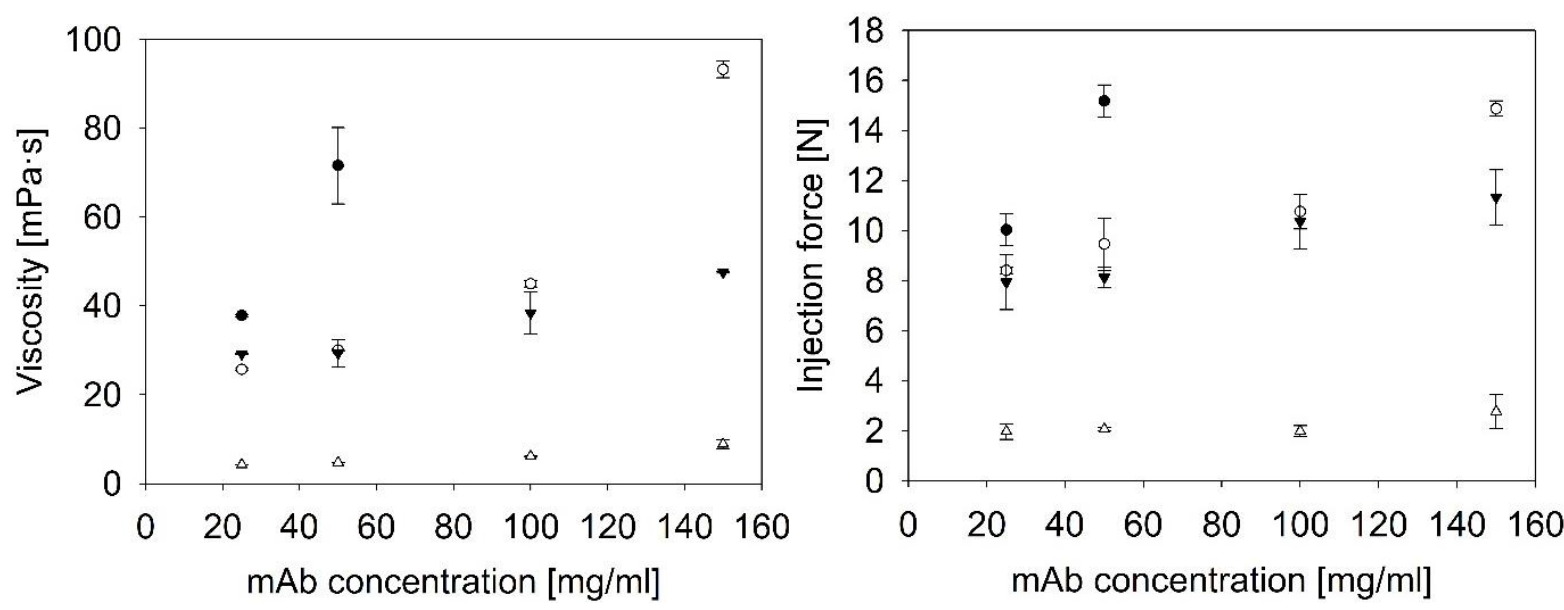

Figure III-15: Viscosity $(5000 \mathrm{1} / \mathrm{s})$ and glide force needed for injection $(0.1 \mathrm{ml} / \mathrm{s})$ of $\mathrm{mAb}$ powder suspensions (25G needle). Suspensions in MCT with a protein to sucrose ratio of 1:6 (•), 1:1 (0), 7:3 ( $\boldsymbol{\nabla})$ and in F6H8 of 7:3 $(\triangle)$. Lyophilizates were cryogenic milled at $25 \mathrm{~Hz}$ with $7 \mathrm{~mm}$ milling balls and a BPM of 1:14.

Figure III-15 shows, how the protein to stabilizer ratio affects the resulting viscosity and glide force needed for injection of suspensions in MCT and F6H8. Minimal viscosity at high protein concentrations for MCT formulations was obtained when milled powder with a protein to sucrose ratio of 7:3 was used. Suspensions in F6H8 showed much lower viscosities compared to the respective suspensions in MCT. This can be explained by the fact, that suspension rheology is directly proportional to the dispersion vehicles inherent viscosity $(\eta(\mathrm{MCT})=25 \mathrm{mPa} \cdot \mathrm{s} ; \eta(\mathrm{F} 6 \mathrm{H} 8)=3.4 \mathrm{mPa} \cdot \mathrm{s}) \cdot{ }^{40,41} \mathrm{~A}$ high concentration formulation containing $150 \mathrm{mg} / \mathrm{ml}$ of the $\mathrm{mAb}$ in $\mathrm{F} 6 \mathrm{H} 8$ resulted in a suspension with a viscosity $<10 \mathrm{mPa} \cdot \mathrm{s}$. For example, Shire et al. reported the viscosity of a solution containing $140 \mathrm{mg} / \mathrm{ml} \mathrm{mAb}$ to be above $120 \mathrm{mPa} \cdot \mathrm{s}^{25}$ Suspensions were easy injectable $(<20 \mathrm{~N})$ and no peaks in the injection profile, evident during needle clogging, were observed. Results indicate, that a low stabilizer content $\leq 50 \%(\mathrm{~m} / \mathrm{m})$ is needed in order to yield low injection forces at high concentrations. 


\section{Conclusion}

In this study, we compared three different methods for preparation of protein powder suspensions by milling of protein lyophilizates. Methods included wet media milling, dry milling and cryogenic dry milling. Wet media milling offers the advantage of combining dispersing and milling in a one step process. Injectable formulations could be obtained by wet media milling, but also a substantial damage to the mAb, indicated by a monomer loss of more than $10 \%$ and increased subvisible particle counts, occurred. The damage can be contributed to the absence of process cooling, counteracting the generated heat during particle breakage. This hypothesis was further confirmed by substantial protein damage in a dry ball milling process without cooling. In contrast, cryogenic ball milling resulted in good preservation of protein integrity during the micronization process. Yet, cryogenic milling is a more complex manufacturing step compared to wet media milling. Not only the additional dispersing step, but also an additional sieving step, as well as the liquid nitrogen handling makes it more complex. Process parameters such as frequency and ball diameter had a strong influence on protein integrity in cryogenic milling. Reducing the milling frequency as well as the milling ball diameter, was beneficial for mAb integrity. Furthermore, optimization of the ball to powder mass ratio improves the process. The final powder particle size distribution was independent of the process parameters in cryogenic ball milling and obtained powders were slightly smaller than wet media milled preparations. Also at high protein:sugar ratios, mAb integrity during milling was preserved. Additionally, based on the cake rigidity, a method to predict the required milling duration for micronization was established. For the suspensions of cryogenic milled lyophilizates an additional sieving step of the milled powder was necessary to obtain injectable suspensions. It was important, that the mAb represented at least $50 \%$ of the total powder mass of the lyophilizate in order to keep the total powder concentration in the suspension low. In this case, suspensions in F6H8 and MCT showed low viscosities at high protein concentrations $(\geq 100 \mathrm{mg} / \mathrm{ml})$ and were easily injectable trough a $25 \mathrm{G}$ needle $\left(F_{\text {injection }}<20 \mathrm{~N}\right)$.

We showed, that cryogenic ball milling is a potential technique for the preparation of protein powder for the use in non-aqueous suspensions. The findings of this study are not only relevant in the field of protein powder suspensions but can also be applied to other protein powder containing formulations techniques for drug delivery such as sustained release formulations or formulations for intradermal protein delivery. 
Wet media milling was not an appropriate suspensions preparation technique, as substantial protein damage occurred. Only cryogenic milling of lyophilizates with high protein content, combined with an additional sieving step resulted in powder suitable for the preparation of protein powder suspensions in non-aqueous vehicles. Using this approach, a mAb suspension in $\mathrm{F} 6 \mathrm{H} 8$ with a protein concentration of up to $150 \mathrm{mg} / \mathrm{ml}$ was successfully prepared which only needed a glide force of $4 \mathrm{~N}$ for injection trough a $25 \mathrm{G}$ needle. 


\section{References}

1. Schüle, S., Schulz-Fademrecht, T., Garidel, P., Bechtold-Peters, K. \& Frieß, W. Stabilization of IgG1 in spray-dried powders for inhalation. Eur. J. Pharm. Biopharm. 69, 793-807 (2008).

2. Maa, Y. F., Nguyen, P.-A., Sweeney, T., Shire, S. J. \& Hsu, C. C. Protein inhalation powders: spray drying vs spray freeze drying. Pharm. Res. 16, 249-254 (1999).

3. Shoyele, S. A. \& Cawthorne, S. Particle engineering techniques for inhaled biopharmaceuticals. Adv. Drug Deliv. Rev. 58, 1009-1029 (2006).

4. Vollrath, M., Engert, J. \& Winter, G. Long-term release and stability of pharmaceutical proteins delivered from solid lipid implants. Eur. J. Pharm. Biopharm. 117, 244-255 (2017).

5. Lee, P. W., Maia, J. \& Pokorski, J. K. Milling solid proteins to enhance activity after meltencapsulation. Int. J. Pharm. 533, 254-265 (2017).

6. Etzl, E. E., Winter, G. \& Engert, J. Toward intradermal vaccination: preparation of powder formulations by collapse freeze-drying. Pharm. Dev. Technol. 19, 213-222 (2014).

7. Anamur, C., Winter, G. \& Engert, J. Stability of collapse lyophilized influenza vaccine formulations. Int. J. Pharm. 483, 131-141 (2015).

8. Engert, J. et al. A pilot study using a novel pyrotechnically driven prototype applicator for epidermal powder immunization in piglets. Int. J. Pharm. 545, 215-228 (2018).

9. Bowen, M., Armstrong, N. \& Maa, Y.-F. Investigating High-Concentration Monoclonal Antibody Powder Suspension in Nonaqueous Suspension Vehicles for Subcutaneous Injection. J. Pharm. Sci. 101, 4433-4443 (2012).

10. Pena, L. E., Possert, P. L., Stearns, J. F., Lee, B. L. \& Hageman, M. J. Rheological characterization of rbSt oil suspensions. Int. J. Pharm. 113, 89-96 (1995).

11. Miller, M. A., Engstrom, J. D., Ludher, B. S. \& Johnston, K. P. Low viscosity highly concentrated injectable nonaqueous suspensions of lysozyme microparticles. Langmuir 26, 1067-1074 (2011).

12. Knepp, V. M., Muchnik, A., Oldmark, S. \& Kalashnikova, L. Stability of nonaqueous suspension formulations of plasma derived factor IX and recombinant human alpha interferon at elevated temperatures. Pharm. Res. 15, 1090-1095 (1998).

13. Gesche, G., Bernhard, G., Dieter, S. \& Anthony, P. EP3024484A1 - Stabilized antibody compositions. (2016).

14. Guenther, B. et al. EP2806886B1 - Stabilised protein compositions based on semifluorinated alkanes. (2013).

15. Gikanga, B. et al. Manufacturing of High-Concentration Monoclonal Antibody Formulations via Spray Drying--the Road to Manufacturing Scale. PDA J. Pharm. Sci. Technol. 69, 59-73 (2015).

16. Berkenhoff, K. Subcutaneous suspensions of therapeutic proteins formulated as 
protein-coated microcrystals. (LMU Munich, 2013).

17. Gottschalk, S. Crystalline monoclonal antibodies: process development for large scale production, stability and pharmaceutical applications. (LMU Munich, 2008).

18. Ehmer, A. Micronization of proteins by Jet Milling. (University of Regensburg, 2009).

19. Rutz, A. Oily suspensions as parenteral depot systems of recombinant proteins. (LMU Munich, 2007).

20. Patel, R. Parenteral suspension: an overview. Int. J. Curr. Pharm. Res. 2, 4-13 (2010).

21. Floyd, A. G. Injectable Emulsions and Suspensions, in Pharmaceutical Dosage Forms: Disperse Systems. (Taylor \& Francis Inc, 1996).

22. Zijlstra, G. S., Hinrichs, W. L. J., Boer, A. H. De \& Frijlink, H. W. The role of particle engineering in relation to formulation and de-agglomeration principle in the development of a dry powder formulation for inhalation of cetrorelix. Eur. J. Pharm. Sci. 23, 139-149 (2004).

23. Irngartinger, M., Camuglia, V., Damm, M., Goede, J. \& Frijlink, H. W. Pulmonary delivery of therapeutic peptides via dry powder inhalation: effects of micronisation and manufacturing. Eur. J. Pharm. Biopharm. 58, 7-14 (2004).

24. Etzl, E. Collapse dried protein powders for needle-free ballistic injection. (LMU Munich, 2016).

25. Shire, S. J., Shahrokh, Z. \& Liu, J. Challenges in the Development of High Protein Concentration Formulations. J. Pharm. Sci. 93, 1390-1402 (2004).

26. Allmendinger, A. et al. Rheological characterization and injection forces of concentrated protein formulations: An alternative predictive model for non-Newtonian solutions. Eur. J. Pharm. Biopharm. 87, 318-328 (2014).

27. Mathaes, R., Koulov, A., Joerg, S. \& Mahler, H. C. Subcutaneous Injection Volume of Biopharmaceuticals - Pushing the Boundaries. J. Pharm. Sci. 105, 2255-2259 (2016).

28. Alford, J. R., Kendrick, B. S., Carpenter, J. F. \& Randolph, T. W. High Concentration Formulations of Recombinant Human Interleukin-1 Receptor Antagonist: II. Aggregation Kinetics. Int. J. Drug Dev. Res. 3, 26-33 (2011).

29. Saluja, A. \& Kalonia, D. S. Nature and consequences of protein-protein interactions in high protein concentration solutions. Int. J. Pharm. 358, 1-15 (2008).

30. Emami, F., Vatanara, A., Park, E. J. \& Na, D. H. Drying technologies for the stability and bioavailability of biopharmaceuticals. Pharmaceutics 10, 1-22 (2018).

31. Weiguo Dai, Beth Hill, Kui Liu, C. M. US 20120076800 - Non-aqueous high concentration reduced viscosity suspension formulations of antibodies. (2012).

32. Cleland, J. L. et al. A specific molar ratio of stabilizer to protein is required for storage stability of a lyophilized monoclonal antibody. J. Pharm. Sci. 90, 310-321 (2001).

33. Gervasi, V. et al. Parenteral protein formulations: An overview of approved products within the European Union. Eur. J. Pharm. Biopharm. 131, 8-24 (2018). 
34. European Pharmacopoeia 9.0 - 2.9.19. (European Directorate For The Quality Of Medicine, 2016).

35. Stein, J., Fuchs, T. \& Mattern, C. Advanced Milling and Containment Technologies for Superfine Active Pharmaceutical Ingredients. Chem. Eng. Technol. 1464-1470 (2010).

36. Weichert, R. \& Schoenert, K. Temperatur an der Bruchspitze. Chemie Ing. Tech. 48, (1976).

37. Asmus, L. R. et al. Injectable formulations for an intravitreal sustained-release application of a novel single-chain VEGF antibody fragment. Eur. J. Pharm. Biopharm. 95, 250-260 (2015).

38. Patterson, J. E. et al. Preparation of glass solutions of three poorly water soluble drugs by spray drying, melt extrusion and ball milling. Int. J. Pharm. 336, 22-34 (2007).

39. Descamps, M., Willart, J. F., Dudognon, E. \& Caron, V. Transformation of Pharmaceutical Compounds upon Milling and Comilling: The Role of Tg. J. Pharm. Sci. 96, 1398-1407 (2007).

40. Krieger, I. M. \& Dougherty, T. J. A Mechanism for Non-Newtonian Flow in Suspensions of Rigid Spheres. Trans. Soc. Rheol. 3, 137-152 (1959).

41. Toda, K. \& Furuse, H. Extension of Einstein's viscosity equation to that for concentrated dispersions of solutes and particles. J. Biosci. Bioeng. 102, 524-528 (2006).

42. Schuele, S. Stabilization of Antibodies in Spray-dried Powders for Inhalation. (LMU Munich, 2005).

43. Rungseevijitprapa, W. \& Bodmeier, R. Injectability of biodegradable in situ forming microparticle systems (ISM ). Eur. J. Pharm. Sci. 36, 524-531 (2008).

44. Burckbuchler, V. et al. Rheological and syringeability properties of highly concentrated human polyclonal immunoglobulin solutions. Eur. J. Pharm. Biopharm. 76, 351-356 (2010). 


\section{Chapter IV}

\section{Protein powder suspensions - formulation performance at high concentration}

\section{Abstract}

High concentration protein formulations for subcutaneous injection represent a substantial number of development projects in the pharmaceutical industry. Such concentrated aqueous protein solutions face some specific challenges such as increased viscosity and aggregation propensity. Protein powder suspensions in non-aqueous vehicles could be an alternative providing lower viscosity than the respective aqueous solution. The choice of potential suspension vehicles is limited as traditional non-aqueous liquids, such as oils, show an inherent high viscosity. We studied suspensions prepared by dispersing spray-dried protein powder in different vehicles including sesame oil and medium chain triglycerides, as well as fluorinated and semifluorinated alkanes. We found, that semifluorinated alkanes enable formulations with high concentrations up to $280 \mathrm{mg} / \mathrm{ml}$ monoclonal antibody with a low viscosity of less than $10 \mathrm{mPa} \cdot \mathrm{s}$ and low injection forces. The glide force of suspensions containing $210 \mathrm{mg} / \mathrm{ml}$ protein was not affected by the particle size of the spray-dried powders with medians ranging from 1 to $14 \mu \mathrm{m}$. In contrast, suspensions prepared with cryo-milled powder showed higher viscosities and were not injectable at the same concentration. Protein powder suspensions prepared with spray-dried powder were syringeable using a $25 \mathrm{G}$ needle. Vial filling using a peristaltic pump was possible and lead to a uniform filling. Sedimentation of the suspension was slow and did not lead to challenges upon vial filling during manufacturing or transfer of the suspension into syringes. Thus, we could show that dispersions of spraydried protein powders in non-aqueous vehicles, such as semifluorinated alkanes, are a promising alternative to aqueous protein solutions at high concentrations. 


\section{Introduction}

The outpatient treatment by subcutaneous (s.c.) injection is the desired route for application of protein drugs for chronic diseases. Especially prefilled syringes and autoinjectors are showing simplified administration at the patient's home or by the patient himself. ${ }^{1,2}$ This route of application is also preferred for monoclonal antibodies, where often more than $100 \mathrm{mg}$ of the active pharmaceutical ingredient per therapeutic dose are needed. ${ }^{2,3}$ Due to this and the volume restriction of the s.c. route, high concentration protein formulations above $100 \mathrm{mg} / \mathrm{ml}$ are a hot topic in pharmaceutical industry. ${ }^{2,3}$

Specific challenges of these concentrated aqueous solutions are the increased viscosity and decreased protein stability. ${ }^{3-5}$ A suitable technique to counteract decreased protein stability is the removal of water typically by lyophilization or, more rarely, by spray-drying. ${ }^{6-8}$ As nonaqueous powder suspensions contain the protein in the solid state embedded in a matrix, physical and chemical stability should be improved. Knepp et al. showed, that suspensions of Factor IX or $\alpha$-interferon lyophilizates in PFD showed high protein stability at elevated temperatures for up to one year. ${ }^{9}$

Another challenge of highly concentrated protein solutions is the high viscosity, which strongly depends on the protein-protein-interactions, which are influenced by $\mathrm{pH}$, ionic strength and other excipients such as salts, amino acids or sugars. ${ }^{5,10-14}$ Thus, the concentration dependant increase in viscosity is specific for each protein. ${ }^{5,15,16}$ The high viscosity can lead to undesired injection forces above $25 \mathrm{~N}$ with the use of thin needles ( $\geq 26 \mathrm{G})$ which are required for s.c. injection. ${ }^{2,15,17,18}$ A less viscous alternative to aqueous solutions are protein powder suspensions in non-aqueous vehicles. ${ }^{19-22}$ Due to a pronounced shear-thinning behaviour, suspension viscosity can be remarkably low at high shear rates, which occur during injection through thin needles $\left(>10^{4} 1 / \mathrm{s}\right) \cdot{ }^{15,22}$ Besides shape, size and concentration of the suspended powders, the vehicle's inherent viscosity determines the suspension viscosity. ${ }^{19,23,24}$ Suspension vehicles for highly concentrated suspensions should show a low viscosity of less than $10 \mathrm{mPa} \cdot \mathrm{s}$, depending on the protein concentration. ${ }^{19}$ As a consequence, the choice of vehicles for s.c. injection is limited as many of the oils approved for parenteral use exhibit a high viscosity. ${ }^{19,25}$ Interesting candidate vehicles include ethyl lactate, ethyl oleate, benzyl benzoate, medium chain triglycerides and perfluorodecalin (PFD)..$^{9,19,22,25}$ Further alternatives for high concentration protein powder formulations would be of high interest. 
Knepp et al. reported, that a suspension containing albumin, lysozyme or trypsinogen in perfluorodecalin at protein concentrations of $350 \mathrm{mg} / \mathrm{ml}$ ( $700 \mathrm{mg} / \mathrm{ml}$ total solid content) "extruded evenly and completely with little effort". ${ }^{26}$ However, more detailed informations about suspension rheology or glide forces are necessary. This study additionally demonstrated the suitability of fluorinated liquids as vehicles for protein powder suspensions.

In our study we investigated semifluorinated alkanes (SFAs) as vehicle for protein powder suspensions with a focus on high concentrations. SFAs are diblock molecules, which consist of a linear perfluorinated hydrocarbon segment and a linear alkyl group. ${ }^{27,28}$ The SFAs used in this study, perfluorobutylpentan (F4H5) and perfluorohexyloctane (F6H8) are colorless liquids with a higher density than water..$^{29,30}$ Their low viscosity makes them promising candidates as vehicles for protein powder suspensions. Suspensions containing SFAs as a vehicle can benefit from their exceptional physico-chemical properties, such as the low intermolecular attraction forces leading to an exceptional wettability and the inert character which limits unwanted reactions during storage. ${ }^{31}$ Previous studies indicated high compatibility of SFAs with protein drugs. ${ }^{31,32}$ In the present study, the use of spray-drying to prepare the suspended protein powder particles was applied. The prepared suspensions were investigated with respect to their rheological behaviour at high concentrations, glide forces during injection, syringeability, potential for vial filling with a peristaltic pump as well as sedimentation behaviour. 


\section{Materials and Methods}

\subsection{Materials}

Lysozyme (Lys) bulk solutions were prepared by dissolution of pure lysozyme (Dalian Greensnow Egg Products Development Co. Ltd., Liaoning, China) in $10 \mathrm{mM}$ histidine buffer at $\mathrm{pH}$ 6.0. A monoclonal IgG1 antibody produced in CHO cells (mAb) in $25 \mathrm{mM}$ histidine, $1.6 \mathrm{mM}$ glycine buffer $\mathrm{pH} 6.0$ at $57 \mathrm{mg} / \mathrm{ml}$ was used $\left(\varepsilon 280 \mathrm{~nm}=1.49 \mathrm{ml} \mathrm{g}^{-1} \mathrm{~cm}^{-1}\right)$. Bevacizumab (Beva) was acquired from a local pharmacy as marketed product Avastin ${ }^{\circledR}$ (Roche, Basel, Switzerland). Formulations were prepared in highly purified water prepared with an ELGA Purelab system (ELGA LabWater, Celle, Germany) using trehalose (Tre) (Hayashibara, Okayama, Japan), Lhistidine and L-histidine-monohydrochloride monohydrate (Sigma-Aldrich, St. Louis, USA). Perfluorobutylpentane (F4H5), perfluorohexyloctane (F6H8) and perfluorodecalin were provided by Novaliq (Heidelberg, Germany). Further, medium chain triglycerides (MCT) (Miglyol ${ }^{\circledR} 812$ by Caesar \& Loretz, Hilden, Germany), ethyl oleate (EO) and ethyl lactate (SigmaAldrich, St. Louis, USA) were used as suspension vehicles. Dispersion medium for laser diffraction measurement contained isooctane and Span 80 (Merck, Darmstadt, Germany).

\subsection{Formulations for spray- and freeze-drying}

Solutions for spray-drying had a total solid content (ts) of $1.0,7.5$ or $30.0 \%(\mathrm{~m} / \mathrm{m})$, solutions for freeze-drying of $5.0 \%(\mathrm{~m} / \mathrm{m})$. Trehalose was used at a protein to stabilizer ratio of 70:30 (m/m). All solutions were prepared in a $10 \mathrm{mM}$ histidine buffer at $\mathrm{pH}$ 6.0. Buffer exchange was performed using Spectra/Por regenerated cellulose dialysis tubes with a molecular weight cut off (MWCO) of 6-8 kDa (Spectrum Laboratories, Los Angeles, USA). Before spray-drying, the solutions were filtered using a VWR $0.2 \mu \mathrm{m}$ polyethersulfone syringe filter (VWR, Radnor, USA).

\subsection{UV-Vis}

Protein concentrations were measured with a NanoDrop 2000 spectrophotometer (Thermo Scientific, Waltham, USA) at $280 \mathrm{~nm}$. 


\subsection{Spray-drying}

Spray-drying was conducted using a Büchi B290 (Büchi, Flawil, Switzerland) equipped with a high-efficiency cyclone and a two fluid nozzle $(0.7 \mathrm{~mm}$ orifice) at a drying air-flow rate of $600 \mathrm{ml} / \mathrm{min}$, an atomizing air flow rate of $670 \mathrm{ml} / \mathrm{min}$, a feed flow rate of $3 \mathrm{ml} / \mathrm{min}$ and an inlet/outlet temperature of $130 / 70^{\circ} \mathrm{C}$. Process yields were above $80 \%$.

\subsection{Additional drying step of spray-dried powder}

Spray-dried powders (SPDs) were transferred into 10R type 1 glass vials (MGlas, Muennerstadt, Germany) and a lyophilization stopper was attached (Helvoet Pharma, Tilburg, Netherlands). Samples were then dried using a Christ 2-6D (Martin Christ Gefriertrocknungsanlagen, Osterode, Germany) at $32^{\circ} \mathrm{C}, 0.1 \mathrm{mBar}$ for $24 \mathrm{~h}$ and fully stoppered in the freeze-drier under nitrogen gas atmosphere at 800 mbar according to Schuele et al. ${ }^{33}$

\subsection{Freeze-drying and preparation of milled lyophilizates}

Freeze-drying and milling were performed as described in Chapter III in 10R vials (MGlas). Briefly, lyophilizates were prepared using a conventional freeze-drying cycle in a Christ 2-6D freeze-drier (Martin Christ). Milling was conducted using a Retsch CryoMill (Retsch, Haan, Germany). Lyophilizates $(1 \mathrm{~g})$ were then filled in a milling jar containing 10 milling balls with a diameter of $7 \mathrm{~mm}$. Before milling a cooling step of $10 \mathrm{~min}$ was conducted with liquid nitrogen. The milling was performed for $5 \mathrm{~min}$ and the obtained powder was sieved through a mesh size of $40 \mu \mathrm{m}$.

\subsection{Powder handling}

Powder handling was conducted under nitrogen environment in a custom-made glove box to prevent water uptake.

\subsection{Karl-Fischer}

The amount of residual water was analyzed using a Karl-Fischer-Titrator Aqua 40.00 (Analytik Jena, Jena, Germany) equipped with a head space module at a chamber temperature of $100^{\circ} \mathrm{C}$. 


\subsection{Powder true density}

Powder true density was analyzed using an AccuPyc 1330 helium pycnometer (Micrometrics, Aachen, Germany). In total 10 cleaning cycles were conducted prior to analysis. About $200-$ $300 \mathrm{mg}$ of the powder was filled into the sample container. Powder true density results are based on the average of 6 measurements.

\subsection{Scanning electron microscopy}

Prepared powders were investigated on self-adhesive carbon tapes on aluminium stubs using a FEI Helios G3 UC (Thermo Fisher Scientific, Waltham, USA).

\subsection{HPLC-SEC}

Protein stability was analyzed after reconstitution by HP-SEC using an Agilent 1100 with UV detection at $280 \mathrm{~nm}$ (Agilent Technologies, Santa Clara, USA) equipped with a TSKgel G3000SWXL column (Tosoh, Japan, Tokyo). As eluent a buffer at pH 6.8 containing $100 \mathrm{mM}$ sodium phosphate and $100 \mathrm{mM}$ sodium sulfate was used at a flow rate of $0.5 \mathrm{ml} / \mathrm{min}$.

\subsection{Light obscuration}

Subvisible particles were analyzed with a particle counter SVSS-C (PAMAS, Partikelmess- und Analysesysteme, Rutesheim, Germany). Powder was reconstituted in HPW and evacuated at $100 \mathrm{mbar}$ for $30 \mathrm{~min}$ to remove air bubbles.

\subsection{Fourier Transform Infrared spectroscopy}

Fourier Transform Infrared spectroscopy (FTIR) of reconstituted samples was conducted using a Bruker Tensor 27 FTIR spectrometer (Bruker, Billerica, USA) equipped with a Bruker BIO-ATR unit. For each transmission spectrum a 100 - scan interferogram was created at a single beam mode with a $4 \mathrm{~cm}^{-1}$ resolution. Vector-normalized second derivative amide I-spectra were created using the protein dynamics software Opus 6.5. 


\subsection{Dispersion techniques and suspension preparation}

The effect of different dispersing techniques on protein integrity and powder dispersion efficiency was tested by preparation of $5 \mathrm{ml}$ of a $210 \mathrm{mg} / \mathrm{ml} \mathrm{mAb}$ powder suspension in $\mathrm{F} 6 \mathrm{H} 8$ in 6R vials (MGlas, Muennerstadt, Germany) closed with a Teflon coated serum stopper (Westpharma, Exton, USA). Suspensions were prepared by i) high shear homogenization (HSH) with an Ultra turrax IKA T10 (IKA-Werke, Staufen, Germany) for 2 min at 20000 rpm; ii) wet media milling (WMM) in a Retsch MM 301 swing mill (Retsch, Haan, Germany) equipped with a $25 \mathrm{ml}$ milling jar filled with $407 \mathrm{~mm}$ stainless steel milling balls at a frequency of $10 \mathrm{~Hz}$ for 1 min; iii) ultrasonic probe treatment (USP) using a Sonopuls ultrasonic homogenizer with a MS72 probe (Bandelin, Berlin, Germany) 4 times for $30 \mathrm{~s}$ at $20 \%$ intensity with $3 \mathrm{~s}$ alternating dispersion and pause step; iv)/v) using a VWR Ultrasonic cleaner (VWR, Radnor, USA) with or without ice for $4 \times 5 \mathrm{~min}$ (USB/USB $\mathrm{Booled}_{\text {) }}$.

All other suspensions were prepared using the $\mathrm{USB}_{\text {cooled }}$ method in $6 \mathrm{R}, 10 \mathrm{R}$ or $20 \mathrm{R}$ glass vials (MGlas, Muennerstadt, Germany). Concentrations are given as the protein concentration in suspensions.

\subsection{Protein extraction from prepared suspensions}

For protein extraction powder suspensions were covered with HPW and rotated at $25 \mathrm{rpm}$ using a SU1100 vertical rotator (Sunlab, Mannheim, Germany) until clearance of the F6H8 phase.

\subsection{Laser diffraction}

Particle size distribution (volume based) was analyzed in isooctane containing 1\% Span 80 using the Laser Diffraction Particle Size Analyzer LA-960 by Horiba (Horiba, Kyoto, Japan). The dispersion medium was filtered through a VWR $0.22 \mu \mathrm{m}$ PTFE syringe filter before use. For particle size determination, particles were suspended manually in the dispersion vehicle. Samples were then homogenized using a Sonopuls ultrasonic homogenizer with a MS72 probe (Bandelin, Berlin, Germany) for $30 \mathrm{~s}$ at $10 \%$ intensity. This additional homogenization step was not conducted for investigating the effect of the dispersion techniques. 


\subsection{Preparation of aqueous mAb solutions}

MAb solutions for rheology and injectability investigations was prepared by dissolving the (spray-dried powder) in HPW.

\subsection{Rheology}

Rheological properties were investigated with an Anton Paar Physica MCR 100 cone-plate rheometer (Anton Paar, Graz, Austria) with a cone diameter of $50 \mathrm{~mm}$. Shear ramps were performed either from 1-1000 1/s (up and down) or $100-50001 / \mathrm{s}$ (up only) at $25^{\circ} \mathrm{C}$. Yield points were determined using the Casson equation. Thixotropy was examined using the hysteresis area between the up and the down curve.

\subsection{Injectability}

Syringe glide force measurements of different injection systems were performed using a Texture Analyzer XT plus (Stable Micro Systems, Godalming, UK). Suspensions stored in vials were drawn into a $1 \mathrm{ml} \mathrm{B.} \mathrm{Braun} \mathrm{Inject} \mathrm{F} \mathrm{single-use} \mathrm{syringe} \mathrm{(B.} \mathrm{Braun,} \mathrm{Melsungen,} \mathrm{Germany)}$ and a 25, 26 or 27 G Terumo Agani needle (Terumo, Tokyo, Japan) was then attached. For the determination of glide forces needed for injection, the plunger speed was set to obtain a volume flow of $0.5,1$ and $2 \mathrm{ml} / 10 \mathrm{~s}$.

\subsection{Maximum Volume fraction}

The maximum volume fractions of the spray-dried powders were determined visually in EO. Suspensions were filled in N 13-2 glass vials (Macherey-Nagel, Düren, Germany) and rotated for $2 \mathrm{~h}$ at $2000 \mathrm{rpm}$.

\subsection{Syringeability}

Syringeability from filled $2 R$ vials was tested using a $1 \mathrm{ml}$ Injekt F syringe (B. Braun) with a 25G needle attached.

\subsection{Filling and content uniformity}

For filling tests of suspensions, a Flexicon PD 12 peristaltic pump (Watson-Marlow Flexicon, Ringsted, Denmark) with $1.6 \mathrm{~mm}$ (inner diameter) Santopren TPV tubes and a $3.2 \mathrm{~mm}$ filling 
needle (Bausch and Lomb, Laval, Canada) was used. Tubes were double y-connected $(35 \rightarrow 2 \times 20 \rightarrow 35 \mathrm{~cm})$. As a feed reservoir, a 20R vial filled with the suspension, which was stirred with a magnetic bar was used. Filling was conducted at filling speeds of around $200 \mathrm{ml} / \mathrm{min}$. The pump was calibrated for each formulation. Between the filling steps a $15 \mathrm{~s}$ break was added. For each suspension $62 \mathrm{R}$ vials were filled with $2 \mathrm{ml}$ and the first two vials were discarded. Mass variation and content uniformity were evaluated according to Ph. Eur 2.9.40 with an acceptability constant $k$ of 2.4 and a maximum allowed acceptance value of 15.0. ${ }^{34}$ For analysis $200 \mu$ l suspension were added to $14 \mathrm{ml}$ of HPW, protein was extracted (see 3.15) and the protein concentration determined (see 3.3).

\subsection{Sedimentation behaviour}

In order to study the sedimentation behaviour, suspensions containing 70, 140, 210 or $280 \mathrm{mg} / \mathrm{ml}$ lysozyme powder were filled in N 13-2 glass vials (Macherey-Nagel) and examined after $1 \mathrm{~h}, 2 \mathrm{~h}, 12 \mathrm{~h}, 1 \mathrm{~d}, 2 \mathrm{~d}, 7 \mathrm{~d}$, and $1 \mathrm{~m}$ storage at room temperature. 


\section{Results and discussion}

\subsection{Powder properties}

The two main techniques for preparation of powders containing biopharmaceuticals are lyophilization with an additional milling step ${ }^{35,36}$ and spray-drying ${ }^{19,37,38}$. In this study spraydrying was used since more spherical particles in the lower micrometre range, suitable for the use in injectable protein powder suspensions, can be prepared directly. ${ }^{19,39,40}$ In order to assure injectability of the formulations through thin needles, e.g. $27 \mathrm{G}$ needle with $210 \mu \mathrm{m}$ inner diameter, the powder particles have to show a diameter in the lower micrometre range. Different values for maximum particle size for injectable suspensions are described ranging from 10 to $150 \mu \mathrm{m} .{ }^{41,42}$ The particle size should not exceed $1 / 8-1 / 3$ of the needle inner diameter to prevent needle clogging, which translates to $26-70 \mu \mathrm{m}$ for a $27 \mathrm{G}$ needle (see Chapter III). ${ }^{41,43}$ To study the effect of particle size and morphology, protein powders were prepared using different spray-drying conditions. For comparison, powder was prepared by cryogenic milling. The spray-dried powders containing trehalose and mAb or lysozyme showed the typical spherical morphology, whereas the milled lyophilizate showed a shed-like morphology (Figure IV-1). By varying the atomizing air flow rate and the ts, the particle size could be controlled between D50 values of approximately 1 to $15 \mu \mathrm{m}$. The D50 of the milled lyophilizates was approximately $8 \mu \mathrm{m}$. The type of protein did not influence the powder particle morphology or size. As a consequence of the additional vacuum drying step after spray-drying, the residual moisture content of all powders was below $0.5 \%$, which has been shown to be beneficial for protein stability during storage. ${ }^{37,44}$ The true density of all powders were approximately $1.32 \mathrm{~g} / \mathrm{cm}^{3}$. The protein powders were prepared with a low protein to stabilizer ratio of $70: 30(\mathrm{~m} / \mathrm{m})$ equivalent to a molar ratio of $1: 188$ for the mAb formulation. For good storage stability of mAb lyophilizates, higher molar ratios of protein to stabilizer such as $1: 300$ or $1: 360$ are recommended. ${ }^{3,45}$ Previous studies indicated sufficient stabilization of mAbs in spray-dried powders already at a protein to stabilizer molar ratio of 1:110 during storage at elevated temperatures. ${ }^{19,33}$ This low ratio is important to enable preparation of highly concentrated protein powder suspensions keeping the powder fraction and thus viscosity low. ${ }^{19,23,24}$ 


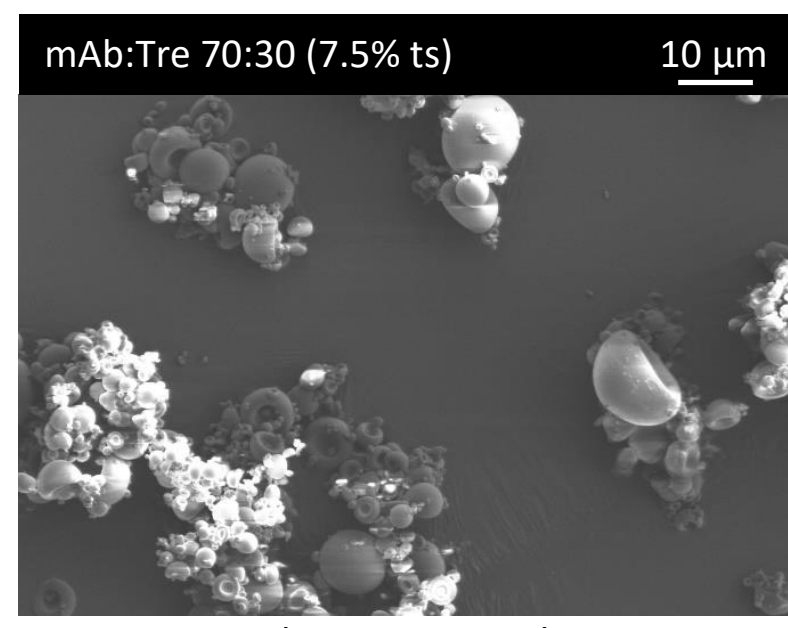

Preparation technique: Spray-drying D50: $5.9 \pm 0.2 \mu \mathrm{m} \quad$ Span: $1.2 \pm 0.1$

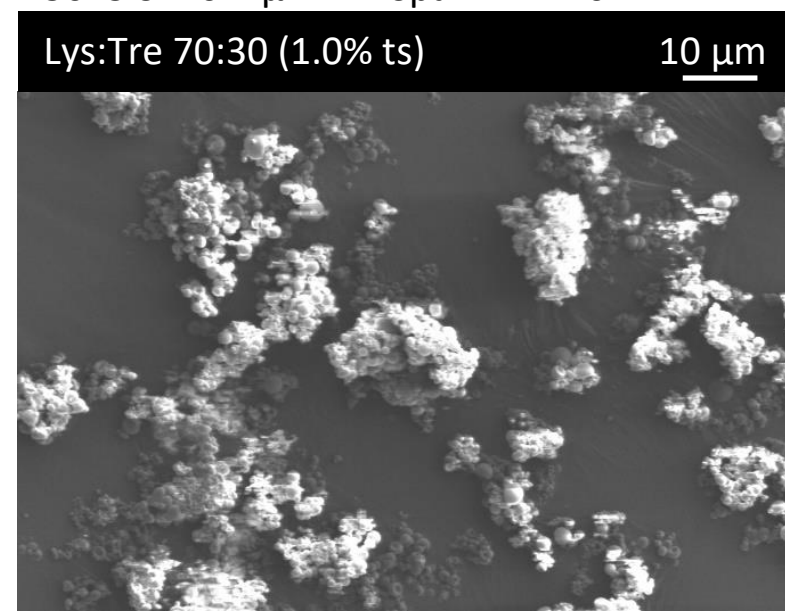

Preparation technique: Spray-drying

D50: $1.1 \pm 0.0 \mu \mathrm{m} \quad$ Span: $1.1 \pm 0.0$

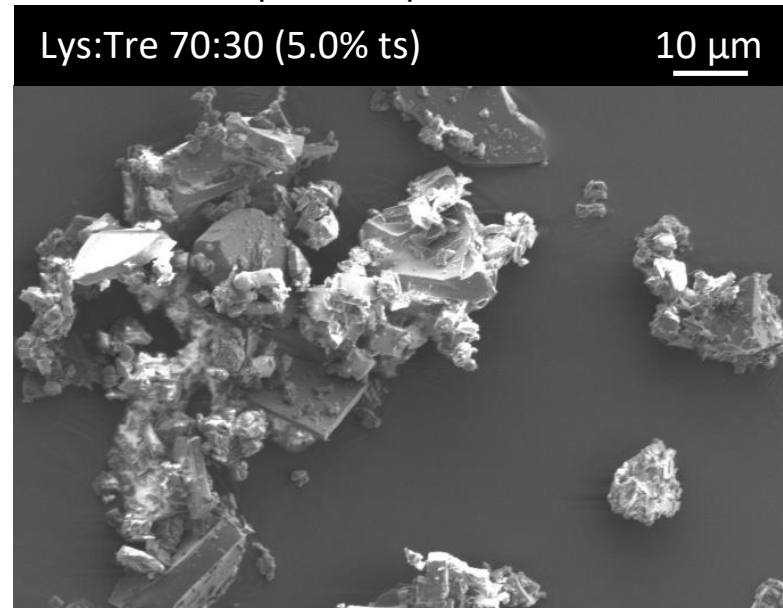

Preparation technique: Milling

D50: $8.1 \pm 0.7 \mu \mathrm{m} \quad$ Span: $1.1 \pm 0.0$

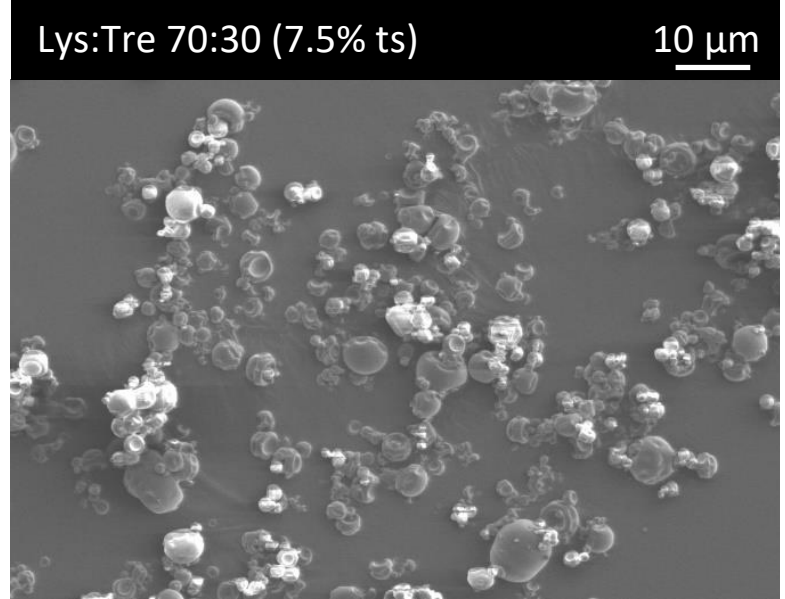

Preparation technique: Spray-drying D50: $4.5 \pm 0.6 \mu \mathrm{m} \quad$ Span: $1.3 \pm 0.0$

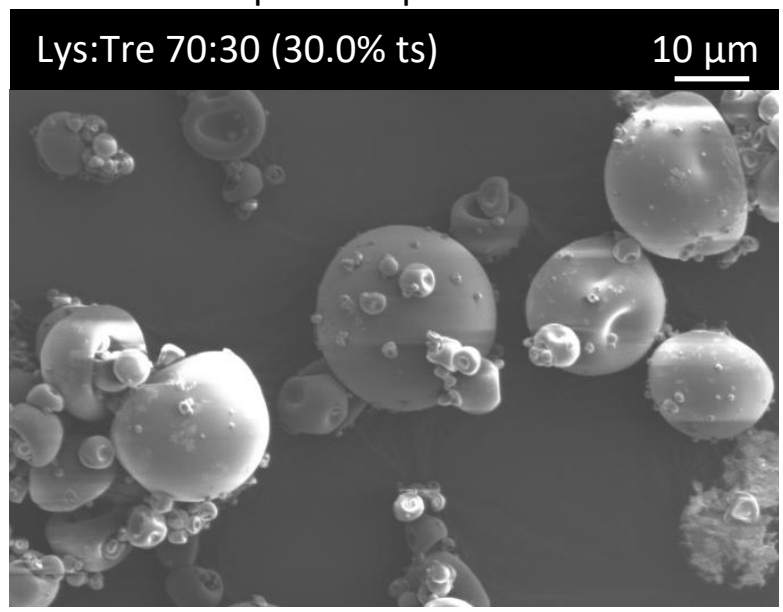

Preparation technique: Spray-drying D50: $14.2 \pm 1.1 \mu \mathrm{m} \quad$ Span: $1.1 \pm 0.0$

Figure IV-1: SEM images and particle sizes of protein powders. 
Spray-drying did not affect the mAb integrity. The number of subvisible particles was very low and did only minimally increase, which can be explained by the fact, that no particle-controlled environment was used for spray-drying (sd) (cumulative particle counts $\geq 10 \mu \mathrm{m}$ : before sd 56 \pm 27 , after sd $218 \pm 69 ; \geq 25 \mu \mathrm{m}$ : before sd $27 \pm 2$, after sd $17 \pm 5$ ). The amount of soluble aggregates after spray-drying ( $0.5 \pm 0.0$ vs $0.9 \pm 0.1 \%)$ as well as the monomer recovery $(98.9$ $\pm 0.4 \%)$ did not indicate drastic protein damage. No change in the FTIR spectra as a sign for a change of the protein conformation was detectable (Figure IV-2). The spectra showed the typical Amide-l-band of $\beta$-sheets, at 1635 - $1645 \mathrm{~cm}^{-1} .46,47$ Thus spray-drying of protein formulations at a low mAb to trehalose molar ratio of 1:188 is suitable to produce protein powders for high concentration powder suspensions.

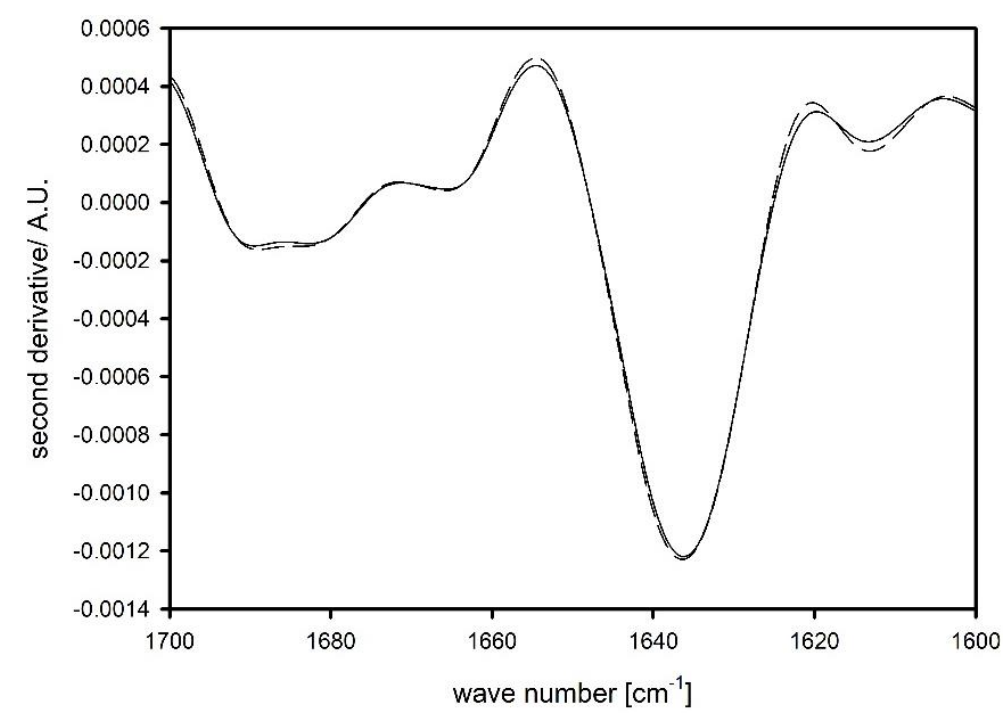

Figure IV-2: FTIR second derivative spectra of mAb:Tre 70:30 feed solution (-) and reconstituted mAb:Tre 70:30 (7.5\% ts) SDP (- - -).

\subsection{Suspension preparation and protein integrity}

In order to obtain injectable formulations on a defined and reproducible quality level, homogeneity of the suspensions is essential. Potential preparation methods include high shear homogenization, wet media milling, ultrasound probe or ultrasound bath treatment. ${ }^{19,48}$ Their effect on dispersion efficiency and protein integrity was tested. The poorest dispersion quality resulted with the high shear homogenizer, followed by wet media milling, ultrasound probe and ultrasound bath cooled and not cooled with ice (Figure IV-3). All suspensions were injectable through a $27 \mathrm{G}$ needle. 
An increase in the amount of soluble aggregates from 0.9 to 1.5 and $1.3 \%$ after ultrasound probe and ultrasound bath treatment and a corresponding decrease in monomer recovery of 97.2 and $96.7 \%$, respectively, were found. Such damage during the homogenization step is a consequence of local high energy input. All other treatments did not result in significant protein damage.

Additionally, protein powder adhered to the ultrasound probe $(0.2 \%)$ and the high shear homogenizer (1.3\%). Thus homogenization in cooled ultrasound bath, worked best overall and was used further in this study.

A

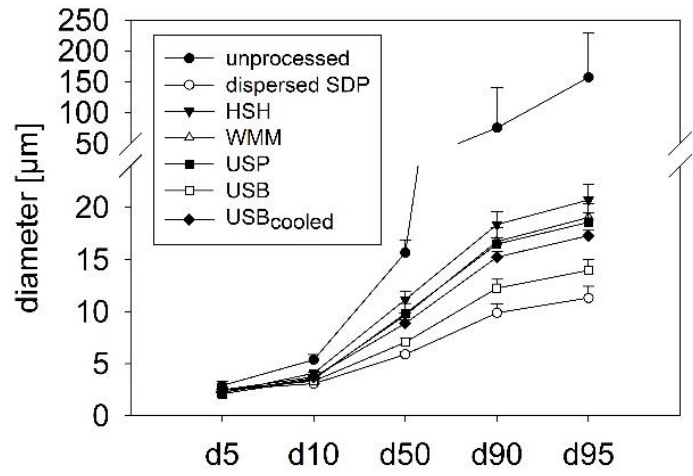

C

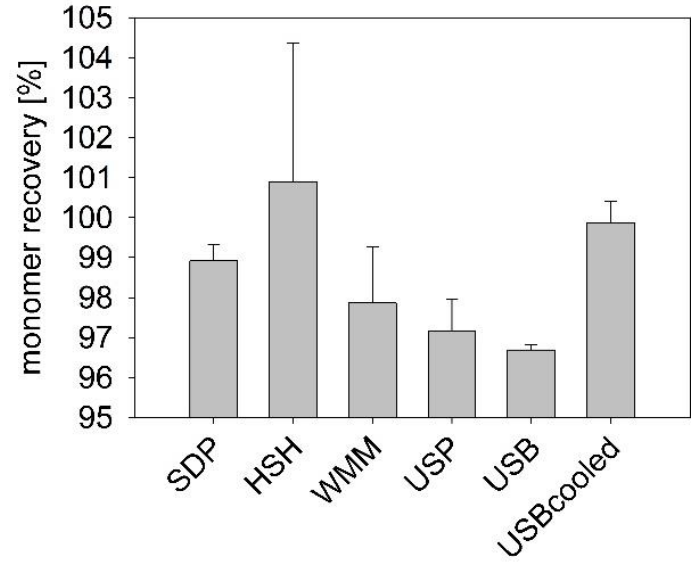

B

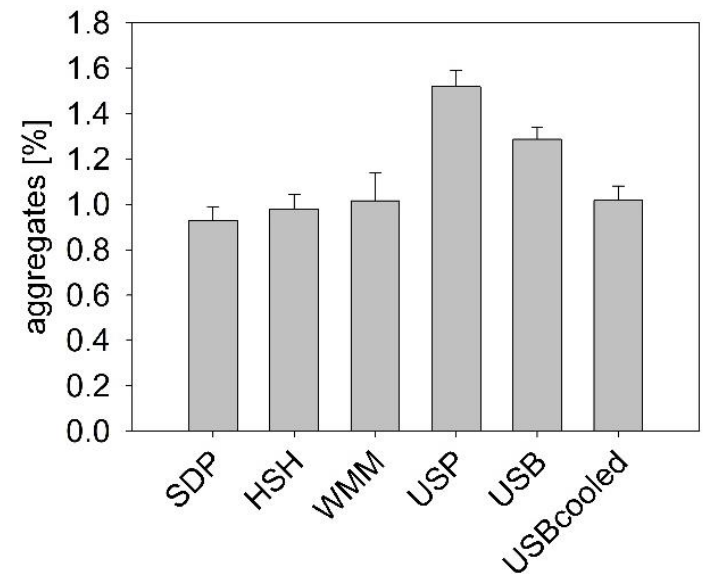

Figure IV-3: Effect of dispersing technique on dispersion quality $(A)$, the amount of soluble aggregates (B) and monomer recovery (C) of $210 \mathrm{mg} / \mathrm{ml} \mathrm{mAb:Tre} \mathrm{70:30} \mathrm{(7.5 \%} \mathrm{ts)} \mathrm{suspensions}$ in F6H8. Particle size was compared to SDP dispersed in the dispersion vehicle (see 3.16). SDP = unprocessed spray-dried powder; $\mathrm{HSH}=$ high shear homogenizer; $\mathrm{WMM}=$ wet media milling; USP = ultrasound probe; USB = ultrasound bath; $\mathrm{USB}_{\text {cooled }}=$ ultrasound bath cooled with ice. 


\subsection{Effect of protein and suspension vehicle on suspension rheology and glide force needed for injection}

One of the main objectives of the study was to identify and select suspension vehicles for the potential use in highly concentrated protein powder suspensions. High suspension viscosity may result in inadequate injection forces. The glide force of a syringe during injection can be calculated according to equation (1) which is a modification based on the Hagen-Poiseuille law and uses the injection devices geometrical dimensions as well as the formulation viscosity. ${ }^{15}$

$$
\mathrm{F}=\frac{8 \frac{\mathrm{dV}}{\mathrm{dt}} \cdot \mathrm{l} \cdot r_{\text {syringe }}^{2}}{\mathrm{r}_{\text {needle }}^{4}} \cdot \eta+\mathrm{F}_{\text {friction } ; \mathrm{f}\left(\frac{\mathrm{dV}}{\mathrm{dt}}\right)}
$$

The resulting glide force $F(N)$ is hereby described by the volume flow $d V / d t\left(m^{3} / s\right)$, the length of the needle $I(m)$, the inner radius of the syringe $r_{\text {syringe }}$ and the needle $r_{\text {needle }}(m)$, the dynamic viscosity $\eta(\mathrm{mPa} \cdot \mathrm{s})$, as well as the frictional forces between stopper and barrel of the syringe $\mathrm{F}_{\text {friction }}(\mathrm{N}) .{ }^{15}$ The equation shows, that the formulation viscosity has a strong effect on the glide force needed for injection. This gets even more important if thin needles, such as $26 \mathrm{G}$ or $27 \mathrm{G}$ needles are applied. Mathematical approaches for estimating the viscosity of highly concentrated suspensions described by Toda et al. (equation 2) or by Krieger and Dougherty (equation 3 ) show that the suspension vehicles inherent viscosity has a strong impact on the resulting suspension viscosity. ${ }^{23,24}$ According to Toda et al., the influence of the viscosity of the pure vehicle $\eta_{0}(\mathrm{mPa} \cdot \mathrm{s}$ ) in concentrated suspensions, on the resulting viscosity $\eta$ can be described by equation (2), a modification of the Einstein's equation, using the volume fraction of the solute $\varphi .{ }^{24}$ The Krieger-Dougherty equation further includes the maximum volume fraction $\varphi_{\max }$ as well as the intrinsic viscosity $\left[\eta_{\text {int }}\right] .{ }^{23}$

$$
\begin{gathered}
\eta=\eta_{0} \frac{(1-0.5 \varphi)}{(1-\varphi)^{3}} \\
\eta=\eta_{0}\left[1-\frac{(\varphi)}{\left(\varphi_{\max }\right)}\right]^{-\left[\eta_{\text {int }}\right] \varphi_{\max }}
\end{gathered}
$$

The vehicle has a strong influence on the resulting viscosity (equation 2 and 3) and stability. ${ }^{9,19,21}$ Thus, suspension vehicles for highly concentrated suspensions should show a viscosity below $10 \mathrm{mPa}$.s limiting the choice of vehicles for protein powder suspensions for s.c. 
injection as many of the oils approved for parenteral use show high viscosity above $10 \mathrm{mPa} \cdot \mathrm{s}^{19,25}$ Previously studied suspension vehicles for the use in highly concentrated suspensions include ethyl lactate $(\eta=2 \mathrm{mPa} \cdot \mathrm{s})$, ethyl oleate $(\eta=5 \mathrm{mPa} \cdot \mathrm{s})$, benzyl benzoate ( $\eta$ $=10 \mathrm{mPa} \cdot \mathrm{s}$ ) and propylene glycol diesters of medium chain fatty acids $(\eta=10 \mathrm{mPa} \cdot \mathrm{s}) \cdot{ }^{19,39}$ Fluorinated and semifluorinated alkanes could be interesting alternatives, as they provide a

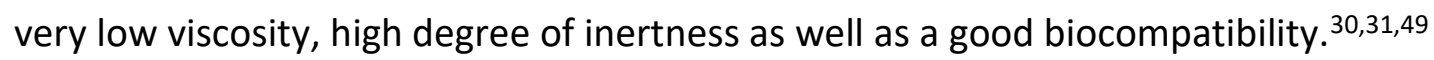
Mab:Tre 70:30 powder suspensions were prepared in F4H5 ( $\eta=1.1 \mathrm{mPa} \cdot \mathrm{s}), \mathrm{F} 6 \mathrm{H} 8(\eta=$ $3.4 \mathrm{mPa} \cdot \mathrm{s})$ and PFD $(\eta=5 \mathrm{mPa} \cdot \mathrm{s})$ at different concentrations and the rheological behavior was compared to the respective aqueous solutions.

A

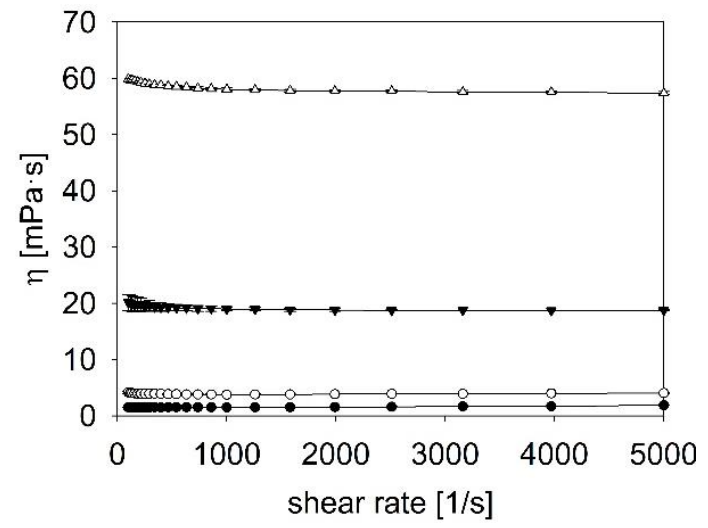

C

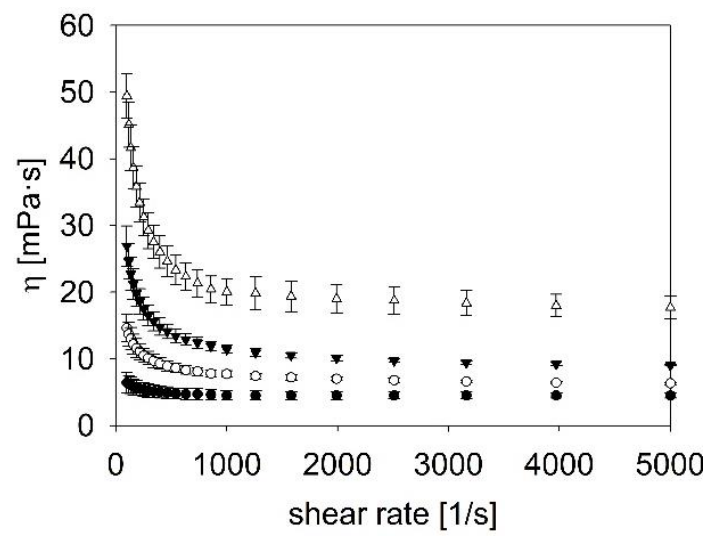

B

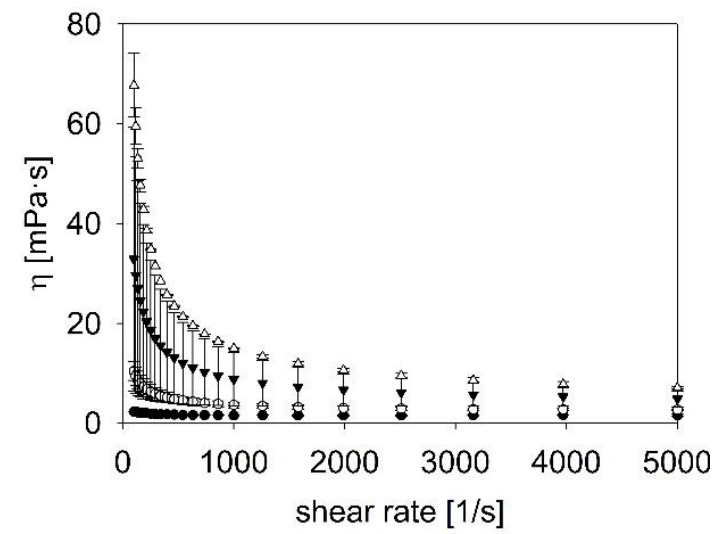

D

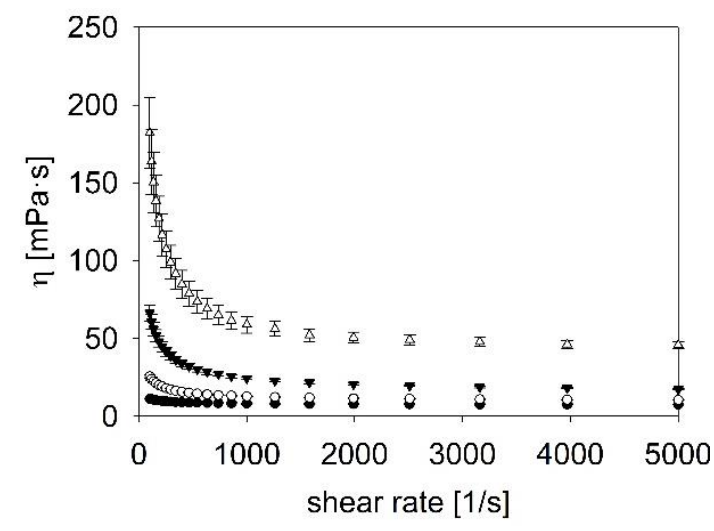

Figure IV-4: Dynamic viscosity of mAb:Tre 70:30 aqueous solution (A) or suspensions in F4H5 (B), F6H8 (C) or PFD (D) containing $70(\bullet), 140(0), 210(\nabla)$ or $280 \mathrm{mg} / \mathrm{ml}(\triangle)$.

The powder suspensions showed non-Newtonian behavior with pronounced shear-thinning, especially at higher powder concentrations, whereas the aqueous solutions showed Newtonian behavior in the analyzed shear-rate range (Figure IV-4). To estimate the glide force which is needed for injection, the viscosity at a shear rate larger than $3 \times 10^{4} 1 / \mathrm{s}$ is relevant. ${ }^{15}$ Since this shear rate could not be reached with the rheometer used and the viscosity reached 
the infinite shear rate viscosity plateau above approximately $10001 / \mathrm{s}$ the viscosity at the maximum shear rate of 5000 1/s was used for further evaluation.
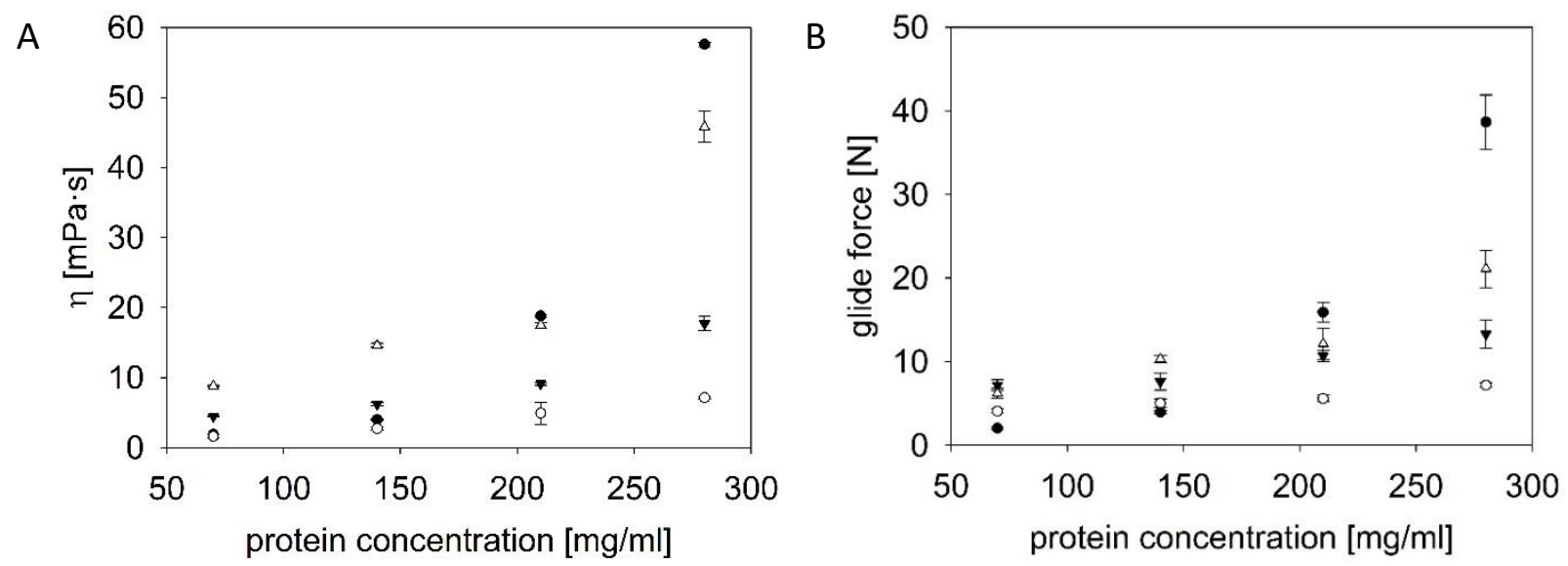

Figure IV-5: Viscosity at $50001 / \mathrm{s}(\mathrm{A})$ and glide force at $0.1 \mathrm{ml} / \mathrm{s}(\mathrm{B})$ of $\mathrm{mAb}$ :Tre 70:30 aqueous solution $(\bullet)$ and powder suspensions in F4H5 (0), F6H8 ( $\nabla)$ or PFD $(\triangle)$.

Highly concentrated aqueous solutions containing $280 \mathrm{mg} / \mathrm{ml} \mathrm{mAb}$ exhibited high viscosities of larger than $50 \mathrm{mPa} \cdot \mathrm{s}$ (Figure IV-5). The tested suspensions in F4H5, F6H8 and PFD showed substantially lower viscosities of $7.1,17.7$ and $45.8 \mathrm{mPa} \cdot \mathrm{s}$, respectively. Overall lowest viscosities were obtained with suspensions in $\mathrm{F} 4 \mathrm{H} 5$ at all tested concentrations. MAb suspensions in F6H8 and PFD showed higher viscosities than the aqueous solutions at 70 and $140 \mathrm{mg} / \mathrm{ml}$. But the concentration dependent increase in viscosity was more pronounced for the aqueous solutions compared to the suspensions and at concentrations of 210 and $280 \mathrm{mg} / \mathrm{ml}$ the suspensions in F6H8 and PFD showed lower viscosities than the aqueous mAb solution. A similar trend as seen for the viscosity was detected for the glide forces. High glide forces were obtained for highly concentrated mAb solutions, especially at $280 \mathrm{mg} / \mathrm{ml}$, whereas the respective suspensions showed markedly lower glide forces $\left(F_{\text {solution }}=38.7 \mathrm{~N}\right.$, $\mathrm{F}_{\mathrm{F} 4 \mathrm{H} 5}=7.2 \mathrm{~N}, \mathrm{~F}_{\mathrm{FGH} 8}=13.3 \mathrm{~N}$ and $\mathrm{F}_{\mathrm{PFD}}=21.1 \mathrm{~N} ; \mathrm{C}_{\mathrm{mAb}}=280 \mathrm{mg} / \mathrm{ml}$ ). In terms of glide force needed for injection, mAb suspensions were only superior over the solution at high concentrations ( $\geq 210 \mathrm{mg} / \mathrm{ml}$ ). Lower glide forces were obtained for the $\mathrm{mAb}$ solution at 70 and $140 \mathrm{mg} / \mathrm{ml}$.

To test the influence of the protein on viscosity and glide force during injection, Lys:Tre 70:30 $(7.5 \% \mathrm{ts})$ formulations were prepared as aqueous solutions, as well as powder suspensions in F4H5, F6H8 and PFD. 

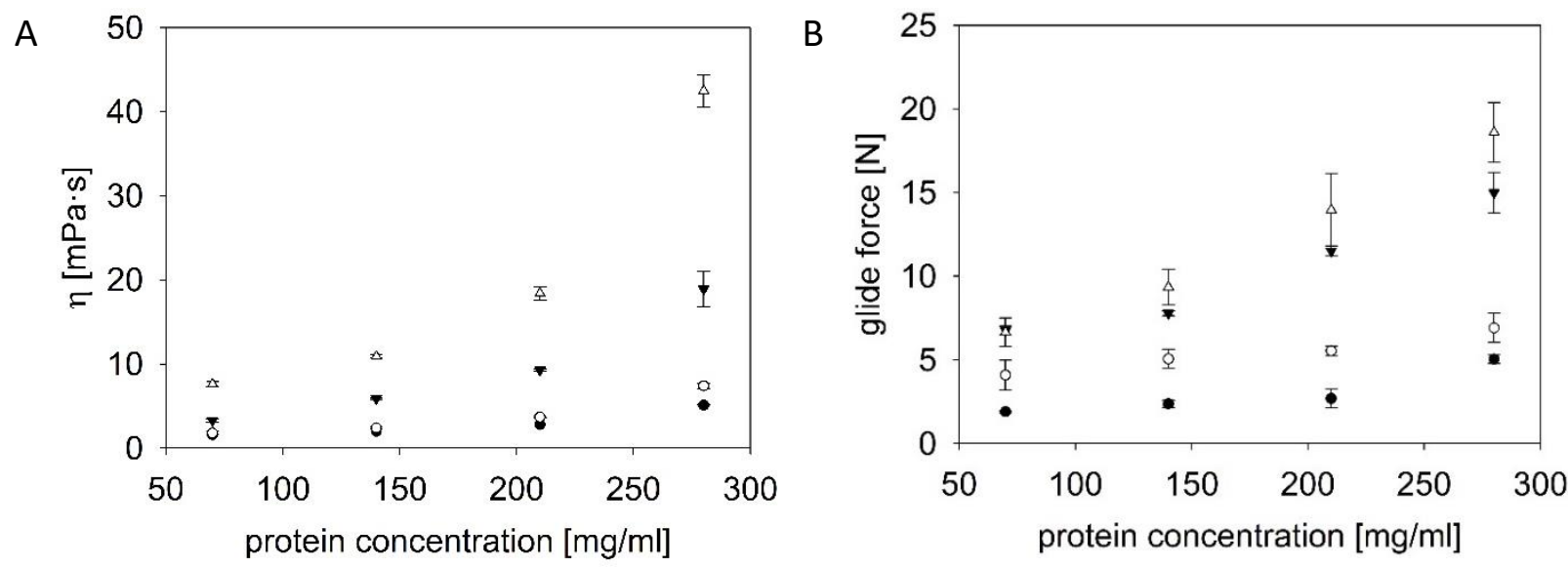

Figure IV-6: Viscosity at 5000 1/s (A) and glide force at $0.1 \mathrm{ml} / \mathrm{s}(\mathrm{B})$ of Lys:Tre 70:30 aqueous solution $(\bullet)$ and powder suspensions in F4H5 (०), F6H8 ( $\nabla)$ or PFD $(\triangle)$.

Aqueous Lys:Tre 70:30 solutions showed lower viscosity at all tested concentrations compared to the respective powder suspensions (Figure IV-6). Even at high protein concentrations of $280 \mathrm{mg} / \mathrm{ml}$ the aqueous solution was superior in terms of viscosity and glide forces $\left(\eta_{\text {solution }}=\right.$ $5.1 \mathrm{mPa} \cdot \mathrm{s}, \eta_{\mathrm{F} 4 \mathrm{H} 5}=7.4 \mathrm{mPa} \cdot \mathrm{s}, \eta_{\mathrm{FGH}}=18.9 \mathrm{mPa} \cdot \mathrm{s}$ and $\eta_{\mathrm{PFD}}=42.5 \mathrm{mPa} \cdot \mathrm{s} ; \mathrm{c}_{\mathrm{Lys}}=280 \mathrm{mg} / \mathrm{ml}$ ). Low glide forces of $5.0 \mathrm{~N}$ were needed for injection of lysozyme solutions, even at high concentrations of $280 \mathrm{mg} / \mathrm{ml}$. Glide forces of lysozyme powder suspensions were comparable to the mAb powder suspensions, with lowest forces obtained for suspensions in $\mathrm{F} 4 \mathrm{H} 5$ followed by F6H8 and PFD.

The type of protein did not show an effect on suspension viscosity and glide forces during injection. These findings confirm results obtained by Bowen et al. who tested the viscosities and glide forces of non-aqueous protein powder suspensions containing different mAbs. ${ }^{19}$ Contrary, drastic differences were seen for the viscosities and glide forces of the aqueous mAb and lysozyme solutions. The strong difference in the increase of viscosity and glide forces in aqueous solution between the two proteins can be explained by different protein-protein intermolecular interactions in aqueous solution. ${ }^{50}$

To compare rheological behavior of SFA suspensions with literature suggested vehicles for highly concentrated protein powder suspensions, additional Lys:Tre 70:30 (7.5\% ts) powder suspensions were investigated. As vehicles ethyl lactate (EL) ( $\eta=2 \mathrm{mPa} \cdot \mathrm{s})$, ethyl oleate (EO) $(\eta=5 \mathrm{mPa} \cdot \mathrm{s})$, medium chain triglycerides $(\mathrm{MCT})(\eta=23 \mathrm{mPa} \cdot \mathrm{s})$ and sesame oil $(\mathrm{SO})(\eta=$ $51 \mathrm{mPa} \cdot \mathrm{s}$ ) were tested (Figure IV-7). Out of these liquids only MCT and SO have approval for parenteral application. ${ }^{51}$ 

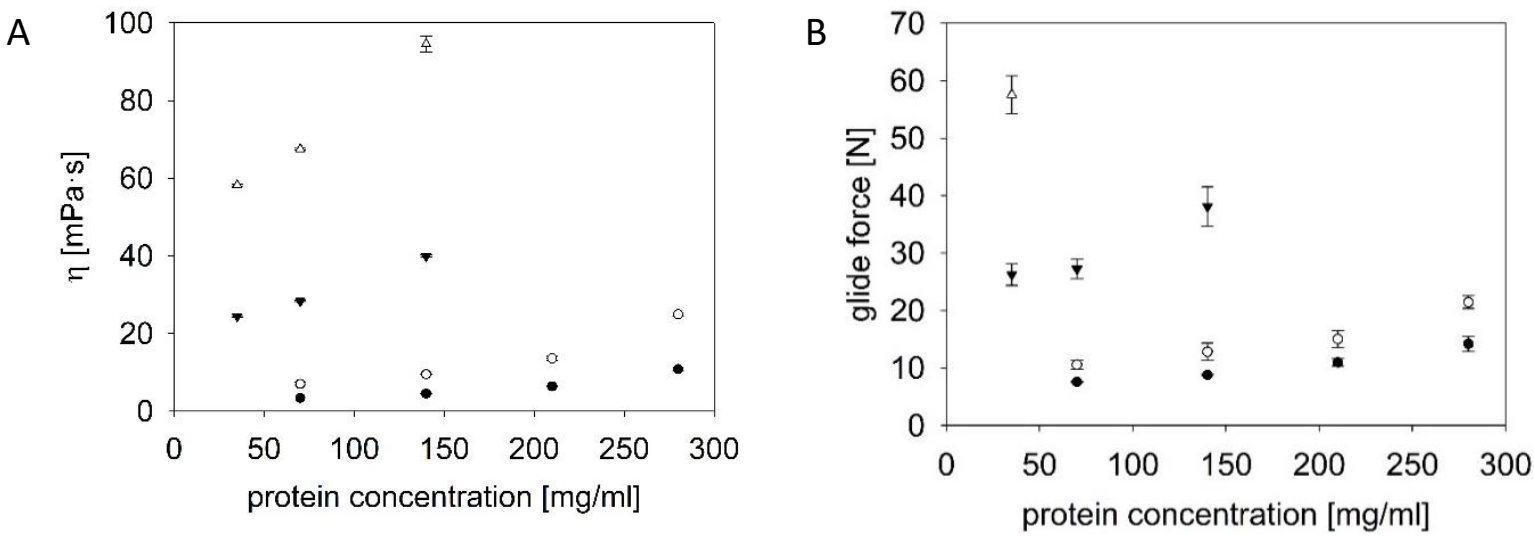

Figure IV-7: Effect of suspension vehicle (EL $(\bullet)$, EO $(0), \operatorname{MCT}(\boldsymbol{\nabla})$ or SO $(\triangle)$ ) on viscosity at $50001 / \mathrm{s}(A)$ and glide force at a volume flow of $0.1 \mathrm{ml} / \mathrm{s}$ (B) (27G needle) of formulations containing Lys:Tre 70:30 powder (7.5\% ts).

Viscosities and glide forces of suspensions in EL and EO were acceptable even at high concentrations of $280 \mathrm{mg} / \mathrm{ml}$ with glide forces below $25 \mathrm{~N}$. Suspensions in MCT and especially in SO showed high viscosities and glide forces. As the injection forces during administration should not exceed 25-30 N, SO and MCT are less suitable, in the presented set-up, for the use in highly concentrated formulations. ${ }^{18,52}$ EL suspensions showed viscosities and glide forces with values between suspensions in $\mathrm{F} 4 \mathrm{H} 5$ and $\mathrm{F} 6 \mathrm{H} 8$, while $\mathrm{EO}$ suspension performance was similar to PFD suspensions (Figure IV-6/-7). Differences in suspension viscosity in the different vehicles correlate with the inherent viscosity $\eta_{0}$ of the vehicle $\left(\eta_{\mathrm{F} 4 \mathrm{H}_{5}}<\eta_{\mathrm{EL}}<\eta_{\mathrm{FGH}}<\eta_{\mathrm{EO}} \approx \eta_{\mathrm{PFD}}<\eta_{\mathrm{MCT}}<\eta_{\mathrm{SO}}\right)$.

Overall results confirm the high potential of protein powder suspensions in SFAs for proteins, with special focus on proteins exhibiting strong viscosity increasing properties in aqueous solution and requiring administration in high doses.

\subsection{Prediction of viscosity and glide force needed for injection}

It is of interest, if equations 1 to 3 can be used to predict the viscosity and glide force for injection of non-aqueous protein powder suspensions. A potential predictability can be used to select or design a suitable injection procedure and system. 
A. Toda et al.

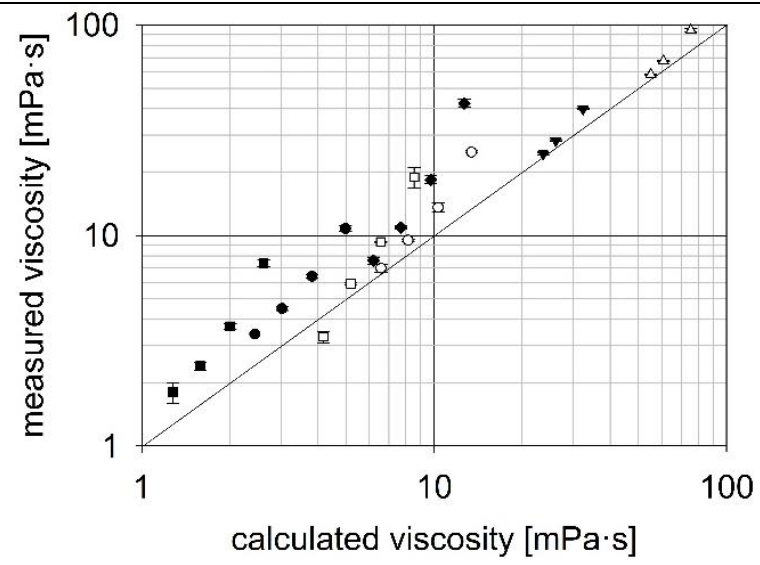

C. equation (1)

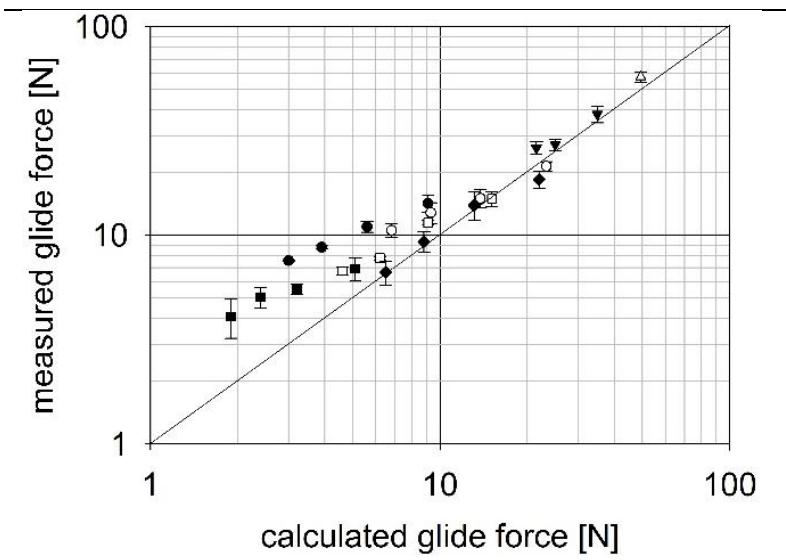

B. Krieger-Dougherty

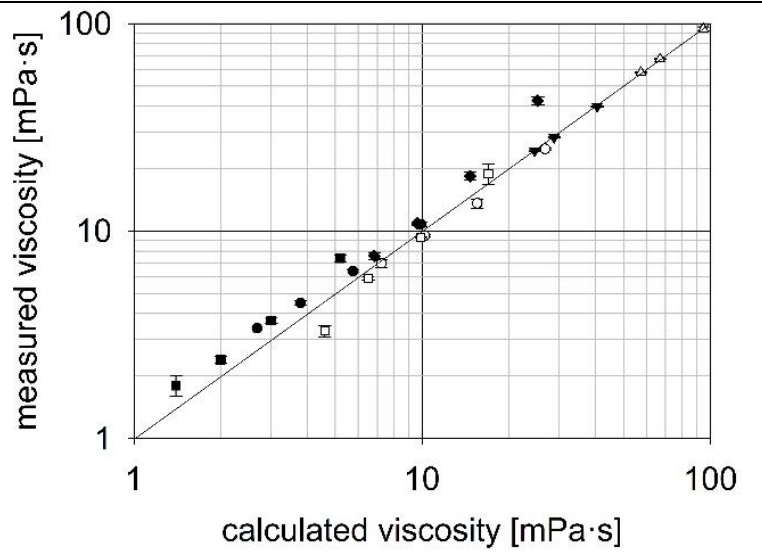

Figure IV-8: Calculated vs measured viscosity according to Toda et al. (A) and KriegerDougherty (B) and glide force during injection according to equation 1 (C) of Lys:Tre (7.5\% ts)

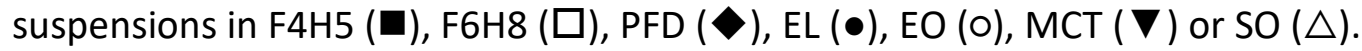

Viscosities were calculated according to equation 2 (Toda et al.) or equation 3 (KriegerDougherty) and compared to measured viscosity values (Figure IV-8). Viscosities calculated according to Krieger-Dougherty correlated well with the experimental results with an average deviation of only $15 \%$. Calculations according to Toda et al. led to an underestimation of the suspension viscosity, which is in accordance with findings by Bowen et al. and deviated on average by $55 \%$ from the experimental results. ${ }^{19}$ Subsequently, glide forces were calculated according to equation 1 using the suspension viscosities which were calculated according to Krieger-Dougherty.

It was possible to estimate resulting glide forces during injection with an underestimation at glide forces below $10 \mathrm{~N}$ of $67 \%$ (Figure IV-8). Overall deviation of predicted glide forces was $44 \%$. Calculated glide forces above $10 \mathrm{~N}$ were in good accordance with measured values with 
an average deviation of only $13 \%$. The underestimation at low glide forces can be explained by a stronger relative effect of the influence of the vehicle on interactions between plunger and syringe barrel, such as lubrication effects, at the low concentration.

\subsection{Effect of particle morphology on suspension rheology and glide force needed for injection}

In general, the particle morphology affects the suspension rheology. ${ }^{21,39}$ In order to have a deeper look into this phenomenon Lys:Tre 70:30 powders of different sizes were prepared by varying the total solid content of the feed solution and the atomization pressure. Additionally, milled Lys:Tre 70:30 powder was evaluated. After the additional drying step following spraydrying, a comparable residual moisture content resulted. SEM images as well as particle sizes are shown in Figure IV-1.

Table IV-1: Effect of particle morphology on rheological properties of $210 \mathrm{mg} / \mathrm{ml}$ Lys:Tre 70:30 suspensions in $\mathrm{F} 6 \mathrm{H} 8$.

\begin{tabular}{c|c|c|c|c} 
& \multicolumn{3}{|c|}{ Spray-dried } & Milled \\
\hline $\mathrm{D} 50[\mu \mathrm{m}]$ & $1.1 \pm 0.0$ & $4.5 \pm 0.6$ & $14.2 \pm 1.1$ & $8.1 \pm 0.7$ \\
\hline $\begin{array}{c}\boldsymbol{\eta}[\mathrm{mPa} \cdot \mathrm{s}] \\
(50001 / \mathrm{s})\end{array}$ & $10.5 \pm 0.5$ & $9.8 \pm 0.1$ & $10.6 \pm 0.2$ & $13.9 \pm 0.8$ \\
\hline $\begin{array}{c}\mathrm{F}[\mathrm{N}] \\
(26 \mathrm{G} ;\end{array}$ & $8.9 \pm 0.6$ & $9.3 \pm 0.5$ & $8.3 \pm 0.5$ & Not injectable \\
$0.1 \mathrm{ml} / \mathrm{s})$ & $0.58 \pm 0.02$ & $0.53 \pm 0.03$ & $0.53 \pm 0.02$ & $0.39 \pm 0.04$ \\
\hline$\phi_{\max }$ & $3.7 \pm 0.1$ & $3.6 \pm 0.1$ & $3.8 \pm 0.1$ & $4.2 \pm 0.2$
\end{tabular}

Particle D50 diameters of the spray-dried powders ranged from 1.1 to $14.2 \mu \mathrm{m}$. Suspensions prepared with the spray-dried powders showed similar viscosities and glide forces during injection (Table IV-1). The independence of the resulting viscosity from the powder diameter is in accordance with findings by Bowen et al. ${ }^{19}$ According to the Krieger-Dougherty equation, potential factors affecting the resulting suspension viscosity are the maximum volume fraction $\varphi_{\max }$ and the intrinsic viscosity $\left[\eta_{\text {int }}\right]$ (equation 3$) .{ }^{23}$ Both, $\varphi_{\max }$ and $\left[\eta_{\text {int }}\right]$ are not influenced by the particle size. In contrast to that, $\varphi_{\max }$ can be influenced by the particle size distribution. ${ }^{53}$ In suspensions containing a broad particle size distribution, the smaller particles are able to occupy space between the larger particles leading to an increase of the maximum volume fraction. Additionally, smaller particles are able to act as a lubricant for larger 
particles. ${ }^{53}$ The particle shape has a strong influence on $\left[\eta_{\text {int }}\right]$, with the lowest possible value of 2.5 for rigid spheres. Suspensions prepared with spray-dried powders with different particle sizes do not show drastic differences for $\varphi_{\max }$ and $\left[\eta_{\text {int }}\right]$. This is a consequence of similar sphericity and particle size distribution (Figure IV-1). Deviations from the optimum sphere usually results in an increase of $\left[\eta_{\text {int }}\right]$ as a consequence of an extra energy dissipation. ${ }^{53}$ This explains the higher viscosity of suspensions containing the non-spherical milled powder. Suspensions prepared with milled Lys:Tre $70: 30$ powder at $210 \mathrm{mg} / \mathrm{ml}$ lysozyme were not injectable and lead to needle clogging. As the milled powder was sieved with a mesh size of $40 \mu \mathrm{m}$, the clogging cannot be attributed to presence of individual large particle with a diameter larger than the inner diameter of the needle $(260 \mu \mathrm{m})$. The needle clogging is a consequence of a bridging effect of single milled particles and a consequent formation of agglomerates at the needle-barrel intersection of the syringe leading to complete blockage of the system. No needle clogging was observed during injection of spray-dried powder suspensions. Results show, that spray-drying is superior over milling and thus the powder preparation method of choice for injectable high concentration protein powder suspensions.

\subsection{Effect of injection speed and needle size on suspension rheology and glide force needed for injection}

According to equation 1, altering the injection speed or changing to a needle with a larger diameter (e.g. 25G) is an option to decrease the glide forces to an acceptable value. Figure IV9 shows the influence of the injection speed on the resulting glide force during injection of different mAb:Tre 70:30 formulations. 


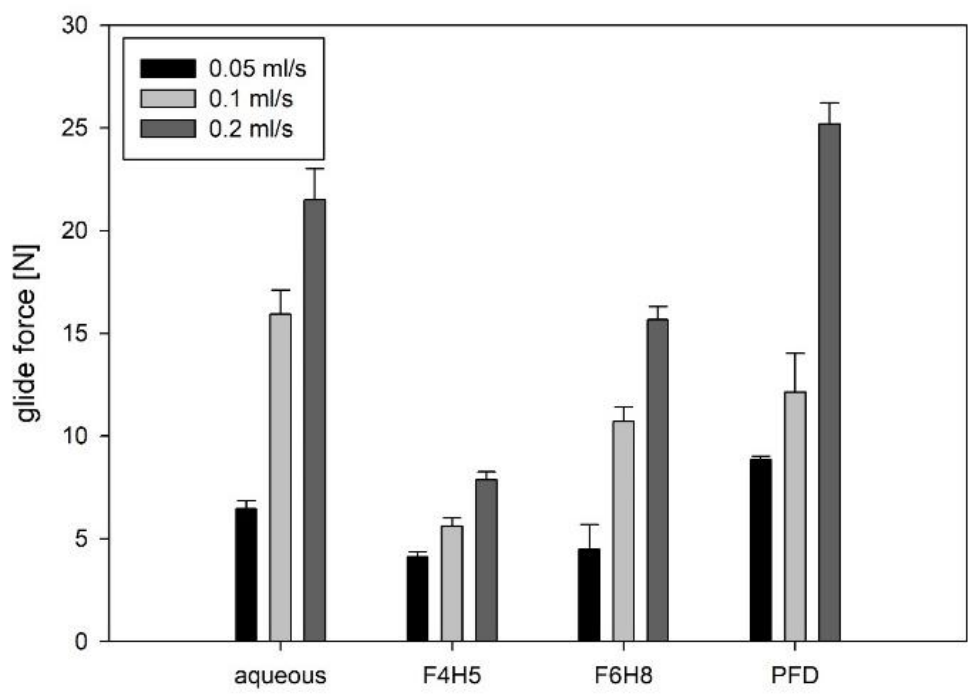

Figure IV-9: Glide force of $210 \mathrm{mg} / \mathrm{ml} \mathrm{mAb}:$ Tre 70:30 (7.5\% ts) formulations at injection speeds of $0.05,0.1$ and $0.2 \mathrm{ml} / \mathrm{s}$.

The glide forces increased with increasing injection speed and thus volume flow according to equation 1 (see Figure IV-9). At $210 \mathrm{mg} / \mathrm{ml}$ the two tested protein powder suspensions in SFAs showed glide forces below the target threshold of $25 \mathrm{~N}$ even at injection speeds of $0.2 \mathrm{ml} / \mathrm{s}$. This effect was especially pronounced for $\mathrm{F} 4 \mathrm{H} 5$, for which, according to equation 1 and 2, a theoretical injection speed at the limit of $25 \mathrm{~N}$ of 0.99 and $0.55 \mathrm{ml} / \mathrm{s}$ at protein concentrations of 210 and $280 \mathrm{mg} / \mathrm{ml}$, respectively, would be feasible using a $27 \mathrm{G}$ needle.

MCT

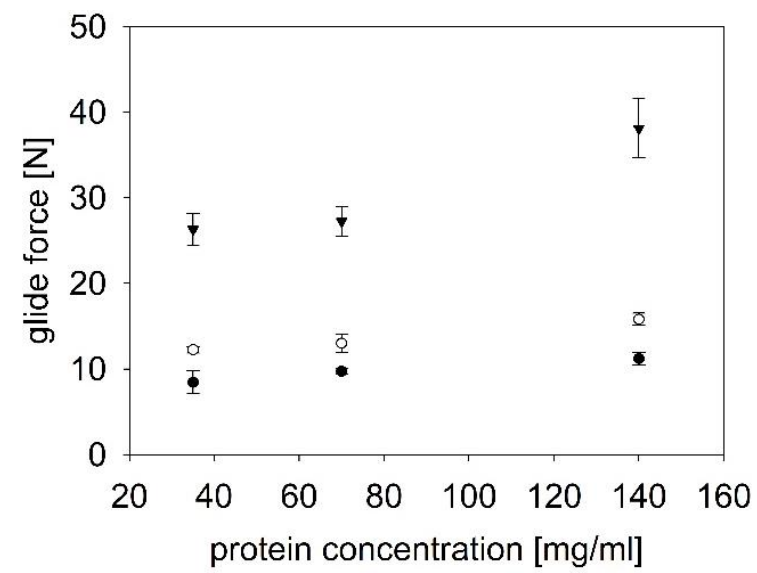

F6H8

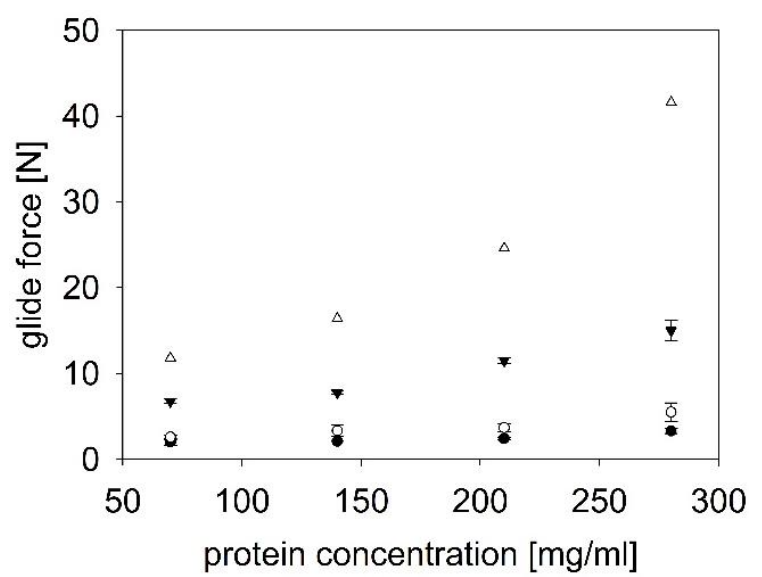

Figure IV-10: Effect of needle size and protein concentration on glide forces during injection of mAb:Tre $70.30(7.5 \% \mathrm{ts})$ suspensions in MCT or F6H8 at $0.1 \mathrm{ml} / \mathrm{s}$ through needles of $\bullet 25 \mathrm{G}$, ○ 26G, $\nabla 27 \mathrm{G}$ (empirical) or $\Delta 30 \mathrm{G}$ (calculated according to equation 1 and 2). 
Glide forces larger than $25 \mathrm{~N}$ resulted for suspensions in MCT at $0.1 \mathrm{ml} / \mathrm{s}$ when a $27 \mathrm{G}$ needle was used. By the use of needles with a larger needle inner diameter (25 or 26G needles), the injection force could be reduced substantially enabling easy injection (Figure IV-10). Regarding pain, as well as potential bleeding after the injection, it is recommended to use hypodermic needles with small diameters down to $31 \mathrm{G}$, especially for treatment of chronic diseases. ${ }^{17}$ For high concentration formulations this is not applicable due to high forces needed for injection. As a consequence needle sizes of 26 and $27 \mathrm{G}$ are recommended for high concentration formulations, but also larger diameters such as 23 and $25 \mathrm{G}$ can be used. ${ }^{3,54}$ Overall modulation of the injection speed as well as the needle diameter are potential routes to allow injection of formulations with high viscosities up to $40 \mathrm{mPa} \cdot \mathrm{s}$ (e.g. $140 \mathrm{mg} / \mathrm{ml}$ protein in MCT). Suspensions in $\mathrm{F} 6 \mathrm{H} 8$ showed much lower glide forces. Glide forces of F6H8 suspensions through $30 \mathrm{G}$ needles were calculated as described above. Injection through $30 \mathrm{G}$ needles were not conducted, but previous findings in literature indicated that injection of highly concentrated suspensions containing spray-dried protein powder through $30 \mathrm{G}$ needles is feasible for powder concentrations up to $700 \mathrm{mg} / \mathrm{ml} .{ }^{26}$ Nevertheless, at a mAb concentration of $210 \mathrm{mg} / \mathrm{ml}$, the glide force was already near the target threshold of $25 \mathrm{~N}$ with a calculated force of $24.6 \mathrm{~N}$ and a $280 \mathrm{mg} / \mathrm{ml}$ suspension in $\mathrm{F} 6 \mathrm{H} 8$ would feature a glide force of $41.6 \mathrm{~N}$ when injected trough a $30 \mathrm{G}$ needle. Calculation for a $280 \mathrm{mg} / \mathrm{ml} \mathrm{mAb}$ suspension in $\mathrm{F} 4 \mathrm{H} 5$ yielded a glide force substantially below $25 \mathrm{~N}$ with $13.3 \mathrm{~N}$.

Overall results show the high potential of SFA protein powder suspensions. Especially, suspensions in $\mathrm{F} 4 \mathrm{H} 5$ yield formulations with good injectability at high concentrations even at high injection speeds, as well as when combined with thin needles such as $30 \mathrm{G}$ needles.

\subsection{Syringeability of protein powder suspensions}

Protein powder suspensions can be provided either in a vial, in a prefillable syringe or a cartridge. If a vial is selected, withdrawal into a syringe has to be realizable. The withdrawal should not take too long, but more importantly, it should not affect the protein concentration. During the process of syringing, the suspension has to undergo different stages. First a suction force by drawing back the plunger is created. At this point, the suspension has to overcome the yield point to guarantee a suspension flow. The protein powder suspension then gets sucked into the needle and flows into the syringe. Additionally, the suspension has to flow sufficiently down along the vial wall. An important characteristic for the suspension 
formulation is its yield point, which describes the minimum force required to initiate flow. During the described stages the formulation is affected by different shear rates $\dot{\gamma}$. These shear rates can be calculated according to equation $4 .{ }^{22,48}$

$$
\dot{\gamma}=\frac{4 \frac{d V}{d t}}{\pi R_{\text {needle }}^{3}}
$$

The passage of the needle is less difficult, as here high shear forces are present, due to the high volume flow (approximately $10^{3}-72 \times 10^{3} 1 / \mathrm{s}$ depending on the formulation). The flow of the suspension down the vial wall (inner diameter $=14 \mathrm{~mm}$ ) is more critical due to the low shear rates of 0.07 to $0.461 / \mathrm{s}$, leading to high viscosity of the pseudoplastic suspensions. At such low shear rates a high variability in the measured apparent viscosities is present, as a consequence of a heterogenous nature, possible structural fracture and potential slip of the protein powder suspension. ${ }^{48,55}$ Because of this, it is usually recommended to study rheological behavior at shear rates larger than $51 / \mathrm{s}$ in order to evaluate the behavior during the syringing process. ${ }^{48,55}$

Yield points of the protein powder suspensions were determined using the Casson model. ${ }^{48}$ Low concentration Lys:Tre 70:30 formulations did not show yield points $(<0.01 \mathrm{~Pa})$ and even high concentration formulations featured rather low yield points below $1 \mathrm{~Pa}$ (Table IV-2).

Table IV-2: Effect of protein concentration and suspension vehicle on yield point of Lys:Tre 70:30 (7.5\% ts) suspensions determined according to the Casson model.

\begin{tabular}{|c|c|c|}
\hline & \multicolumn{2}{|c|}{ Yield points [Pa] } \\
\hline CProtein $[\mathrm{mg} / \mathrm{ml}]$ & F6H8 & MCT \\
\hline 35 & $<0.01$ & $<0.01$ \\
\hline 70 & $<0.01$ & $0.01 \pm 0.00$ \\
\hline 140 & $0.04 \pm 0.03$ & - \\
\hline 210 & $0.13 \pm 0.05$ & - \\
\hline 280 & $0.66 \pm 0.16$ & \\
\hline
\end{tabular}




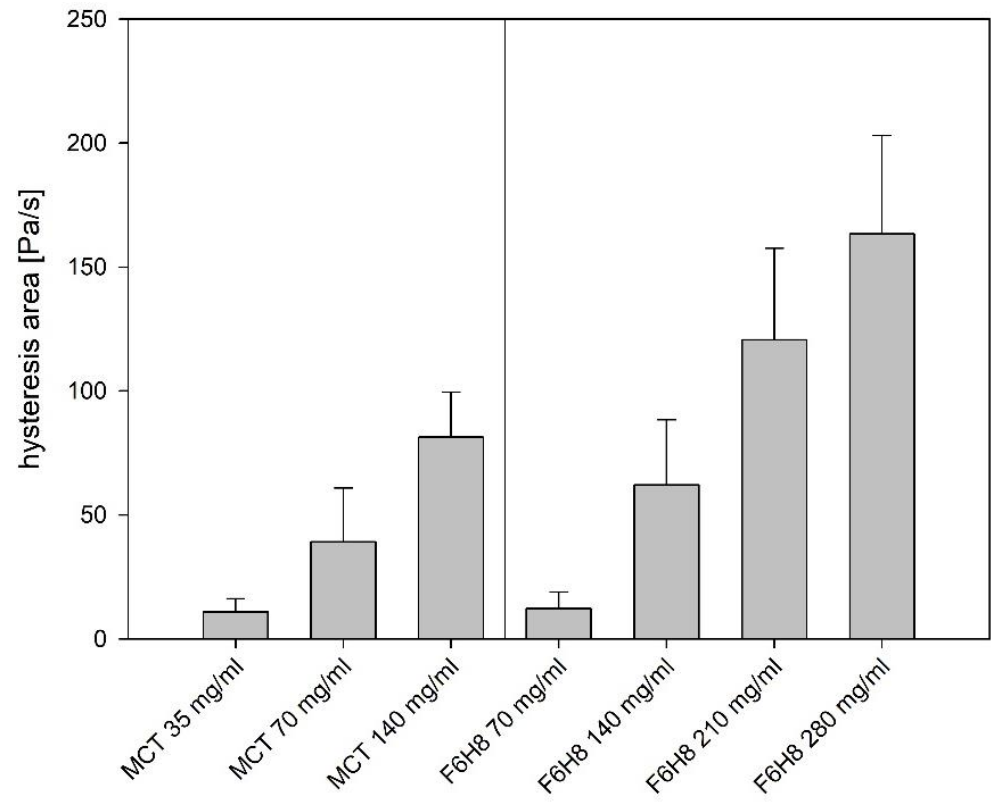

Figure IV-11: Effect of protein concentration and suspension vehicle on hysteresis areas of 70:30 Lys:Tre (7.5\% ts) suspensions. Ramp from 1-1000 1/s up and down in $60 \mathrm{~s}$.

The suspensions showed slight thixotropic behaviour with only small hysteresis areas (Figure IV-11). An increase in the solid content hereby led to more pronounced hysteresis area. Thus, application of shear stress on a highly concentrated suspension by shaking or drawing into a syringe leads to a temporary viscosity decrease, but the system returns to a higher viscosity state quickly. Highly concentrated suspensions potentially benefit from this behaviour, as this results in lower sedimentation speeds and by this in a more accurate dosing. 


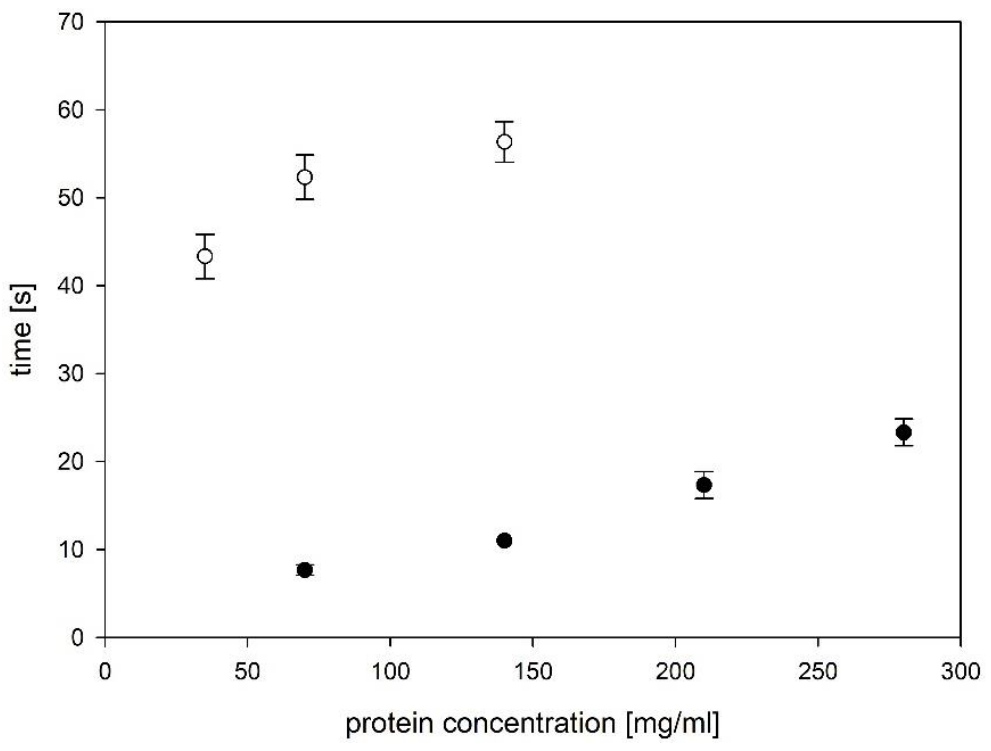

Figure IV-12: Effect of protein concentration on time needed to withdraw $1 \mathrm{ml}$ of a Lys:Tre $70: 30(7.5 \% \mathrm{ts})$ suspension in either $\mathrm{F} 6 \mathrm{H} 8(\bullet)$ or $\mathrm{MCT}(\mathrm{O})$ from a vial into a syringe through a $25 G$ needle.

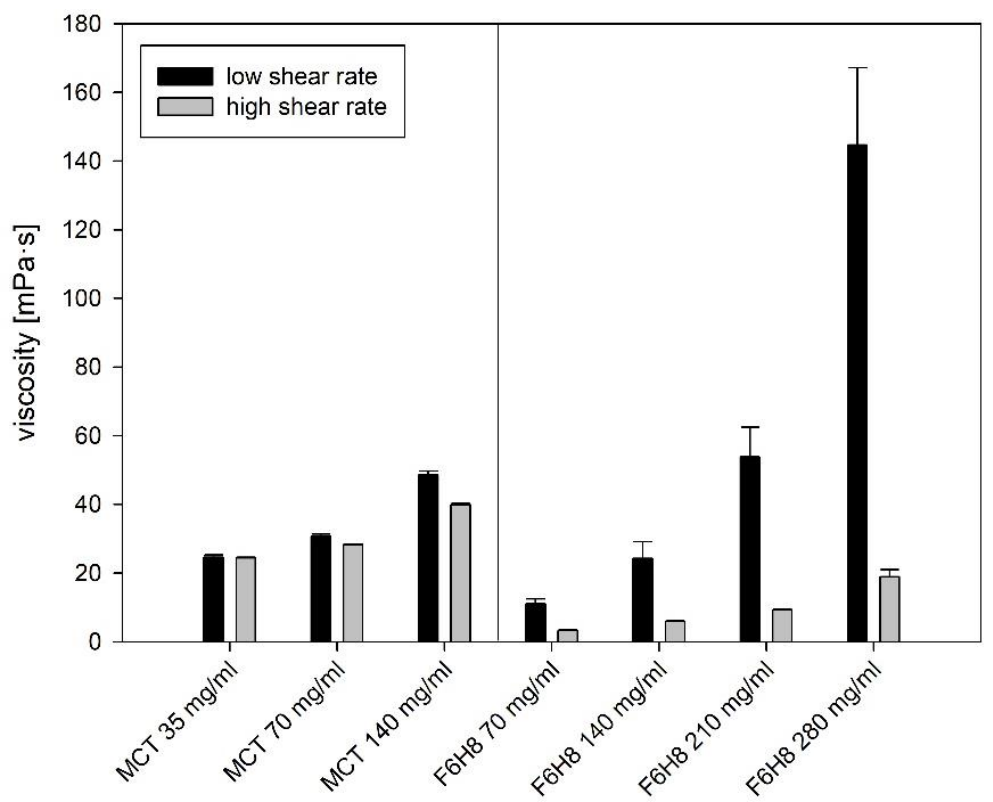

Figure IV-13: Effect of protein concentration and suspension vehicle on apparent viscosity at low $(10.81 / \mathrm{s})$ and high shear rates (5000 1/s) of Lys:Tre 70:30 (7.5\% ts) powder suspensions.

Lys:Tre 70:30 suspensions were easily withdrawn into a syringe through a $25 \mathrm{G}$ needle (Figure IV-12). Suspensions based on F6H8 required much less time compared to MCT suspensions. Thus, viscosity at high shear rate, rather than at low shear rate was determining the time for withdrawal of suspensions (Figure IV-13). The protein concentration of withdrawn 
Lys:Tre $70: 30$ suspensions differed by less than $6 \%$ from the initial suspension in the vial (Figure IV-14).

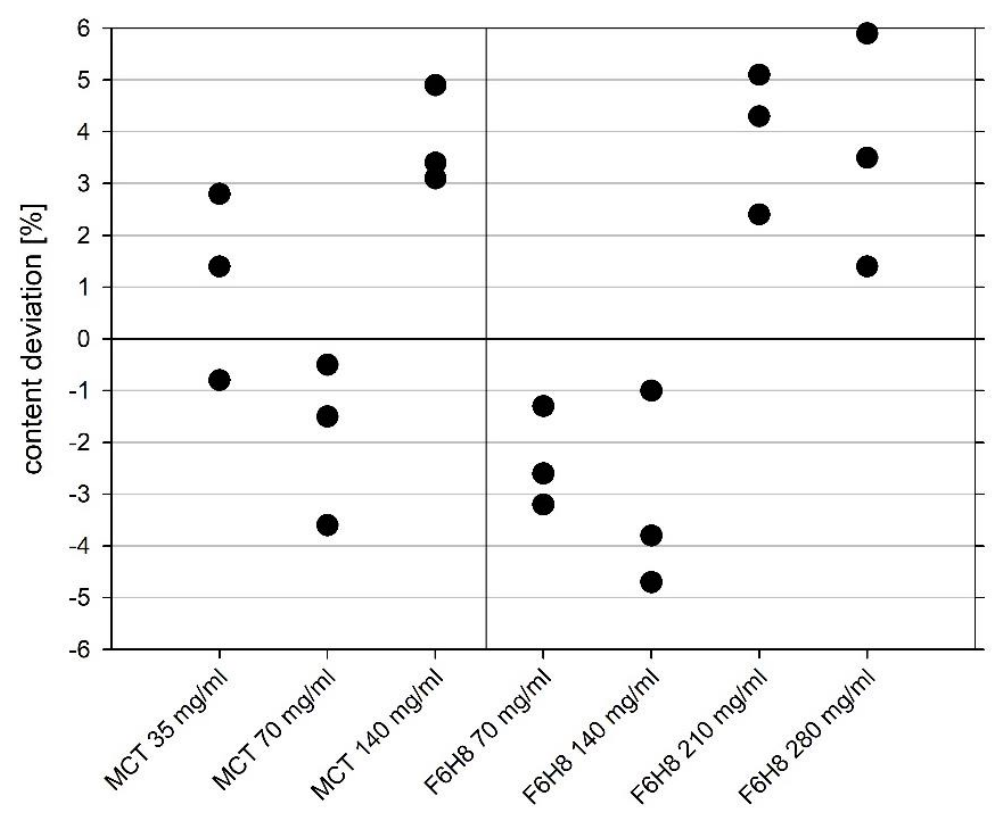

Figure IV-14: Effect of protein concentration and suspension vehicle on protein content after withdrawal of $1 \mathrm{ml}$ Lys:Tre $70: 30$ (7.5\% ts) from a vial using a syringe with a $25 \mathrm{G}$ needle.

\subsection{Suspension filling process using a peristaltic pump}

For manufacturing of protein powder suspensions, a reliable filling process is of high importance. We tested, if protein powder suspensions containing Lys:Tre 70:30 powder can be adequately dispensed into vials using a peristaltic pump. This type of pump is frequently used for industrial vial filling in the field of aqueous protein solution. ${ }^{56,57}$ Tests for mass deviation and content uniformity were performed according to Ph. Eur. 2.9.40.. ${ }^{34}$ Acceptance values $(A V)$ are based on $n=4$ due to material constraints as compared to $n=10$ minimum. All AVs were below the maximum allowed value of 15.0 (Table IV-3). Results demonstrated that large scale filling of protein powder suspensions in a manufacturing environment by the use of a peristaltic pump is feasible. 

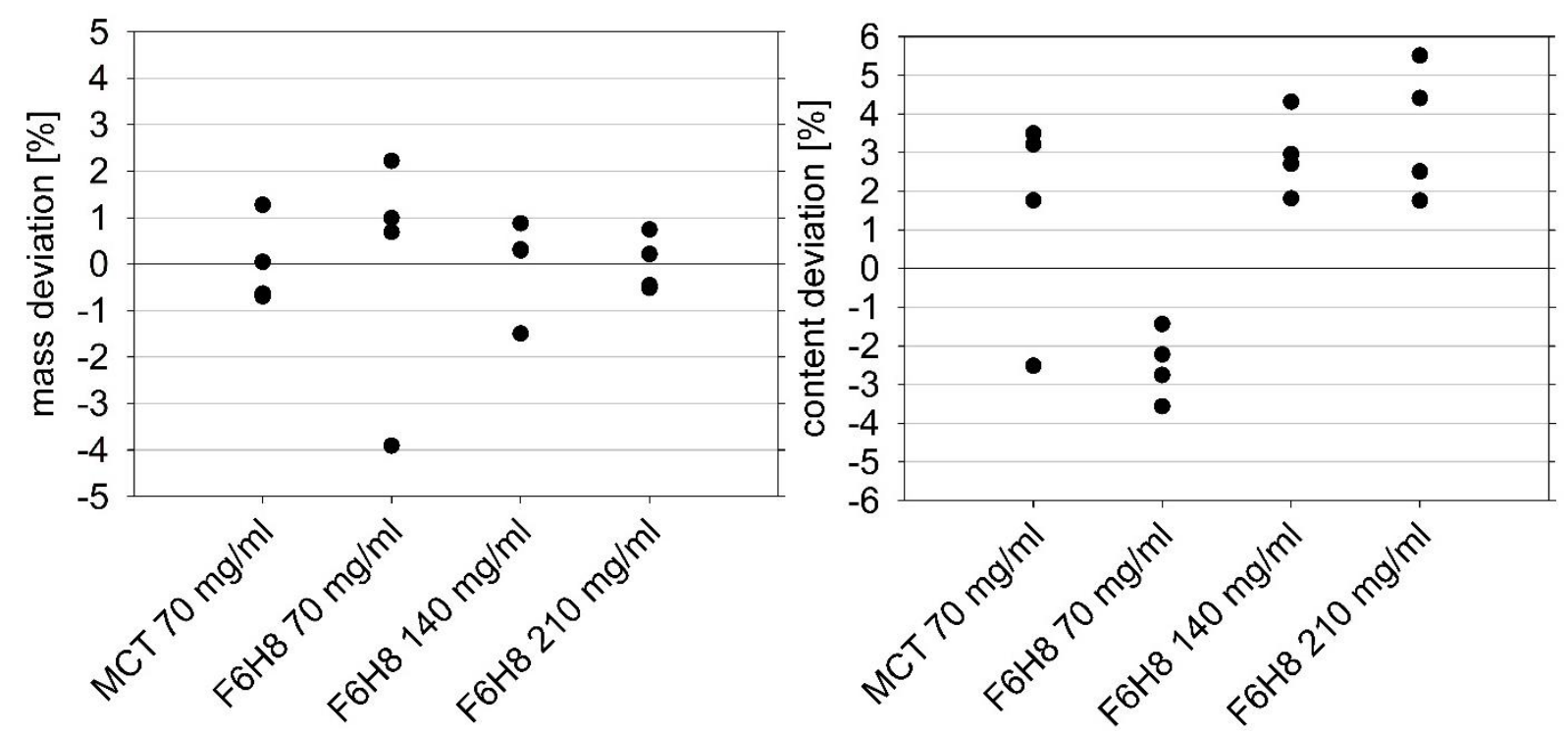

Figure IV-15: Effect of vial filling with Lys:Tre 70:30 suspensions by the use of a peristaltic pump on mass and content deviation.

Table IV-3: Acceptance values for mass variation and content uniformity of $2 \mathrm{R}$ vials filled with $1 \mathrm{ml}$ of Lys:Tre 70:30 suspensions by the use of a peristaltic pump.

\begin{tabular}{|c|c|c|}
\hline Formulation & AV mass variation & AV content uniformity \\
\hline $\mathrm{MCT} 70 \mathrm{mg} / \mathrm{ml}$ & 2.2 & 6.6 \\
\hline $\mathrm{F} 6 \mathrm{H} 870 \mathrm{mg} / \mathrm{ml}$ & 6.4 & 3.2 \\
\hline $\mathrm{F} 6 \mathrm{H} 8140 \mathrm{mg} / \mathrm{ml}$ & 2.3 & 3.9 \\
\hline $\mathrm{F} 6 \mathrm{H} 8210 \mathrm{mg} / \mathrm{ml}$ & 3.2 & 6.1 \\
\hline
\end{tabular}

\subsection{Sedimentation behaviour of protein powder suspensions}

The effect of the suspension vehicle as well as the Lys:Tre 70:30 powder concentration on sedimentation behaviour was studied visually (Figure IV-16). The sedimentation volume after $1 \mathrm{~h}$ was compared to calculated settling rates. These were based on modified settling rates $\mathrm{v}_{\mathrm{m}}$, considering particle crowding, which is especially pronounced at high powder concentrations, according to equation (5) based on the settling rate $v$ from Stokes law. ${ }^{22,43}$

$$
v_{m}=v(1-\varphi)^{6.55}
$$




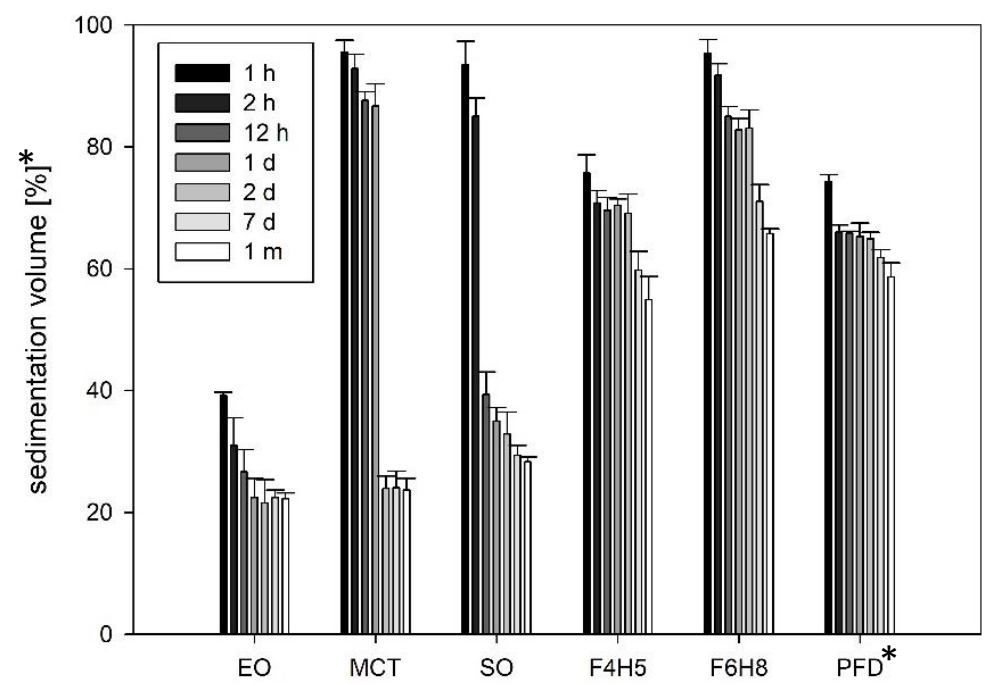

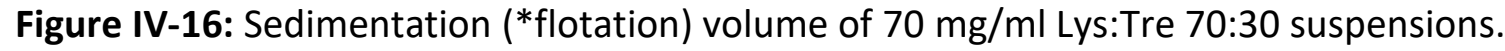

Table IV-4: Sedimentation/Flotation volume of Lys:Tre 70:30 suspensions after 1 month of storage at room temperature.

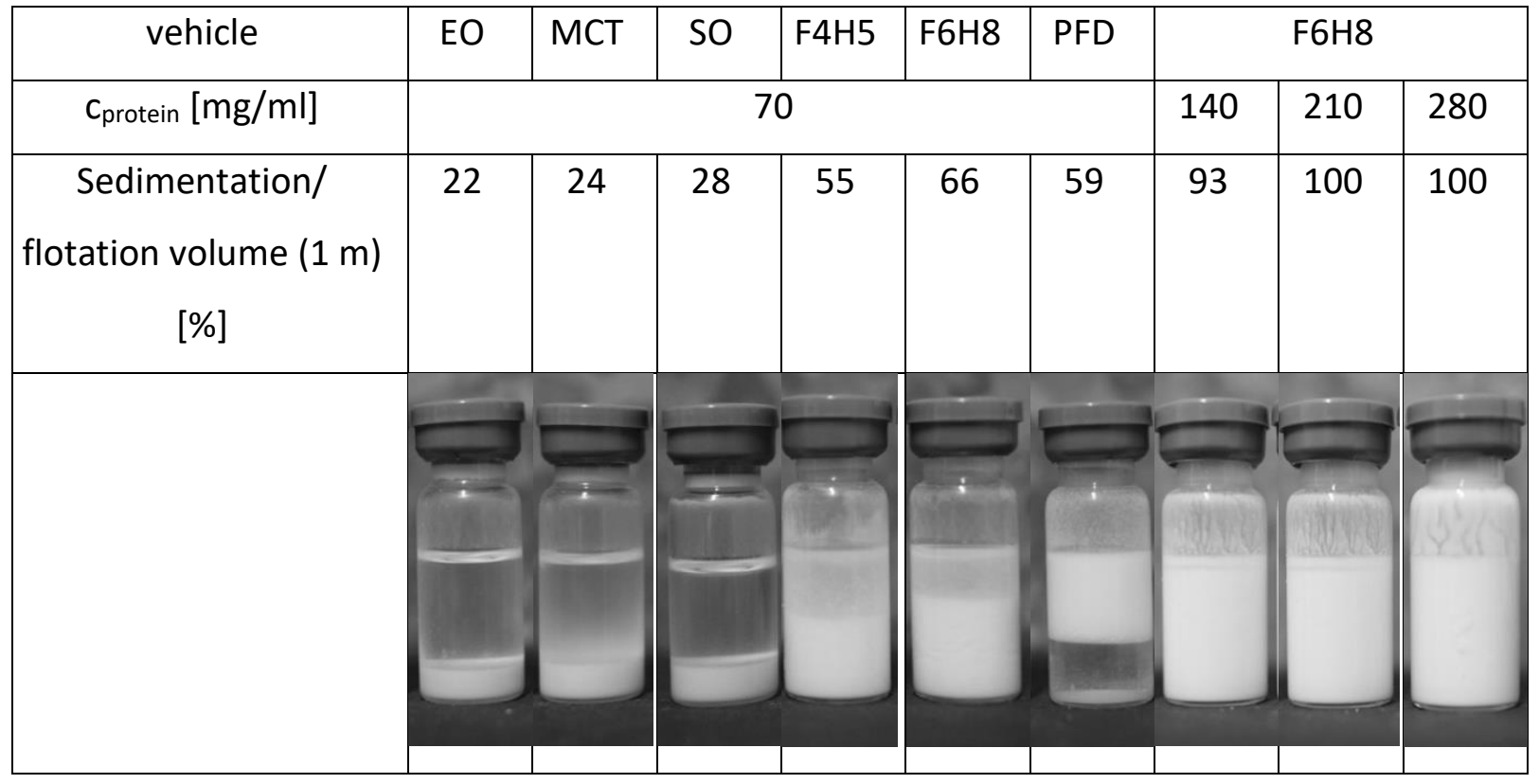

Lys:Tre 70:30 suspensions in EO, MCT and SO showed a more deflocculated sedimentation behaviour with a dense cake after 1 month of storage at room temperature featuring a sedimentation volume of less than $30 \%$ (Figure IV-16, Table IV-4). Suspensions in semifluorinated and fluorinated alkanes featured a flocculated behaviour with less dense cakes with a sedimentation/flotation volume of $55-66 \%$. The difference in flocculation behaviour can be explained by a different extent of particle-particle and particle-vehicle interactions in the respective vehicle classes. 
All suspensions showed sedimentation, except of suspensions in PFD, which featured flotation. This can be explained by the density of PFD $\left(1.91 \mathrm{~g} / \mathrm{cm}^{3}\right)$, which is much higher compared to the density of the powder $\left(1.33 \mathrm{~g} / \mathrm{cm}^{3}\right)$. Suspensions in $\mathrm{F} 4 \mathrm{H} 5$ and $\mathrm{F} 6 \mathrm{H} 8$ showed a cloudy supernatant as the powder particles show a similar density as the vehicle $\left(\rho_{\mathrm{F} 4 \mathrm{H} 5}=1.28 \mathrm{~g} / \mathrm{cm}^{3}\right.$, $\rho_{\mathrm{F} 4 \mathrm{H} 5}=1.33 \mathrm{~g} / \mathrm{cm}^{3}$ ). While sedimentation of the deflocculated suspensions was already completed after $12 \mathrm{~h}$ (EO), 1 day (MCT) and 7 days (SO), suspensions in semifluorinated and fluorinated vehicles still showed further sedimentation after 7 days of storage. Increasing of the powder concentration in SFA suspensions resulted in an increase the sedimentation volume in $140 \mathrm{mg} / \mathrm{ml}$ suspensions to $93 \%$, while no sedimentation was detected in suspensions containing 210 or $280 \mathrm{mg} / \mathrm{ml}$ lysozyme after one month of storage.

Table IV-5: Calculated settling rates $\mathrm{V}_{\mathrm{m}}$ and sedimentation/flotation volume of Lys:Tre 70:30 suspensions after $1 \mathrm{~h}$ of storage at room temperature.

\begin{tabular}{|c|c|c|c|c|c|c|c|c|c|c|}
\hline vehicle & EO & MCT & SO & F4H5 & F6H8 & PFD & \multicolumn{3}{c|}{ F6H8 } \\
\hline Cprotein [mg/ml] & \multicolumn{6}{|c|}{70} & & 140 & 210 & 280 \\
\hline $\mathrm{Vm}_{\mathrm{m}}[\mu \mathrm{m} / \mathrm{s}]$ & 2.21 & 0.46 & 0.21 & 1.01 & -0.08 & -3.11 & -0.04 & -0.02 & -0.01 \\
\hline $\begin{array}{c}\text { Sedimentation/ } \\
\text { flotation volume (1 h) } \\
{[\%]}\end{array}$ & 39 & 96 & 93 & 76 & 95 & 74 & 100 & 100 & 100 \\
& & & & & & & & & \\
\hline
\end{tabular}

Additionally, sedimentation rates were calculated according to equation 5 and compared to sedimentation/flotation volumes after $1 \mathrm{~h}$ of storage (Table IV-5). Overall, the calculated settling rates were in good accordance with the sedimentation/flotation volume after $1 \mathrm{~h}$. The highest rates were calculated for PFD with $-3.11 \mu \mathrm{m} / \mathrm{s}$ (flotation) followed by EO with $2.21 \mu \mathrm{m} / \mathrm{s}$ (sedimentation). The smaller sedimentation volume of EO suspensions compared to suspensions in PFD is a consequence of the difference in flocculation behaviour. Calculation of $\mathrm{F} 4 \mathrm{H} 5$ suspension settling rates yielded medium values of $1.0 \mu \mathrm{m} / \mathrm{s}$. Suspensions in MCT, SO and $\mathrm{F} 6 \mathrm{H} 8$ featured low calculated settling rates below $1.0 \mu \mathrm{m} / \mathrm{s}$ and sedimentation volumes after $1 \mathrm{~h}$ larger than $90 \%$. As MCT and SO show similar densities as EO between 0.87 and $0.95 \mathrm{~g} / \mathrm{cm}^{3}$, the low settling rates in MCT and SO can be explained by the high viscosity above $20 \mathrm{mPa} \cdot \mathrm{s}$ of MCT and SO. The rather low calculated settling rate of $-0.08 \mu \mathrm{m} / \mathrm{s}$ and large sedimentation volume of $95 \%$ in $\mathrm{F} 6 \mathrm{H} 8$ suspensions is due to the similar density of vehicle 
$\left(1.33 \mathrm{~g} / \mathrm{cm}^{3}\right)$ and powder $\left(1.32 \mathrm{~g} / \mathrm{cm}^{3}\right)$. The deviation between calculated flotation of the $\mathrm{F} 6 \mathrm{H} 8$ suspensions and the observed sedimentation rate can be explained by a slight underestimation of the powder true densities.

Lys:Tre suspensions containing $\geq 140 \mathrm{mg} / \mathrm{ml}$ protein in $\mathrm{F} 6 \mathrm{H} 8$ did not show profound sedimentation after $1 \mathrm{~h}$ (Table IV-5) as the settling rates are decreased with increasing protein concentration due to particle crowding.

All suspensions were resuspendable and injectable (27G needle) after one month of storage at room temperature. Overall results indicate that SFAs are extremely suitable as suspension vehicles for non-aqueous protein powder suspensions due to the slow sedimentation rate as well as the flocculated sedimentation behaviour. 


\section{Conclusion}

This work provided a greater understanding of protein powder suspensions prepared with spray-dried powders in non-aqueous vehicles and their characterization. It demonstrated the suitability of SFAs as potential vehicles to prepare such formulations. The protein powder suspensions were easy injectable through a thin needle of $27 \mathrm{G}$ even at a high protein concentration of $280 \mathrm{mg} / \mathrm{ml}$. Spray-drying was confirmed as a suitable approach to produce the suspended protein powder. Spray-drying did not cause significant protein degradation even though a low molar stabilizer to protein ratio of 188:1 was used. Best suspension quality in terms of dispersion efficiency and protein integrity was achieved using a cooled ultrasound bath. Especially at high mAb concentrations above $200 \mathrm{mg} / \mathrm{ml}$, suspensions in the two tested SFAs, F4H5 and F6H8, were superior over aqueous solutions in terms of viscosity and glide force. Lowest glide forces were obtained with $\mathrm{F} 4 \mathrm{H} 5$ and a glide force of $8.3 \pm 0.4 \mathrm{~N}$ compared to $40.8 \pm 0.2 \mathrm{~N}$ for a respective aqueous solution at $280 \mathrm{mg} / \mathrm{ml} \mathrm{mAb}$. Traditional non-aqueous vehicles for pharmaceutical suspensions such as MCT and SO showed high viscosities already at low powder concentrations. This was especially pronounced for SO, making it an unsuitable candidate for the use in highly concentrated formulations. By increasing the needle size from $27 \mathrm{G}$ to a $25 \mathrm{G}$ needle, MCT suspensions resulted in acceptable injection forces. Further EL, EO and PFD led to suspensions with low viscosity and low glide forces during injection. The particle size of spray-dried powders did not impact suspension rheology and glide forces, while suspensions containing non-spherical shed like milled lyophilizates resulted in slightly higher viscosities as well as clogging of $26 \mathrm{G}$ needles.

It is possible to predict the viscosity and glide force of the suspensions based on the KriegerDougherty equation and the Hagen-Poiseuille law using the powder concentration, the intrinsic viscosity, the vehicle viscosity and the needle geometries. This is of high importance when it comes to selection or development of a suitable container closure system or application device. Protein powder suspensions were syringeable and could be filled using a peristaltic pump. These are important attributes for a large-scale manufacturing process of protein powder suspensions.

The selection of a suitable suspension vehicle for pharmaceutical highly concentrated protein powder suspensions is of main importance. Different potential vehicles were tested regarding their suitability for the use in protein powder suspensions. Especially SFAs were highly promising due to their low viscosity, low glide forces at high concentrations and flocculated 
sedimentation behavior. Other potential advantages of protein powder suspensions in SFAs such as high protein stability during storage will be investigated in the following chapters. 


\section{Literature}

1. Jezek, J., Darton, N. J., Derham, B. K., Royle, N. \& Simpson, I. Biopharmaceutical formulations for pre-filled delivery devices. Expert Opin. Drug Deliv. 10, 811-828 (2013).

2. Mathaes, R., Koulov, A., Joerg, S. \& Mahler, H. C. Subcutaneous Injection Volume of Biopharmaceuticals - Pushing the Boundaries. J. Pharm. Sci. 105, 2255-2259 (2016).

3. Shire, S. J., Shahrokh, Z. \& Liu, J. Challenges in the Development of High Protein Concentration Formulations. J. Pharm. Sci. 93, 1390-1402 (2004).

4. Alford, J. R., Kendrick, B. S., Carpenter, J. F. \& Randolph, T. W. High Concentration Formulations of Recombinant Human Interleukin-1 Receptor Antagonist: II. Aggregation Kinetics. Int. J. Drug Dev. Res. 3, 26-33 (2011).

5. Saluja, A. \& Kalonia, D. S. Nature and consequences of protein-protein interactions in high protein concentration solutions. Int. J. Pharm. 358, 1-15 (2008).

6. Arakawa, T., Prestrelski, S. J., Kenney, W. C. \& Carpenter, J. F. Factors affecting shortterm and long-term stabilities of proteins. Adv. Drug Deliv. Rev. 46, 307-326 (2001).

7. Manning, M. C., Patel, K. \& Borchardt, R. T. Stability of Protein Pharmaceuticals. Pharm. Res. 6, 903-918 (1989).

8. Chang, L. L. \& Pikal, M. J. Mechanisms of protein stabilization in the solid state. J. Pharm. Sci. 98, 2886-2908 (2009).

9. Knepp, V. M., Muchnik, A., Oldmark, S. \& Kalashnikova, L. Stability of nonaqueous suspension formulations of plasma derived factor IX and recombinant human alpha interferon at elevated temperatures. Pharm. Res. 15, 1090-1095 (1998).

10. Buzzell, J. G. \& Tanford, C. The Effect of Charge and Ionic Strength on the Viscosity of Ribonuclease. J. Phys. Chem. 60, 1204-1207 (1956).

11. van Megen, W. H. Solubility behavior of soybean globulins as a function of $\mathrm{pH}$ and ionic strength. J. Agric. Food Chem. 22, 126-129 (1974).

12. Du, W. \& Klibanov, A. M. Hydrophobic salts markedly diminish viscosity of concentrated protein solutions. Biotechnol. Bioeng. 108, 632-636 (2011).

13. Hung, J. J. et al. Improving Viscosity and Stability of a Highly Concentrated Monoclonal Antibody Solution with Concentrated Proline. Pharm. Res. 35, 1-14 (2018).

14. Nidhi, K., Indrajeet, S., Khushboo, M., Gauri, K. \& Sen, D. J. Screening of Monoclonal Antibody Formulations Based on. Int. J. Drug Dev. Res. 3, 26-33 (2011).

15. Allmendinger, A. et al. Rheological characterization and injection forces of concentrated protein formulations: An alternative predictive model for non-Newtonian solutions. Eur. J. Pharm. Biopharm. 87, 318-328 (2014).

16. Yadav, S. et al. Establishing a link between amino acid sequences and self-associating and viscoelastic behavior of two closely related monoclonal antibodies. Pharm. Res. 28, 1750-1764 (2011). 
17. Arendt-Nielsen, L., Egekvist, H. \& Bjerring, P. Pain following controlled cutaneous insertion of needles with different diameters. Somatosens. Mot. Res. 23, 37-43 (2006).

18. Rungseevijitprapa, W. \& Bodmeier, R. Injectability of biodegradable in situ forming microparticle systems (ISM ). Eur. J. Pharm. Sci. 36, 524-531 (2008).

19. Bowen, M., Armstrong, N. \& Maa, Y.-F. Investigating High-Concentration Monoclonal Antibody Powder Suspension in Nonaqueous Suspension Vehicles for Subcutaneous Injection. J. Pharm. Sci. 101, 4433-4443 (2012).

20. Srinivasan, C., Weight, A. K., Bussemer, T. \& Klibanov, A. M. Non-aqueous suspensions of antibodies are much less viscous than equally concentrated aqueous solutions. Pharm. Res. 30, 1749-1757 (2013).

21. Pena, L. E., Possert, P. L., Stearns, J. F., Lee, B. L. \& Hageman, M. J. Rheological characterization of rbSt oil suspensions. Int. J. Pharm. 113, 89-96 (1995).

22. Miller, M. A., Engstrom, J. D., Ludher, B. S. \& Johnston, K. P. Low viscosity highly concentrated injectable nonaqueous suspensions of lysozyme microparticles. Langmuir 26, 1067-1074 (2011).

23. Krieger, I. M. \& Dougherty, T. J. A Mechanism for Non-Newtonian Flow in Suspensions of Rigid Spheres. Trans. Soc. Rheol. 3, 137-152 (1959).

24. Toda, K. \& Furuse, H. Extension of Einstein's viscosity equation to that for concentrated dispersions of solutes and particles. J. Biosci. Bioeng. 102, 524-528 (2006).

25. Berkenhoff, K. Subcutaneous suspensions of therapeutic proteins formulated as protein-coated microcrystals. (LMU Munich, 2013).

26. Knepp, V. M., Prestrelski, S., Smith, J. \& Huang, M. US20040151779A1 - Stable flowable protein and nucleic acid formulations using non-aqueous, anhydrous, aprotic, hydrophobic, non-polar vehicles with low reactivity. (2004).

27. Krafft, M. P. \& Riess, J. G. Chemistry, physical chemistry, and uses of molecular fluorocarbon- hydrocarbon diblocks, triblocks, and related compounds-unique 'apolar' components for self-assembled colloid and interface engineering. Chem. Rev. 109, 1714-1792 (2009).

28. Napoli, M. Diblock and triblock semifluorinated n-alkanes: Preparations, structural aspects and applications. J. Fluor. Chem. 79, 59-69 (1996).

29. Meinert, H. \& Roy, T. Semifluorinated alkanes - A new class of compounds with outstanding properties for use in ophthalmology. Eur. J. Ophthalmol. 10, 189-197 (2000).

30. Tsagogiorgas, C. et al. Semifluorinated alkanes - A new class of excipients suitable for pulmonary drug delivery. Eur. J. Pharm. Biopharm. 76, 75-82 (2010).

31. Guenther, B. et al. EP2806886B1 - Stabilised protein compositions based on semifluorinated alkanes. (2013). 
32. Gesche, G., Bernhard, G., Dieter, S. \& Anthony, P. EP3024484A1 - Stabilized antibody compositions. (2016).

33. Schuele, S. Stabilization of Antibodies in Spray-dried Powders for Inhalation. (LMU Munich, 2005).

34. European Pharmacopoeia 9.0 - 2.9.40. (European Directorate For The Quality Of Medicine, 2016).

35. Shoyele, S. A. \& Cawthorne, S. Particle engineering techniques for inhaled biopharmaceuticals. Adv. Drug Deliv. Rev. 58, 1009-1029 (2006).

36. Etzl, E. E., Winter, G. \& Engert, J. Toward intradermal vaccination: preparation of powder formulations by collapse freeze-drying. Pharm. Dev. Technol. 19, 213-222 (2014).

37. Schüle, S., Schulz-Fademrecht, T., Garidel, P., Bechtold-Peters, K. \& Frieß, W. Stabilization of IgG1 in spray-dried powders for inhalation. Eur. J. Pharm. Biopharm. 69, 793-807 (2008).

38. Gikanga, B. et al. Manufacturing of High-Concentration Monoclonal Antibody Formulations via Spray Drying--the Road to Manufacturing Scale. PDA J. Pharm. Sci. Technol. 69, 59-73 (2015).

39. Weiguo Dai, Beth Hill, Kui Liu, C. M. US 20120076800 - Non-aqueous high concentration reduced viscosity suspension formulations of antibodies. (2012).

40. Vehring, R. Pharmaceutical particle engineering via spray drying. Pharm. Res. 25, 9991022 (2008).

41. Floyd, A. G. Injectable Emulsions and Suspensions, in Pharmaceutical Dosage Forms: Disperse Systems. (Taylor \& Francis Inc, 1996).

42. Reithmeier, H., Herrmann, J. \& Göpferich, A. Lipid microparticles as a parenteral controlled release device for peptides. J. Control. Release 73, 339-350 (2001).

43. Patel, R. Parenteral suspension: an overview. Int. J. Curr. Pharm. Res. 2, 4-13 (2010).

44. Maa, Y. F., Nguyen, P. A. T. \& Hsu, S. W. Spray-drying of air-liquid interface sensitive recombinant human growth hormone. J. Pharm. Sci. 87, 152-159 (1998).

45. Cleland, J. L. et al. A specific molar ratio of stabilizer to protein is required for storage stability of a lyophilized monoclonal antibody. J. Pharm. Sci. 90, 310-321 (2001).

46. Yang, H., Yang, S., Kong, J., Dong, A. \& Yu, S. Obtaining information about protein secondary structures in aqueous solution using Fourier transform IR spectroscopy. Nat. Protoc. 10, 382-396 (2015).

47. Matheus, S., Friess, W. \& Mahler, H.-C. FTIR and nDSC as Analytical Tools for HighConcentration Protein Formulations. Pharm. Res. 23, 1350-1363 (2006).

48. Birk, G. Formulation development of a highly concentrated suspension of Cilengitide. (LMU Munich, 2015). 
49. Tsagogiorgas, C. et al. Evaluation of pharmacokinetic properties and anaesthetic effects of propofol in a new perfluorohexyloctane ( $\mathrm{F} 6 \mathrm{H} 8)$ emulsion in rats - A comparative study. Int. J. Pharm. 486, 69-76 (2015).

50. Kanai, S., Liu, J., Patapoff, T. W. \& Shire, S. J. Reversible Self-Association of a Concentrated Monoclonal Antibody Solution Mediated by Fab-Fab Interaction That Impacts Solution Viscosity. J. Pharm. Sci. 97, 4219-4227 (2008).

51. FDA Inactive Ingredient List

https://www.accessdata.fda.gov/scripts/cder/iig/index.Cfm - accessed on 13.01.2019.

52. Burckbuchler, V. et al. Rheological and syringeability properties of highly concentrated human polyclonal immunoglobulin solutions. Eur. J. Pharm. Biopharm. 76, 351-356 (2010).

53. Genovese, D. B. Shear rheology of hard-sphere, dispersed, and aggregated suspensions, and filler-matrix composites. Adv. Colloid Interface Sci. 171-172, 1-16 (2012).

54. Beirne, P. V. et al. Needle size for vaccination procedures in children and adolescents. Cochrane Database Syst. Rev. 6, (2015).

55. Zhou, Z., Scales, P. J. \& Boger, D. V. Chemical and physical control of the rheology of concentrated metal oxide suspensions. Chem. Eng. Sci. 56, 2901-2920 (2001).

56. Saller, V. et al. Particle Shedding from Peristaltic Pump Tubing in Biopharmaceutical Drug Product Manufacturing. J. Pharm. Sci. 104, 1440-1450 (2015).

57. Saller, V. et al. Preservative loss from silicone tubing during filling processes. Eur. J. Pharm. Biopharm. 112, 109-118 (2017). 


\section{Chapter V}

\section{Long-term stability of protein powder suspensions in non-aqueous vehicles part I - suspension physical stability}

\section{Abstract}

Protein drugs are typically formulated in aqueous solutions or as lyophilizates, which require reconstitution prior to use. This makes lyophilizates less patient and healthcare provider friendly. Suspensions of protein powders in non-aqueous vehicles provide an interesting alternative. They combine ready to use with the higher stability of proteins in the dry state. But physical stability of the suspensions in terms of particle size, resuspendability and injectability have to be assured. In this study we prepared powder suspensions of spray-dried lysozyme, bevacizumab as well as another monoclonal antibody in ethyl oleate, medium chain triglycerides and semifluorinated alkanes and tested the suspension physical stability. Resuspendability, particle size and injectability were preserved even at elevated temperature of $40^{\circ} \mathrm{C}$ for up to 12 months. An important parameter for initial dispersion quality as well as the suspension stability was the residual moisture of the suspended microparticles. Suspensions markedly benefitted of an additional drying step of the spray-dried powder, providing a residual moisture content of less than $0.5 \%$. The work showed the high potential of non-aqueous protein powder suspensions and proved their long-term physical stability. 


\section{Introduction}

During the last decades the therapeutic relevance of protein drugs strongly emerged. A lot of new biopharmaceuticals are entering the market and also biosimilars play an important role, as patent protection for highly successful protein drugs expired. ${ }^{1-3}$ Marketed protein drugs are either formulated as aqueous solutions or lyophilizates. Both formulation approaches face different challenges. Aqueous solutions can show more limited protein stability. This can be counteracted by the removal of water via freeze-drying. ${ }^{4-6}$ The protein is embedded in a solid stabilizer matrix minimizing aggregation and chemical degradation, but the dried powders have to be reconstituted before use, making them less patient and health care provider friendly.

Protein powder suspensions in non-aqueous vehicles represent a promising innovative alternative. They combine the ready to use feature of the liquid formulation approach, also suitable for prefillable syringes or cartridges for autoinjectors, with the higher stability of the protein in the solid state. ${ }^{7,8}$ Knepp et al. found high stability of lyophilized factor IX and interferon suspended in perfluorodecalin at elevated temperatures for up to a year. ${ }^{7}$ In soybean oil the stability was reduced, due to the presence of reactive species like peroxides and aldehydes as well as the higher water content. ${ }^{7}$ Several other investigations reported of high protein stability comparable to the solid state and superior to aqueous solutions. ${ }^{8-10}$ Little is known regarding the suspension's physical stability. Only Miller et al. reported, that a suspension of milled lysozyme in benzyl benzoate at room temperature did not change in particle size after two months and was visually resuspendable after 1 year of storage. ${ }^{11}$ Preserving consistent powder particle size and resuspendability is important. Additionally, injectability is crucial, as needle clogging presents a serious challenge. ${ }^{12}$ Yordanova showed, that a suspension of milled decapeptide in various non-aqueous vehicles was injectable after 12 months of storage at elevated temperatures. ${ }^{13}$ In order to assure injectability, the particle sizes should not exceed $1 / 8$ to $1 / 3$ of the needle inner diameter (see Chapter III). ${ }^{11,12,14}$ The two main techniques to prepare protein powders in the lower micrometre range are lyophilization, followed by a milling step ${ }^{15,16}$ or spray-drying ${ }^{17-19}$. Freeze-drying is the method of choice for drying of proteins and several therapeutic proteins are marketed in this form. ${ }^{3}$ In contrast to that the additional milling step is critical as it can damage the protein (see Chapter III). Suspensions compromising milled particles might lead to entanglement resulting in needle clogging, which especially occurs at high concentrations (Chapter IV). Spray-dried 
powders commonly show a high residual moisture content of about $3-5 \%$ as compared to lyophilizates with less than $1 \% .{ }^{17,19}$ Remaining water acts as a plasticizer enhancing particle fusion and risk of excipient crystallization. ${ }^{20-24}$ Further, remaining water might lead to less protein stability due to enhanced mobility and chemical instability, with water molecules as part of the degradation reaction. ${ }^{25,26} \mathrm{~A}$ potential technique to counteract this challenge is an additional drying step. ${ }^{27,28}$ Due to the spherical shape of the spray-dried powder particles, high concentration protein powder suspension formulations with protein concentrations higher than $300 \mathrm{mg} / \mathrm{ml}$ protein are feasible (see Chapter IV)..$^{17,29}$

In our study, spray-drying was used to prepare protein powder of lysozyme (Lys), bevacizumab (Beva) as well as another monoclonal antibody (mAb). Protein powder contained either sucrose (Suc) or trehalose (Tre) as stabilizer, at protein:stabilizer mass ratios of 50:50 and 70:30. The powder was suspended in ethyl oleate (EO), medium chain triglycerides (MCT) and two different semifluorinated alkanes (SFAs). Suspensions were then stored at 5,25 and $40^{\circ} \mathrm{C}$ for up to 6 (Beva, mAb) or 12 months (Lys). Physical suspension stability, described by resuspendability, particle size, particle morphology and injectability was investigated. The effect of the additional drying step on the initial dispersing quality as well as the long-term stability was analyzed. 


\section{Materials and Methods}

\subsection{Materials}

Lysozyme (Lys) bulk solutions were prepared by dissolution of pure lysozyme (Ovobest, Neuenkirchen-Voerden, Germany) in $10 \mathrm{mM}$ histidine buffer at pH 6.0. A monoclonal IgG1 antibody produced in chinese hamster ovary cells (mAb) in $25 \mathrm{mM}$ histidine, $1.6 \mathrm{mM}$ glycine buffer pH 6.0 at $57 \mathrm{mg} / \mathrm{ml}$ was used $\left(\varepsilon 280 \mathrm{~nm}=1.49 \mathrm{ml} \mathrm{g}^{-1} \mathrm{~cm}^{-1}\right)$. Bevacizumab (Beva) was acquired as marketed product Avastin ${ }^{\circledR}$ (Roche, Basel, Switzerland). Formulations were prepared in highly purified water prepared with an ELGA Purelab system (ELGA LabWater, Celle, Germany) using trehalose (Tre) (Hayashibara, Okayama, Japan), sucrose (Suc), Lhistidine, L-histidine-monohydrochloride monohydrate (Sigma-Aldrich, St. Louis, USA) and polysorbate 20 (PS20) (Merck, Darmstadt, Germany). Perfluorobutylpentane (F4H5) and perfluorohexyloctane (F6H8) were provided by Novaliq (Heidelberg, Germany). Further medium chain triglycerides (MCT) (Miglyol ${ }^{\circledR} 812$ by Caesar \& Loretz, Hilden, Germany) and ethyl oleate (EO) (Sigma-Aldrich, St. Louis, USA) were used as suspension vehicles. Dispersion medium for laser diffraction measurement contained isooctane and Span 80 (Merck, Darmstadt, Germany).

\subsection{Formulations for spray-drying}

Feed solutions for spray-drying with a total solid content of $7.5 \%(\mathrm{~m} / \mathrm{V})$ contained trehalose or sucrose at different protein to stabilizer mass ratios. All solutions were prepared in a $10 \mathrm{mM}$ Histidine buffer at pH6.0. Buffer exchange was performed using either Spectra/Por regenerated cellulose dialysis tubes with a molecular weight cut off (MWCO) of 6-8 kDa (Spectrum Laboratories, Los Angeles, USA) (Lys, mAb) or using 12-30 ml slide a lyzer dialysis cassettes with a MCWO of 20 kDA (Thermo Scientific, Waltham, USA) (Beva). Before spraydrying, the solutions were filtered using a VWR $0.2 \mu \mathrm{m}$ Polyethersulfone syringe filter (VWR, Radnor, USA). Formulations are described in Table.

\subsection{UV-Vis}

Protein concentrations were measured with a NanoDrop 2000 spectrophotometer (Thermo Scientific, Waltham, USA) at $280 \mathrm{~nm}$. 


\subsection{Spray-drying}

Spray-drying was conducted using a Büchi B290 (Büchi, Flawil, Switzerland) equipped with a high-efficiency cyclone and a two fluid nozzle $(0.7 \mathrm{~mm}$ orifice) at a drying air-flow rate of $600 \mathrm{ml} / \mathrm{min}$, an atomizing air flow rate of $670 \mathrm{ml} / \mathrm{min}$, a feed flow rate of $3 \mathrm{ml} / \mathrm{min}$ and an inlet/outlet temperature of $125 / 65^{\circ} \mathrm{C}$ (formulation $3-10$ ) or $130 / 70^{\circ} \mathrm{C}$ (see Table). Process yields were above $80 \%$.

\subsection{Additional drying of spray-dried powder}

Spray-dried powders were transferred into 10R type 1 glass vials (MGlas, Muennerstadt, Germany) and a lyophilization stopper was attached (Helvoet Pharma, Tilburg, Netherlands). Samples were then dried using a Christ 2-6D (Martin Christ Gefriertrocknungsanlagen, Osterode, Germany) at $32^{\circ} \mathrm{C}, 0.1 \mathrm{mBar}$ for $24 \mathrm{~h}$ and fully stoppered in the freeze-drier under nitrogen gas atmosphere at 800 mbar according to Schuele et al. ${ }^{27}$

\subsection{Powder handling}

Powder handling was conducted under nitrogen environment in a custom-made glove box to prevent water uptake.

\subsection{Karl-Fischer}

The amount of residual water was analyzed using a Karl-Fischer-Titrator Aqua 40.00 (Analytik Jena, Jena, Germany) equipped with a head space module at a chamber temperature of $100^{\circ} \mathrm{C}$.

\subsection{Powder true density}

Powder true density was analyzed using an AccuPyc 1330 helium pycnometer (Micrometrics, Aachen, Germany). In total 10 cleaning cycles were conducted prior to analysis. About $200-$ $300 \mathrm{mg}$ of the powder was filled into the sample container. Powder true density results are based on the average of 6 measurements. 


\subsection{Scanning electron microscopy}

Powders were investigated on self-adhesive carbon tapes stuck on aluminium stubs using a FEI Helios G3 UC (Thermo Fisher Scientific, Waltham, USA). In order to investigate the effect of storage, suspensions were pipetted directly on the carbon tape and dried in a VTS-2 vacuum drier (Memmert, Schwabach, Germany) for $24 \mathrm{~h}$ at 10 mbar.

\subsection{Suspension preparation}

Suspensions were prepared in either 2R (Schott, Mainz, Germany) (Beva), 6R (mAb), or 20R (Lys) (MGlas, Muennerstadt, Germany) type 1 glass vials. The amount of suspension vehicle was calculated based on the determined true density. Suspensions were then homogenized using either a high shear homogenizer Ultraturrax T10 (IKA-Werke, Staufen, Germany) (2 min/ $20000 \mathrm{rpm}$ ) or in an Ultrasonic cleaner USC 1200TH (VWR, Radnor, USA) cooled with ice (20 min with additional shaking by hand after 5, 10 and $15 \mathrm{~min}$ ).

\subsection{Stability studies}

Suspensions were filled in $1 \mathrm{ml}$ glass vials (Beva; $0.4 \mathrm{ml}$ ) (Macherey-Nagel, Düren, Germany), 2R glass vials (Lys, mAb:Suc; $1 \mathrm{ml}$ ) or in 27G Terumo Plajex prefillable cyclic olefin polymer (COP) syringes (mAb:Tre; $1 \mathrm{ml}$ ) (Terumo, Tokyo, Japan). Filling was conducted manually using a B. Braun Injekt (B. Braun, Melsungen, Germany) syringe with a Terumo Agani 30G (Terumo, Tokyo, Japan) needle attached (inner diameter $\approx 160 \mu \mathrm{m}$ ). Vials were closed using Teflon coated injection stoppers and capped (Westpharma, Exton, USA). The prefillable syringes were filled from behind and the plunger was set manually. The needle tip was then removed and the plunger was pushed to remove remaining air. Stability studies were then conducted at $5-8^{\circ} \mathrm{C}, 25^{\circ} \mathrm{C}$ and $40^{\circ} \mathrm{C}$.

\subsection{Resuspendability}

Resuspendability was tested using two different methods. The first test (rotation) was conducted using an SU1100 vertical rotator (Sunlab, Mannheim, Germany), at a rotation speed of $25 \mathrm{rpm}$, according to Birk. ${ }^{30}$ The time until complete visual resuspension was recorded. The experiment was terminated after $15 \mathrm{~min}$. The second method (shaking) was performed using a Retsch swing mill MM 400 (Retsch, Haan, Germany). The vial containing the suspension, was fixed and shaken at $5 \mathrm{~Hz}$ for $30 \mathrm{~s}$. If no or incomplete resuspension was 
visually observed, this procedure was repeated with a $2.5 \mathrm{~Hz}$ higher frequency. If after an increase in frequency resuspension was still incomplete, vials were shaken again at a $2.5 \mathrm{~Hz}$ higher frequency up to a maximum frequency of $30 \mathrm{~Hz}$.

\subsection{Wettability}

Wettability of the spray-dried powder by the suspension vehicles was tested using a drop shape analyzer Kruess DSA25E (Kruess, Hamburg, Germany). A tablet consisting of spray-dried Lys:Tre 70:30 powder was prepared using a hydraulic FTIR press (Specac, Orpington, United Kingdom).

\subsection{Syringeability}

Syringeability was tested manually. A 236 needle (Terumo, Tokyo, Japan) was attached to a $1 \mathrm{ml} \mathrm{B.} \mathrm{Braun} \mathrm{Inject} \mathrm{F} \mathrm{single-use} \mathrm{syringe} \mathrm{(B.} \mathrm{Braun,} \mathrm{Melsungen,} \mathrm{Germany).} \mathrm{The} \mathrm{suspensions}$ were then withdrawn from the vials by completely moving the plunger to the end of the syringe.

\subsection{Laser diffraction}

Particle size distribution was analyzed in isooctane containing $1 \%$ Span 80 , as a dispersing medium, using the Laser Diffraction Particle Size Analyzer LA-960 (Horiba, Kyoto, Japan). In order not to affect the initial dispersion quality, no additional dispersion step in the dispersing medium was conducted. Particle sizes after storage were analyzed after an additional dispersing step using an ultrasonic homogenizer Bandelin Sonoplus (Bandelin electronic, Berlin, Germany) with a MS 72 probe (30 s 20\% intensity).

\subsection{Light microscopy}

Light microscopy was performed using a Keyence Digital microscope VHX 500F (Keyence, Osaka, Japan) with a VH-Z100R lens at 200x magnification. For analysis suspensions were dispersed in MCT to a total powder concentration of $5 \mathrm{mg} / \mathrm{ml}$. The resulting suspension was transferred on a glass slide and investigated. 


\subsection{X-Ray Powder diffraction}

Powder physical state was analyzed using an X-ray diffractometer (XRD) 3000 TT (Seifert, Ahrenburg, Germany) equipped with a copper anode (40 kV, $30 \mathrm{~mA}, 0.15418 \mathrm{~nm}$ ). The sample was placed on a copper sample holder and measured from 5 to $40^{\circ} 2-\Theta$ with $0.5^{\circ} 2-\Theta$ steps for 2 s per step.

\subsection{Injectability}

Syringe glide force measurements of different injection systems were performed using a Texture Analyzer XT plus (Stable Micro Systems, Godalming, UK). Suspensions stored in vials were drawn into a $1 \mathrm{ml} \mathrm{B}$. Braun Inject F single-use syringe (B. Braun, Melsungen, Germany) and a $27 \mathrm{G}$ Terumo Agani needle (Terumo, Tokyo, Japan) was then attached. For determination of glide forces needed for injection the plunger speed was set to obtain a volume flow of $0.1 \mathrm{ml} / \mathrm{s}$. 


\section{Results and discussion}

\subsection{Powder initial characterization and formulation overview}

Spray-drying was conducted using a bench top model. Process yields were around $80 \%$. As stabilizer the two most popular carbohydrates for drying of proteins, sucrose or trehalose, were used. ${ }^{19,31}$ We selected protein to carbohydrate ratios of 50:50 and 70:30 (mass ratio). A minimum stabilizer concentration is crucial to ensure protein integrity during spray-drying and storage. ${ }^{17,27}$ On the other hand, the stabilizer content should be limited to minimize its volume and thus keeping the viscosity of the suspension low. ${ }^{17}$ Protein stability was not part of this work and will be tested for selected formulations based on the outcome of the physical stability testing (see Chapter VI). All spray-dried powders showed a D50 particle size of approximately $4.5-5.5 \mu \mathrm{m}$, which makes them suitable for injection through thin needles (Table V-1). ${ }^{11,17}$ The type of sugar and protein had no substantial impact on powder particle size. Main factors controlling the particle size are atomizing air flow rate, the nozzle diameter and the total solid content of the feed solution, which were all kept constant throughout the study. ${ }^{32}$

Table V-1: Overview of powder characteristics and prepared suspensions

\begin{tabular}{|c|c|c|c|c|c|}
\hline $\begin{array}{l}\text { Formu- } \\
\text { lation }\end{array}$ & $\begin{array}{l}\text { Protein:stabilizer } \\
\text { ratio }(\mathrm{m}: \mathrm{m})\end{array}$ & $\begin{array}{l}\text { Additional } \\
\text { drying step }\end{array}$ & $\begin{array}{l}\text { Residual } \\
\text { moisture } \\
{[\%](\mathrm{m} / \mathrm{m})}\end{array}$ & $\begin{array}{l}\mathrm{D} 50 \\
{[\mu \mathrm{m}]}\end{array}$ & Suspension vehicle \\
\hline 1 & Lys:Tre (70:30) & $\checkmark$ & $0.1 \pm 0.0$ & $4.5 \pm 0.5$ & $\mathrm{~F} 4 \mathrm{H} 5, \mathrm{~F} 6 \mathrm{H} 8, \mathrm{EO}, \mathrm{MCT}$ \\
\hline 2 & $\begin{array}{c}\text { Lys:Tre (70:30) + } \\
0.1 \% \text { PS20 }\end{array}$ & $\checkmark$ & $0.2 \pm 0.0$ & $5.4 \pm 0.2$ & $\mathrm{~F} 6 \mathrm{H} 8$ \\
\hline 3 & Lys:Tre (50:50) & $\checkmark$ & $0.1 \pm 0.1$ & $4.9 \pm 0.3$ & F6H8 \\
\hline 4 & \multirow[t]{2}{*}{ Lys:Suc (50:50) } & $\checkmark$ & $0.2 \pm 0.1$ & \multirow[t]{2}{*}{$4.4 \pm 0.1$} & \multirow[t]{2}{*}{ F6H8, EO } \\
\hline 5 & & - & $3.6 \pm 0.1$ & & \\
\hline 6 & \multirow[t]{2}{*}{ mAb:Suc (50:50) } & $\checkmark$ & $0.1 \pm 0.0$ & \multirow[t]{2}{*}{$4.6 \pm 0.2$} & F4H5, F6H8, EO, MCT \\
\hline 7 & & - & $4.2 \pm 0.1$ & & F4H5, F6H8 \\
\hline 8 & \multirow[t]{2}{*}{ mAb:Tre (50:50) } & $\checkmark$ & $0.1 \pm 0.0$ & \multirow[t]{2}{*}{$5.4 \pm 0.5$} & F4H5, F6H8 \\
\hline 9 & & - & $3.9 \pm 0.0$ & & $\mathrm{~F} 6 \mathrm{H} 8$ \\
\hline 10 & \multirow[t]{2}{*}{ Beva:Suc (50:50) } & $\checkmark$ & $0.1 \pm 0.0$ & \multirow[t]{2}{*}{$5.6 \pm 0.0$} & \multirow[t]{2}{*}{ F6H8, EO } \\
\hline 11 & & - & $3.5 \pm 0.1$ & & \\
\hline
\end{tabular}



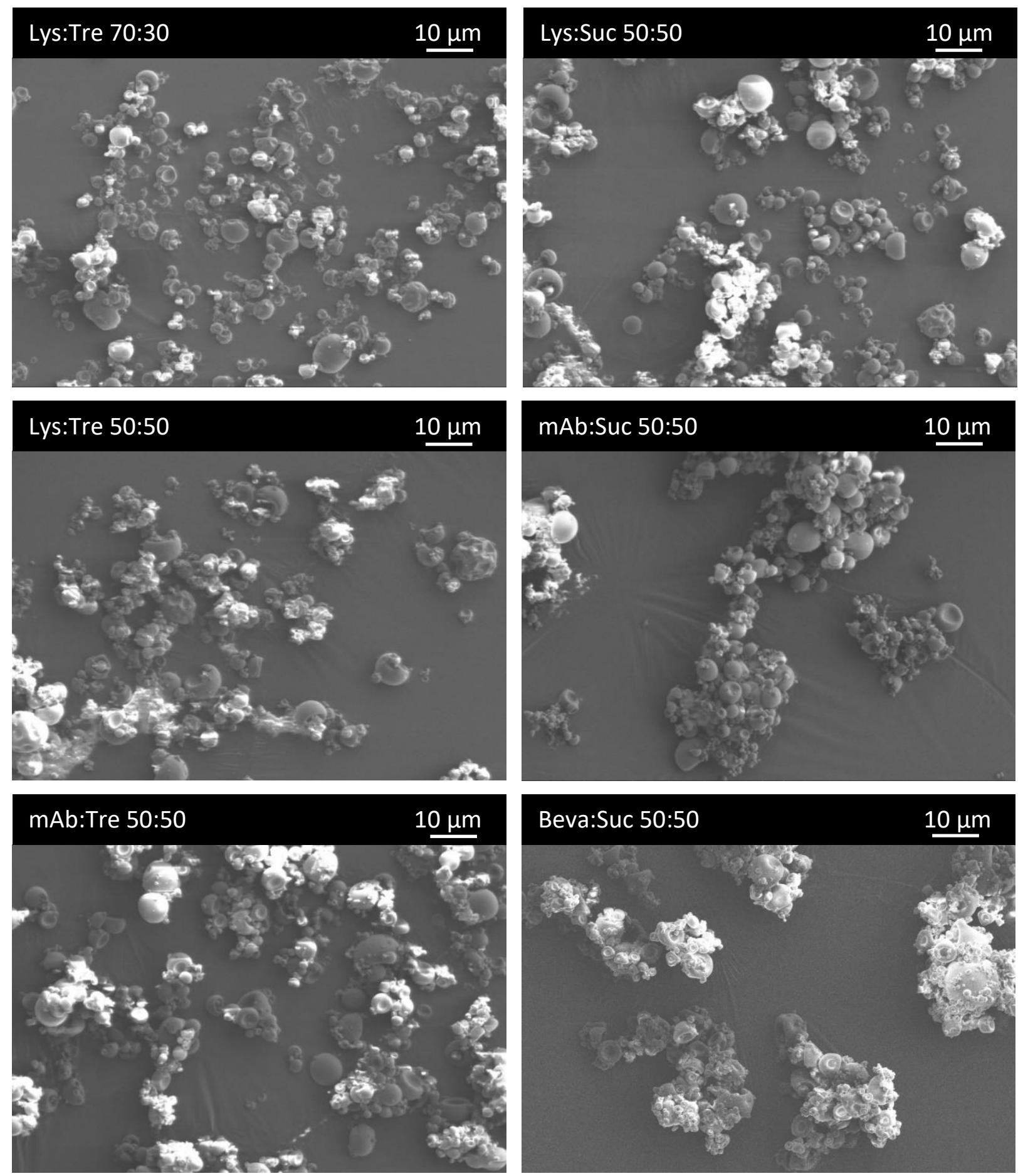

Figure V-1: SEM images of spray-dried powders.

The particle size was further confirmed by SEM (Figure V-1) and the particles were of the typical spherical morphology of spray-dried powders. ${ }^{17,27}$ The additional drying step did not impact the particle morphology. In general the particle morphology is of importance, as it can influence the suspension rheology and injectability (see Chapter IV). ${ }^{33}$ 


\subsection{Suspension preparation and initial dispersion quality}

Initial homogeneous dispersion using a suitable technique is of high importance to yield injectable suspensions. We compared preparation using a cooled ultrasound bath or a high shear homogenizer. Different levels of dispersion were achieved. Additionally dried Lys:Tre 70:30 powder could easily be dispersed in $\mathrm{F} 4 \mathrm{H} 5, \mathrm{~F} 6 \mathrm{H} 8$, EO and $\mathrm{MCT}$ at a protein concentration of $70 \mathrm{mg} / \mathrm{ml}$ using an ultrasound bath (Figure V-2). The resulting D50 values were around $5 \mu \mathrm{m}$ and thus comparable to the powder D50 values (Table V-1). The approach also worked well for $\mathrm{F} 6 \mathrm{H} 8$ at high concentration ( $\mathrm{C}_{\mathrm{Lys}}=210 \mathrm{mg} / \mathrm{ml}$ ), for PS20 containing formulations, as well as for formulations with a higher trehalose content (Figure V-3). Interestingly the additional drying step had a substantial impact on initial quality of Lys:Suc 50:50 suspensions at a protein concentration of $50 \mathrm{mg} / \mathrm{ml}$. Without the additional drying step ( $3.6 \pm 0.1 \mathrm{vs} 0.2 \pm 0.1 \%$ residual moisture) a lower degree of dispersion efficiency resulted using the ultrasound bath (Figure V4). Similar observations were made with suspensions containing mAb:Suc 50:50 powder in $\mathrm{F} 4 \mathrm{H} 5, \mathrm{~F} 6 \mathrm{H} 8$, EO and MCT (4.2 \pm 0.1 vs $0.1 \pm 0.0 \%$ residual moisture; $\mathrm{C}_{\text {Lys }}=50 \mathrm{mg} / \mathrm{ml}$ ) (Figure V5). Dispersion of not additionally dried mAb:Suc powder was especially poor in F4H5, F6H8 and MCT with D50 values between 15 and $20 \mu \mathrm{m}$. Laser diffraction results were confirmed by light microscopy (Figure V-6). MAb suspensions containing trehalose instead of sucrose (ratio of 50:50), as well as Bevacizumab containing formulations further benefitted of the additional drying step in terms of dispersion quality (Figure V-7/-8). All suspensions prepared with the ultrasound bath were injectable through a $27 \mathrm{G}$ needle. 


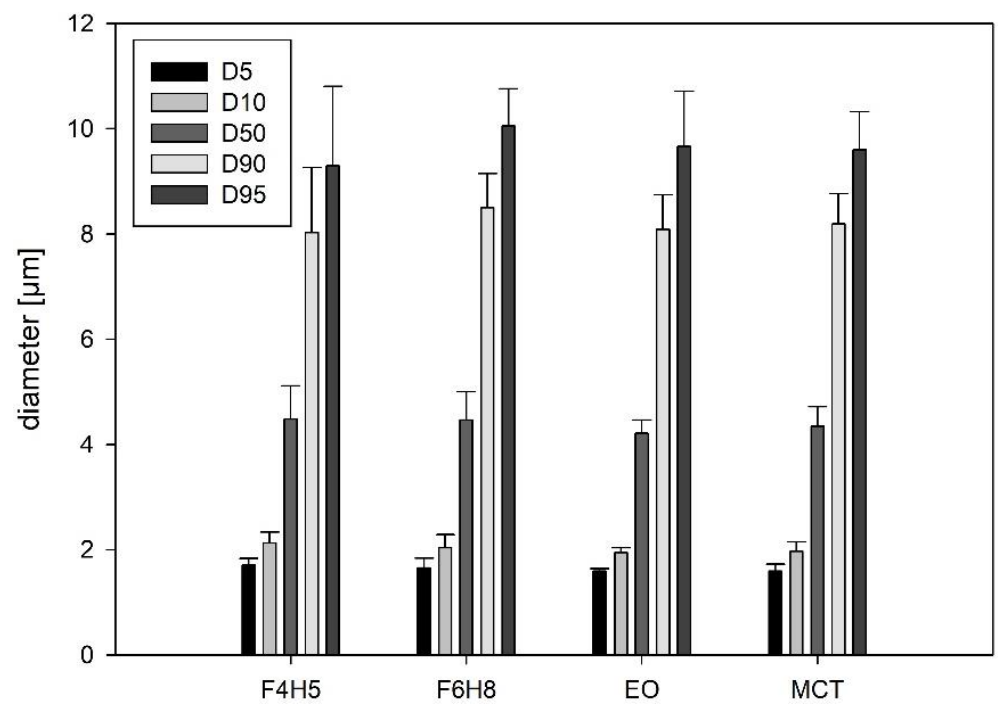

Figure V-2: Particle size distribution of Lys:Tre 70:30 suspensions prepared in an ultrasound bath at a lysozyme concentration of $70 \mathrm{mg} / \mathrm{ml}$. Powders were additionally dried.

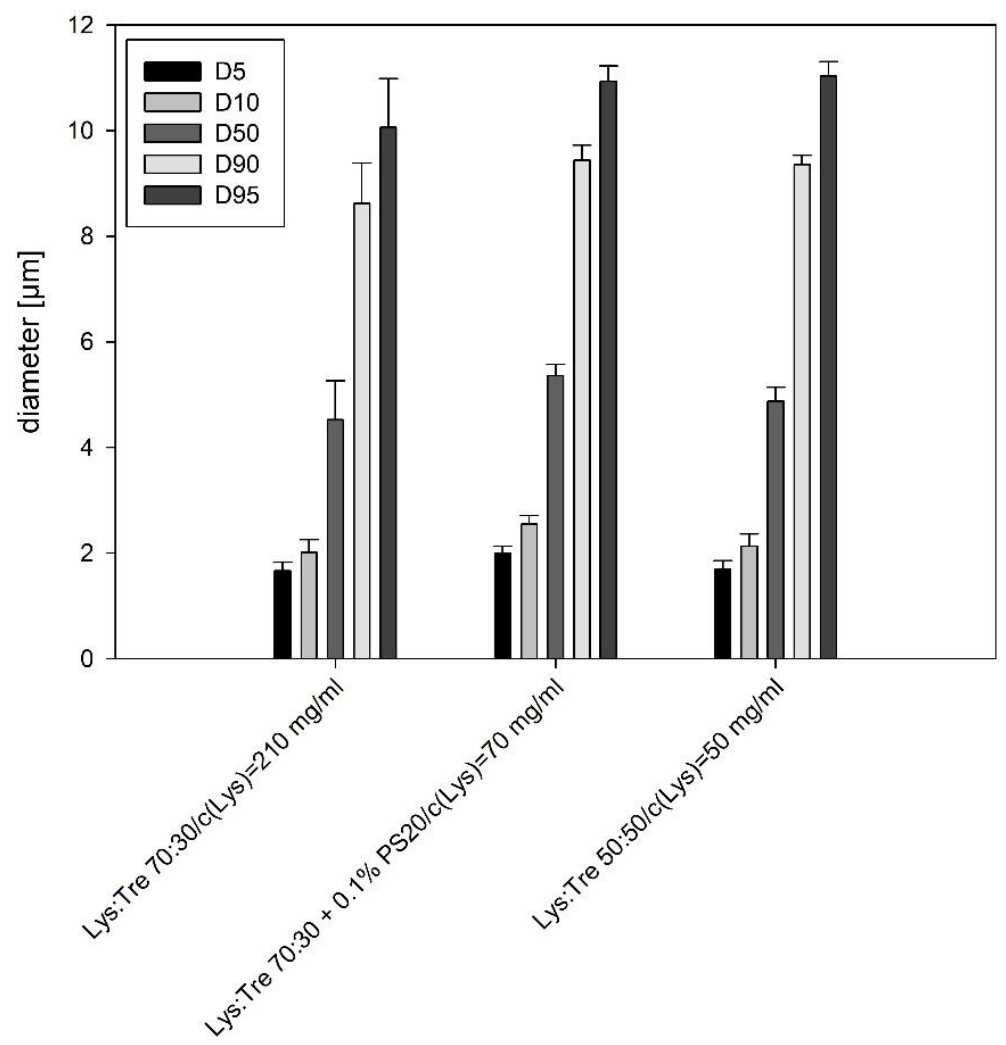

Figure V-3: Particle size distribution of Lys:Tre 70:30 suspensions at a protein concentration of $210 \mathrm{mg} / \mathrm{ml}$, Lys:Tre 70:30 + 0.1\% PS20 suspensions at a protein concentration of $70 \mathrm{mg} / \mathrm{ml}$ and Lys:Tre 50:50 suspensions in $\mathrm{F} 6 \mathrm{H} 8$ at a protein concentration of $50 \mathrm{mg} / \mathrm{ml}$ prepared in an ultrasound bath. Powders were additionally dried. 


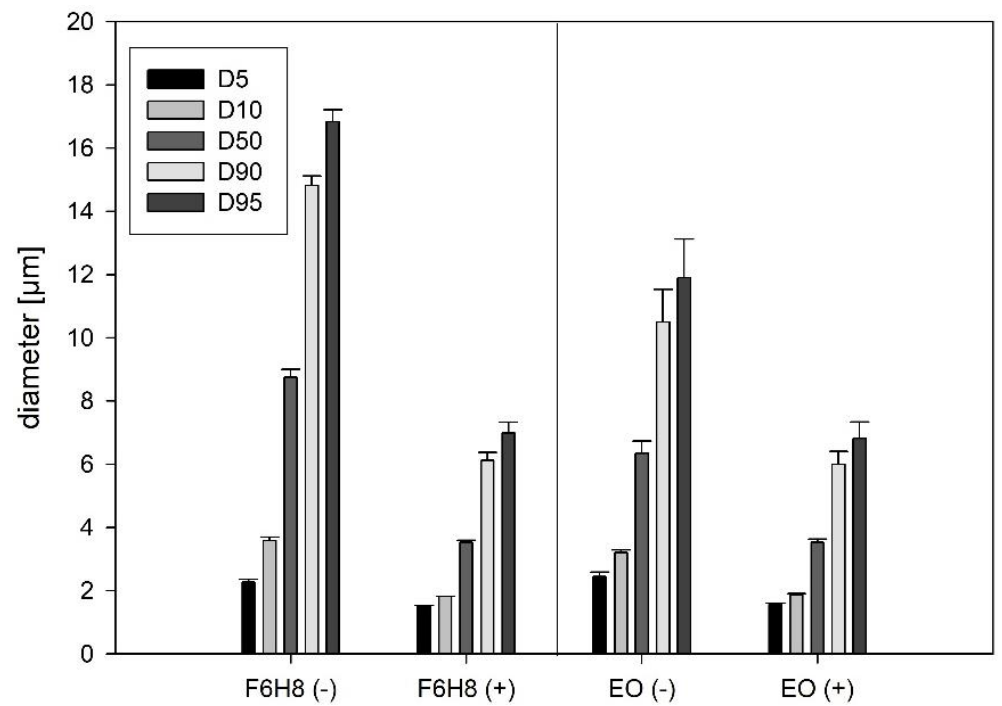

Figure V-4: Particle size distribution of suspensions containing not additionally dried (-) and additionally dried (+) Lys:Suc 50:50 powders at a protein concentration of $50 \mathrm{mg} / \mathrm{ml}$ prepared in an ultrasound bath.

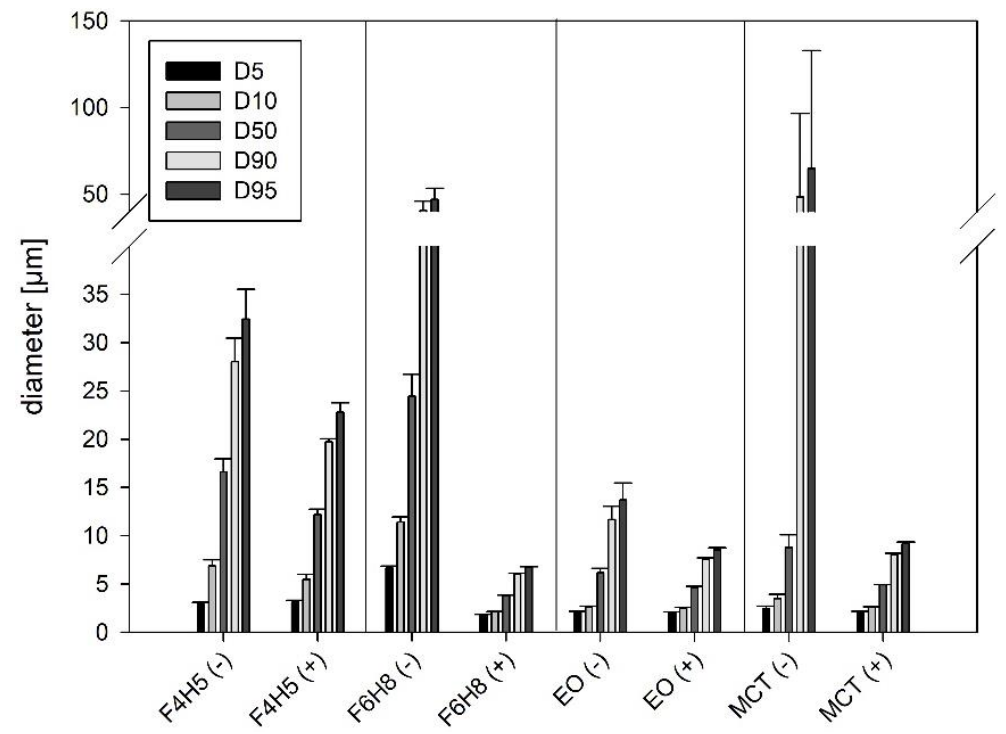

Figure V-5: Particle size distribution of suspensions containing not additionally dried (-) and additionally dried (+) mAb:Suc 50:50 powder at a protein concentration of $50 \mathrm{mg} / \mathrm{ml}$ prepared in an ultrasound bath. 


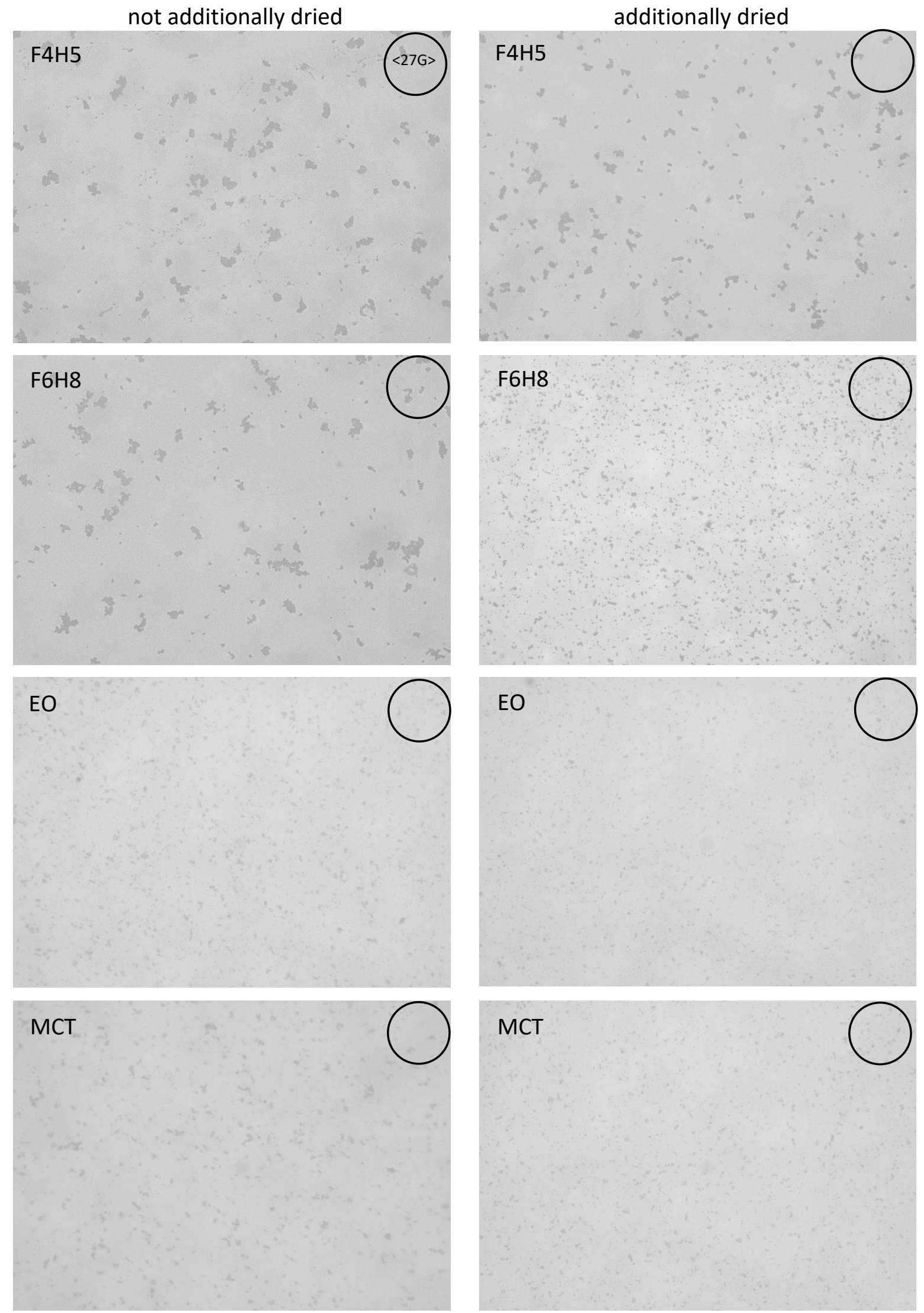

FigureV-6: Microscope images of mAb:Suc 50:50 suspensions at a protein concentration of $50 \mathrm{mg} / \mathrm{ml}$ prepared using an ultrasound bath; circles represent the inner diameter of a $27 \mathrm{G}$ needle $(210 \mu \mathrm{m})$. All suspensions were injectable through a $27 \mathrm{G}$ needle. 


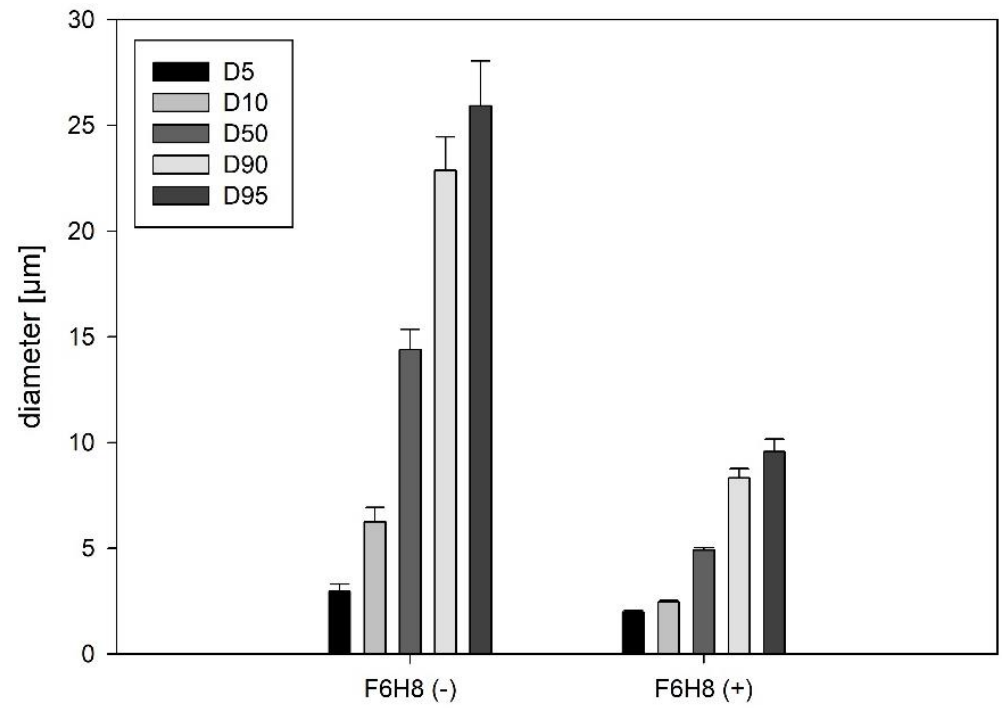

Figure V-7: Particle size distribution of suspensions containing not additionally dried (-) and additionally dried (+) mAb:Tre 50:50 powder at a protein concentration of $50 \mathrm{mg} / \mathrm{ml}$ prepared using an ultrasound bath.

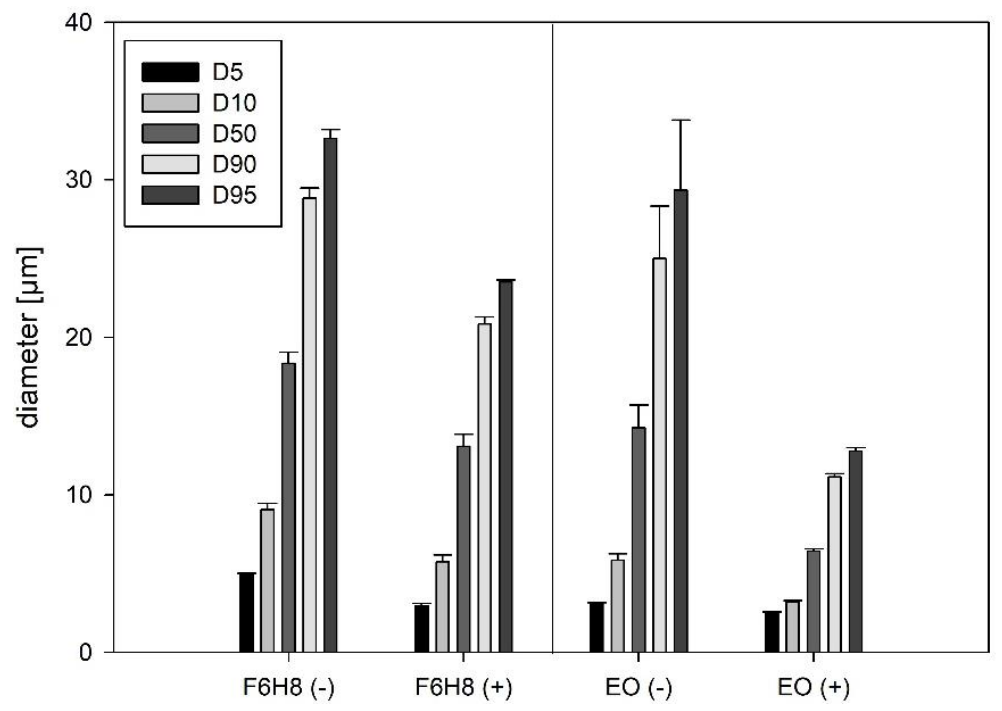

Figure V-8: Particle size distribution of suspensions containing not additionally dried (-) and additionally dried (+) Beva:Suc 50:50 powder at a protein concentration of $50 \mathrm{mg} / \mathrm{ml}$ prepared using an ultrasound bath.

If a high shear homogenizer was used, poorer dispersion quality resulted compared to using an ultrasound bath. Suspensions prepared with a high shear homogenizer only were injectable when additionally dried powder was used. Not additionally dried powder could only be dispersed incompletely with the high shear homogenizer. Laser diffraction and microscopy showed agglomerates with diameters $\geq 200 \mu \mathrm{m}$ in suspensions containing not additionally 
dried powder (Figure V-9/-10). These large particles led to needle clogging of a $27 \mathrm{G}$ needle (inner diameter of around $210 \mu \mathrm{m}$ ). The superior suspension quality with the ultrasound bath confirmed previous findings (Chapter IV). Overall the type of suspension vehicle had an influence on the dispersion quality. Better dispersion of not additionally dried Lys:Suc 50:50 powder was achieved in EO compared to F6H8. Dispersions of additionally dried Lys:Suc 50:50 powder did not show such differences (Figure V-4), whereas dispersions of additionally dried mAb:Suc 50:50 powder in $\mathrm{F} 4 \mathrm{H} 5$ resulted in poorer dispersion quality compared to $\mathrm{F} 6 \mathrm{H} 8, \mathrm{EO}$ and MCT. The best dispersion quality with not additionally dried mAb:Suc 50:50 powder was achieved in EO (Figure V-5). Bowen et al. showed different dispersion qualities of antibody powder in different vehicles. ${ }^{17}$ Based on heat of sorption data analyzed by gas chromatography and laser diffraction data, they concluded, that this behaviour is a consequence of differences in the strength of particle-particle and particle-vehicle interactions. Accordingly, at higher residual moisture levels in the spray-dried powder, particle-particle interactions may be increased, probably by capillary forces, and particlevehicle interactions decreased by a lowered hydrophobic interaction. This explains the poorer dispersion quality when not additionally dried powder was used for suspension preparation.

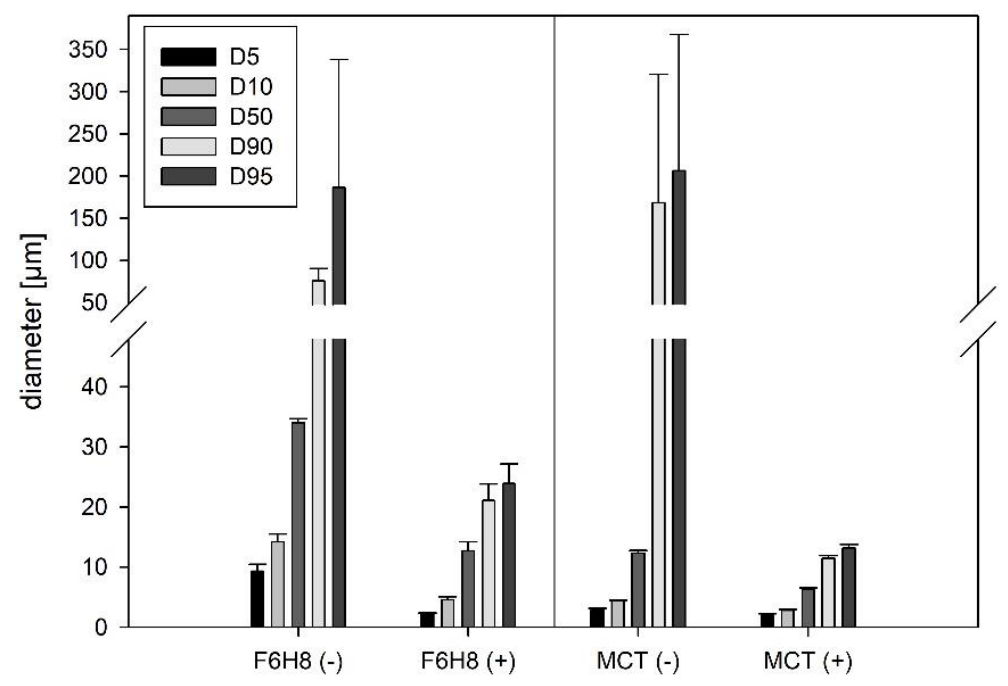

Figure V-9: Particle size distribution of suspensions containing not additionally dried (-) and additionally dried (+) mAb:Suc 50:50 powder at a protein concentration of $50 \mathrm{mg} / \mathrm{ml}$ prepared with a high shear homogenizer. 
not additionally dried

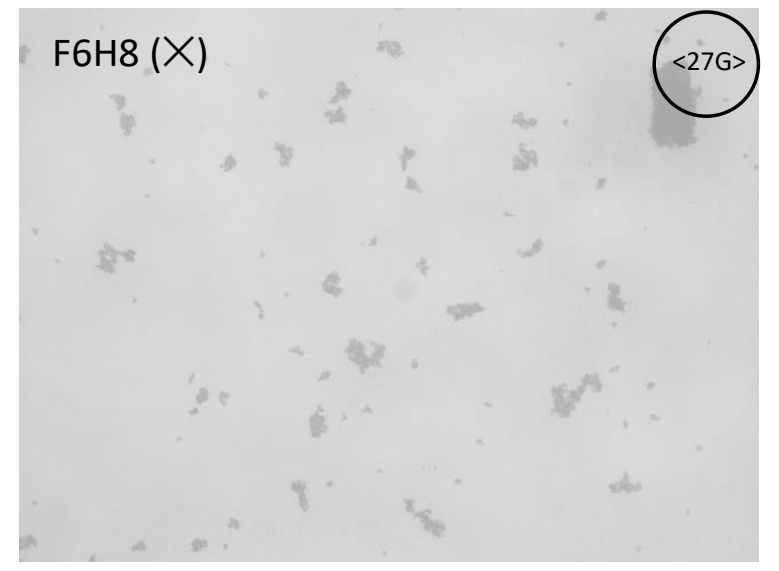

$\operatorname{MCT}(X)$ additionally dried

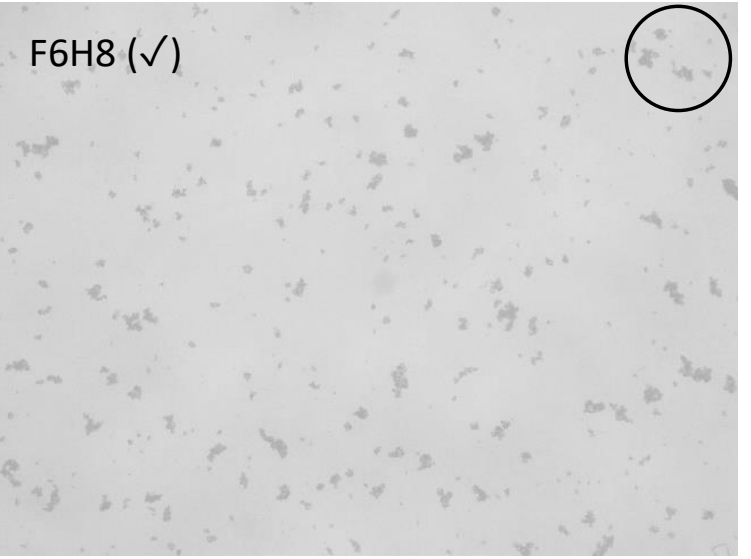

$\operatorname{MCT}(\checkmark)$

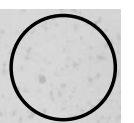

Figure V-10: Microscope images of $\mathrm{mAb}:$ Suc $50: 50$ suspensions $\left(\mathrm{c}_{\mathrm{mAb}}=50 \mathrm{mg} / \mathrm{ml}\right)$ prepared using a high shear homogenizer; circles represent the inner diameter of a $27 \mathrm{G}$ needle $(210 \mu \mathrm{m})$; $\checkmark=$ injectable, $X=$ not injectable.

\subsection{Resuspendability after storage}

Resuspendability is an important factor for pharmaceutical suspensions. According to the Ph. Eur., suspensions have to be redispersible by gentle manual shaking. Resuspension should not take too long, in order to provide a safe and easy application by the medical personal or the patient. Especially, if the suspensions are intended to be provided in a prefillable syringe, this attribute is of high importance, due to the small head space volume which makes resuspension more difficult. We selected two different methods to study the redispersion behaviour. In the first method, adapted from Birk, vials were attached to a vertical rotator and the time needed for redispersion was determined. ${ }^{30}$ Figure $\mathrm{V}-11$ shows the impact of the suspension vehicle on the time needed for resuspension of Lys:Tre 70:30 suspensions containing $70 \mathrm{mg} / \mathrm{ml}$ protein after storage. 


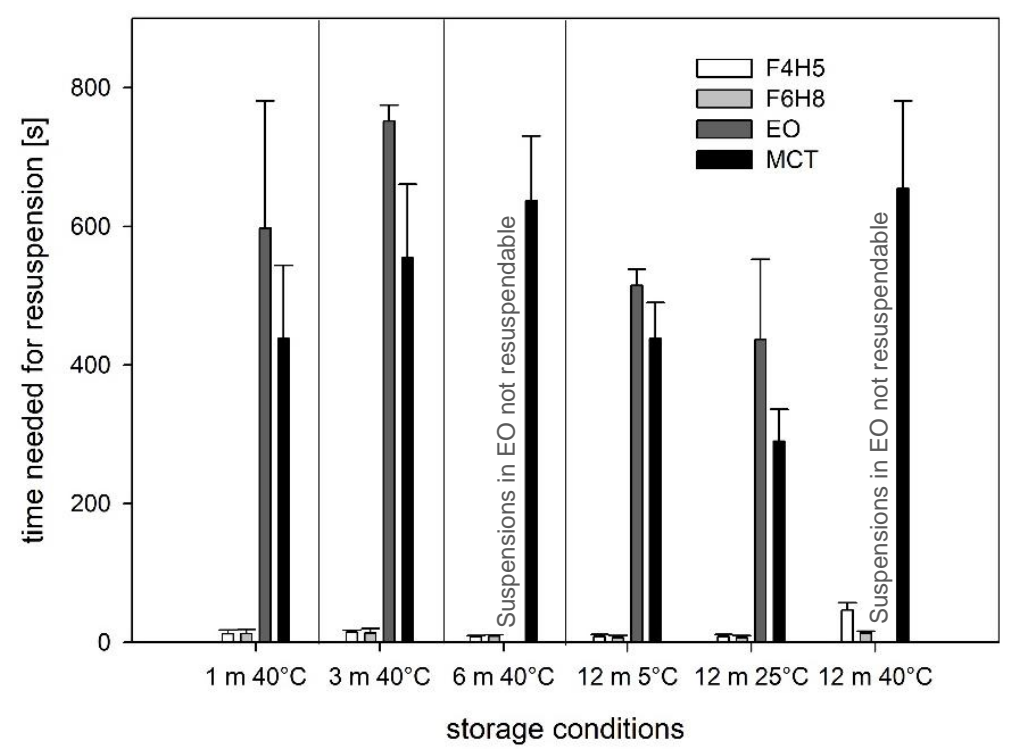

Figure V-11: Effect of suspension vehicle on resuspendability of Lys:Tre 70:30 suspensions ( $\left.\mathrm{C}_{\mathrm{Lys}}=70 \mathrm{mg} / \mathrm{ml}\right)$, tested by vertical vial rotation.

Suspensions containing Lys:Tre 70:30 powder, at a protein concentration of $70 \mathrm{mg} / \mathrm{ml}$, in F4H5 and $\mathrm{F} 6 \mathrm{H} 8$ were easily resuspended within $20 \mathrm{~s}$ after 12 months of storage, with the exception of the $\mathrm{F} 4 \mathrm{H} 5$ formulation, which increased to $46 \mathrm{~s}$ after 12 months at $40^{\circ} \mathrm{C}$. Lys:Tre 70:30 suspensions based on MCT required 400-700 s for resuspension. Suspensions based on EO showed a similar behavior, but after 6 months at $40^{\circ} \mathrm{C}$, they were not resuspendable within 15 min. EO and MCT suspensions showed a much lower sediment volume after storage and formed more dense cakes (Figure V-12). The sediment of F4H5 and F6H8 suspensions was less dense, which could be a consequence of a more flocculated sedimentation behavior. Suspensions comprising SFAs as a suspension vehicle potentially benefit from their low cohesive energy leading to easy spreading and by this to an enhanced wettability. ${ }^{34}$ Figure V14 illustrates the difference in spreading behavior. Contact angles for EO and MCT were higher, with $30-35^{\circ}$, compared to $\mathrm{F} 4 \mathrm{H} 5$ and $\mathrm{F} 6 \mathrm{H} 8$, with $\leq 15^{\circ}$, reflecting the superior wettability behavior of the SFAs. 


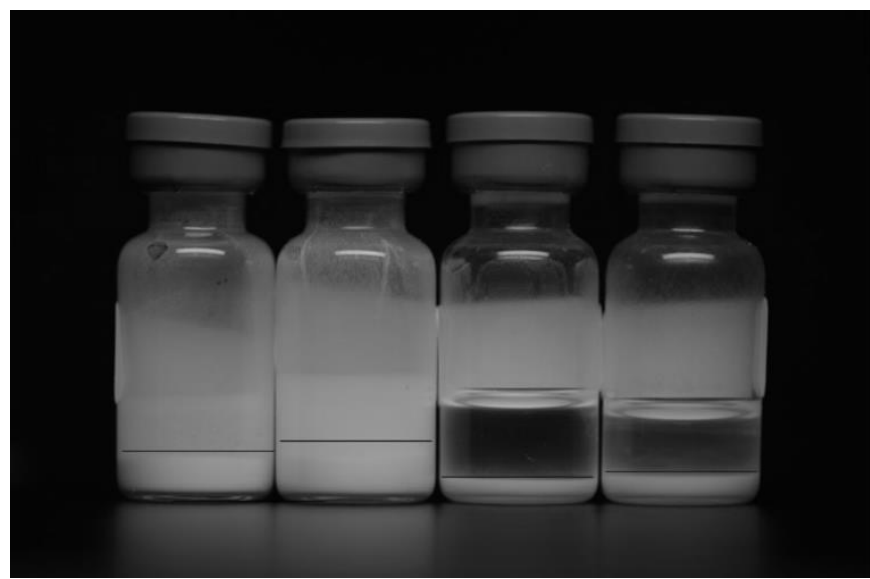

Figure V-12: Sediment volume of Lys:Tre $70: 30$ powder suspensions ( $c_{\text {Lys }}=70 \mathrm{mg} / \mathrm{ml}$ ) after 6 months of storage at $40^{\circ} \mathrm{C}$ (from left to right: $\mathrm{F} 4 \mathrm{H} 5, \mathrm{~F} 6 \mathrm{H} 8, \mathrm{EO}, \mathrm{MCT}$; lines indicating the sediment volume are added to guide the eye).
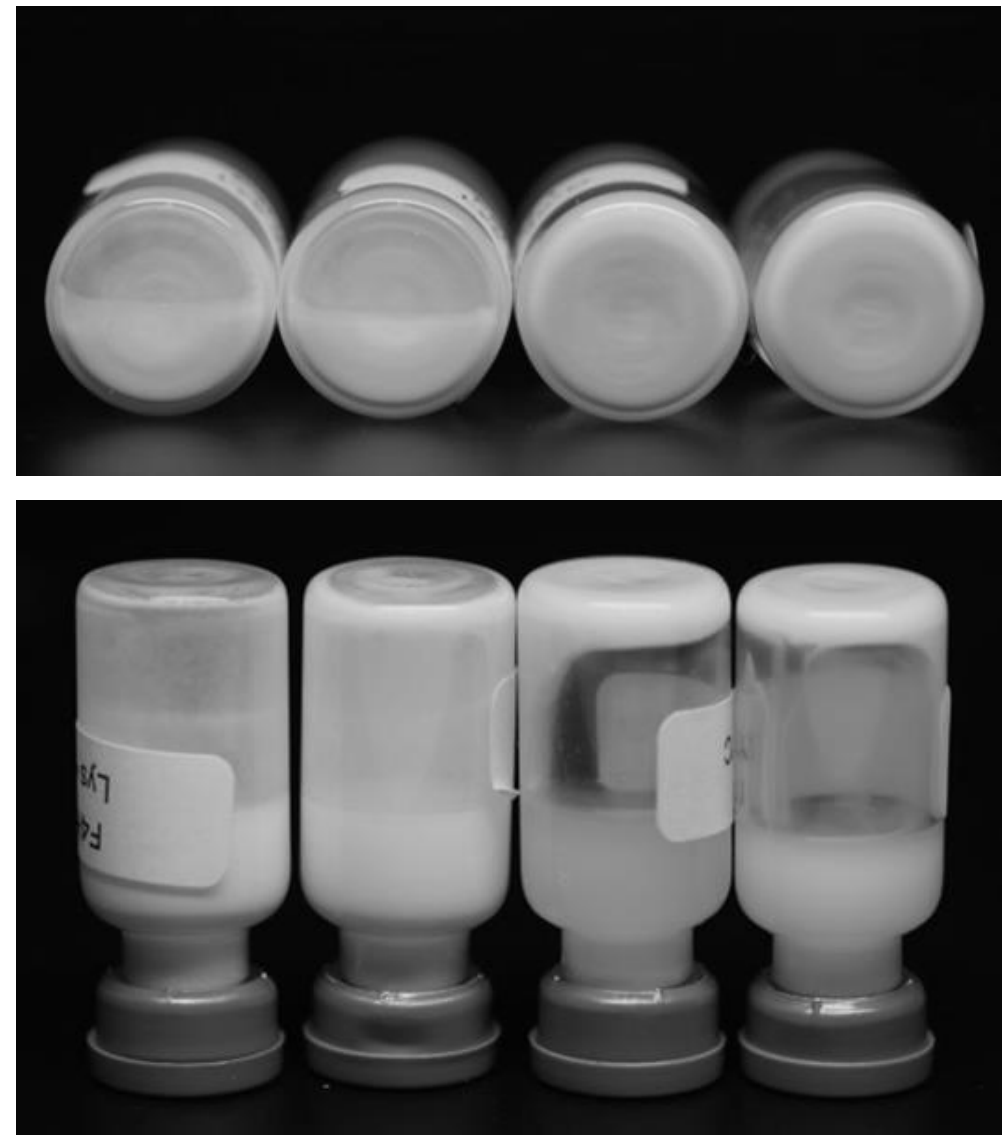

Figure V-13: Lys:Tre 70:30 powder suspensions ( $\mathrm{C}_{\mathrm{Lys}}=70 \mathrm{mg} / \mathrm{ml}$ ) after 6 months of storage at $40^{\circ} \mathrm{C}$ after one minute vertical rotation (from left to right: $\mathrm{F} 4 \mathrm{H} 5, \mathrm{~F} 6 \mathrm{H} 8, \mathrm{EO}, \mathrm{MCT}$ ). 
F4H5

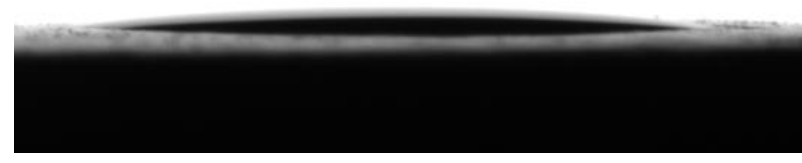

$<15^{\circ}$

EO

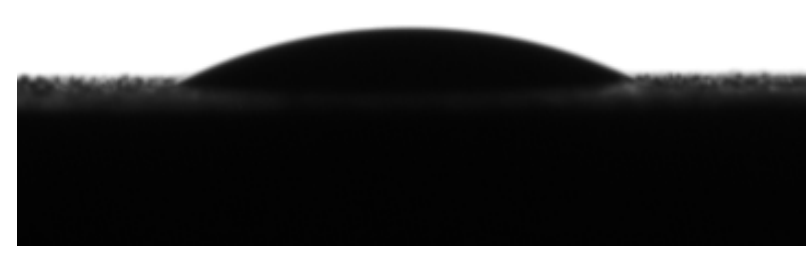

$30.9 \pm 4.2^{\circ}$
F6H8

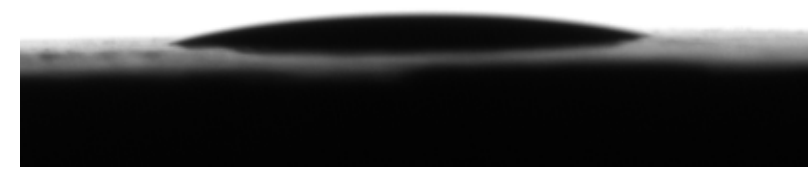

$15.9 \pm 3.8^{\circ}$

MCT

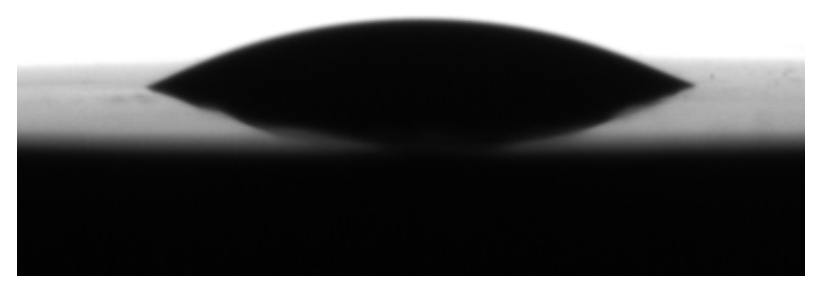

$33.8 \pm 3.3^{\circ}$

Figure V-14: Contact angle between tablet consisting of spray-dried Lys:Tre 70:30 powder and suspension vehicles.

Formulations containing higher powder concentrations (Lys:Tre 70:30; $\mathrm{C}_{\mathrm{Lys}}=210 \mathrm{mg} / \mathrm{ml}$ ), Polysorbate 20 or a higher sugar stabilizer concentration (Lys:Tre 50:50; CLys $=50 \mathrm{mg} / \mathrm{ml}$ ) in $\mathrm{F} 6 \mathrm{H} 8$ were easy redispersible in less than a minute. They did not show any differences in resuspendability compared to the Lys:Tre 70:30 formulation in F6H8.

Formulations containing Lys:Suc 50:50 powder showed a similar behaviour as suspensions of Lys:Tre 70:30 powder, with easier resuspendability of suspensions in $\mathrm{F} 6 \mathrm{H} 8$ compared to EO (Figure V-15A). After 6 months of storage at $40^{\circ} \mathrm{C}$, Lys:Suc 50:50 suspensions stored in EO were not resuspendable within $15 \mathrm{~min}$ by vertical rotation. At lower storage temperatures of 5 and $25^{\circ} \mathrm{C}$ the redispersion behaviour was less negatively impacted. The additional drying step did not significantly influence the time needed for resuspension for Lys:Suc 50:50 formulations. The sedimentation volume was slightly lower for additionally dried formulations, indicating a more deflocculated type of sedimentation (Figure V-16). Lys:Suc 50:50 suspensions in F6H8 showed larger sedimentation volumes compared to formulations in EO, as already seen for Lys:Tre 70:30 formulations (Figure V-12). As EO containing formulations were not resuspendable a harsher redispersion method was applied, which simulates shaking by hand and testes the frequency needed for resuspension (Figure V-15B). Lys:Suc 50:50 suspensions in $\mathrm{F} 6 \mathrm{H} 8$ were easy redispersible at a frequency of $5 \mathrm{~Hz}$, which is the frequency an average 
person uses for this operation. ${ }^{35}$ For EO formulations (Lys:Suc 50:50) higher frequencies of up to $15 \mathrm{~Hz}$ were required. Especially samples stored at $40^{\circ} \mathrm{C}$ benefitted from the additional drying step.

A

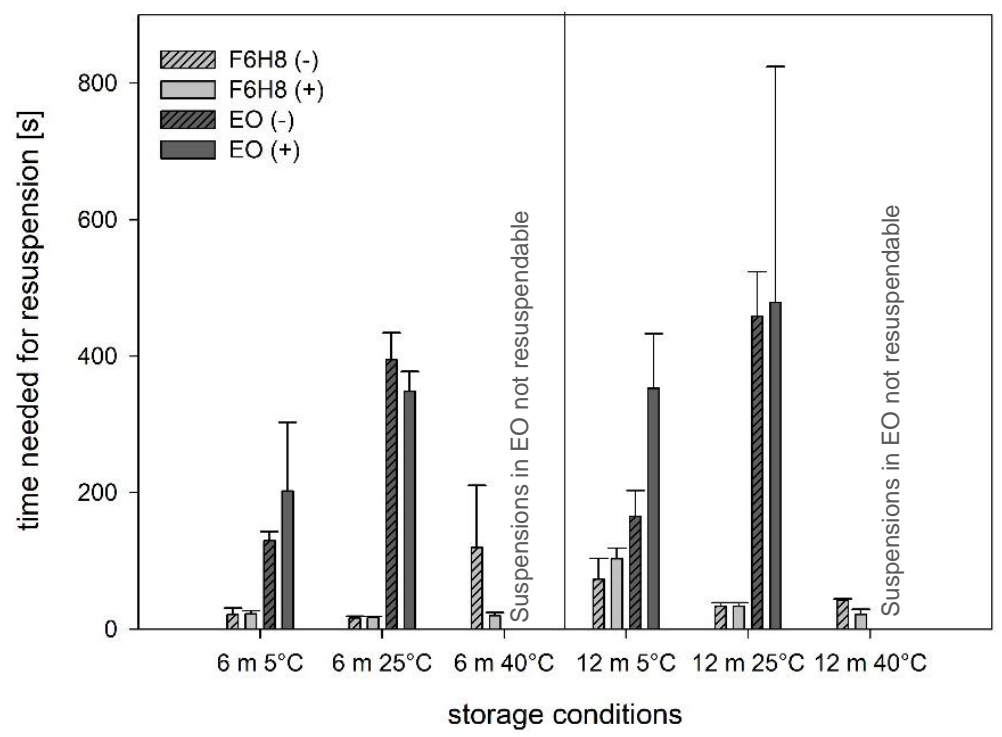

B

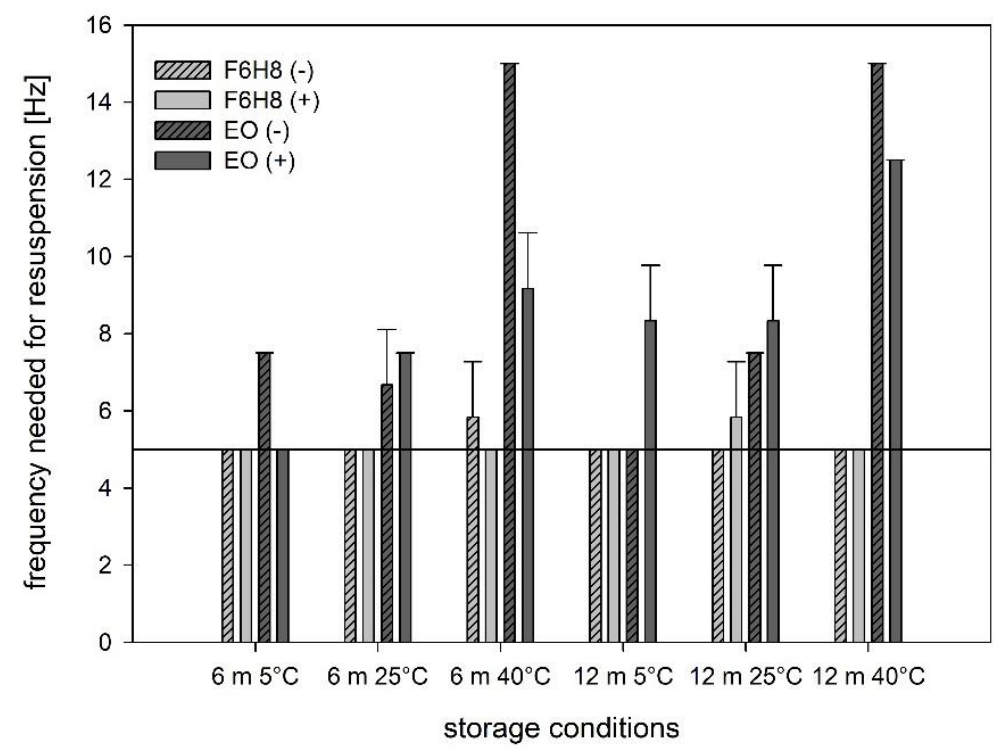

Figure V-15: Effect of suspension vehicle on resuspension of not additionally dried (-) and additionally dried ( + ) Lys:Suc 50:50 suspensions ( $\mathrm{C}_{\mathrm{Lys}}=50 \mathrm{mg} / \mathrm{ml}$ ) tested by rotation $(\mathrm{A})$ or by shaking (B). Horizontal line at $5 \mathrm{~Hz}$ describes the frequency an average person uses. ${ }^{35}$ 


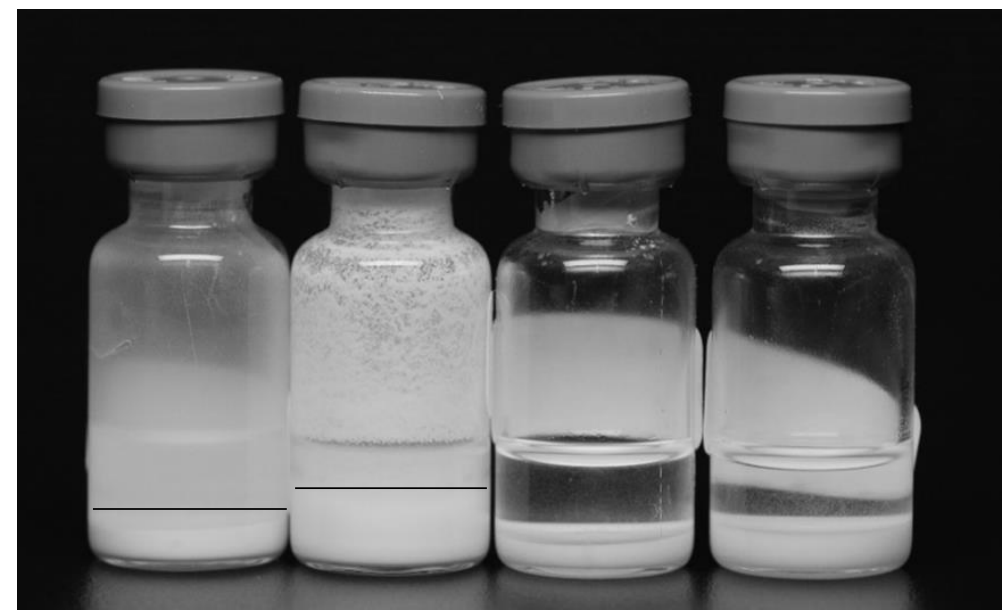

Figure V-16: Sediment volume of Lys:Suc 50:50 powder suspensions ( $\mathrm{C}_{\mathrm{Lys}}=50 \mathrm{mg} / \mathrm{ml}$ ) after 12 months of storage at $40^{\circ} \mathrm{C}$ (from left to right: $\mathrm{F} 6 \mathrm{H} 8$ additionally dried, $\mathrm{F} 6 \mathrm{H} 8$, EO additionally dried, EO; lines indicating the sediment volume are added to guide the eye).

Interestingly $\mathrm{F} 4 \mathrm{H} 5$ and $\mathrm{F} 6 \mathrm{H} 8$ suspensions containing not additionally dried mAb:Suc 50:50 powder were not as easily resuspendable as respective suspensions containing Lys:Suc 50:50 powder. They were not resuspended after $15 \mathrm{~min}$ of vertical rotation at $25 \mathrm{rpm}$ or shaking at $5 \mathrm{~Hz}$ as a consequence of strong network formation (Figure V-17). The strong particle agglomeration and interparticular cohesive forces in the not additionally dried powders can be explained by capillary bridges by residual water. ${ }^{36}$ While flocculation or network formation is usually considered beneficial for suspension stability, it had a negative impact for the mAb:Suc 50:50 powder suspensions. ${ }^{12}$ Suspensions containing additionally dried $m A b: S u c 50: 50$ powder, were redispersible at $5 \mathrm{~Hz}$ after 6 months of storage at $40^{\circ} \mathrm{C}$. Furthermore the syringeability was tested, by drawing the suspension through a 236 needle into a syringe. After 6 months of storage at $40^{\circ} \mathrm{C}$, only $4-5 \%$ of the volume of not additionally dried mAb:Suc 50.50 powder suspensions were removable from the vial and mainly air was drawn into the syringe (Figure V-18 and Table V-2). MAb:Suc 50:50 suspensions containing additionally dried powder in $\mathrm{F} 4 \mathrm{H} 5$ or $\mathrm{F} 6 \mathrm{H} 8$ were nearly completely removable. After destroying the network, which was built up in not additionally dried mAb:Suc 50:50 suspensions, at a frequency of $30 \mathrm{~Hz}$, suspensions adhered to the vial wall and did not flow properly (Figure V-17). This shows the high importance of an additional drying step for the mAb suspensions. While suspensions in EO containing additionally dried mab:Suc 50:50 powder were resuspendable at a frequency of $5 \mathrm{~Hz}$ after 6 months of storage at $40^{\circ} \mathrm{C}, \mathrm{MCT}$ 
suspensions showed a slight increase from 5 ( 3 months) to $7.5 / 10 \mathrm{~Hz}$ (6 months) (see Figure V19).
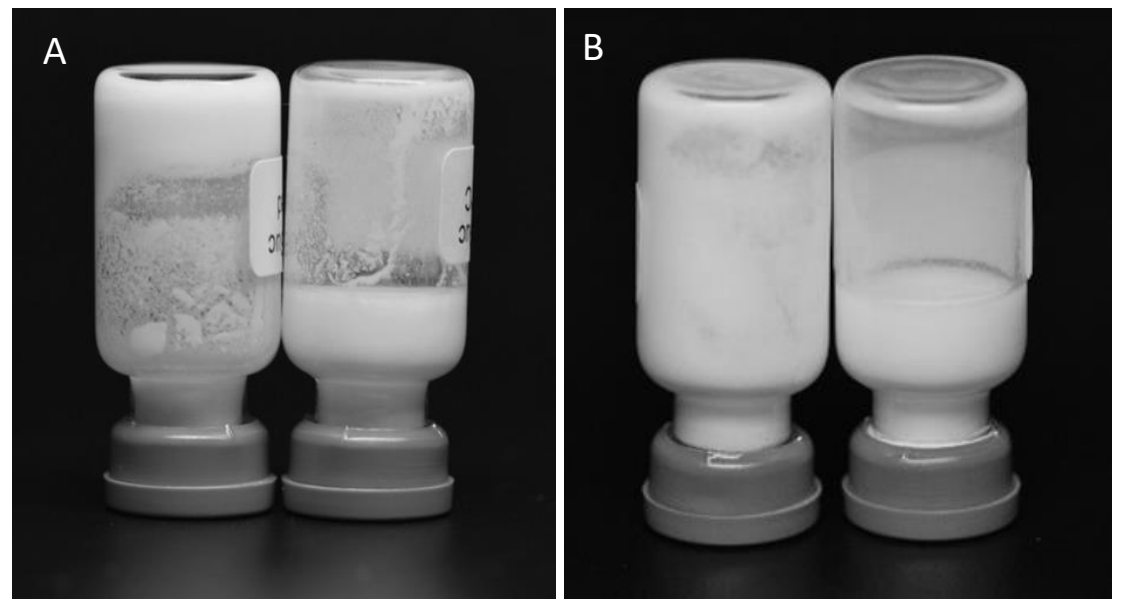

Figure V-17: Resuspendability of mAb:Suc 50:50 powder suspensions in $\mathrm{F} 6 \mathrm{H} 8\left(\mathrm{c}_{\mathrm{mAb}}=50 \mathrm{mg} / \mathrm{ml}\right)$. Suspensions contained not additionally dried (left) or additionally dried (right) powder. A: $15 \mathrm{~min}$ of vertical rotation of suspensions stored for 1 month at $40^{\circ} \mathrm{C}$. B: Shaking at $30 \mathrm{~Hz}$ of suspensions stored for 3 months at $40^{\circ} \mathrm{C}$.

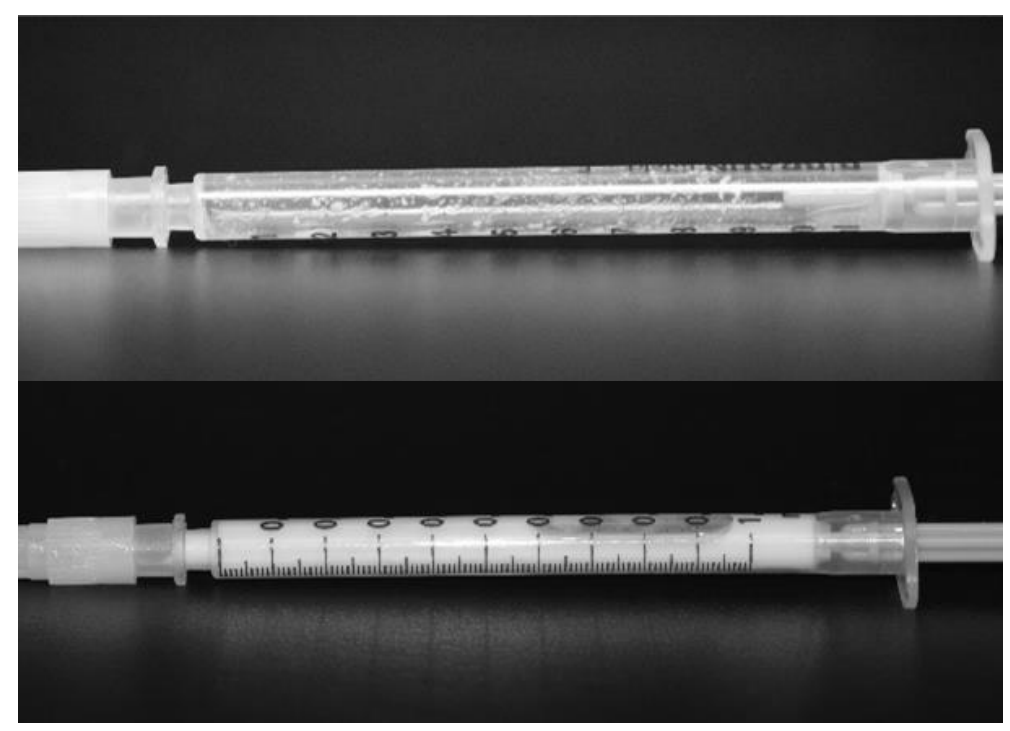

Figure V-18: Feasibility of drawing of mAb:Suc 50:50 F6H8 suspensions into a syringe through a 23G needle containing not additionally dried (top) and additionally dried (bottom) powder after storage for 3 months at $40^{\circ} \mathrm{C}$. 


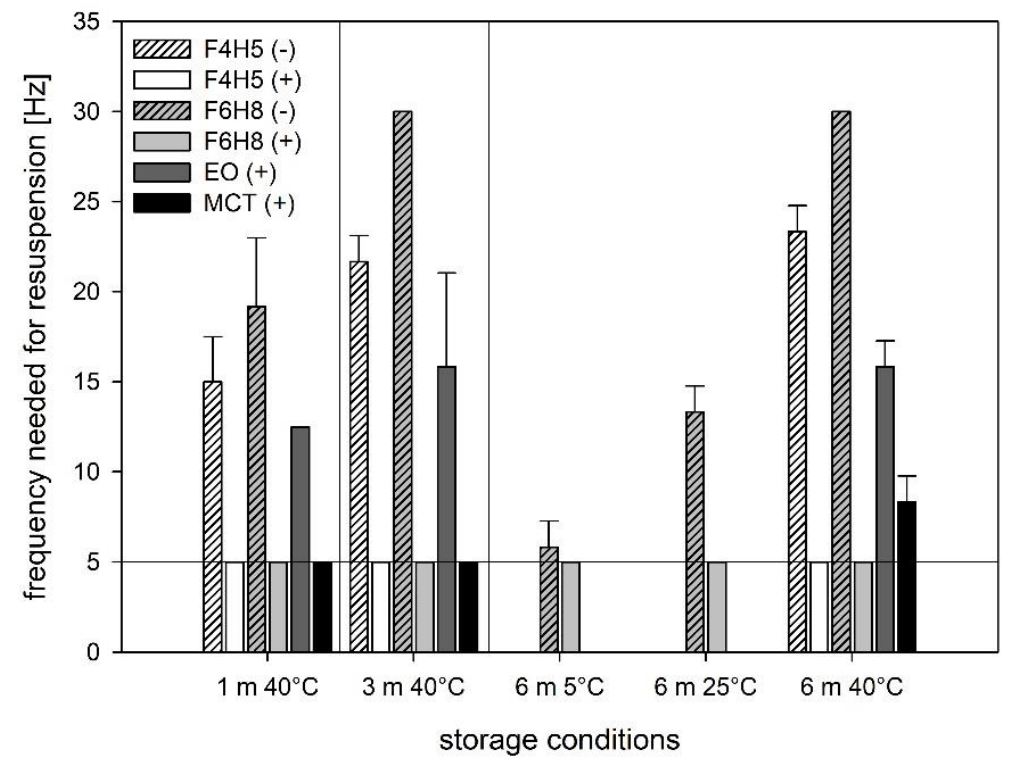

Figure V-19: Effect of suspension vehicle on resuspendability of not additionally dried (-) and additionally dried $(+)$ mAb:Suc $50: 50$ suspensions $\left(c_{m A b}=50 \mathrm{mg} / \mathrm{ml}\right)$ tested by shaking. Horizontal line at $5 \mathrm{~Hz}$ describes the frequency an average person uses. ${ }^{35}$

Resuspending suspensions containing Beva:Suc 50:50 powder confirmed previous findings. Suspensions containing not additionally dried and additionally dried Beva:Suc 50:50 powder in $\mathrm{F} 6 \mathrm{H} 8$ at a protein concentration of $50 \mathrm{mg} / \mathrm{ml}$ were easy redispersible at $5 \mathrm{~Hz}$. Suspensions containing the same powder in EO benefited from the additional drying step. Frequencies needed for resuspensions were $22.5 \mathrm{~Hz}$ (not additionally dried) and 12.5-15 Hz (additionally dried). No significant differences with regard to the additional drying step were found in drawing the Beva:Suc 50:50 suspensions through a 23G needle into a syringe (Table V-2). 
Table V-2: Removable volume after storage of mAb:Suc and Beva:Suc formulations $\left(\mathrm{C}_{\mathrm{mAb} / \mathrm{Beva}}=50 \mathrm{mg} / \mathrm{ml}\right)$.

\begin{tabular}{|c|c|c|c|}
\hline Protein & Vehicle & Storage conditions & $\begin{array}{l}\text { Removable Volume [\%] } \\
\text { not additionally dried (-) or dried (+) }\end{array}$ \\
\hline \multirow[t]{2}{*}{$\mathrm{mAb}$} & $\mathrm{F} 4 \mathrm{H} 5$ & $6 \mathrm{~m} 40^{\circ} \mathrm{C}$ & $\begin{array}{c}4.7 \pm 0.3(-) \\
92.0 \pm 3.2(+)\end{array}$ \\
\hline & $\mathrm{F} 6 \mathrm{H} 8$ & $6 \mathrm{~m} \mathrm{40}{ }^{\circ} \mathrm{C}$ & $\begin{array}{c}4.3 \pm 1.0(-) \\
92.0 \pm 3.2(+)\end{array}$ \\
\hline \multirow[t]{3}{*}{ Beva } & \multirow[t]{2}{*}{$\mathrm{F} 6 \mathrm{H} 8$} & $3 \mathrm{~m} 40^{\circ} \mathrm{C}$ & $\begin{array}{l}69.0 \pm 4.2(-) \\
78.6 \pm 3.3(+)\end{array}$ \\
\hline & & $6 \mathrm{~m} \mathrm{40}{ }^{\circ} \mathrm{C}$ & $\begin{array}{l}72.0 \pm 7.0(-) \\
79.5 \pm 0.6(+)\end{array}$ \\
\hline & EO & $6 \mathrm{~m} \mathrm{4} 40^{\circ} \mathrm{C}$ & $\begin{array}{l}82.8 \pm 3.4(-) \\
84.8 \pm 3.5(+)\end{array}$ \\
\hline
\end{tabular}

\subsection{Powder particle size}

A consistent particle size after storage is of importance and also a general quality attribute for suspensions. ${ }^{13} \mathrm{An}$ increase of the particle size might induce needle clogging or alter dissolution and release kinetics. ${ }^{37,38}$ The type of suspension vehicle did not show an effect on the powder particle size after storage for 12 months of suspensions containing Lys:Tre 70:30 powder at a protein concentration of $70 \mathrm{mg} / \mathrm{ml}$ (Figure V-20) with $\mathrm{D} 50$ (t0/12 months $40^{\circ} \mathrm{C}$ ) values of: 4.5 $\pm 0.6 \mu \mathrm{m} / 5.3 \pm 0.0 \mu \mathrm{m}$ (F4H5), $4.5 \pm 0.5 \mu \mathrm{m} / 5.3 \pm 0.1 \mu \mathrm{m}$ (F6H8), $4.2 \pm 0.3 \mu \mathrm{m} / 4.5 \pm 0.1 \mu \mathrm{m}$ (EO) and $4.3 \pm 0.4 \mu \mathrm{m} / 4.4 \pm 0.3 \mu \mathrm{m}$ (MCT). Data obtained from laser diffraction measurements was confirmed by light microscopy. Increasing the protein concentration to $210 \mathrm{mg} / \mathrm{ml}$, adding PS20 or decreasing the protein ratio did not negatively impact powder particle stability in $\mathrm{F} 6 \mathrm{H} 8$ (Figure V-21). 

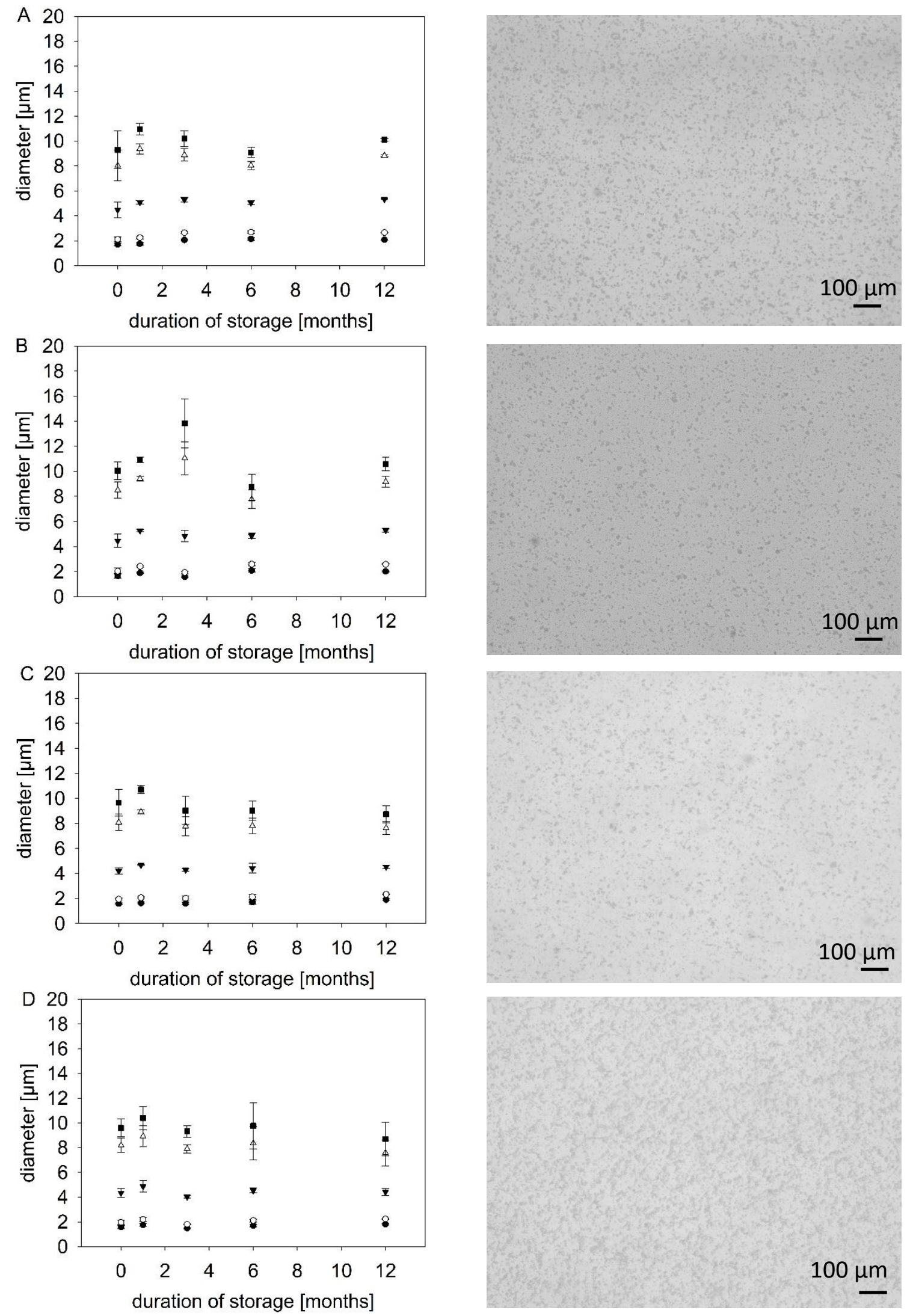

Figure V-20: Particle size and microscopy images of Lys:Tre 70:30 ( $\left.\mathrm{c}_{\mathrm{Lys}}=70 \mathrm{mg} / \mathrm{ml}\right)$ after 12 months at $40^{\circ} \mathrm{C}$ in F4H5 (A), F6H8 (B), EO (C), MCT (D). D5 (•), D10 (o), D50 ( $\left.\mathbf{\nabla}\right)$, D90 ( $\left.\triangle\right)$ and D95 ( $\bullet$ ). 

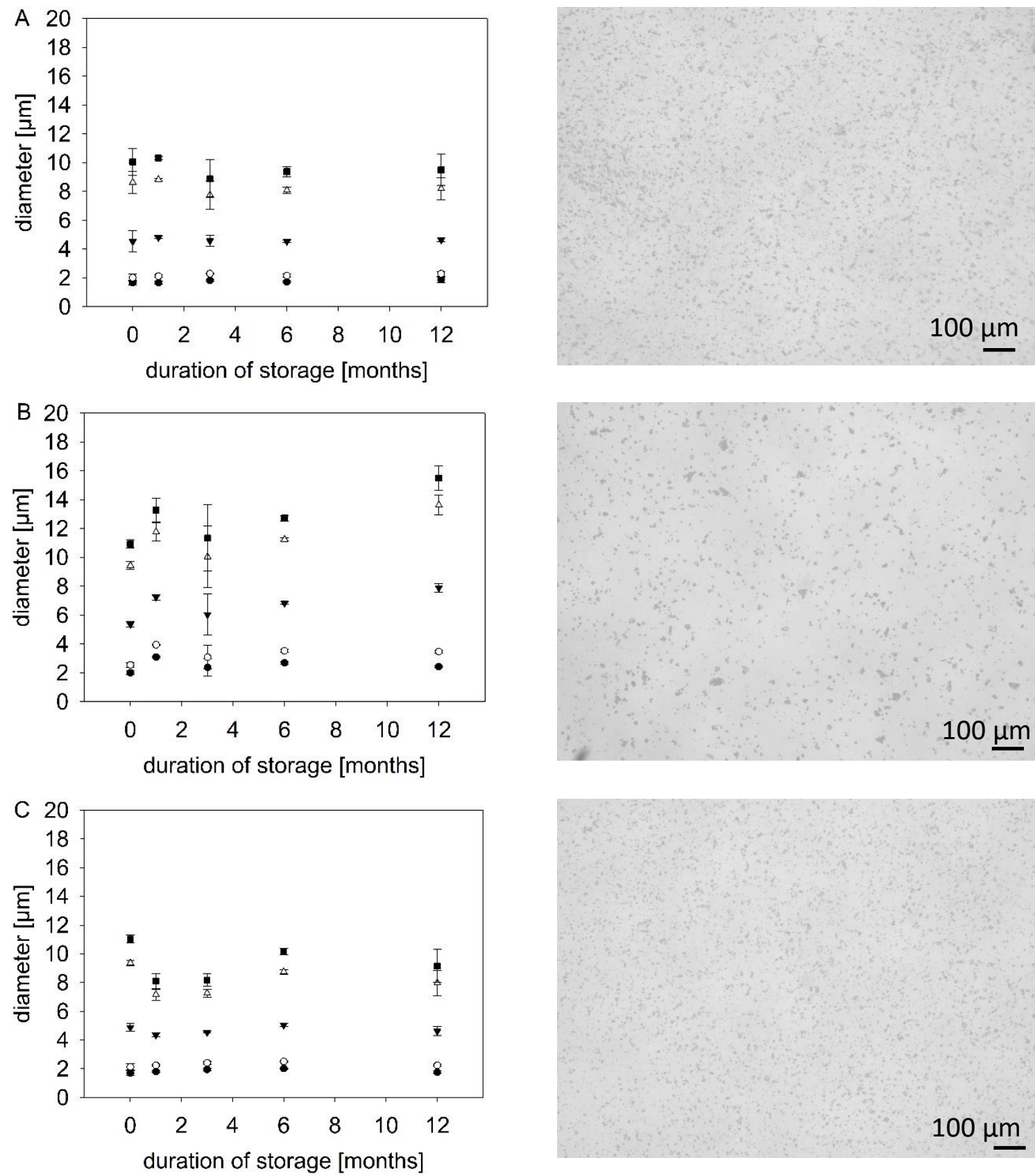

Figure V-21: Particle size and microscopy images of suspensions in F6H8 after 12 months at $40^{\circ} \mathrm{C}$. (A) Lys:Tre 70:30; CLys $=210 \mathrm{mg} / \mathrm{ml}$ (B) PS 20 containing Lys:Tre 70:30; Clys $=70 \mathrm{mg} / \mathrm{ml}$ (C)

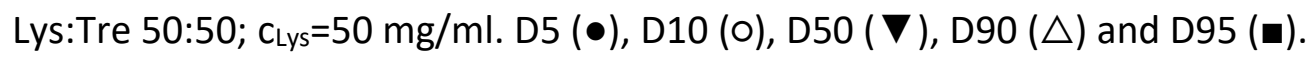


To study the effect of residual moisture on particle size stability, Lys:Suc 50:50 and mAb:Suc 50:50 powder were stored in $\mathrm{F} 6 \mathrm{H} 8$ and in $\mathrm{EO}$ at a protein concentration of $50 \mathrm{mg} / \mathrm{ml}$. For Lys:Suc 50:50 suspensions, containing either not additionally dried or additionally dried powder, no difference in particle size was found after 12 months of storage at $40^{\circ} \mathrm{C}$ in $\mathrm{F} 6 \mathrm{H} 8$ or EO (Figure V-22). The findings from laser diffraction were further confirmed by SEM (Figure V23). SEM demonstrated, that no change of the particle morphology or sintering of Lys:Suc 50:50 powder particles occurred during 12 months of storage at $40^{\circ} \mathrm{C}$. Microscopy indicated agglomerates in suspensions containing not additionally dried Lys:Suc 50:50 powder (see Figure V-22). The fact, that these agglomerates were not seen in laser diffraction indicates reversible powder particle agglomeration without the presence of particle sintering. 

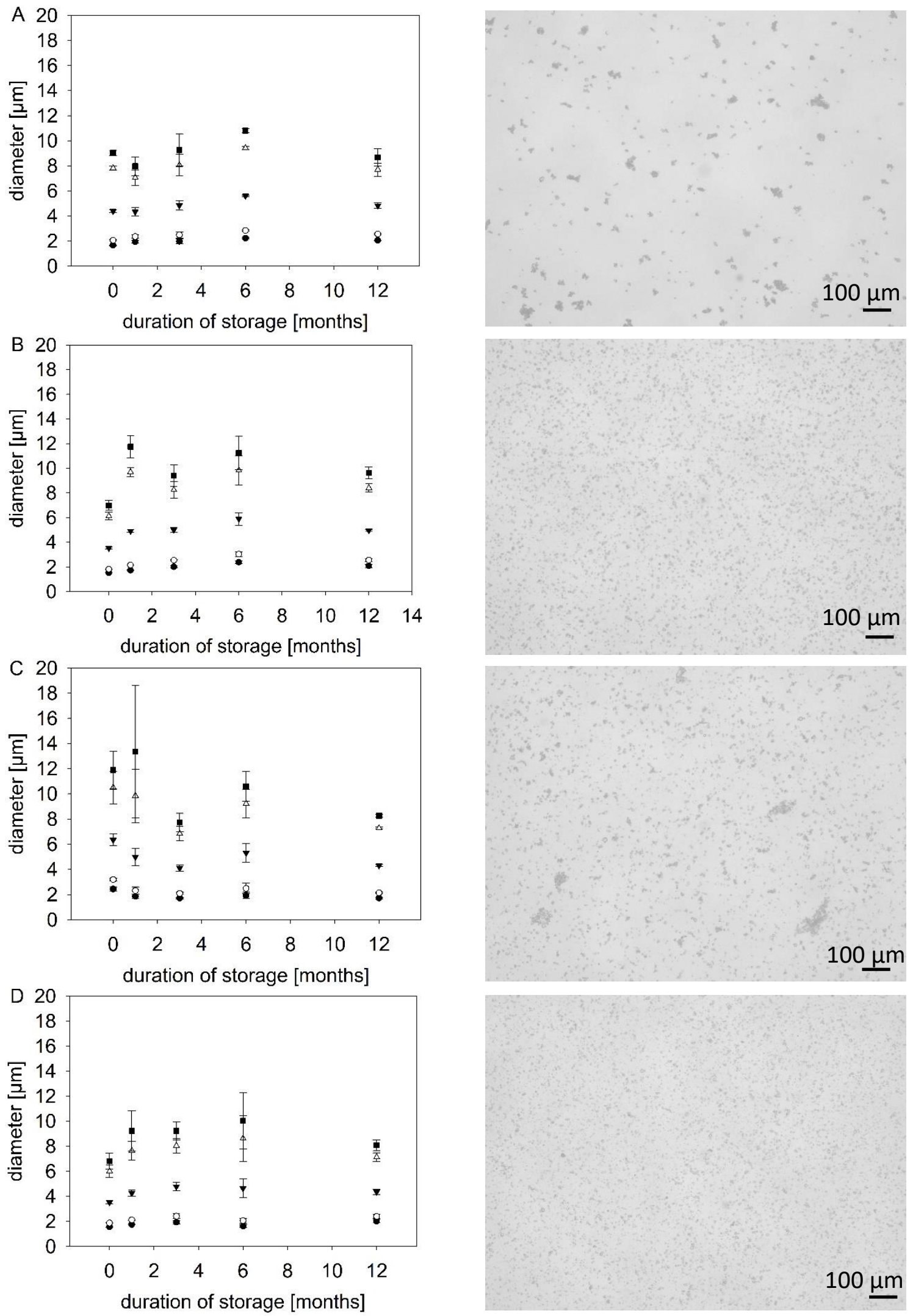

Figure V-22: Particle size and microscopy images of Lys:Suc $50: 50$ suspensions ( $\mathrm{C}_{\mathrm{Lys}}=50 \mathrm{mg} / \mathrm{ml}$ ) after 12 months at $40^{\circ} \mathrm{C}$, containing not-additionally dried powder $(\mathrm{A})$ and additionally dried powder in $\mathrm{F} 6 \mathrm{H} 8$ (B) or not-additionally dried powder (C) and additionally dried powder in

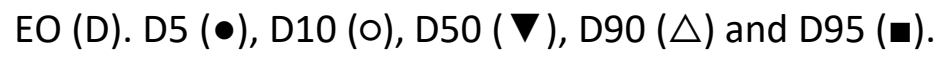



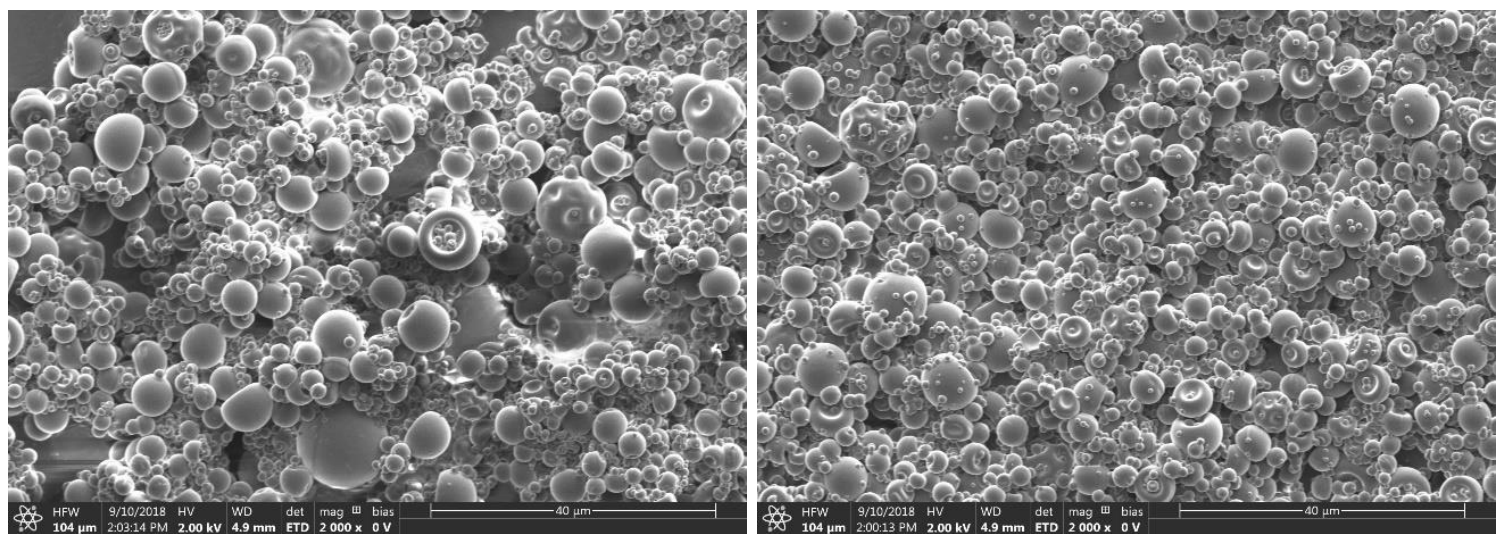

Figure V-23: SEM images of Lys:Suc 50:50 suspensions after 12 months at $40^{\circ} \mathrm{C}$ in $\mathrm{F} 6 \mathrm{H} 8$ (Clys $=50 \mathrm{mg} / \mathrm{ml}$ ), containing not additionally dried (left) and additionally dried powder (right).

Formulations containing the mAb, which were additionally dried did not show an increase in particle size stored in F4H5, F6H8, EO and MCT (Figure V-24/-27). In contrast, for suspensions containing not additionally dried mAb:Suc 50:50 powder in either $\mathrm{F} 4 \mathrm{H} 5$ or $\mathrm{F} 6 \mathrm{H} 8$, a drastic increase in the particle size after 6 months of storage at 25 and $40^{\circ} \mathrm{C}$ was detected (Figure V24/-26). The D50 value increased from approximately $5 \mu \mathrm{m}$ to $17.6 \pm 7.6$ for $\mathrm{F} 4 \mathrm{H} 5$ and to 12.8 $\pm 1.0 \mu \mathrm{m}$ for suspensions in $\mathrm{F} 6 \mathrm{H} 8$. No change in the particle size was found, if stored at $5^{\circ} \mathrm{C}$ (Figure V-26). Formation of needle like structures indicated crystallization effects as a root cause for the increase in the measured particle size (Figure V-24). This assumption was further confirmed by XRD analysis showing peaks of crystalline sucrose after 6 months of storage at 25 or $40^{\circ} \mathrm{C}$, but not after storage at $5^{\circ} \mathrm{C}$ (Figure V-25). Additionally dried formulations remained amorphous. These findings can be explained by the plasticizing effect of the residual water content of the not additionally dried powder. By lowering the formulations' glass transitions temperature local mobility is increased, leading to recrystallization of the sugar. ${ }^{22,24}$ The recrystallization of the sucrose not only has a negative impact in particle size stability, but could also negatively impact protein stability.

No change in powder particle size was found for additionally dried suspensions of mAb:Tre $50: 50$ in $\mathrm{F} 6 \mathrm{H} 8$, stored in a prefillable COP syringe at a protein concentration of $50 \mathrm{mg} / \mathrm{ml}$ (Figure V-28). Furthermore, both additionally and not additionally dried Beva:Suc 50:50 powder containing suspensions in $\mathrm{F} 6 \mathrm{H} 8$ and $\mathrm{EO}$ at a protein concentration of $50 \mathrm{mg} / \mathrm{ml}$ did not show a change in particle size or morphology after 6 months of storage at $40^{\circ} \mathrm{C}$ (Figure $\mathrm{V}$ 30). 

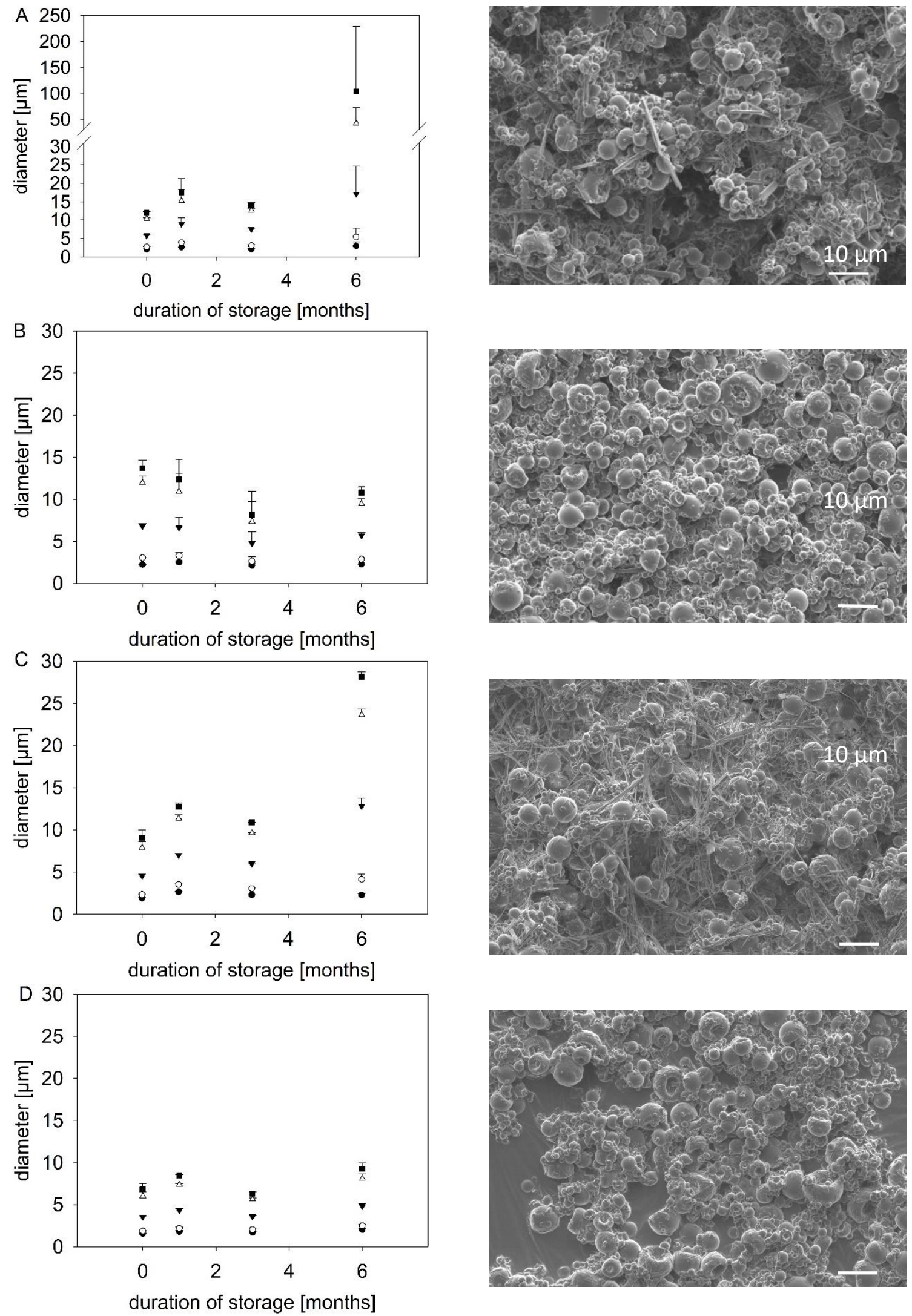

Figure V-24: Particle size and SEM images of mAb:Suc 50:50 suspensions after 6 months at $40^{\circ} \mathrm{C}\left(\mathrm{C}_{\mathrm{mAb}}=50 \mathrm{mg} / \mathrm{ml}\right)$, containing not additionally dried $(\mathrm{A})$ and additionally dried powder (B) in F4H5 or not additionally dried (C) and additionally dried powder (D) in F6H8. D5 (•), D10 (O), $\mathrm{D} 50(\boldsymbol{\nabla}), \mathrm{D} 90(\triangle)$ and D95 ( $\mathbf{\square})$. 


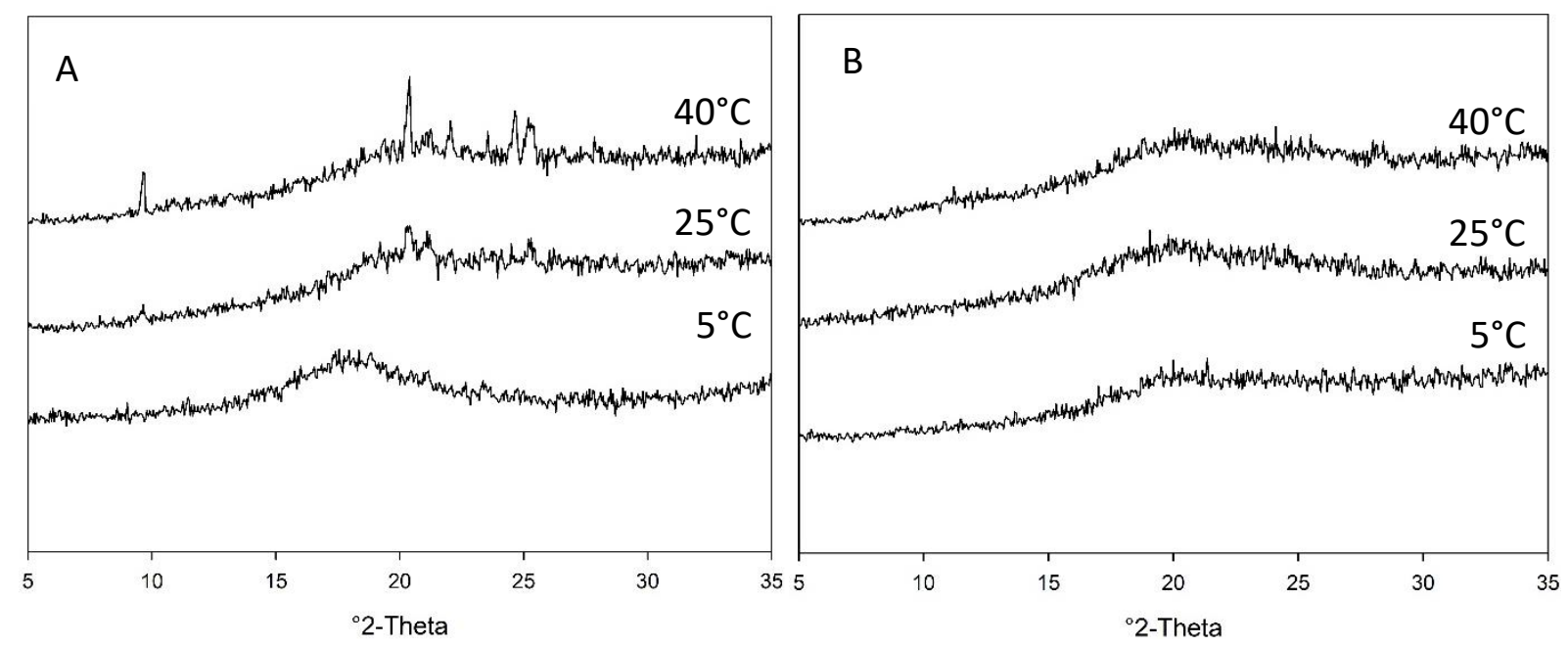

Figure V-25: XRD spectra of mAb:Suc 50:50 suspensions after 6 months of storage in $\mathrm{F} 6 \mathrm{H} 8$ $\left(\mathrm{C}_{\mathrm{mAb}}=50 \mathrm{mg} / \mathrm{ml}\right)$, containing not additionally dried $(\mathrm{A})$ and additionally dried $(\mathrm{B})$ powder.

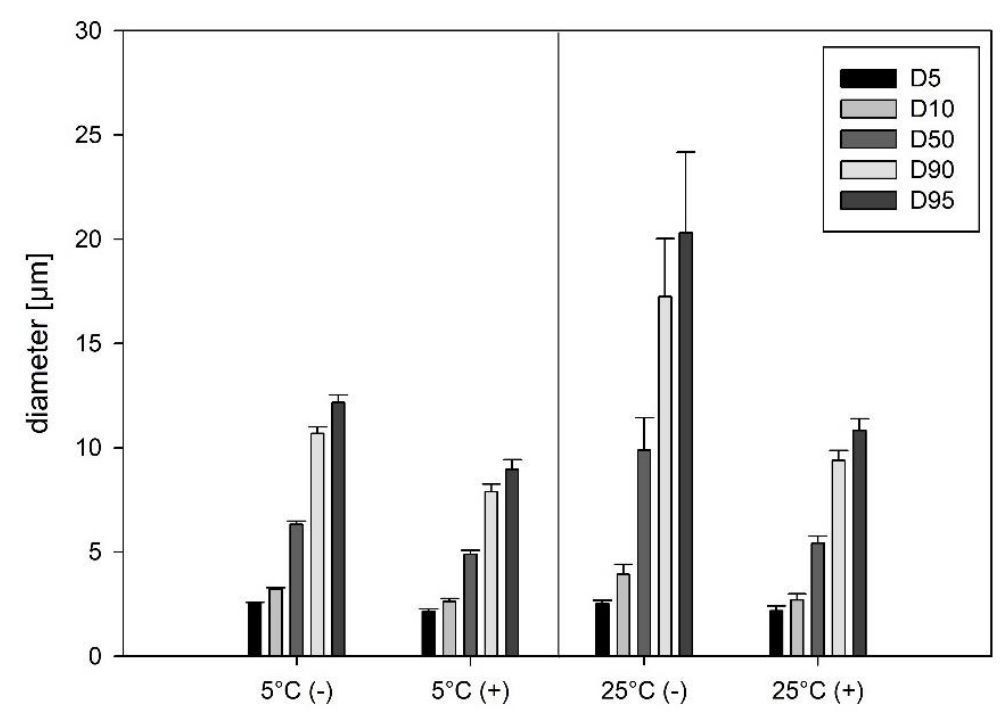

Figure V-26: Particle size of mAb:Suc 50:50 suspensions after 6 months of storage $\left(c_{\mathrm{mAb}}=50 \mathrm{mg} / \mathrm{ml}\right)$, containing not additionally dried $(-)$ or additionally dried powder $(+)$ in $\mathrm{F} 6 \mathrm{H} 8$. 

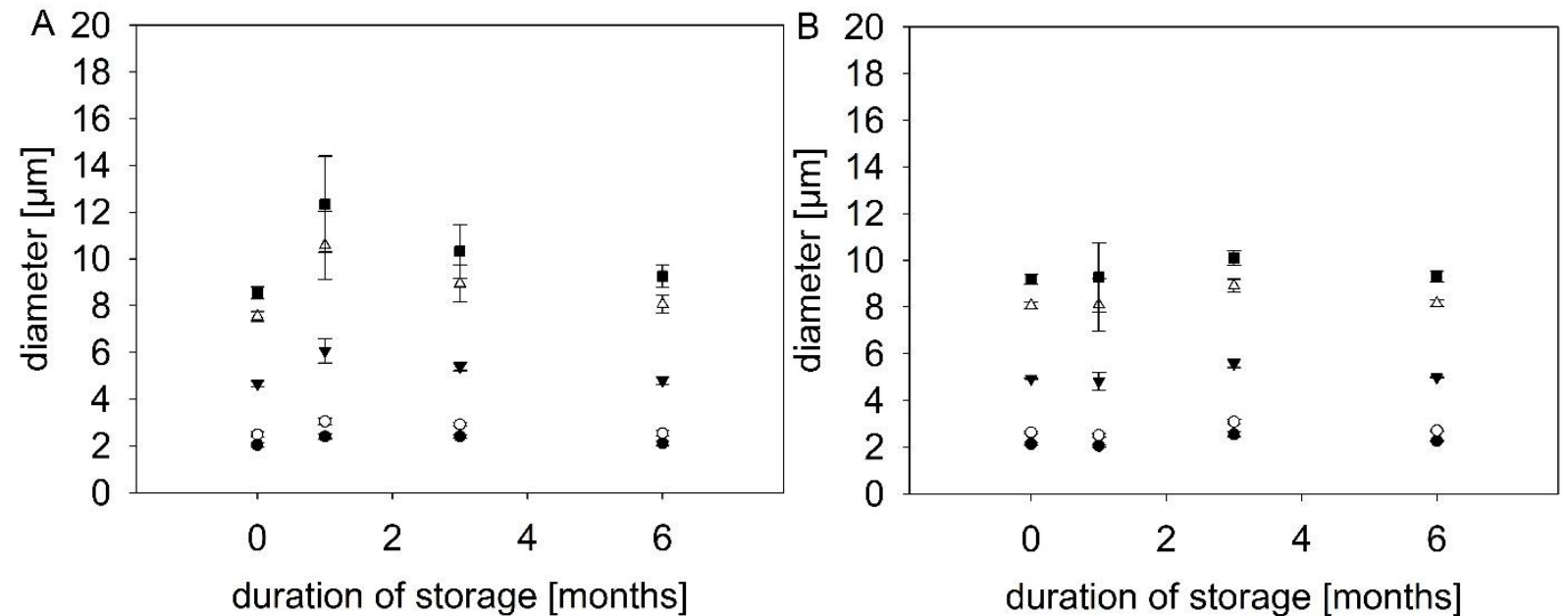

Figure V-27: Particle size of $\mathrm{mAb}: S u c 50: 50$ suspensions after storage at $40^{\circ} \mathrm{C}\left(\mathrm{c}_{\mathrm{mAb}}=50 \mathrm{mg} / \mathrm{ml}\right)$,

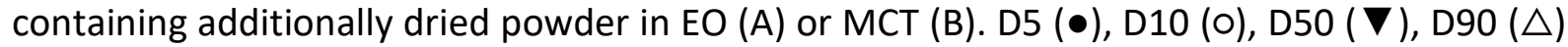

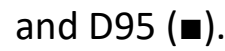
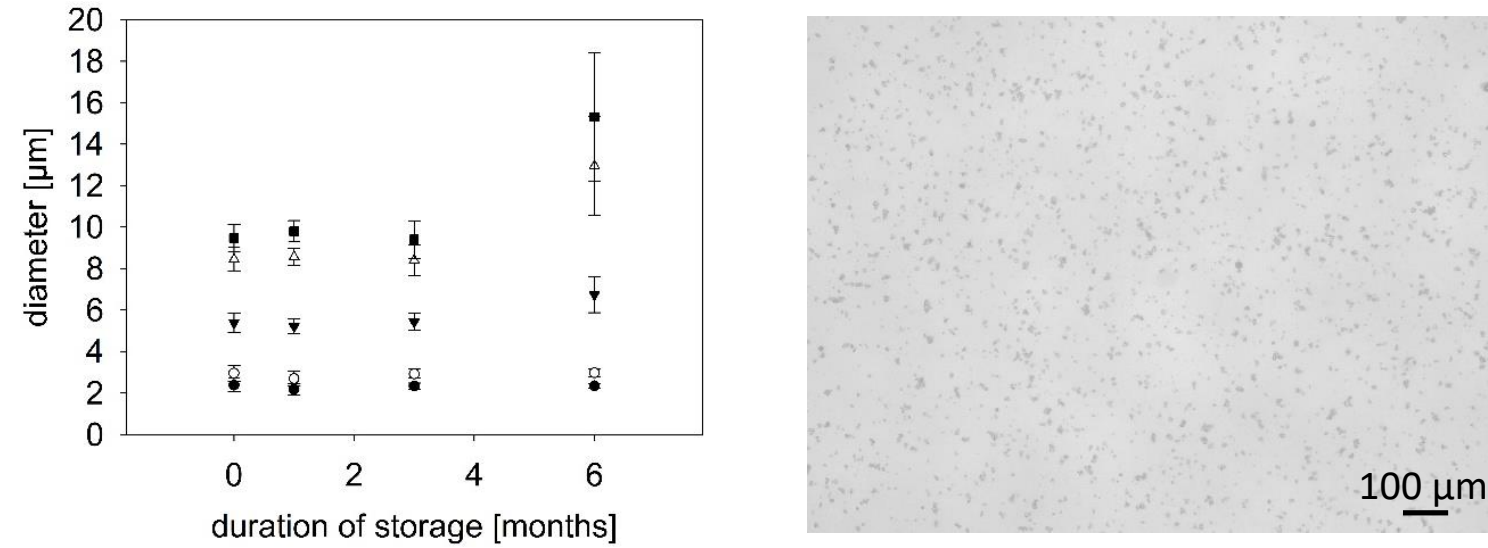

Figure V-28: Particle size and microscopy image of mAb:Tre suspensions $\left(c_{\mathrm{mAb}}=50 \mathrm{mg} / \mathrm{ml}\right)$ containing additionally dried 50:50 powder in $\mathrm{F} 6 \mathrm{H} 8$ after storage in a prefillable COP syringe at $40^{\circ} \mathrm{C}$. D5 $(\bullet), \mathrm{D} 10(0), \mathrm{D} 50(\boldsymbol{\nabla}), \mathrm{D} 90(\triangle)$ and D95 (घ) values. 


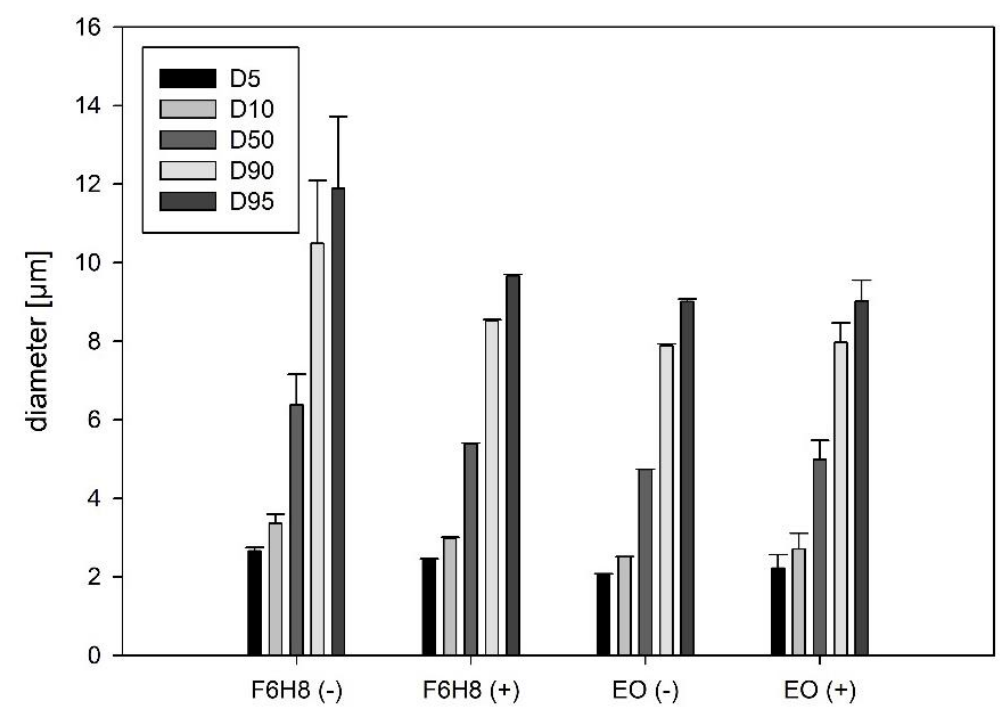

Figure V-29: Powder particle size of Beva:Suc 50:50 suspensions ( $\mathrm{C}_{\text {Beva }}=50 \mathrm{mg} / \mathrm{ml}$ ) after 6 months of storage at $40^{\circ} \mathrm{C}$, containing not additionally dried (-) or additionally dried (+) powder.
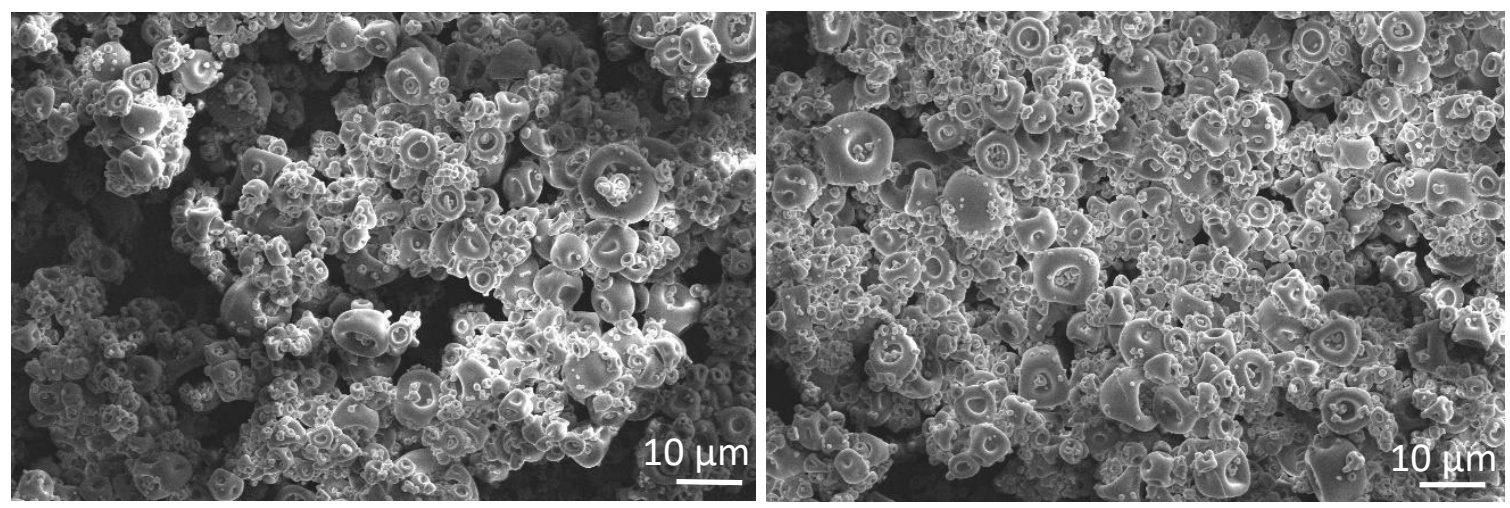

Figure V-30: SEM images of Beva:Suc $50: 50$ suspensions ( $C_{B e v a}=50 \mathrm{mg} / \mathrm{ml}$ ) after 6 months of storage at $40^{\circ} \mathrm{C}$, containing not additionally dried (left) or additionally dried powder (right) in F6H8.

\subsection{Injectability}

Injectability is crucial for the intended parenteral application of the suspension and needle clogging caused by aggregated particles can be a challenge. ${ }^{30}$ As a rule of thumb, particles should not exceed $1 / 8-1 / 3$ of the needle's inner diameter (see Chapter III). ${ }^{12,14}$ In our study $27 \mathrm{G}$ needles were used, with an inner diameter of $210 \mu \mathrm{m}$. For suspensions containing the additionally dried Lys:Tre 70:30 powder at a lysozyme concentration of $70 \mathrm{mg} / \mathrm{ml}$, no needle clogging was observed after one year of storage at $40^{\circ} \mathrm{C}$ in $\mathrm{F} 4 \mathrm{H} 5, \mathrm{~F} 6 \mathrm{H} 8$, EO or MCT (Figure V31). The same was the case for formulations containing Lys:Tre 70:30 powder at a protein 
concentration of $210 \mathrm{mg} / \mathrm{ml}$, PS20 containing powder at a protein concentration of $70 \mathrm{mg} / \mathrm{ml}$, as well as Lys:Tre 50:50 formulations in $\mathrm{F} 6 \mathrm{H} 8$ at a lysozyme concentration of $50 \mathrm{mg} / \mathrm{ml}$ (Figure V-32).
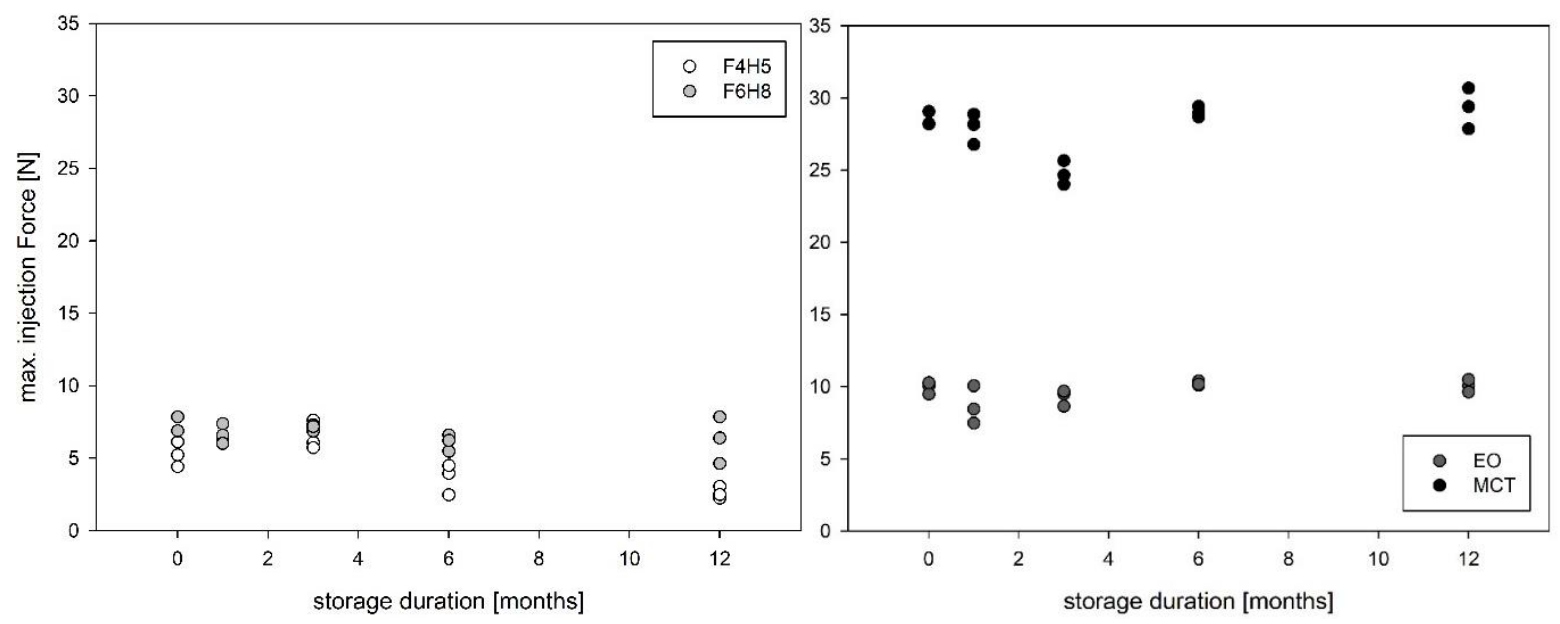

Figure V-31: Maximum gliding force of Lys:Tre 70:30 suspensions after storage at $40^{\circ} \mathrm{C}$ $\left(c_{\text {Lys }}=70 \mathrm{mg} / \mathrm{ml}\right)$.
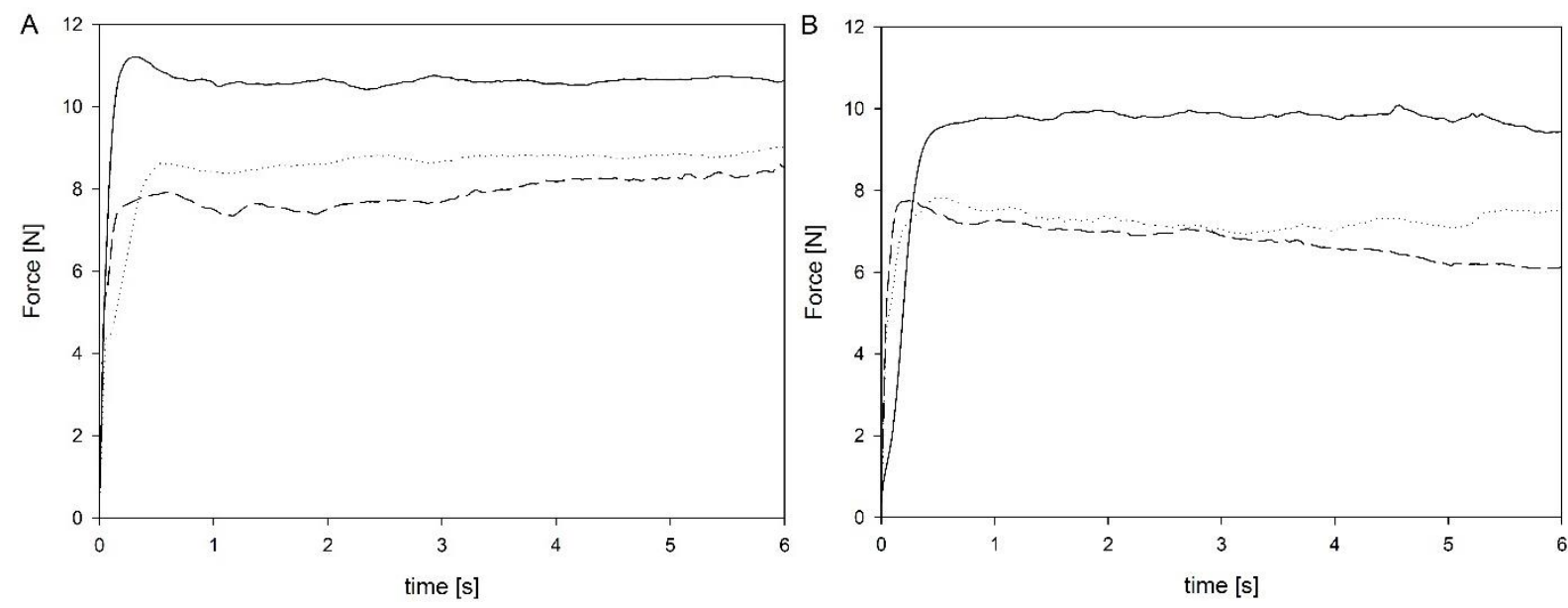

Figure V-32: Exemplary glide force profiles of protein powder suspensions at to $(A)$ and after 12 months storage at $40^{\circ} \mathrm{C}$ (B). Lys:Tre $70: 30$ at protein concentration of $210 \mathrm{gm} / \mathrm{ml}(-)$, Lys:Tre 70:30 + 0.1\% PS20 at a protein concentration of $70 \mathrm{mg} / \mathrm{ml} \mathrm{(-} \mathrm{-} \mathrm{-)} \mathrm{and} \mathrm{Lys:Tre} \mathrm{50:50} \mathrm{at} \mathrm{a}$ protein concentration of $50 \mathrm{mg} / \mathrm{ml}(\cdots)$ in $\mathrm{F} 6 \mathrm{H} 8$.

Additionally dried and not additionally dried powder suspensions in $\mathrm{F} 4 \mathrm{H} 5$ and $\mathrm{F} 6 \mathrm{H} 8$ containing the $\mathrm{mAb}$ were still injectable after 6 months of storage at $40^{\circ} \mathrm{C}$. The crystallization of sucrose in not additionally dried formulations had no impact on injectability of formulations in $\mathrm{F} 4 \mathrm{H} 5$ 
and F6H8. No needle clogging was observed (Figure V-33). Suspensions of additionally dried $\mathrm{mAb}: S u c 50: 50$ powder in EO and MCT were easy injectable after 6 months of storage at $40^{\circ} \mathrm{C}$ (Figure V-34). A suspension containing mAb:Tre 50:50 powder at a protein concentration of $50 \mathrm{mg} / \mathrm{ml}$ in $\mathrm{F} 6 \mathrm{H} 8$ stored in a prefillable COP syringe at $40^{\circ} \mathrm{C}$ was still injectable after 6 months of storage at $40^{\circ} \mathrm{C}$ (Figure $\mathrm{V}-35$ ). No change in the maximum force or glide force during injection was observed. Monitoring the weight of the suspensions stored in the PFS showed a slight weight loss indicating evaporation of the suspension vehicle (F6H8 $-5.2 \pm 0.5 \%$ after 6 months of storage at $40^{\circ} \mathrm{C}$ ). A potential explanation for this finding is the manual filling of the PFS which was accompanied with removal and reattachment of the needle cap leading to potential loss of container closure integrity. Bevacizumab containing formulations in $\mathrm{F} 6 \mathrm{H} 8$ were injectable after 6 months of storage at $40^{\circ} \mathrm{C}$ in $\mathrm{F} 6 \mathrm{H} 8$ and $\mathrm{EO}$ (Figure V-36). In summary, injectability through $27 \mathrm{G}$ needles after long term storage was not a critical feature for the investigated protein powder suspensions. Glide forces for injection of EO and MCT suspensions were higher compared to suspensions in $\mathrm{F} 4 \mathrm{H} 5$ and $\mathrm{F} 6 \mathrm{H} 8$. This can be explained by the higher intrinsic viscosities of these vehicles (Chapter IV). ${ }^{17}$
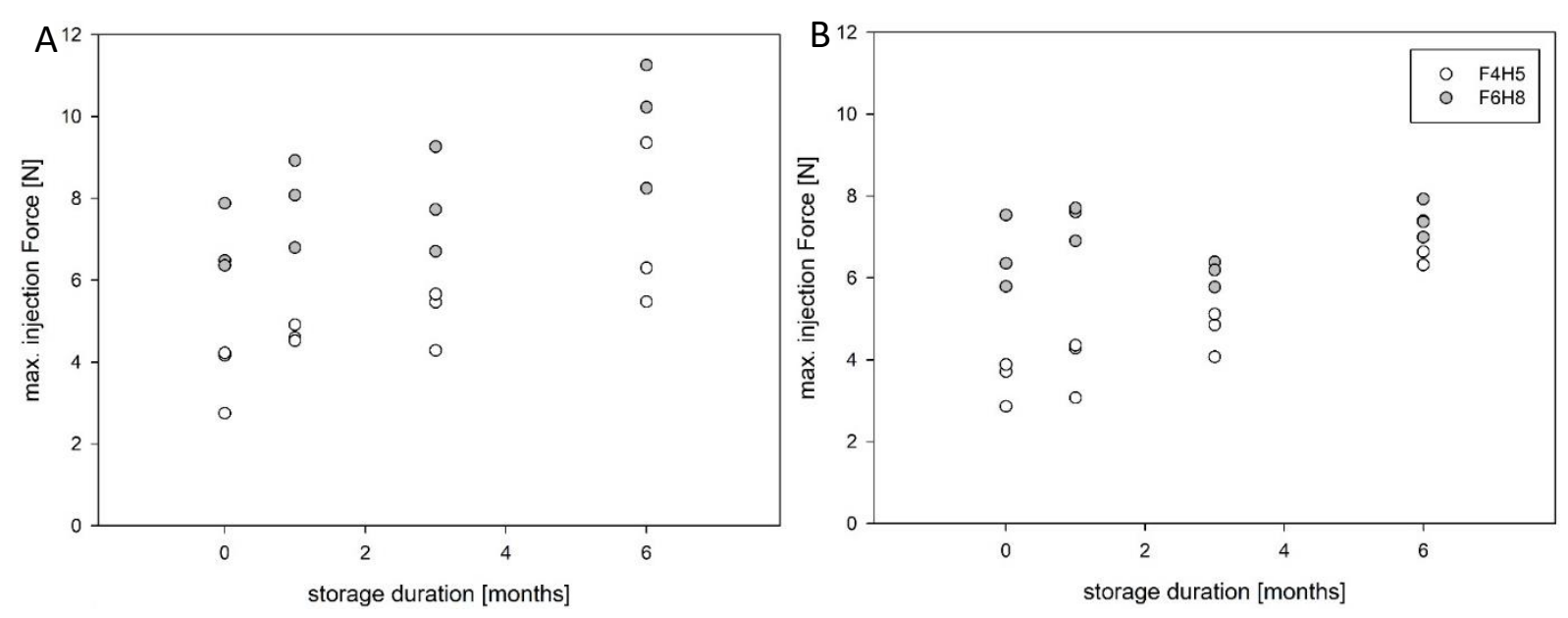

Figure V-33: Injectability of not additionally dried (A) or additionally dried (B) mAb:Suc $50: 50$ suspensions $\left(\mathrm{C}_{\mathrm{mAb}}=50 \mathrm{mg} / \mathrm{ml}\right)$ after storage at $40^{\circ} \mathrm{C}$. 

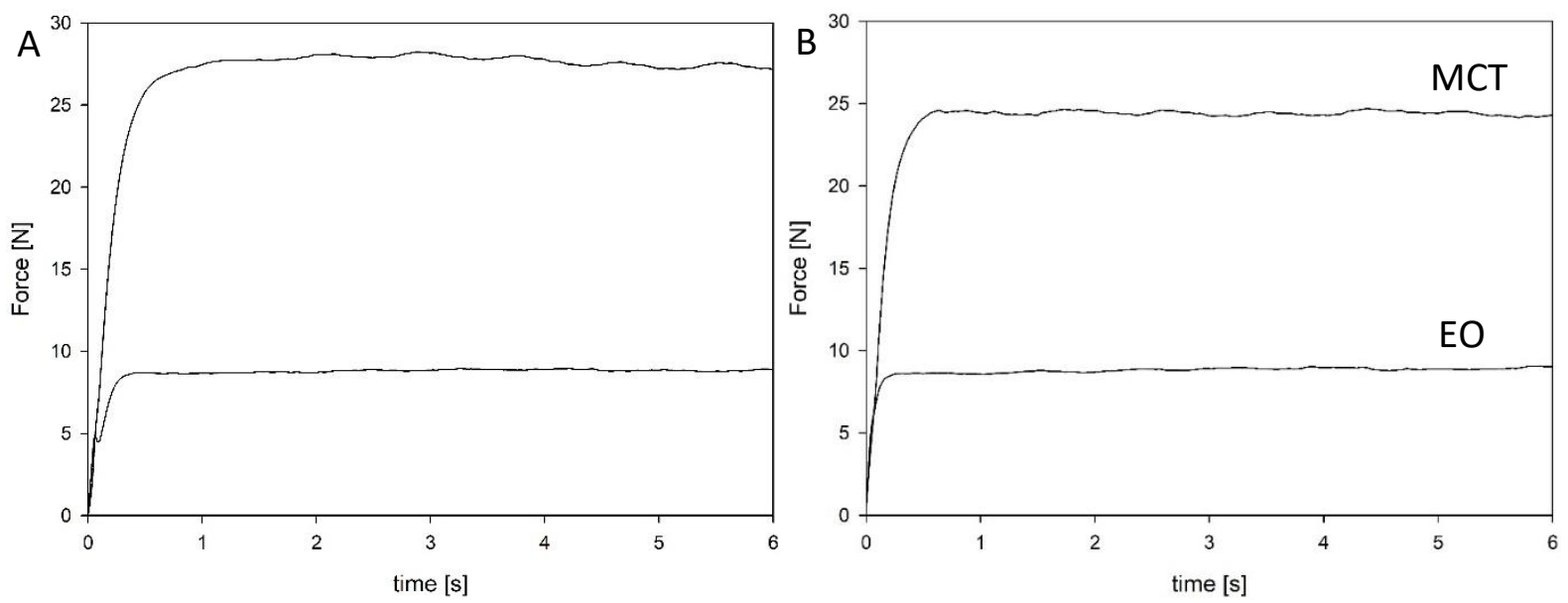

Figure V-34: Injection profiles of additionally dried mAb:Suc 50:50 suspensions $\left(c_{m A b}=50 \mathrm{mg} / \mathrm{ml}\right)$ at t0 $(A)$ and after storage at $40^{\circ} \mathrm{C}$ for 6 months $(B)$.

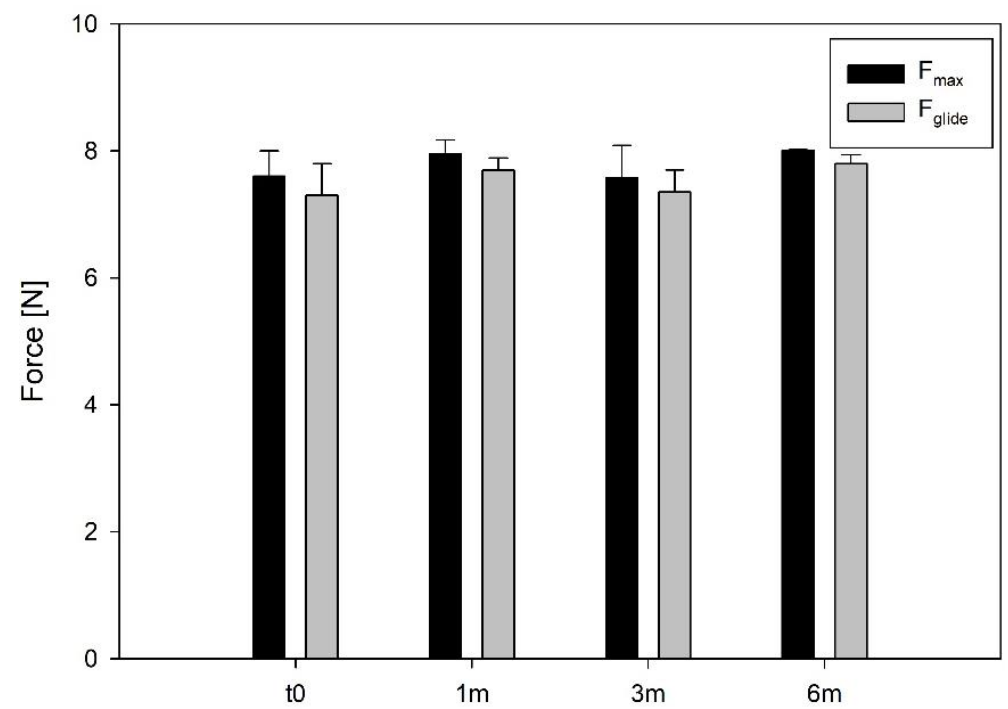

Figure V-35: Maximum injection force and glide force of mAb:Tre 50:50 suspensions at a protein concentration of $50 \mathrm{mg} / \mathrm{ml}$ after storage at $40^{\circ} \mathrm{C}$ in a PFS. 


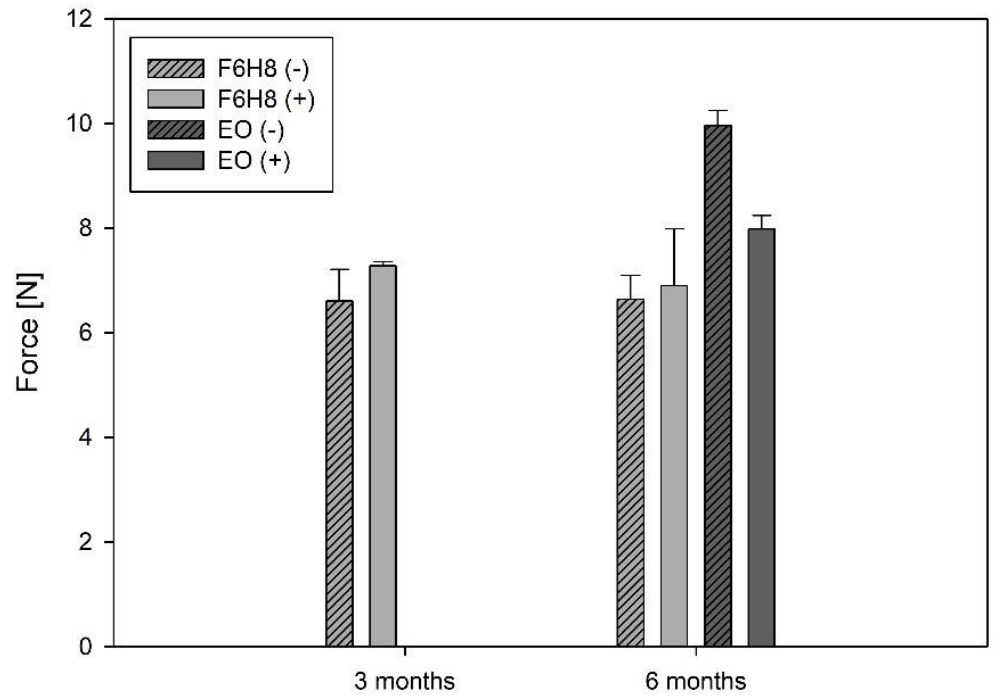

Figure V-36: Maximum injection force of Beva:Suc 50:50 suspensions at a protein concentration of $50 \mathrm{mg} / \mathrm{ml}$ after storage at $40^{\circ} \mathrm{C}$. 


\section{Conclusion}

This study successfully demonstrated the high potential of protein powder suspensions in nonaqueous vehicles for subcutaneous or intramuscular protein delivery. Previous studies mainly focussed on protein stability. ${ }^{8-10}$ Findings by Miller et al. demonstrated the potential of protein powder suspensions to be redispersible after 12 months of storage. ${ }^{11}$ We hereby show that the suspension physical stability also in terms of resuspendability, powder particle size and injectability can be preserved during long-term storage at elevated temperatures.

Residual moisture seems to be a key factor for initial dispersibility of protein powder suspensions. This can be explained by stronger cohesive particle-particle interaction as a consequence of capillary bridges as well as less interaction between the hydrophilic particles and the hydrophobic vehicles. ${ }^{36}$ By the use of an additional drying step, the residual moisture content in the spray-dried powder could be decreased significantly from about $4-5 \%$ to below $0.5 \%$, leading to a much more effective initial dispersing step.

Physical stability of formulations containing lysozyme was maintained up to 12 months of storage at $40^{\circ} \mathrm{C}$ in a variety of different suspension vehicles (F4H5, F6H8, EO and MCT). Suspensions were resuspendable and injectable through a $27 \mathrm{G}$ needle. No change in powder particle size was detectable. As the importance of high concentration formulations of biopharmaceuticals is constantly growing, we further tested a highly concentrated Lys:Tre $70: 30$ formulation $\left(210 \mathrm{mg} / \mathrm{ml}\right.$ protein) for suspension physical stability. ${ }^{39,40}$ Additionally we investigated the effect of polysorbate 20. Surfactants such as polysorbates have the ability to protect the protein from interface stresses during spray-drying. ${ }^{41}$ Both formulations were stable for up to a year of storage at $40^{\circ} \mathrm{C}$.

Furthermore, mAb suspensions at a protein concentration of $50 \mathrm{mg} / \mathrm{ml}$ formulated with sucrose or trehalose as a stabilizer at a protein:stabilizer ratio of 50:50, were tested. Residual moisture in mAb:Suc 50:50 suspensions in $\mathrm{F} 4 \mathrm{H} 5$ and $\mathrm{F} 6 \mathrm{H} 8$ had a high impact on particle size stability. Not additionally dried suspensions showed recrystallization of sucrose leading to an increase in the particle size. An increase in the particle size has to be prevented, as it can cause clogging of the thin needle. As crystalline sucrose is not able to function as a stabilizer of the protein in the dried state, this also has a potential negative impact on protein stability during storage. Additionally dried mAb:Suc 50:50 suspensions in F4H5, F6H8, EO and MCT did not show an increase in particle size and were easily injectable after 6 months of storage at $40^{\circ} \mathrm{C}$. 
$\mathrm{EO}$ and $\mathrm{MCT}$ formulations required high frequencies of more than $10 \mathrm{~Hz}$ to get resuspended after storage $(>10 \mathrm{~Hz})$. An average person uses a frequency of approximately $5 \mathrm{~Hz}$ for resuspending preparations. ${ }^{35}$ Potential methods to counteract the difficult resuspendability would be the use of resuspendability enhancing excipients or adding beads. ${ }^{13,30,42}$ Suspensions in $\mathrm{F} 4 \mathrm{H} 5$ and $\mathrm{F} 6 \mathrm{H} 8$ containing mAb:Suc 50:50 powder at a protein concentration of $50 \mathrm{mg} / \mathrm{ml}$ which was additionally vacuum dried were easy resuspendable at $5 \mathrm{~Hz}$. In contrast suspensions containing not additionally dried mAb:Suc 50:50 powder in $\mathrm{F} 4 \mathrm{H} 5$ or $\mathrm{F} 6 \mathrm{H} 8$ were not manually resuspendable after 1 month of storage at $40^{\circ} \mathrm{C}$. The mAb:Tre 50:50 suspension at a protein concentration of $50 \mathrm{mg} / \mathrm{ml}$ was stable at $40^{\circ} \mathrm{C}$ for 6 months in $\mathrm{F} 6 \mathrm{H} 8$. Suspensions of bevacizumab stabilized by sucrose in $\mathrm{F} 6 \mathrm{H} 8$ and $\mathrm{EO}$ were resuspendable and injectable and did not show an increase in the powder particle size after 6 months of storage at $40^{\circ} \mathrm{C}$. Future work will focus on protein stability in the described formulations (see Chapter VI). Overall the study showed the high potential of protein powder suspensions. Optimized suspensions were physically stable with respect to resuspendability, particle size as well as injectability through hypodermic needles. 


\section{Literature}

1. Grilo, A. L. \& Mantalaris, A. The Increasingly Human and Profitable Monoclonal Antibody Market. Trends Biotechnol. 1-7 (2018).

2. Rémuzat, C. et al. Key drivers for market penetration of biosimilars in Europe. J. Mark. Access Heal. Policy 5, 1272308 (2017).

3. Gervasi, V. et al. Parenteral protein formulations: An overview of approved products within the European Union. Eur. J. Pharm. Biopharm. 131, 8-24 (2018).

4. Arakawa, T., Prestrelski, S. J., Kenney, W. C. \& Carpenter, J. F. Factors affecting shortterm and long-term stabilities of proteins. Adv. Drug Deliv. Rev. 46, 307-326 (2001).

5. Manning, M. C., Patel, K. \& Borchardt, R. T. Stability of Protein Pharmaceuticals. Pharm. Res. 6, 903-918 (1989).

6. Chang, L. L. \& Pikal, M. J. Mechanisms of protein stabilization in the solid state. J. Pharm. Sci. 98, 2886-2908 (2009).

7. Knepp, V. M., Muchnik, A., Oldmark, S. \& Kalashnikova, L. Stability of nonaqueous suspension formulations of plasma derived factor IX and recombinant human alpha interferon at elevated temperatures. Pharm. Res. 15, 1090-1095 (1998).

8. Weiguo Dai, Beth Hill, Kui Liu, C. M. US 20120076800 - Non-aqueous high concentration reduced viscosity suspension formulations of antibodies. (2012).

9. Guenther, B. et al. EP2806886B1 - Stabilised protein compositions based on semifluorinated alkanes. (2013).

10. Rutz, A. Oily suspensions as parenteral depot systems of recombinant proteins. (LMU Munich, 2007).

11. Miller, M. A., Engstrom, J. D., Ludher, B. S. \& Johnston, K. P. Low viscosity highly concentrated injectable nonaqueous suspensions of lysozyme microparticles. Langmuir 26, 1067-1074 (2011).

12. Patel, R. Parenteral suspension: an overview. Int. J. Curr. Pharm. Res. 2, 4-13 (2010).

13. Yordanova, Y. Oil-Based Parenteral Depot Formulation for Veterinary Peptide Delivery. (LMU Munich, 2018).

14. Floyd, A. G. Injectable Emulsions and Suspensions, in Pharmaceutical Dosage Forms: Disperse Systems. (Taylor \& Francis Inc, 1996).

15. Shoyele, S. A. \& Cawthorne, S. Particle engineering techniques for inhaled biopharmaceuticals. Adv. Drug Deliv. Rev. 58, 1009-1029 (2006).

16. Etzl, E. E., Winter, G. \& Engert, J. Toward intradermal vaccination: preparation of powder formulations by collapse freeze-drying. Pharm. Dev. Technol. 19, 213-222 (2014).

17. Bowen, M., Armstrong, N. \& Maa, Y.-F. Investigating High-Concentration Monoclonal Antibody Powder Suspension in Nonaqueous Suspension Vehicles for Subcutaneous Injection. J. Pharm. Sci. 101, 4433-4443 (2012). 
18. Schüle, S., Schulz-Fademrecht, T., Garidel, P., Bechtold-Peters, K. \& Frieß, W. Stabilization of IgG1 in spray-dried powders for inhalation. Eur. J. Pharm. Biopharm. 69, 793-807 (2008).

19. Gikanga, B. et al. Manufacturing of High-Concentration Monoclonal Antibody Formulations via Spray Drying--the Road to Manufacturing Scale. PDA J. Pharm. Sci. Technol. 69, 59-73 (2015).

20. Zhou, P., Liu, D., Chen, X., Chen, Y. \& Labuza, T. P. Stability of whey protein hydrolysate powders: Effects of relative humidity and temperature. Food Chem. 150, 457-462 (2014).

21. Ahlneck, C. \& Zografi, G. The molecular basis of moisture effects on the physical and chemical stability of drugs in the solid state. Int. J. Pharm. 62, 87-95 (1990).

22. Carstensen, J. T. \& Van Scoik, C. Amorphous-to-Crystalline Transformation of Sucrose. Pharm. Res. 7, 1278-1281 (1990).

23. Hageman, M. J. The role of moisture in protein stability. Drug Dev. Ind. Pharm. 14, 2047-2070 (1988).

24. Heljo, V. P. et al. The effect of water plasticization on the molecular mobility and crystallization tendency of amorphous disaccharides. Pharm. Res. 29, 2684-2697 (2012).

25. Lai, M. C. \& Topp, E. M. Solid-state chemical stability of proteins and peptides. J. Pharm. Sci. 88, 489-500 (1999).

26. Liu, W. R., Langer, R. \& Klibanov, A. M. Moisture-induced aggregation of lyophilized proteins in the solid state. Biotechnol. Bioeng. 37, 177-184 (1991).

27. Schuele, S. Stabilization of Antibodies in Spray-dried Powders for Inhalation. (LMU Munich, 2005).

28. Maa, Y. F. et al. Effect of spray drying and subsequent processing conditions on residual moisture content and physical/biochemical stability of protein inhalation powders. Pharm. Res. 15, 768-775 (1998).

29. Srinivasan, C., Weight, A. K., Bussemer, T. \& Klibanov, A. M. Non-aqueous suspensions of antibodies are much less viscous than equally concentrated aqueous solutions. Pharm. Res. 30, 1749-1757 (2013).

30. Birk, G. Formulation development of a highly concentrated suspension of Cilengitide. (LMU Munich, 2015).

31. Batens, M., Massant, J., Teodorescu, B. \& Van den Mooter, G. Formulating monoclonal antibodies as powders for reconstitution at high concentration using spray drying: Models and pitfalls. Eur. J. Pharm. Biopharm. 127, 407-422 (2018).

32. Vehring, R. Pharmaceutical particle engineering via spray drying. Pharm. Res. 25, 9991022 (2008).

33. Mueller, S., Llewellin, E. W. \& Mader, H. M. The rheology of suspensions of solid particles. Proc. R. Soc. A 466, 1201-1228 (2009).

34. Meinert, H. \& Roy, T. Semifluorinated alkanes - A new class of compounds with 
outstanding properties for use in ophthalmology. Eur. J. Ophthalmol. 10, 189-197 (2000).

35. Deicke, A. \& Süverkrüp, R. Dose uniformity and redispersibility of pharmaceutical suspensions. I: Quantification and mechanical modelling of human shaking behaviour. Eur. J. Pharm. Biopharm. 48, 225-232 (1999).

36. Hoffmann, S., Koos, E. \& Willenbacher, N. Using capillary bridges to tune stability and flow behavior of food suspensions. Food Hydrocoll. 40, 44-52 (2014).

37. Buckwalter, F. H. \& Dickison, H. L. The Effect of Vehicle and Particle Size on the Absorption, by the Intrasmuscular Route, of Procaine Penicillin G Suspensions. J. Am. Pharm. Assoc. 47, 661-666 (1958).

38. Noyes, A. A. \& Whitney, W. R. The rate of solution of solid substances in their own solutions. J. Am. Chem. Soc. 19, 930-934 (1897).

39. Shire, S. J., Shahrokh, Z. \& Liu, J. Challenges in the Development of High Protein Concentration Formulations. J. Pharm. Sci. 93, 1390-1402 (2004).

40. Mathaes, R., Koulov, A., Joerg, S. \& Mahler, H. C. Subcutaneous Injection Volume of Biopharmaceuticals - Pushing the Boundaries. J. Pharm. Sci. 105, 2255-2259 (2016).

41. Adler, M. \& Lee, G. Stability and surface activity of lactate dehydrogenase in spray-dried trehalose. J. Pharm. Sci. 88, 199-208 (1999).

42. Grau, U. \& Pohler, W. EP19870102367 - Device for dispensing medicinal suspensions. (1987). 


\section{Chapter VI}

\section{Long-term stability of protein powder suspensions in non-aqueous vehicles part II - monoclonal antibody stability}

\section{Abstract}

Monoclonal antibodies (mAbs) are important substances in today's portfolio for the treatment of several diseases including autoimmune diseases and cancer. MAbs have inherent stability problems in aqueous environment caused by chemical alteration and aggregation. As a consequence, mAbs are often formulated as a freeze-dried product to assure protein stability over the shelf-life due to reduced degradation kinetics in the dried state. The freeze-dried cakes have to be reconstituted before application. Protein powder suspensions in nonaqueous vehicles represent a promising alternative. Here the product is ready-to-use like an aqueous solution and the solid state assures high protein stability. We studied the stability of two different monoclonal antibodies, including bevacizumab, dispersed as spray-dried powders in different suspension vehicles by size exclusion chromatography, protein $A$ chromatography, light obscuration, FTIR, CD and ELISA. Integrity of the biopharmaceuticals was preserved at elevated temperatures for up to 12 months and was superior to the respective aqueous formulation. An important feature for the monoclonal antibody stability was the type of suspension vehicle. High stabilities were obtained for suspensions in semifluorinated alkanes, as well as medium chain triglycerides. In contrast suspensions in ethyl oleate showed increased damage to the protein which was attributed to the unsaturated fatty acid content. The increased protein stability of protein powder suspensions in nonaqueous vehicles showed in this study, combined with the ready to use approach, shows the high potential of this formulation approach. 


\section{Introduction}

During the last decades the relevance of protein drugs strongly emerged and many new biopharmaceuticals are coming to the market. ${ }^{1,2}$ Monoclonal antibodies (mAb) play an important role representing approximately one third of the marketed protein drugs. ${ }^{1}$ MAb products are either formulated as aqueous solution or lyophilizate. ${ }^{1,3}$ If sufficient protein stability cannot be achieved in solution removal of water by freeze-drying is typically used..$^{4-7}$ To stabilize the protein drug during drying and storage, carbohydrates such as sucrose or trehalose are added as cryo- and lyoprotectants. ${ }^{3,6}$ After drying the protein is embedded in an amorphous stabilizer matrix, minimizing aggregation and chemical degradation kinetics. ${ }^{3} \mathrm{~A}$ disadvantage of lyophilizates is the necessity of an additional reconstitution step making the application more time consuming and complex. This may be overcome by dual chamber systems. ${ }^{8,9}$ MAb powder suspensions in non-aqueous vehicles represent another promising innovative option combining the ready-to-use liquid formulation approach with the high stability of the protein in the solid state. Such formulations might be provided in a prefillable syringe enabling easy administration.

The protein powder to be used in such suspensions can be prepared in different ways. The two main techniques are lyophilization with an additional milling step ${ }^{10,11}$ and spraydrying $^{12-14}$. Alternatives include supercritical fluid drying ${ }^{15-17}$ and precipitation techniques ${ }^{18,19}$. In this study mAb powders were prepared by spray-drying. Spray-drying enables direct creation of individual spherical particles, which is of advantage over the shed like morphology of milled freeze-dried particles which might lead to entanglement resulting in needle clogging especially at high concentrations (Chapter IV).

For the protein powder suspensions both mAb stability as well as physical suspension stability over the shelf-life are of importance. In the previous chapter we showed, that the physical suspension stability of protein powder suspensions, such as resuspendability, consistancy of powder particle size and injectability can be maintained during storage.

The focus of this study lies on the protein stability in the suspensions. Previous work showed, that the protein stability in protein powder suspensions can be maintained during storage at elevated temperatures and is comparable to freeze-dried formulations. Knepp et al. reported, that suspended lyophilizates of $\alpha$-interferon and factor IX in perfluorodecalin (PFD) showed high protein stability at elevated temperatures for up to a year. ${ }^{20}$ When the protein powders were stored in soybean oil lower stability was observed. This was attributed to reactive species 
like peroxides and aldehydes as well as a higher water content in the vehicle. ${ }^{20}$ Additionally high stability of several peptides and small proteins such as lysozyme, calcitonine, insulin and human growth hormone in non-aqueous protein powder suspension has been reported. ${ }^{21-23}$ Also mAb stability has been investigated previously. Antibody activity, monomer content and secondary structure of spray-dried golilumab in mixtures of ethyl oleate (EO) and sesame oil (SO) were preserved after six months of storage at $40^{\circ} \mathrm{C}$ and the stability was superior compared to an aqueous reference solution. ${ }^{24} \mathrm{~A}$ potential disadvantage of SO as suspension vehicle, is its significant viscosity, which can result in high formulation viscosities at increased protein concentrations leading to inacceptable injection forces (Chapter IV). ${ }^{14}$

Semifluorinated alkanes (SFA) are an interesting class of vehicles due to their low viscosity, pronounced inertness and biocompatibility. ${ }^{21,25,26}$ In Chapter $V$, it was shown, that suspensions in SFAs show much better resuspendability characteristics compared to traditional oily vehicles such as EO and medium chain triglycerides (MCT). Another study reported the high stability of a freeze-dried antibody in SFAs, with activity levels preserved after 1 year of storage at $40^{\circ} \mathrm{C} .{ }^{27}$

Spray-dried powders commonly show a high residual moisture content of about 3 to $5 \% .{ }^{13,14}$ The remaining water acts as a plasticizer, decreasing the formulations glass transition temperature, increasing the molecular mobility and potentially leading to enhanced protein instability. ${ }^{28-32}$ Additionally, higher water content promotes chemical instabilities. ${ }^{33,34}$ Higher moisture levels can also enhance particle agglomeration and lead to a loss of resuspendability (Chapter V). To counteract this phenomenon we applied an additional drying step decreasing the water content in the powder below $1 \%$ (Chapter V). ${ }^{34}$

In this study we wanted to generate insight into the parameters which influence the long-term stability of proteins in non-aqueous suspensions and how optimum protein stability can be obtained. For this purpose, the effect of formulation parameters and suspension vehicle on the stability of two different mAbs, including bevacizumab, was investigated. Important biopharmaceutical quality attributes such as aggregation, subvisible particles, structural integrity and activity were analyzed. Suspension vehicles included EO, MCT, F4H5 and F6H8. The impact of the two most widely spread stabilizers in protein formulation sucrose and trehalose was studied. We also investigated the role of the protein to stabilizer ratio, the influence of the residual moisture content as well as the type of packaging material on protein stability. 


\section{Materials and Methods}

\subsection{Materials}

A monoclonal IgG1 antibody produced in $\mathrm{CHO}$ cells (mAb) in $25 \mathrm{mM}$ histidine, $1.6 \mathrm{mM}$ glycine buffer $\mathrm{pH} 6.0$ at $57 \mathrm{mg} / \mathrm{ml}$ was used $\left(\varepsilon 280 \mathrm{~nm}=1.49 \mathrm{ml} \mathrm{g}^{-1} \mathrm{~cm}^{-1}\right)$. Bevacizumab (Beva) was obtained from LGM Pharma (Nashville, United States). Formulations were prepared in highly purified water (HPW) prepared with an ELGA Purelab system (ELGA LabWater, Celle, Germany) using trehalose dihydrate (Tre) (Hayashibara, Okayama, Japan), sucrose (Suc), L-histidine, Lhistidine-monohydrochloride monohydrate (Sigma-Aldrich, St. Louis, USA), monosodium phosphate dihydrate (Grüssing, Filsum, Germany), disodium phosphate dihydrate (Bernd Kraft GmbH, Duisburg, Germany) and Polysorbate 20 (PS20) (Merck, Darmstadt, Germany). Perfluorobutylpentane (F4H5) and perfluorohexyloctane (F6H8) were provided by Novaliq (Heidelberg, Germany). Further, medium chain triglycerides (MCT) (Miglyol ${ }^{\circledR} 812$ by Caesar \& Loretz, Hilden, Germany) and ethyl oleate (EO) (Sigma-Aldrich, St. Louis, USA) were used as suspension vehicles. F6H8 used for suspension preparation of formulation 2 was additionally degassed with nitrogen for $20 \mathrm{~min}$. Protein extraction was performed by washing the suspensions with isooctane (Merck, Darmstadt, Germany). Running buffer for high pressure size exclusion chromatography (HP-SEC) of the mAb contained HPW, sodium sulfate (Grüssing $\mathrm{GmbH}$, Filsum, Germany), monosodium phosphate dihydrate (Grüssing GmbH, Filsum, Germany) and disodium phosphate dihydrate (Bernd Kraft GmbH, Duisburg, Germany). Running buffer HP-SEC of Beva contained HPW and VWR phosphate buffer saline tablets (VWR, Radnor, USA).

\subsection{UV-Vis}

Protein concentrations were measured with a NanoDrop 2000 spectrophotometer (Thermo Scientific, Waltham, USA) at $280 \mathrm{~nm}$.

\subsection{Formulations for spray-drying and aqueous formulations}

MAb feed solutions for spray-drying with a total solid content of $7.5 \%(\mathrm{~m} / \mathrm{V})$ contained trehalose or sucrose at different protein to stabilizer mass ratios. MAb solutions were prepared in $10 \mathrm{mM}$ histidine buffer at $\mathrm{pH}$ 6.0. Beva formulations were formulated as the marketed product Avastin ${ }^{\circledR}$ at a concentration of $25 \mathrm{mg} / \mathrm{ml}$ in $51 \mathrm{mM}$ sodium phosphate 
buffer $\mathrm{pH}$ 6.2, $60 \mathrm{mg} / \mathrm{ml}$ trehalose dihydrate and 0.04\% PS20. The aqueous solution was also used as feed solution for spray-drying. Buffer exchange was performed using either Spectra/Por regenerated cellulose dialysis tubes with a molecular weight cut off (MWCO) of 6-8 kDa (Spectrum Laboratories, Los Angeles, USA) (mAb) or using 12-30 ml Slide-A-Lyzer dialysis cassettes with a MWCO of 20 kDa (Thermo Scientific, Waltham, USA) (Beva). Before spray-drying, the solutions were filtered using a VWR $0.2 \mu \mathrm{m}$ polyethersulfone syringe filter (VWR, Radnor, USA). Formulations are described in Table VI-1.

\subsection{Spray-drying}

Spray-drying was conducted using a Büchi B290 (Büchi, Flawil, Switzerland) equipped with a high-efficiency cyclone and a two fluid nozzle $(0.7 \mathrm{~mm}$ orifice) at a drying air-flow rate of $600 \mathrm{ml} / \mathrm{min}$, an atomizing air flow rate of $670 \mathrm{ml} / \mathrm{min}$, a feed flow rate of $3 \mathrm{ml} / \mathrm{min}$ and an inlet/outlet temperature of $125 / 65^{\circ} \mathrm{C}$ (formulation $3-5$ ) or $130 / 70^{\circ} \mathrm{C}$ (formulation 1 and 2) (see Table VI-1). Process yields were above $80 \%$.

\subsection{Additional drying of spray-dried powder}

Spray-dried powders (SDP) were transferred into 10R type 1 glass vials (MGlas, Muennerstadt, Germany) and a lyophilization stopper was attached (Helvoet Pharma, Tilburg, Netherlands). Samples were then dried using a Christ 2-6D (Martin Christ Gefriertrocknungsanlagen, Osterode, Germany) at $32^{\circ} \mathrm{C}, 0.1 \mathrm{mBar}$ for $24 \mathrm{~h}$ and fully stoppered in the freeze-drier under nitrogen gas atmosphere at 800 mbar according to Schuele et al. ${ }^{34}$

\subsection{Powder handling}

Powder handling was conducted under nitrogen environment in a custom-made glove box to prevent water uptake.

\subsection{Karl-Fischer}

The amount of residual water was analyzed using a Karl-Fischer-Titrator Aqua 40.00 (Analytik Jena, Jena, Germany) equipped with a head space module at a chamber temperature of $100^{\circ} \mathrm{C}$. 


\subsection{Powder true density}

Powder true density was analyzed using an AccuPyc 1330 helium pycnometer (Micrometrics, Aachen, Germany). In total 10 cleaning cycles were conducted prior to analysis. About $200-$ $300 \mathrm{mg}$ of the powder was filled into the sample container. Powder true density results are based on the average of 6 measurements.

\subsection{Suspension preparation}

Suspensions were prepared by addition of the non-aqueous vehicle to the spray-dried powder. The amount of suspension vehicle was calculated based on the true densities of the powders. Suspensions were then homogenized using an Ultrasonic cleaner USC 1200TH (VWR, Radnor, USA) for 20 min cooled with ice with additional shaking by hand after 5, 10 and $15 \mathrm{~min}$.

\subsection{Stability studies}

MAb suspensions and aqueous solutions were stored in 2R type 1 glass vials (Schott, Mainz, Germany). Aqueous solutions were sterile filtered using VWR $0.2 \mu \mathrm{m}$ polyethersulfone syringe filters (VWR, Radnor, USA) and aseptically filled in the vials under laminar air flow conditions. Formulation 2 was additionally stored in 27G Terumo Plajex prefillable cyclic olefin polymer (COP) syringes (PFS) (Terumo, Tokyo, Japan). Vials were closed using Teflon coated injection stoppers and capped (Westpharma, Exton, USA). The prefillable syringes were filled from behind and the plunger was set manually. The needle tip was then removed and the plunger was pushed to remove remaining air. Stability studies were conducted at $5-8^{\circ} \mathrm{C}, 25^{\circ} \mathrm{C}$ and $40^{\circ} \mathrm{C}$.

\subsection{Protein extraction}

Protein extraction for formulations 1,3 and 4 was conducted by washing with filtered (0.22 $\mu \mathrm{m}$ PFTE syringe filter, VWR, Radnor, USA) isooctane. The suspensions were transferred into $15 \mathrm{ml}$ centrifugation tubes (VWR, Radnor, USA) and isooctane was added up to $14 \mathrm{ml}$. The diluted suspension was then homogenized with a laboratory vortexer, subsequently centrifuged at $1500 \mathrm{rpm}$ for $3 \mathrm{~min}$ and the supernatant was discarded. This step was repeated 5 times. The obtained sediment was dried in a VTS-2 vacuum drier (Memmert, Schwabach, Germany) for 2 days at 100 mbar to remove the remaining isooctane. The powder was then reconstituted with HPW. Formulations 2 and 5 were extracted by adding HPW to the 
suspension with subsequent vertical rotation at $25 \mathrm{rpm}$ (Sunlab vertical rotator, Mannheim, Germany) until visual clearance of the suspension vehicle.

\subsection{High performance size exclusion chromatography}

Protein stability of the mAb was analyzed after reconstitution by HP-SEC using an Agilent 1100 with UV detection at $280 \mathrm{~nm}$ (Agilent Technologies, Santa Clara, USA) equipped with a TSKgel G3000SWXL column (Tosoh, Tokyo, Japan). As an eluent a $100 \mathrm{mM}$ phosphate, $100 \mathrm{mM}$ sulfate buffer at pH 6.8 was used at a flow rate of $0.5 \mathrm{ml} / \mathrm{min}$. The buffer was filtered before use employing a Sartorius pressure vessel equipped with a Sartorius $0.2 \mu \mathrm{m}$ cellulose acetate membrane filter (Sartorius, Goettingen, Germany). Beva stability was analyzed using an Agilent Infinity 1260 bioinert with UV detection at $280 \mathrm{~nm}$ (Agilent Technologies, Santa Clara, USA) equipped with a Wyatt SEC Protein Column for MALS (5 $\mu \mathrm{m}, 300 \AA ̊)$ (Wyatt, Santa Barbara, USA). As an eluent a PBS buffer at pH 7.4 was used at a volume of $0.5 \mathrm{ml} / \mathrm{min}$.

\subsection{Protein A chromatography}

The amount of oxidized species was determined by protein A chromatography according to Loew et al. using a Agilent 1200 with UV detection at $280 \mathrm{~nm}$ (Agilent Technologies, Santa Clara, USA). ${ }^{35}$

\subsection{Light obscuration}

The amount of subvisible particles was examined by light obscuration (LO) using a particle counter SVSS-C (PAMAS, Partikelmess- und Analysesysteme GmbH, Rutesheim, Germany). Powder was reconstituted in HPW and then transferred into a vacuum chamber at $100 \mathrm{mbar}$ for $30 \mathrm{~min}$ to remove air bubbles which were formed during the powder reconstitution step. The system was rinsed with $10 \mathrm{ml} \mathrm{HPW}$ after each run. The pre-run volume, as well as the measurement volume were $0.3 \mathrm{ml}$ (number of measurements per sample: 3 ).

\subsection{Fourier Transform Infrared spectroscopy}

Fourier Transform Infrared spectroscopy (FTIR) of reconstituted samples was conducted using a Bruker Tensor 27 FTIR spectrometer (Bruker, Billerica, USA) equipped with a Bruker BIO-ATR unit. For each transmission spectrum a 100 - scan interferogram was created at a single beam 
mode with a $4 \mathrm{~cm}^{-1}$ resolution. The spectrum was then processed using the protein dynamics software Opus 6.5 in order to create a vector-normalized second derivative amide I-spectrum.

\subsection{Circular Dichroism spectroscopy}

Far and Near-UV Circular Dichroism (CD) spectra were recorded using a Jasco J1100 (Jasco, Easton, USA). For analysis, the samples were diluted in PBS buffer pH 7.4 to either 0.125 (FarUV) or $5 \mathrm{mg} / \mathrm{ml}$ (Near-UV) and filled in a quartz cuvette with a $1 \mathrm{~mm}$ path length. Data was collected at $25^{\circ} \mathrm{C}$. Data was collected at a scanning speed $50 \mathrm{~nm} / \mathrm{min}$, a data pitch of $0.5 \mathrm{~nm}$, a digital integration time of $2 \mathrm{~s}$ and a bandwidth of $1 \mathrm{~nm}$. In total 4 scans were accumulated for each sample, the buffer spectra were subtracted and the resulting curve was smoothed according to the Savitzky-Golay function.

\subsection{Enzyme-linked immunosorbent assay}

An enyzme-linked immunosorbent assay (ELISA) was used to determine bevacizumab binding activity after storage. For this purpose, an Immunoguide ${ }^{\circledR}$ Enzyme immunoassay for the quantitative determination of free bevacizumab in serum and plasma was used according to manufacturer's instructions (Tani Medikal, Ankara, Turkey). 


\section{Results and discussion}

\subsection{Spray-drying}

Spray-drying is a well-established and easy to scale-up technique for producing protein powders. ${ }^{13,34}$ As stabilizer generally sugars such as sucrose or trehalose are used. ${ }^{3,14}$ In this study protein to carbohydrate ratios up to $50: 50$ and 70:30 were selected. The high amount of protein is important to minimize the volume contribution and by this the viscosity of the system (Chapter IV). ${ }^{14}$ Nevertheless a minimum protein stabilizer concentration is crucial to ensure the integrity of the active biopharmaceutical drug during storage. ${ }^{14,34}$ Previous studies indicated sufficient stabilization of mAbs in spray-dried powders at a protein:stabilizer molar ratio of $1: 220$ to $1: 110$ during storage at elevated temperatures. ${ }^{14,34}$ This equals protein:stabilizer mass ratios of $80: 20$ or $66: 33$. The ratio of protein to stabilizer is also key for a high process yield of around $80 \% .^{34}$

Spray-drying leads to powder particle sizes in the lower micrometre range making them suitable for injection through thin needles. ${ }^{22,14}$ The spray-dried formulations 1-4 showed similar D50 values of approximately $5 \mu \mathrm{m}$, as the type of sugar and protein have only minor effect on particle size (see Table VI-1) (Chapter IV and V) and the main parameters affecting the particle size, (atomizing air flow rate and total solid content of the feed solution) were kept constant in this study. ${ }^{36}$ Spray-drying did not show drastic damage to the protein and only led to a slight increase in the amount of soluble aggregates from 0.6 to $1.2 \%$. No changes in monomer recovery and protein structure analyzed by FTIR were detected.

Except of formulation 4, all formulations were additionally dried to feature low residual moisture contents of around $0.1 \%$. This has been shown to improve formulation performance in various ways. First, protein stability is potentially increased, as remaining water might lead to enhanced mobility and chemical instability, with water molecules as part of the instability reaction. ${ }^{30,33}$ The potential benefit of an additional drying step on protein stability in spraydried protein powders has been shown before. ${ }^{34,37}$ Second, the remaining water acts as a plasticizer enhancing particle fusion and risk of excipient crystallization. This can lead to a particle size increase and thus to an increased risk of needle clogging (Chapter V). ${ }^{28,29,31,32,38}$ Third, additionally dried powders are easier dispersible in the suspension vehicles leading to a more homogeneous suspension, minimizing the risk of needle clogging (Chapter V). 
Table VI-1: Overview of formulations and spray-dried powder characterization.

\begin{tabular}{|l|l|l|l|l|l|l|}
\hline $\begin{array}{l}\text { Formu- } \\
\text { lation }\end{array}$ & $\begin{array}{l}\text { Protein: } \\
\text { stabilizer } \\
\text { ratio }(\mathrm{m} / \mathrm{m})\end{array}$ & $\begin{array}{l}\text { Additional } \\
\text { drying step }\end{array}$ & $\begin{array}{l}\text { Residual } \\
\text { moisture } \\
{[\%]}\end{array}$ & $\begin{array}{l}\text { Suspension } \\
\text { vehicles }\end{array}$ & $\begin{array}{l}\text { Protein } \\
\text { conc. } \\
\text { suspension } \\
\text { [mg/ml] }\end{array}$ & $\begin{array}{l}\text { Additional } \\
\text { information }\end{array}$ \\
\hline 1 & $\begin{array}{l}\text { mAb:Tre } \\
70: 30\end{array}$ & Yes & $0.2 \pm 0.1$ & $\begin{array}{l}\text { F4H5, F6H8, } \\
\text { EO, MCT }\end{array}$ & 70 & \\
\hline 2 & $\begin{array}{l}\text { mAb:Tre } \\
50: 50\end{array}$ & Yes & $0.1 \pm 0.1$ & F6H8 & 50 & $\begin{array}{l}\text { Stored in } \\
\text { glass vial or } \\
\text { PFS }\end{array}$ \\
\hline 3 & $\begin{array}{l}\text { mAb:Suc } \\
50: 50\end{array}$ & Yes & $0.1 \pm 0.0$ & $\begin{array}{l}\text { F4H5, F6H8, } \\
\text { EO, MCT }\end{array}$ & 50 & $\begin{array}{l}\text { F4H5, F6H8, } \\
\text { EO, MCT }\end{array}$ \\
\cline { 3 - 7 } & No & $4.2 \pm 0.1$ & 50 & $0.4 \mathrm{mg} / \mathrm{ml}$ \\
\hline 5 & $\begin{array}{l}\text { Beva:Tre } \\
\text { (dihydrate) } \\
25: 60\end{array}$ & Yes & $0.1 \pm 0.1$ & F4H5, F6H8 & 25 & PS20 \\
\hline
\end{tabular}

\subsection{Effect of suspension vehicle on mAb stability}

The effect of the suspension vehicles on protein stability during storage was studied with mAb:Tre 70:30 suspensions in F4H5, F6H8, EO and MCT and compared to the spray-dried powder stored in absence of a vehicle.

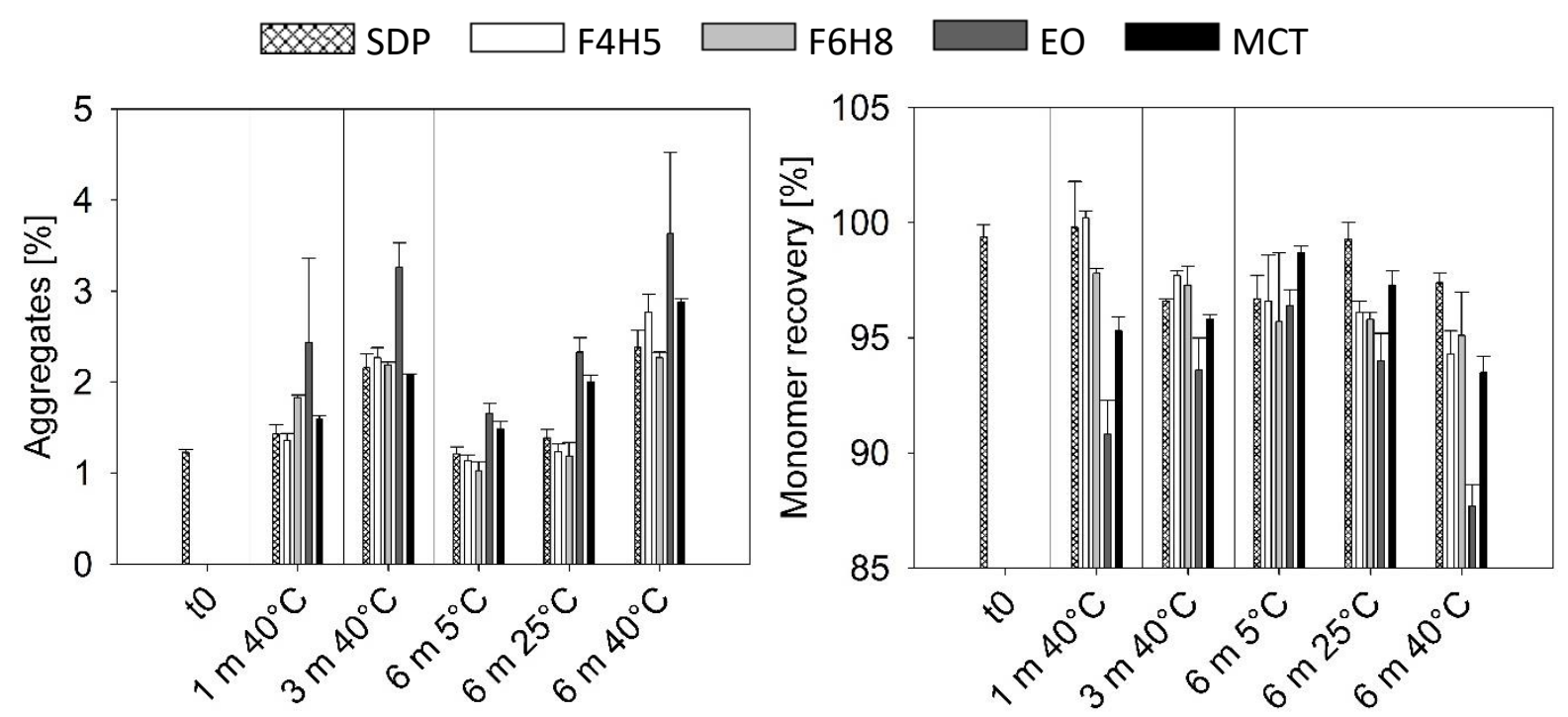

Figure VI-1: Effect of suspension vehicle on the amount of soluble aggregates and monomer recovery of $\mathrm{mAb}:$ Tre $70: 30$ suspensions $\left(\mathrm{c}_{\mathrm{mAb}}=70 \mathrm{mg} / \mathrm{ml}\right)$. 
After 6 months of storage at $40^{\circ} \mathrm{C}$ a slight increase of the amount of soluble aggregates from 1.2 to $2-3 \%$ was detected for the mAb:Tre $70: 30$ formulations including the spray-dried powder stored without the presence of a suspension vehicle. A loss in monomer recovery of around $12 \%$ was detected for EO formulations (Figure VI-1). Suspensions in F4H5, F6H8 and MCT, as well as the spray-dried powder, showed a smaller loss of monomer of around $5 \%$. Less soluble aggregates and a lower monomer loss were detected, when stored at lower temperatures.
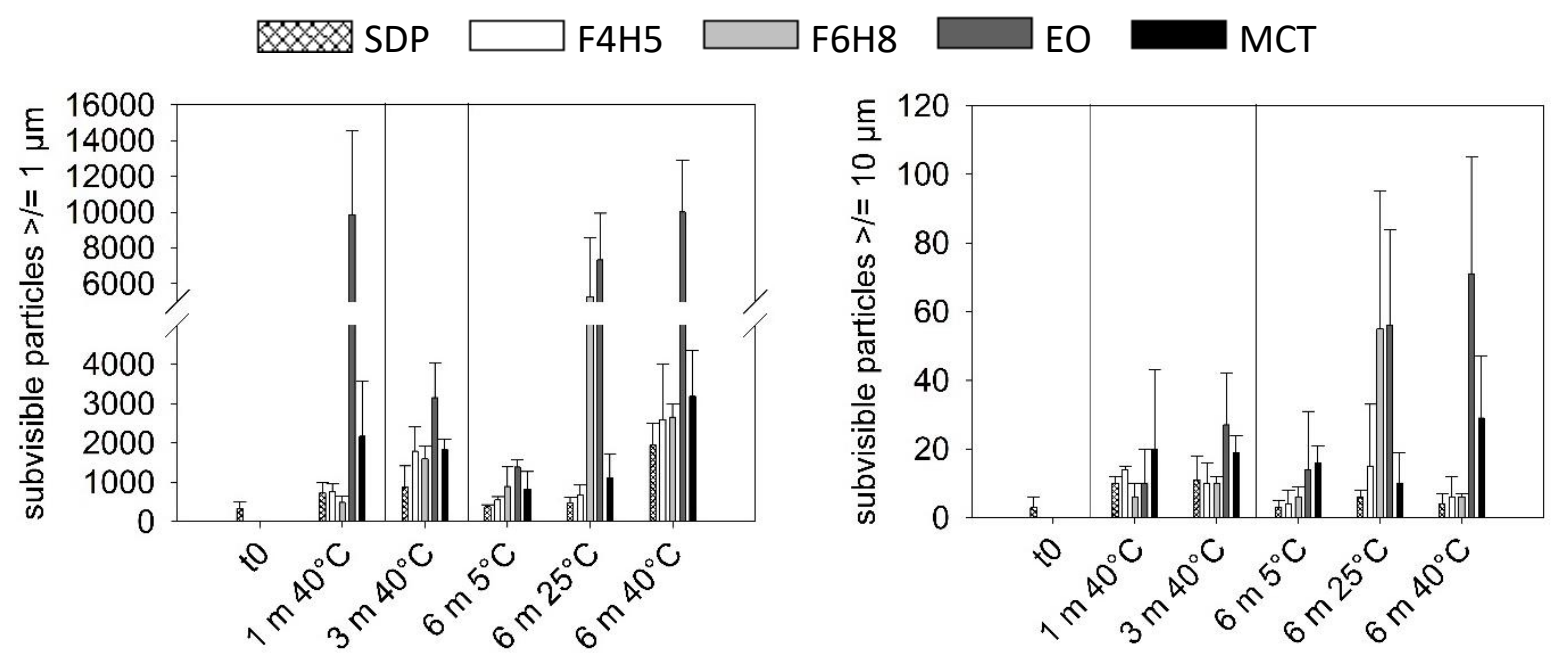

Figure VI-2: Effect of suspension vehicle on the amount of subvisible particles per $\mathrm{mg}$ of protein of $\mathrm{mAb}:$ Tre $70: 30$ suspensions $\left(\mathrm{c}_{\mathrm{mAb}}=70 \mathrm{mg} / \mathrm{ml}\right)$.

The amount of subvisible particles was studied to analyze the formation of insoluble aggregates (Figure VI-2). The total amount of subvisible particles increased for all formulations during storage and was especially pronounced at $40^{\circ} \mathrm{C}$. MAb:Tre 70:30 suspensions in EO showed the highest increase of particles $\geq 1$ and $10 \mu \mathrm{m}$. Suspensions in F4H5, F6H8 and MCT showed counts comparable to the spray-dried powder. 
A

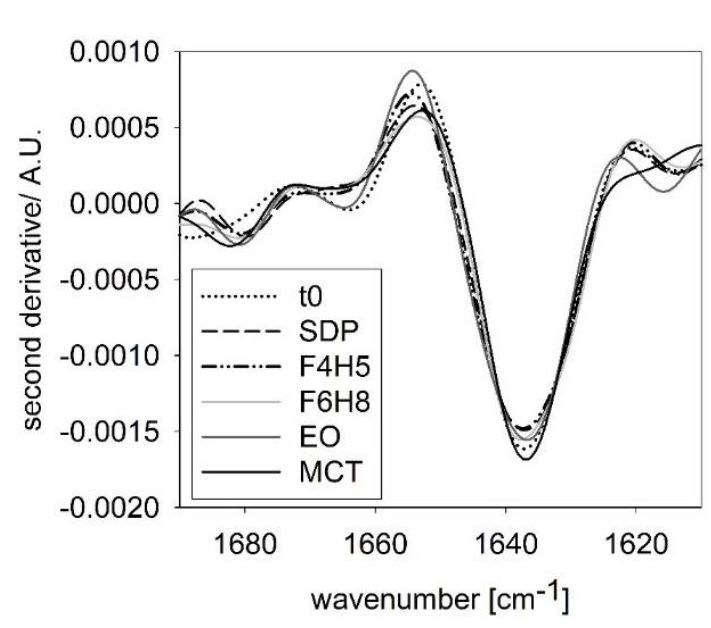

B

SDP $\mathrm{F} 4 \mathrm{H} 5$

Figure VI-3: Effect of suspension vehicle on FTIR spectra after 6 months of storage at $40^{\circ} \mathrm{C}(\mathrm{A})$ and protein oxidation $(B)$ of $\mathrm{mAb}:$ Tre $70: 30$ suspensions $\left(\mathrm{c}_{\mathrm{mAb}}=70 \mathrm{mg} / \mathrm{ml}\right)$.

No change or shift in the FTIR spectra, indicating a change in the protein conformation, was found after 6 months of storage at $40^{\circ} \mathrm{C}$ for all formulations (Figure VI-3). All spectra featured the typical peak at $1635-1645 \mathrm{~cm}^{-1}$, representing the Amide-I-band due to $\mathrm{C}=0$ stretching vibrations, on the basis of the $\beta$-sheet structure. ${ }^{39,40}$

Oxidation can present a serious challenge for biopharmaceuticals as it can lead to decreased biological half-life and activity. ${ }^{41-43}$ Using Protein A chromatography for detecting protein oxidation of mAbs previously gained increasing attention. ${ }^{35,44,45}$ As a consequence of oxidation of methionine residues of the $\mathrm{mAb}$ in the binding region of Protein $\mathrm{A}$, different elution times are obtained..$^{44}$ A slight increase of the amount of oxidized species from initial $5 \%$ to $6-7 \%$ was detected in formulations containing either F4H5, F6H8 or MCT after 6 months of storage at $40^{\circ} \mathrm{C}$ (Figure VI-3). In contrast to that, formulations in EO showed a high amount of oxidized species up to $9 \%$ at 5 or $25^{\circ} \mathrm{C}$ and $21 \%$ at $40^{\circ} \mathrm{C}$. The marked oxidation of the mAb in EO can be explained by the presence of the unsaturated oleate chains, which have high propensity to peroxide formation triggering protein oxidation. ${ }^{20,46,47}$ Additionally, with fatty acid oxidation, aldehyde functions are formed, which can undergo further reactions with the amino acid side chains of the mAb forming Schiff base adducts. ${ }^{20}$ These then can undergo the Amadori rearrangement leading to additional carbonyl functions which are then able to crosslink the mAb monomers. ${ }^{20}$ 
Gel formation of proteins formulated as protein powder suspension in soybean oil after 4 weeks at $37^{\circ} \mathrm{C}$ was explained by the reactivity of unsaturated fatty acids. ${ }^{20}$ Thus, oils with saturated fatty acids are preferred in formulation of peptides or proteins in non-aqueous vehicles. ${ }^{20,47}$ Yordanova investigated gonadorelin stability in a mixture of MCT and castor oil and did not find oxidized peptide variants after 12 months of storage at $40^{\circ} \mathrm{C} .{ }^{47}$ Additional procedures to reduce oxidation, could be treatment of the vehicle with aluminium oxide to remove peroxides, degassing of the vehicle or the addition of methionine as an antioxidant to the powder. ${ }^{24,48,49}$

Overall, suspensions in $\mathrm{F} 4 \mathrm{H} 5, \mathrm{~F} 6 \mathrm{H} 8$ and MCT showed a protein stability which was similar to the stability of spray-dried powder stored in the absence of a non-aqueous vehicle. Besides oxidation, the more substantial damage of the mAb in EO might be explained by a higher water content in this vehicle compared to the others. ${ }^{20}$ Formulating suspensions with powders featuring a high protein to stabilizer ratio is feasible. This is a very important prerequesite for high concentration formulations (Chapter IV). ${ }^{14}$ Interestingly, it was found, that suspensions in EO were not manually resuspendable after 6 months of storage at $40^{\circ} \mathrm{C}$. In previous work, it was shown, that suspensions in SFAs can show superior resuspendability after storage compared to suspensions in other non-aqueous vehicles such as EO and MCT (Chapter 5).

\subsection{Effect of protein to stabilizer ratio and packaging material on mAb stability}

Prefillable syringes (PFS) or cartridges for autoinjectors are preferred as container closure systems for mAb formulations, because of the easy administration, as well as decreased potential for dosing errors and risk of microbial contamination. ${ }^{50,51}$ Besides glass, also cyclic olefin polymer (COP) and cyclic olefin copolymer (COC) are used as material for primary packaging systems. ${ }^{45,51} \mathrm{COP}$ and $\mathrm{COC}$ syringes and cartridges feature several advantages compared to traditional glass, including no need for silicone oil, no residual tungsten, lower protein adsorption and improved mechanical strength. ${ }^{45,51}$ Nevertheless a potential disadvantage of COP and COC containers are their higher permeability for gases including oxygen and thus an increased risk of protein oxidation. ${ }^{45}$ 

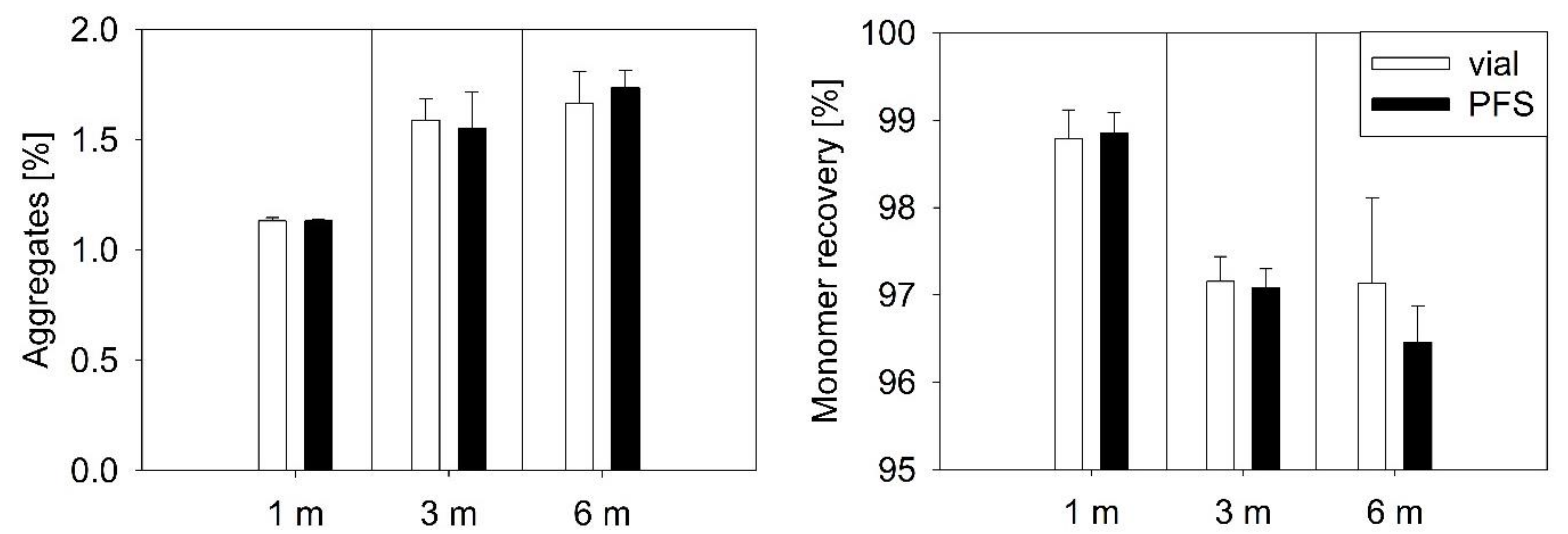

Figure VI-4: Effect of packaging material on the amount of soluble aggregates and monomer recovery of $\mathrm{mAb}:$ Tre $50: 50$ suspensions in $\mathrm{F} 6 \mathrm{H} 8\left(\mathrm{c}_{\mathrm{mAb}}=50 \mathrm{mg} / \mathrm{ml}\right)$ stored at $40^{\circ} \mathrm{C}$.

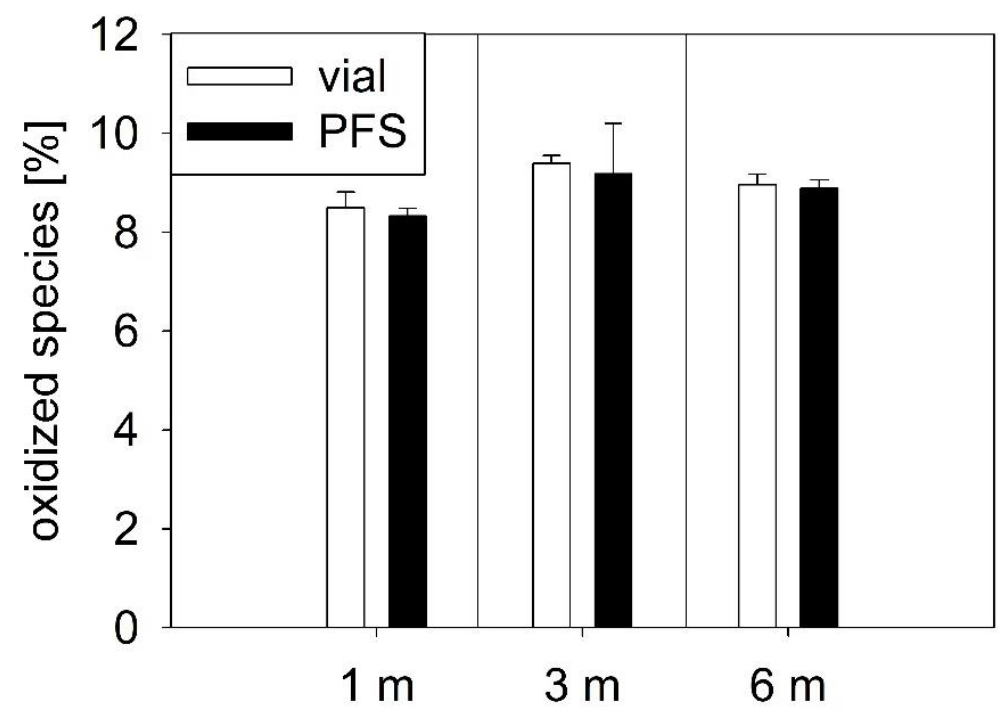

Figure VI-5: Effect of packaging material on protein oxidation of mAb:Tre 50:50 suspensions in $\mathrm{F} 6 \mathrm{H} 8\left(\mathrm{c}_{\mathrm{mAb}}=50 \mathrm{mg} / \mathrm{ml}\right)$ stored at $40^{\circ} \mathrm{C}$.

MAb:Tre 50:50 suspensions in F6H8 were stored in a glass vial or in a COP PFS. The suspension vehicle was degassed with nitrogen before suspension preparation to minimize the initial oxygen level in the formulation. SFAs are well known for their ability to dissolve high amounts of oxygen. ${ }^{52}$ The type of packaging material did not show any influence on the amount of soluble aggregates, monomer recovery or protein oxidation after 6 months of storage at $40^{\circ} \mathrm{C}$ (Figure VI-4/-5). Compared to mAb:Tre 70:30 suspensions in F6H8 (Figure VI-1), mAb:Tre 50:50 formulations showed less soluble aggregates ( 2.3 vs $1.7 \%$ ) as well as a lower monomer loss ( 5 vs $3 \%$ ) after 6 months of storage at $40^{\circ} \mathrm{C}$. This can be explained by the higher amount of trehalose leading to a better protein stabilization. However, this advantage of higher stability might come with a high suspension viscosity especially at high protein concentrations. Neither 
storage in glass vials nor in COP PFS affected powder particle diameters and injectability through a $27 \mathrm{G}$ needle (Chapter V).

\subsection{Effect of residual moisture and the type of sugar on mAb stability}

MAb:Suc 50:50 suspensions were not only prepared with additionally dried spray-dried powder (residual moisture of $0.1 \%$ ), but also with untreated powder featuring a residual moisture content of $4.2 \%$ (Table VI-1). Such high residual water contents are common for powders prepared by spray-drying. ${ }^{13,14}$

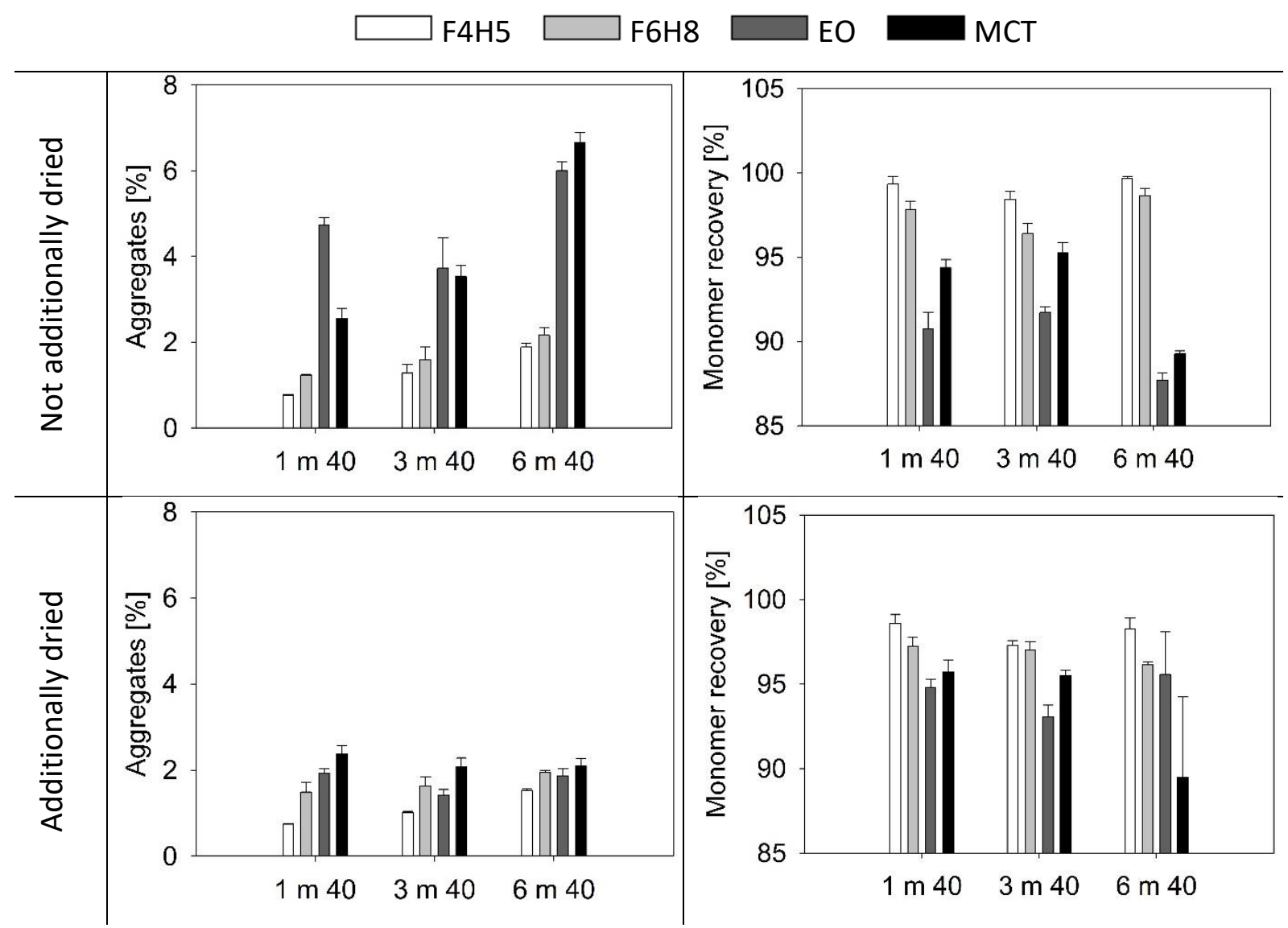

Figure VI-6: Effect of residual moisture content on the amount of soluble aggregates and monomer recovery of mAb:Suc 50:50 suspensions $\left(c_{m A b}=50 \mathrm{mg} / \mathrm{ml}\right)$ stored at $40^{\circ} \mathrm{C}$.

After 6 months of storage, higher amounts of soluble aggregates, as well as a higher monomer loss was observed for not additionally dried powders stored in either F4H5, F6H8, EO or MCT compared to the respective suspensions containing additionally dried powder. This effect was most pronounced for EO and MCT formulations. Suspensions containing additionally dried powder in EO showed $1.9 \%$ soluble aggregates after 6 months of storage at $40^{\circ} \mathrm{C}$, while the 
respective suspensions which were not additionally dried showed an amount of $6.0 \%$ (Figure VI-6). It is well known, that water in the powder can lead to protein instability due to enhanced mobility and chemical instability, with water molecules as part of the instability reaction. ${ }^{30,33}$ Nevertheless, the distinct effect of the suspension vehicle is remarkable. Previous work showed, that the non-additionally dried mAb powder showed recrystallization phenomena, which did not occur in suspensions containing additionally dried powder (Chapter V).

Similar amounts of soluble aggregates were found in mAb:Tre 50:50 (Figure VI-5) and mAb:Suc 50:50 (Figure VI-7) suspensions with additionally dried powder (1.7 vs 1.9\%), while a slightly higher monomer loss in sucrose containing formulations was detected (2.9 vs $3.8 \%$ ). Both disaccharides are widely used in formulation of solid protein pharmaceuticals. ${ }^{3,6}$ In general, trehalose is favoured due to its higher glass transition temperature, lower hygroscopicity, as well as lower reactivity. ${ }^{6,53}$ Nevertheless, the protein stabilizing properties of the two sugars depend on the respective protein and should be evaluated carefully for each system. ${ }^{6,54}$

\subsection{Storage stability of bevacizumab powder suspensions}

Bevacizumab (Beva) stability in suspension was compared to the marketed formulation Avastin $^{\circledR}$, which is an aqueous solution. The feed solution for preparation of spray-dried Beva powder reflected the composition of Avastin ${ }^{\circledR}$. The obtained powder was additionally vacuum dried and suspended in either $\mathrm{F} 4 \mathrm{H} 5$ or $\mathrm{F} 6 \mathrm{H} 8$ to obtain suspensions with the same protein and excipient concentration as the marketed formulation. Besides trehalose, the formulation further compromised PS20. Formulations of biopharmaceuticals can benefit from addition of the surface active PS20 due to its protecting effect towards water-air interface related stresses, both in liquid as well as during the drying process. ${ }^{55,56}$ In previous work, it was shown, that addition of PS20 does not negatively impact physical stability of lysozyme trehalose powder suspensions in F6H8 (Chapter V). 


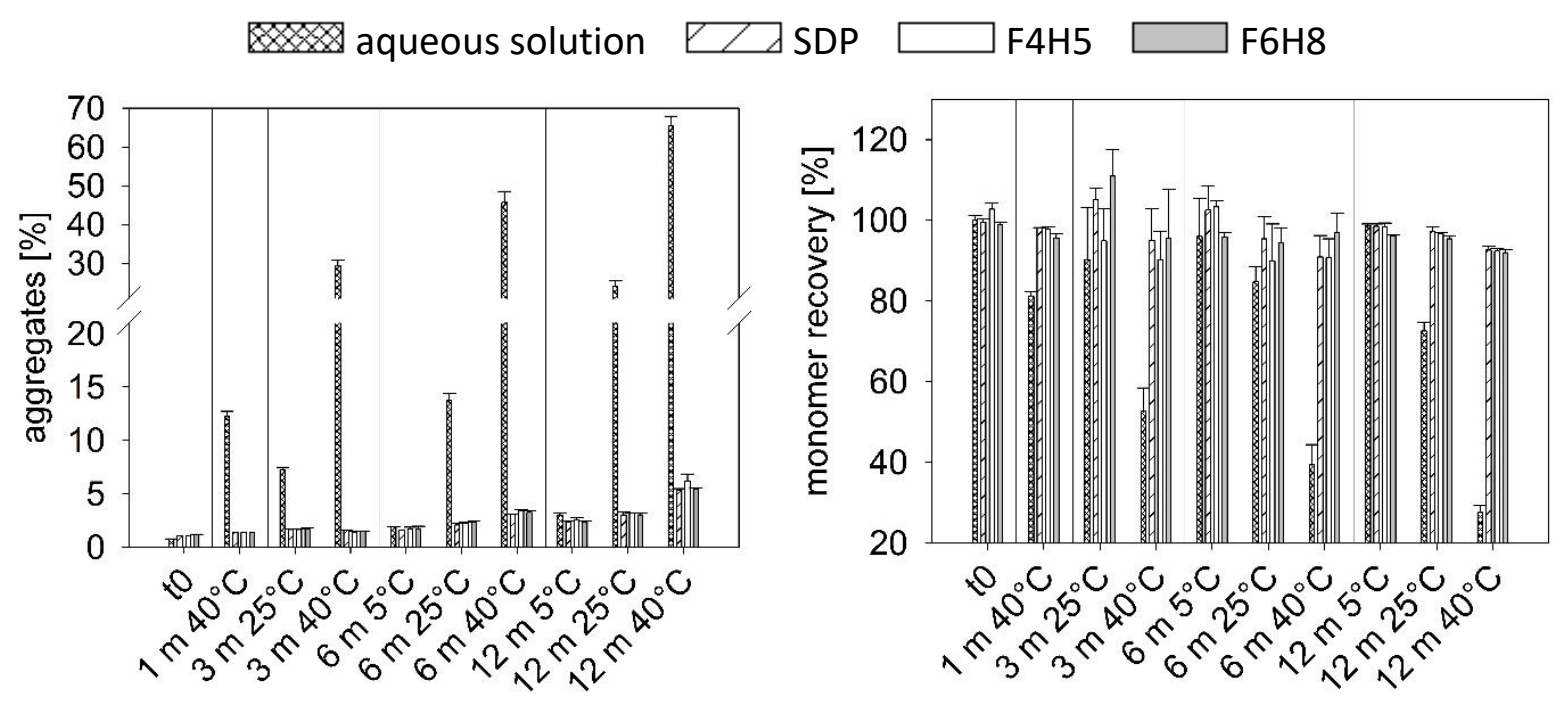

Figure VI-7: Soluble aggregates and monomer recovery of $25 \mathrm{mg} / \mathrm{ml}$ Beva formulations.

Spray-drying of Beva formulations led to a slight increase in the amount of soluble aggregates from initially $0.8 \%$ to $1.1 \%$, while no difference in monomer recovery was detected. After storage at $5^{\circ} \mathrm{C}$ for 12 months, the amount of soluble aggregates only slightly increased for all tested formulations to $2.4-3.0 \%$, while the monomer recovery did not change significantly (Figure $\mathrm{VI}-7$ ). Already after 3 months of storage at $25^{\circ} \mathrm{C}$, the aqueous solution showed an increase of soluble aggregates to $7.3 \%$, while the SDP and the SDP stored in suspension (F4H5 and $\mathrm{F} 6 \mathrm{H} 8$ ) only showed a minimal increase to $1.7 \%$. The monomer recovery after 3 months of storage at $25^{\circ} \mathrm{C}$ did not differ markedly. After 12 months at $25^{\circ} \mathrm{C}$, aqueous formulations showed $24.1 \%$ soluble aggregates and only $72.6 \%$ monomer recovery. At the same time, only 3.0-3.2\% aggregates had formed in the SDP and the suspensions ( $\mathrm{F} 4 \mathrm{H} 5$ and F6H8) with $95.5-$ $97.3 \%$ monomer recovery. At $40^{\circ} \mathrm{C}$ the aqueous formulations contained $65.4 \%$ soluble aggregates and showed a monomer loss of $72.4 \%$. The protein powder suspensions, as well as the spray-dried powder only featured 5.4-6.2\% soluble aggregates and a monomer recovery of 92.0-92.6\%. At all temperatures studied, the Beva SDP and the suspensions in $\mathrm{F} 4 \mathrm{H} 5$ and F6H8 performed very similar as already seen for the mAb (see 4.2). 

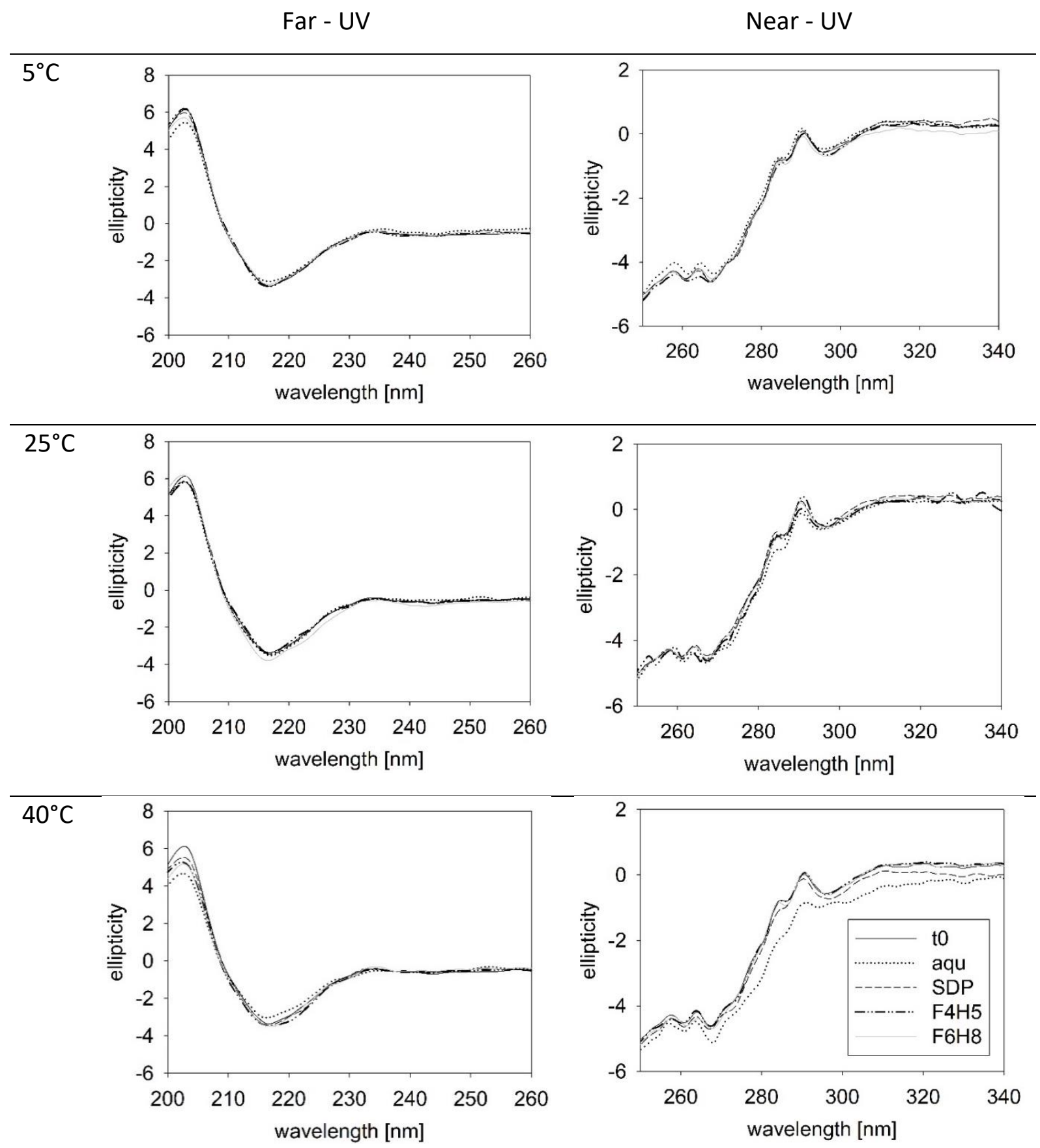

Figure VI-8: Far and Near-UV CD spectra of $25 \mathrm{mg} / \mathrm{ml}$ Beva formulations after 12 months of storage.

The Far-UV spectra $(200-260 \mathrm{~nm})$ did not reveal any differences for any of the tested formulations after 12 months of storage at 5,25 or $40^{\circ} \mathrm{C}$. After 12 months storage at 5 and $25^{\circ} \mathrm{C}$ no differences were found in the Near-UV spectra. When stored for 12 months at $40^{\circ} \mathrm{C}$, the Near-UV spectra of the aqueous Beva formulations were altered, indicating a change in tertiary structure, whereas the spectra of the powder-based formulations were unchanged. 57,58 


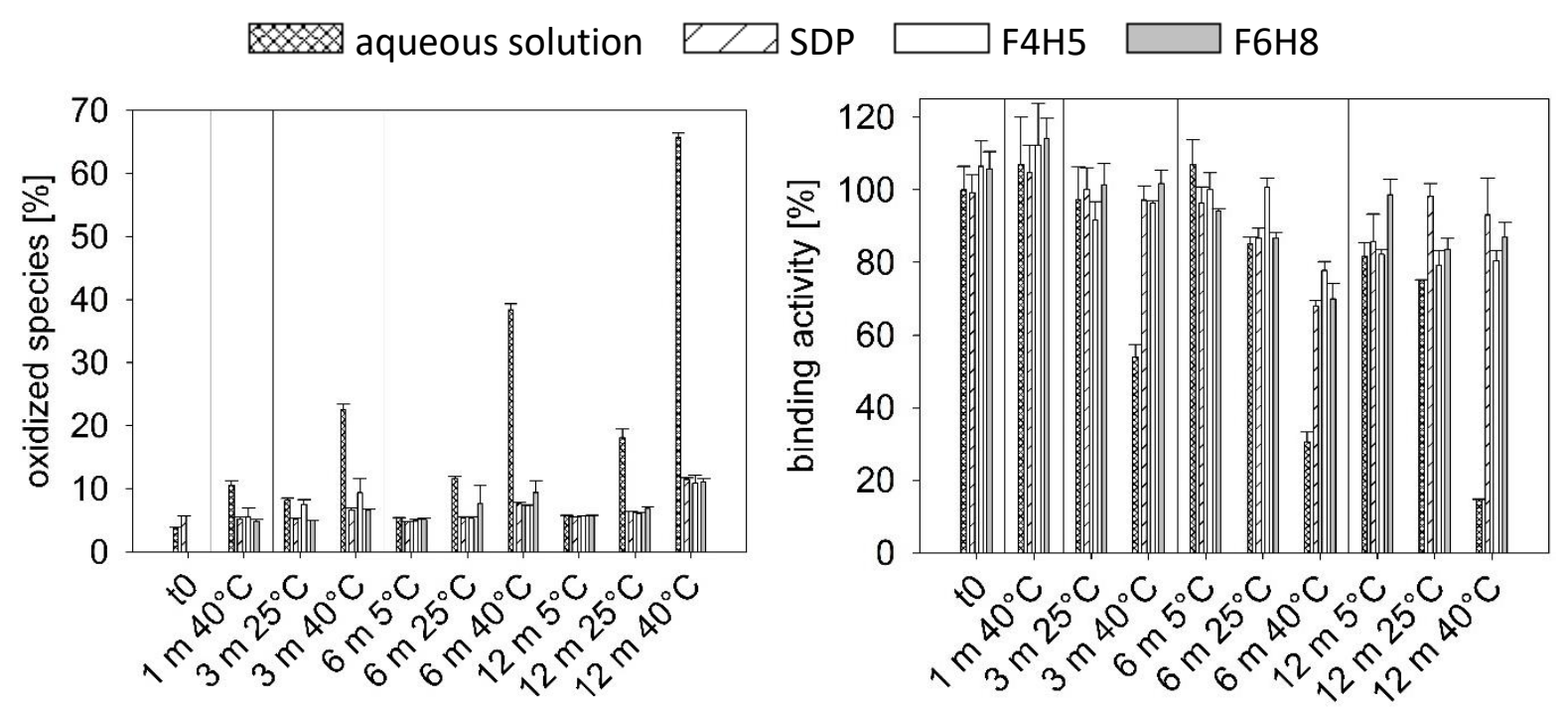

Figure VI-9: Protein oxidation and binding activity of $25 \mathrm{mg} / \mathrm{ml}$ Beva formulations.

Spray-drying led to a slight increase in the amount of oxidized species from 3.8 to $5.7 \%$ (Figure VI-9). The amount of oxidized species did not increase upon 12 months storage at $5^{\circ} \mathrm{C}$. After 12 months at $25^{\circ} \mathrm{C}$, the oxidized species content in powder-based formulations was 6.1 to $7.0 \%$, while $18.1 \%$ were detected in the aqueous solution. After 12 months at $40^{\circ} \mathrm{C} 11 \%$ oxidized species were found for the spray-dried powder and the suspensions, but $65.6 \%$ in the aqueous solution. As for mAb, similar levels of Beva oxidation were found in the suspensions (F4H5 and F6H8) and the powder stored in absence of a suspension vehicle.

No change in binding activity was detected for any formulation after 12 months storage at 5 or $25^{\circ} \mathrm{C}$ (Figure VI-9). At $40^{\circ} \mathrm{C}$, binding activity decreased significantly to $54 \%$ after 3 months and $15 \%$ after 12 months in the aqueous solutions whereas unchanged binding activity after 3 month and 80-90\% binding activity after 1 year were found in powder-based formulations.

Overall the results indicate an increased protein stability in the SDP and the protein powder suspensions in the SFAs for the two antibodies tested as compared to an aqueous solution. This shows the high potential of protein powder suspensions as a formulation technique for biopharmaceuticals potentially enabling storage at higher temperatures, thus eliminating the necessity of cold chain. 


\section{Conclusion}

The goal of this study was to investigate the influence of formulation parameters and the suspension vehicle on protein stability in non-aqueous powder suspensions. Furthermore we compared the protein stability of powder suspensions to conventional aqueous solutions. Based on the assumption, that in a powder suspension, the protein is provided in the solid state, we hypothesized a superior protein stability compared to the aqueous solution.

Overall, we could demonstrate the high potential of protein powder suspensions. Suspensions containing the model mAb or bevacizumab showed high stability for up to 12 months of storage at $40^{\circ} \mathrm{C}$. Best results in term of model mAb stability were obtained for mAb:Tre 70:30 powder suspensions in $\mathrm{F} 4 \mathrm{H} 5, \mathrm{~F} 6 \mathrm{H} 8$ and $\mathrm{MCT}$. For theses formulations, the stability was comparable to the spray-dried powder stored in absence of a suspension vehicle. When the mAb:Tre 70:30 powder was stored in EO, containing oleic acid moieties, a marked damage to the mAb was detected with increased soluble aggregates, decreased monomer recovery, increased oxidation and increased subvisible particle counts, especially pronounced after storage at $40^{\circ} \mathrm{C}$. Decreasing the protein to stabilizer ratio from $70: 30$ to $50: 50$ lead to a slight improvement of protein stability with regard to soluble aggregates. Comparing glass vials with COP PFS, the packaging material had no influence on protein oxidation. Protein stability was similar with sucrose and trehalose as stabilizer. Protein powder suspensions benefited substantially from an additional drying step of the spray-dried powder, especially when EO and MCT were used as a suspension vehicle.

Bevacizumab stability was studied, comparing the marketed aqueous solution and powder/suspension formulations, based on spray-dried powder with the same composition as the marketed drug product. Especially at high temperatures, the powder and suspension formulations showed much higher protein stability with regard to soluble aggregates, monomer recovery, protein oxidation and binding activity. While no differences were detected after 12 months of storage at $5^{\circ} \mathrm{C}$, the aqueous solution showed drastic protein degradation after storage at 25 or $40^{\circ} \mathrm{C}$, while only minimal change was found in powder suspensions based on SFAs. Overall this superior stability confirms previous findings of high protein stability in powder suspensions. ${ }^{20,21,24}$

Also physical stability of protein powder suspensions, described by particle size constancy, resuspendability and injectability, can be maintained during storage (Chapter V). Another valuable feature of protein powder suspension is their low viscosity, enabling easy injection 
of highly concentrated protein formulations (Chapter IV). ${ }^{14,22}$ Combined results highlight the high potential of protein powder suspensions providing protein formulations with improved stability. The increased stability might enable storage at higher temperatures, which can be beneficial in countries with hot climates and limited availability of cold storage options. 


\section{Literature}

1. Gervasi, V. et al. Parenteral protein formulations: An overview of approved products within the European Union. Eur. J. Pharm. Biopharm. 131, 8-24 (2018).

2. Grilo, A. L. \& Mantalaris, A. The Increasingly Human and Profitable Monoclonal Antibody Market. Trends Biotechnol. 1-7 (2018).

3. Mensink, M. A., Frijlink, H. W., Maarschalk, K. van der V. \& Hinrichs, W. L. J. How sugars protect proteins in the solid state and during drying (review): Mechanisms of stabilization in relation to stress conditions. Eur. J. Pharm. Biopharm. 114, 288-295 (2017).

4. Manning, M. C., Patel, K. \& Borchardt, R. T. Stability of Protein Pharmaceuticals. Pharm. Res. 6, 903-918 (1989).

5. Chang, L. L. \& Pikal, M. J. Mechanisms of protein stabilization in the solid state. J. Pharm. Sci. 98, 2886-2908 (2009).

6. Wang, W. Lyophilization and development of solid protein pharmaceuticals. Int. J. Pharm. 203, 1-60 (2000).

7. Arakawa, T., Prestrelski, S. J., Kenney, W. C. \& Carpenter, J. F. Factors affecting shortterm and long-term stabilities of proteins. Adv. Drug Deliv. Rev. 46, 307-326 (2001).

8. Korpus, C., Haase, T., Soennichsen, C. \& Friess, W. Energy Transfer During Freeze-Drying in Dual-Chamber Cartridges. J. Pharm. Sci. 104, 1750-1758 (2015).

9. Korpus, C., Pikal, M. \& Friess, W. Heat Transfer Analysis of an Optimized, Flexible Holder System for Freeze-Drying in Dual Chamber Cartridges Using Different State-of-the-Art PAT Tools. J. Pharm. Sci. 105, 3304-3313 (2016).

10. Shoyele, S. A. \& Cawthorne, S. Particle engineering techniques for inhaled biopharmaceuticals. Adv. Drug Deliv. Rev. 58, 1009-1029 (2006).

11. Etzl, E. E., Winter, G. \& Engert, J. Toward intradermal vaccination: preparation of powder formulations by collapse freeze-drying. Pharm. Dev. Technol. 19, 213-222 (2014).

12. Schüle, S., Schulz-Fademrecht, T., Garidel, P., Bechtold-Peters, K. \& Frieß, W. Stabilization of IgG1 in spray-dried powders for inhalation. Eur. J. Pharm. Biopharm. 69, 793-807 (2008).

13. Gikanga, B. et al. Manufacturing of High-Concentration Monoclonal Antibody Formulations via Spray Drying--the Road to Manufacturing Scale. PDA J. Pharm. Sci. Technol. 69, 59-73 (2015).

14. Bowen, M., Armstrong, N. \& Maa, Y.-F. Investigating High-Concentration Monoclonal Antibody Powder Suspension in Nonaqueous Suspension Vehicles for Subcutaneous Injection. J. Pharm. Sci. 101, 4433-4443 (2012).

15. Jovanović, N. et al. Stabilization of IgG by supercritical fluid drying: Optimization of formulation and process parameters. Eur. J. Pharm. Biopharm. 68, 183-190 (2008).

16. Jovanović, N. et al. Stable sugar-based protein formulations by supercritical fluid drying. 
Int. J. Pharm. 346, 102-108 (2008).

17. Moshashaée, S., Bisrat, M., Forbes, R. T., Nyqvist, H. \& York, P. Supercritical fluid processing of proteins: Lysozyme precipitation from organic solution. Jounral Pharm. Pharmacol. 11, 239-245 (2000).

18. Matheus, S., Friess, W., Schwartz, D. \& Mahler, H. C. Liquid high concentration IgG1 antibody formulations by precipitation. J. Pharm. Sci. 98, 3043-3057 (2009).

19. Berkenhoff, K. Subcutaneous suspensions of therapeutic proteins formulated as protein-coated microcrystals. (LMU Munich, 2013).

20. Knepp, V. M., Muchnik, A., Oldmark, S. \& Kalashnikova, L. Stability of nonaqueous suspension formulations of plasma derived factor IX and recombinant human alpha interferon at elevated temperatures. Pharm. Res. 15, 1090-1095 (1998).

21. Guenther, B. et al. EP2806886B1 - Stabilised protein compositions based on semifluorinated alkanes. (2013).

22. Miller, M. A., Engstrom, J. D., Ludher, B. S. \& Johnston, K. P. Low viscosity highly concentrated injectable nonaqueous suspensions of lysozyme microparticles. Langmuir 26, 1067-1074 (2011).

23. Rutz, A. Oily suspensions as parenteral depot systems of recombinant proteins. (LMU Munich, 2007).

24. Weiguo Dai, Beth Hill, Kui Liu, C. M. US 20120076800 - Non-aqueous high concentration reduced viscosity suspension formulations of antibodies. (2012).

25. Tsagogiorgas, C. et al. Semifluorinated alkanes - A new class of excipients suitable for pulmonary drug delivery. Eur. J. Pharm. Biopharm. 76, 75-82 (2010).

26. Tsagogiorgas, C. et al. Evaluation of pharmacokinetic properties and anaesthetic effects of propofol in a new perfluorohexyloctane (F6H8) emulsion in rats - A comparative study. Int. J. Pharm. 486, 69-76 (2015).

27. Gesche, G., Bernhard, G., Dieter, S. \& Anthony, P. EP3024484A1 - Stabilized antibody compositions. (2016).

28. Hageman, M. J. The role of moisture in protein stability. Drug Dev. Ind. Pharm. 14, 2047-2070 (1988).

29. Heljo, V. P. et al. The effect of water plasticization on the molecular mobility and crystallization tendency of amorphous disaccharides. Pharm. Res. 29, 2684-2697 (2012).

30. Lai, M. C. \& Topp, E. M. Solid-state chemical stability of proteins and peptides. J. Pharm. Sci. 88, 489-500 (1999).

31. Carstensen, J. T. \& Van Scoik, C. Amorphous-to-Crystalline Transformation of Sucrose. Pharm. Res. 7, 1278-1281 (1990).

32. Ahlneck, C. \& Zografi, G. The molecular basis of moisture effects on the physical and chemical stability of drugs in the solid state. Int. J. Pharm. 62, 87-95 (1990). 
33. Liu, W. R., Langer, R. \& Klibanov, A. M. Moisture-induced aggregation of lyophilized proteins in the solid state. Biotechnol. Bioeng. 37, 177-184 (1991).

34. Schuele, S. Stabilization of Antibodies in Spray-dried Powders for Inhalation. (LMU Munich, 2005).

35. Loew, C. et al. Analytical protein A chromatography as a quantitative tool for the screening of methionine oxidation in monoclonal antibodies. J. Pharm. Sci. 101, 42484257 (2012).

36. Vehring, R. Pharmaceutical particle engineering via spray drying. Pharm. Res. 25, 9991022 (2008).

37. Maa, Y. F. et al. Effect of spray drying and subsequent processing conditions on residual moisture content and physical/biochemical stability of protein inhalation powders. Pharm. Res. 15, 768-775 (1998).

38. Zhou, P., Liu, D., Chen, X., Chen, Y. \& Labuza, T. P. Stability of whey protein hydrolysate powders: Effects of relative humidity and temperature. Food Chem. 150, 457-462 (2014).

39. Yang, H., Yang, S., Kong, J., Dong, A. \& Yu, S. Obtaining information about protein secondary structures in aqueous solution using Fourier transform IR spectroscopy. Nat. Protoc. 10, 382-396 (2015).

40. Matheus, S., Friess, W. \& Mahler, H.-C. FTIR and nDSC as Analytical Tools for HighConcentration Protein Formulations. Pharm. Res. 23, 1350-1363 (2006).

41. Wang, W. et al. Impact of methionine oxidation in human IgG1 Fc on serum half-life of monoclonal antibodies. Mol. Immunol. 48, 860-866 (2011).

42. Mo, J. et al. Understanding the Impact of Methionine Oxidation on the Biological Functions of IgG1 Antibodies Using Hydrogen/Deuterium Exchange Mass Spectrometry. (2016). doi:10.1021/acs.analchem.6b01958

43. Burkitt, W., Domann, P. \& Connor, G. O. Conformational changes in oxidatively stressed monoclonal antibodies studied by hydrogen exchange mass spectrometry. 19, 826-835 (2010).

44. Gaza-bulseco, G., Faldu, S., Hurkmans, K., Chumsae, C. \& Liu, H. Effect of methionine oxidation of a recombinant monoclonal antibody on the binding affinity to protein $A$ and protein G. 870, 55-62 (2008).

45. Winter, G., Werner, B. P. \& Sch, C. Silicone Oil-Free Polymer Syringes for the Storage of Therapeutic Proteins. 108, 1148-1160 (2019).

46. Pratt, D. A., Tallman, K. A. \& Porter, N. A. Free Radical Oxidation of Polyunsaturated Lipids: New Mechanistic Insights and the Development of Peroxyl Radical Clocks. Acc. Chem. Res. 44, 458-467 (2012).

47. Yordanova, Y. Oil-Based Parenteral Depot Formulation for Veterinary Peptide Delivery. (LMU Munich, 2018).

48. Armstrong, N. J., Bowen, M. N. \& Maa, Y.-F. EP2849723A1 - High-concentration monoclonal antibody formulations. (2012). 
49. Akers, M. J., Fites, A. L. \& Robison, R. L. Formulation Design and Development of Parenteral Suspensions. J. Parenter. Sci. Technol. 41, 88-96 (1987).

50. Mathaes, R., Koulov, A., Joerg, S. \& Mahler, H. C. Subcutaneous Injection Volume of Biopharmaceuticals - Pushing the Boundaries. J. Pharm. Sci. 105, 2255-2259 (2016).

51. Jezek, J., Darton, N. J., Derham, B. K., Royle, N. \& Simpson, I. Biopharmaceutical formulations for pre-filled delivery devices. Expert Opin. Drug Deliv. 10, 811-828 (2013).

52. Meinert, H. \& Roy, T. Semifluorinated alkanes - A new class of compounds with outstanding properties for use in ophthalmology. Eur. J. Ophthalmol. 10, 189-197 (2000).

53. Pramanick, S., Singodia, D. \& Chandel, V. Excipient Selection In Parenteral Formulation Development. Pharma Times 45, 65-77 (2013).

54. Singh, S. in Challenges in Protein Product Development 63-95 (Springer International Publishing, 2018).

55. Serno, T., Härtl, E., Besheer, A., Miller, R. \& Winter, G. The Role of Polysorbate 80 and HPBCD at the Air-Water Interface of IgG Solutions. Pharm. Res. 30, 117-130 (2013).

56. Maa, Y.-F., Nguyen, P.-A. T. \& Hsu, S. W. Spray-Drying of Air-Liquid Interface Sensitive Recombinant Human Growth Hormone. J. Pharm. Sci. 87, 152-159 (1998).

57. Kelly, S. M., Jess, T. J. \& Price, N. C. How to study proteins by circular dichroism. Biochim. Biophys. Acta 1751, 119-139 (2005).

58. Hawe, A., Christina, J., Friess, W. \& Jiskoot, W. European Journal of Pharmaceutical Sciences Structural properties of monoclonal antibody aggregates induced by freezethawing and thermal stress. 38, 79-87 (2009). 


\section{Chapter VII}

\section{Optimized formulations for topical ocular protein delivery based on protein powder dispersions in non-aqueous vehicles}

\section{Abstract}

The field of ocular diseases, specifically retinal diseases is a successful target area for protein drugs. Besides the intraocular treatment of the retina, the topical treatment of corneal or conjunctival diseases is a promising approach. Topical ocular protein formulations face the challenges of poor penetration and short residence time. In this study we tested suspensions based on the semifluorinated alkane F6H8 to improve topical ocular protein delivery. Such suspensions are well known for the increased protein stability compared to aqueous solutions. Furthermore, $\mathrm{F} 6 \mathrm{H} 8$ is well known as vehicle for ocular delivery due to its easy spreading on the cornea.

Penetration of $a \mathrm{mAb}$ and its Fab fragment from different formulations into the cornea was tested in an ex vivo penetration test. The amount of penetrated protein was increased when protein powder suspensions in $\mathrm{F} 6 \mathrm{H} 8$ were used compared to the respective aqueous solutions. Sodium caprate as penetration enhancer at $5 \mathrm{mg} / \mathrm{ml}$ substantially increased the Fab fragment (7-fold) and the mAb (3-fold) concentration in the corneal tissue when applied as an aqueous solution. The effect was surprisingly more pronounced, when Fab fragment (31-fold) or mAb (13-fold) and the penetration enhancer were formulated as F6H8 suspensions. The same penetration enhancement from suspensions, as seen for $5 \mathrm{mg} / \mathrm{ml}$ sodium caprate formulations, could be achieved with only $2.5 \mathrm{mg} / \mathrm{ml}$ penetration enhancer, which was not the case for the aqueous solution. A test based on stratified human keratinocytes did not indicate eye irritation by the tested formulations.

Additionally, semisolid formulations, which could potentially further improve protein penetration due to a longer residence time, containing $\mathrm{mAb}$ or etanercept powder in white petrolatum, liquid paraffin and F6H8 were prepared. Prepared mAb formulations showed ideal rheologic ointment characteristics. Etanercept formulated in ointments showed superior 
long-term protein stability compared to the marketed aqueous solution with respect to fragmentation, monomer loss and binding activity. Overall results demonstrate the high potential of topical ocular protein delivery using powder suspensions in non-aqueous vehicles based on semifluorinated alkanes. 


\section{Introduction}

Over the last five years, approximately 20 protein pharmaceuticals gained approval by the European Medicine Agency (EMA) each single year. ${ }^{1}$ Nearly all of them are delivered via the subcutaneous, intramuscular or intravenous route or in the field of ocular delivery via intraocular injection. ${ }^{2-4}$ These invasive routes of administration negatively impact compliance and self-administration by patients. ${ }^{5,6}$ Oral and topical bioavailability of protein drugs is poor, as a consequence of the proteins high molecular weight, low $\log \mathrm{P}$, short residence time as well as susceptibility to local degradation e.g. by enzymes. ${ }^{7,8}$ Nevertheless, several studies indicated that other routes of administration, especially local topical delivery of protein drugs is feasible. ${ }^{9-12} \mathrm{~A}$ large interest exists in the field of topical ocular delivery of proteins for corneal diseases. Potential corneal diseases which might be treated with protein therapeutics are ocular surface scarring as a consequence of chemical or thermal burns ${ }^{13}$, corneal neovascularization ${ }^{10}$, neurotrophic keratitis ${ }^{12}$, corneal neoplasia ${ }^{14}$ as well as viral infections ${ }^{15}$. Just recently the FDA and EMA approved Oxervate ${ }^{\circledR}$ a topical ophtalmical solution containing $20 \mu \mathrm{g} / \mathrm{ml}$ recombinant human nerve growth factor (cenegermin) for the treatment of neurotrophic keratitis.

A big disadvantage of the marketed Oxervate ${ }^{\circledR}$ formulation is the fact, that it has to be stored frozen at $-20^{\circ} \mathrm{C}$ to be stable. ${ }^{16}$ Patients receive a 7-day package with one vial per day at a local pharmacy which then has to be stored refrigerated, while applying Oxervate ${ }^{\circledR} 6$ times a day. The following week, the patient has to go to the pharmacy again to get a new 7-day package. Thus, the patient non-compliance is probably high. In the present study different techniques on how topical ocular protein formulations could be improved by the use of protein powder suspensions in non-aqueous vehicles were evaluated. Special focus was on corneal penetration, protein stability and ocular residence time. As the protein is provided in a solid state in the suspension, protein stability should be improved, potentially evading refrigeration of the product. Protein penetration might be improved by a penetration enhancer, but potential eye irritation has to be avoided. Formulating the protein powder in a semi-solid vehicle can improve ocular residence time, but a negative impact on protein stability must be excluded.

Ideal non-aqueous vehicles for the use in such a formulation are semifluorinated alkanes (SFAs) because of their good compatibility with protein drugs ${ }^{17,18}$ and biocompatibility ${ }^{19}$. Eye drops based on SFAs show enhanced spreading on the ocular surface as a consequence of their low 
surface tension, providing intimate covering of the whole cornea and consequently improved penetration. ${ }^{20,21}$

Protein drugs, usually show very poor penetration into the corneal tissue, as they do not penetrate transcellularly through the lipid membrane, and paracellular penetration is very limited due to tight junctions of the corneal epithelium. ${ }^{22,23} \mathrm{~A}$ potential technique to improve corneal permeability is the addition of penetration enhancers. ${ }^{24-26}$ In this study we tested, if proteins can be delivered to the cornea using the protein powder suspension approach combined with the application of sodium caprate. We further investigated if the penetration enhancer leads to corneal irritation at the tested concentrations.

Due to solution drainage, tear turn over and induced lacrimation the precorneal residence time of topically applied liquids is generally very short and the formulation is usually washed away within 15-30 s. ${ }^{27}$ Potential formulation approaches to prolong drug residence time and thus bioavailability are topical ocular ointments. ${ }^{28,29}$ These are usually based on hydrocarbon mixtures such as white petrolatum and liquid paraffin and are common in the area of ocular antibiotic and corticosteroid treatment. ${ }^{29-31}$ We assume, that this technology also offers a high potential for protein therapeutics, but so far no reports about protein compatibility with these excipients have been published.

In this study we investigated different techniques to improve formulations for topical ocular delivery. The effect of formulating a monoclonal antibody $(\mathrm{mAb})$ as well as its Fab fragment in non-aqueous powder suspensions in a semifluorinated alkane, perfluorohexyloctane (F6H8), was studied, including formulations containing sodium caprate. Furthermore, mAb formulations were formulated in ointments and the rheological behaviour was investigated. Finally, etanercept stability in white petrolatum, liquid paraffin and F6H8 was studied and compared to protein stored in the marketed aqueous buffer solution. 


\section{Materials and Methods}

\subsection{Materials}

A monoclonal IgG1 antibody (mAb) produced in chinese hamster ovary cells in $25 \mathrm{mM}$ histidine $1.6 \mathrm{mM}$ glycine buffer $\mathrm{pH} 6.0$ at $57 \mathrm{mg} / \mathrm{ml}$ was used $\left(\varepsilon_{280 \mathrm{~nm}}: 1.49 \mathrm{ml} \mathrm{g}^{-1} \mathrm{~cm}^{-1}\right)$. Etanercept was obtained from LGM Pharma (Nashville, United States). Formulations were prepared in highly purified water (HPW) prepared with an ELGA Purelab system (ELGA LabWater, Celle, Germany) using trehalose (Hayashibara, Okayama, Japan), sucrose, Lhistidine and L-histidine-monohydrochloride monohydrate, L-arginine hydrochloride (SigmaAldrich, St. Louis, United States), sodium chloride, disodium phosphate (Bernd Kraft GmbH, Duisburg, Germany), Potassium chloride and potassium dihydrogen phosphate (VWR, Radnor, United States). Sodium caprate (Sigma-Aldrich, St. Louis, United States) was used as a penetration enhancer. Perfluorohexyloctane (F6H8) (provided by Novaliq, Heidelberg, Germany) was used as suspension vehicle. Hydrophobic base gel (gelatum basalis hydrophobicum) consisting of $5 \%$ polyethylene in liquid paraffin (paraffinum liquidum), and white petrolatum (Caesar \& Loretz, Hilden, Germany) were used for ointment preparation. Dispersion medium for laser diffraction measurement contained isooctane and Span 80 (Merck, Darmstadt, Germany). Running buffer for high pressure size exclusion chromatography (HP-SEC) contained HPW, sodium sulfate, monosodium phosphate dihydrate (Grüssing, Filsum, Germany) and disodium phosphate dihydrate (Bernd Kraft, Duisburg, Germany).

\subsection{UV-Vis}

Protein concentrations were measured with a NanoDrop 2000 spectrophotometer (Thermo Scientific, Waltham, United States) at $280 \mathrm{~nm}$.

\subsection{Fab preparation}

Fab preparation of the model mAb was performed as described by Menzen using a Papain suspension (from papaya latex, Sigma-Aldrich) and an ÄKTA purifier 10 (GE Healthcare, Chalfont St Giles, UK) equipped with a Protein A chromatography cartridge (Thermo Fisher Scientific, Waltham, United States). ${ }^{32}$ Buffer exchange was conducted using a SpectraPor RC 
dialysis membrane with a molecular weight cut off of 6-8 kDa (Spectrum Laboratories, Los Angeles, United States).

\subsection{Fluorescence labelling}

Before labelling, protein buffers were exchanged to PBS buffer, pH 7.4 using a SpectraPor RC dialysis membrane with a molecular weight cut off of 6-8 kDa. Fluorescence labelling was subsequently conducted using NHS-Fluorescein according to the supplier's instruction (Thermo Fisher Scientific, Waltham, United States). Obtained solutions were additionally filtered using a $0.2 \mu \mathrm{m}$ polyethersulfone (PES) syringe filter (VWR). The solutions containing the labelled protein were dialysed for one week with PBS buffer to remove unbound dye.

\subsection{Formulations for spray-drying}

Formulations for spray-drying were prepared in $1 \mathrm{mM}$ histidine buffer at $\mathrm{pH} 7.4$ containing $5 \mathrm{mg} / \mathrm{ml}$ trehalose, $5 \mathrm{mg} / \mathrm{ml}$ protein and sodium caprate (either $0,2.5$ or $5 \mathrm{mg} / \mathrm{ml}$ ). Buffer exchange and up-concentration was conducted using Vivaspin ${ }^{\circledR}$ centrifugation tubes with a molecular weight cut off of $10 \mathrm{kDa}$ (Sartorius, Göttingen, Germany). Before spray-drying the feed solutions were filtered using a $0.2 \mu \mathrm{m}$ polyethersulfone (PES) syringe filter (VWR).

\subsection{Spray-drying}

Spray-drying was conducted using a Büchi B290 (Büchi, Flawil, Switzerland) equipped with a high-efficiency cyclone and a two fluid nozzle $(0.7 \mathrm{~mm}$ orifice) at a drying air-flow rate of $600 \mathrm{ml} / \mathrm{min}$, an atomizing air flow rate of $700 \mathrm{ml} / \mathrm{min}$, a feed flow rate of $3 \mathrm{ml} / \mathrm{min}$ and an inlet/outlet temperature of $125 / 68^{\circ} \mathrm{C}$.

\subsection{Additional drying step}

Spray-dried powders were transferred into 10R type 1 glass vials (MGlas, Muennerstadt, Germany) and a lyophilization stopper was attached (Helvoet Pharma, Tilburg, Netherlands). Samples were then dried using a Christ 2-6D (Martin Christ Gefriertrocknungsanlagen, Osterode, Germany) at $32^{\circ} \mathrm{C}, 0.1 \mathrm{mBar}$ for $24 \mathrm{~h}$ and fully stoppered in the freeze-drier under nitrogen gas atmosphere at 800 mbar according to Schuele et al. ${ }^{33}$ 


\subsection{Powder handling}

Powder handling was conducted under nitrogen environment in a custom-made glove box to prevent water uptake.

\subsection{Karl-Fischer}

The amount of residual water was analyzed using a Karl-Fischer-Titrator Aqua 40.00 (Analytik Jena, Jena, Germany) equipped with a head space module at a chamber temperature of $100^{\circ} \mathrm{C}$.

\subsection{Formulation preparation for corneal penetration study}

Formulations were prepared in $1 \mathrm{ml}$ volumetric flasks with a final protein concentration of $5 \mathrm{mg} / \mathrm{ml}$. Aqueous formulations were prepared by adding PBS buffer $\mathrm{pH} 7.4$ to the spray-dried powder. Suspensions were prepared by adding F6H8. Suspensions were then homogenized using an VWR Ultrasonic cleaner cooled with ice (VWR, Radnor, United States).

Table VII-1: Formulation overview for the corneal penetration study.

\begin{tabular}{|c|c|c|c|}
\hline & $\begin{array}{l}\text { Aqueous solution (aqu) or } \\
\text { Suspension (F6H8) }\end{array}$ & Protein & $\mathrm{C}_{\text {sodium caprate }}[\mathrm{mg} / \mathrm{ml}]$ \\
\hline 1 & Aqueous solution & \multirow[t]{4}{*}{$\mathrm{mAb}$} & - \\
\hline 2 & $\mathrm{~F} 6 \mathrm{H} 8$ & & - \\
\hline 3 & Aqueous solution & & 5 \\
\hline 4 & F6H8 & & 5 \\
\hline 5 & Aqueous solution & \multirow[t]{6}{*}{$\mathrm{Fab}$} & - \\
\hline 6 & $\mathrm{~F} 6 \mathrm{H} 8$ & & - \\
\hline 7 & Aqueous solution & & 2.5 \\
\hline 8 & F6H8 & & 2.5 \\
\hline 9 & Aqueous solution & & 5 \\
\hline 10 & F6H8 & & 5 \\
\hline
\end{tabular}




\subsection{Ex vivo corneal penetration study}

Corneal penetration studies were conducted ex vivo according to Agarwal et al. ${ }^{20}$ Porcine eyes were obtained from the local slaughterhouse. Eyes were investigated and eyes with any signs of corneal damage were not used in the study. After removal of excessive tissue, eyes were placed in a 6-well plate and $2 \mathrm{ml}$ of Hank's balanced salt solution (HBSS) (Biowest, Nuaillé, France) was added. The eyes were then covered with a corneal sleeve (University of Auckland Biomedical Engineering Workshop, New Zealand). A cell culture dish was additionally put on top, in order to minimize evaporation of water. This set up was then equilibrated for $15 \mathrm{~min}$ at $35^{\circ} \mathrm{C}$. After equilibration, $50 \mu \mathrm{l}$ formulation were added onto each cornea. As aqueous formulations showed poor spreading, they were additionally distributed on the corneal surface using the pipette. Eyes were then incubated for $4 \mathrm{~h}$ at $35^{\circ} \mathrm{C}$. After removal the eyes were washed with the HBSS. The corneas were excised, wiped with a tissue and weighed into an Eppendorf tube.

\subsection{Cornea homogenization}

The corneal tissue was homogenized using an Omni Bead ruptor (Omni International, Kennesaw, United States). For this purpose, 6 metallic beads and $600 \mu \mathrm{lPBS}$ buffer (pH 7.4) were filled in the Eppendorf tube. The homogenization was conducted at strength 6 for 5 times, $30 \mathrm{~s}$ with $30 \mathrm{~s}$ breaks in between. The tubes were then centrifugated at $4^{\circ} \mathrm{C}$ at $12000 \mathrm{rpm}$ for $15 \mathrm{~min}$ and the supernatant was collected.

\subsection{Fluorescence spectroscopy}

Quantification of penetrated protein was conducted using the Cary Eclipse fluorescence spectrophotometer (Agilent, Santa Clara, United States), with excitation/ emission wavelength set to $494 / 518 \mathrm{~nm}$.

\subsection{Eye irritation test}

An eye irritation test was conducted by an external laboratory (Bioassay Labor für biologische Analytik, Heidelberg, Germany) using an EpiOcular ${ }^{T M}$ Eye Irritation Test (MatTek, Ashland, United States) according to manufacturer's instructions. The test consists of stratified human keratinocytes embedded in a three-dimensional matrix. The test indicates a non-irritating formulation, if the viability of the cells after incubation is above $60 \%$ referred to tissue treated 
with the negative control sample (distilled water). Investigated formulations consisted of either 5 or $10 \mathrm{mg} / \mathrm{ml}$ sodium caprate suspended in $\mathrm{F} 6 \mathrm{H} 8$. As a positive control methyl acetate was used.

\subsection{Formulations for freeze-drying and aqueous solution for stability study}

Buffer exchange was performed using either Spectra/Por regenerated cellulose dialysis tubes with a molecular weight cut off (MWCO) of 6-8 kDa (Spectrum Laboratories, Los Angeles, United States) (mAb) or using 12-30 ml Slide-A-Lyzer dialysis cassettes with a MWCO of $20 \mathrm{kDa}$ (Thermo Scientific, Waltham, United States) (etanercept). Solutions for freeze-drying were prepared in $10 \mathrm{mM}$ histidine buffer, containing trehalose at a protein to stabilizer ratio of 1:1 $(\mathrm{m} / \mathrm{m})$ and a total solid content in solution of either $5(\mathrm{mAb})$ or $2.5 \%$ (etanercept) $(\mathrm{m} / \mathrm{V})$. Before freeze-drying, the solutions were filtered using a VWR $0.2 \mu \mathrm{m}$ polyethersulfone syringe filter (VWR, Radnor, United States). For freeze-drying, $4 \mathrm{ml}$ of the prepared solution was transferred in 10R type 1 glass vials (MGlas, Muennerstadt, Germany) and a lyophilization stopper was attached (Helvoet Pharma, Tilburg, Netherlands). Vials and stoppers were washed with HPW and dried for $8 \mathrm{~h}$ at 100 and $80^{\circ} \mathrm{C}$, respectively. Aqueous etanercept solutions used in the stability study were formulated in $25 \mathrm{mM}$ L-arginine hydrochloride, $120 \mathrm{mM}$ sodium chloride and $10 \mathrm{mg} / \mathrm{ml}$ sucrose at $\mathrm{pH}$ 6.3.

\subsection{Freeze-drying}

Freeze-drying was conducted using a pilot-scale Christ 2D-6 LSCplus freeze-drier (Martin Christ Gefriertrocknungsanlagen, Osterode, Germany). The freezing step was conducted with a ramp of $1 \mathrm{~K} / \mathrm{min}$ to $-50^{\circ} \mathrm{C}$ followed by a $2 \mathrm{~h}$ hold. For primary drying a vacuum of $0.133 \mathrm{mbar}$ was applied. The shelf temperature was increased by $0.33 \mathrm{~K} / \mathrm{min}$ to $-25^{\circ} \mathrm{C}$ and held for $60 \mathrm{~h}$. Secondary drying was performed at $35^{\circ} \mathrm{C}$ and $0.133 \mathrm{mbar}$ for $12 \mathrm{~h}$ after increasing the temperature by $0.1 \mathrm{~K} / \mathrm{min}$. Lyophilizates were closed under slight vacuum of $800 \mathrm{mbar}$ in the freeze-drier, removed and manually capped using 10R caps (Westpharma, Exton, USA) and stored at $5^{\circ} \mathrm{C}$ in a desiccator until further use. 


\subsection{Cryogenic milling}

Cryogenic dry milling was conducted using a Retsch CryoMill (Retsch, Haan, Germany). A quantity of either 1 (mAb) or $0.5 \mathrm{~g}$ (etanercept) of lyophilizates and 10 stainless-steel milling balls ( $7 \mathrm{~mm}$ diameter) were filled into a $25 \mathrm{ml}$ milling jar. Before milling, the milling jar was precooled with liquid nitrogen for 10 min. Milling was conducted at $25 \mathrm{~Hz}$ for 5 (mAb) or 2 min (etanercept).

\subsection{Scanning electron microscopy (SEM)}

Powders were investigated on self-adhesive carbon tapes stuck on aluminium stubs using a FEI Helios G3 UC (Thermo Fisher Scientific, Waltham, USA).

\subsection{Laser diffraction}

Volume based powder particle size distribution was analyzed in isooctane containing $1 \%$ Span 80 using a Laser Diffraction Particle Size Analyzer LA-960 (Horiba, Kyoto, Japan). The dispersion medium was filtered through a $0.22 \mu \mathrm{m}$ PTFE syringe filter (VWR, Radnor, USA) before use. Dispersions containing the milled powder were additionally homogenized using a Sonopuls ultrasonic homogenizer equipped with a MS72 probe (Bandelin, Berlin, Germany) for $30 \mathrm{~s}$ at $10 \%$ intensity.

\subsection{Ointment preparation for rheological characterization and stability study}

Ointments for rheological characterization were manually prepared using a melamine bowl and pestle. Milled mAb lyophilizates were dispersed in the ointment vehicles until a smooth and uniform mixture was obtained. Formulations are shown in Table VII-2. 
Table VII-2: Ointment formulation overview

\begin{tabular}{|l|l|l|}
\hline Formulation & \multicolumn{1}{|c|}{$\begin{array}{c}\text { Powder concentration } \\
{[\mathrm{mg} / \mathrm{ml}]}\end{array}$} & \multicolumn{1}{c|}{$\begin{array}{c}\text { MAb concentration } \\
{[\mathrm{mg} / \mathrm{ml}]}\end{array}$} \\
\hline Hydrophobic base gel & - & - \\
\cline { 2 - 4 } & 50 & 25 \\
\cline { 2 - 4 } & 100 & 50 \\
\hline White petrolatum & - & - \\
\cline { 2 - 4 } & 50 & 25 \\
\cline { 2 - 4 } & 100 & 50 \\
\hline White petrolatum + F6H8 (70:30) & 100 & 50 \\
\hline
\end{tabular}

Formulations for the stability study contained $10 \mathrm{mg} / \mathrm{ml}$ milled etanercept lyophilizates corresponding to $5 \mathrm{mg} / \mathrm{ml}$ protein. Aqueous etanercept solutions were formulated as the marketed Enbrel $^{\circledR}$ solution for injection as described in 3.15. Solutions were filtered using sterile PVDF syringe filters (Pall, New York, United States), aseptically dispensed in 2R type 1 glass vials (Schott, Mainz, Germany) and stoppered with Teflon coated injection stoppers (Westpharma, Exton, USA) under laminar air flow conditions.

Milled etanercept powder was manually dispersed in white petrolatum using a spatula. Suspensions in liquid paraffin and $\mathrm{F} 6 \mathrm{H} 8$ were prepared using an Ultrasonic water bath USC 1200TH (VWR, Radnor, USA) for 20 min cooled with ice. Formulations were dispensed in 2R type 1 glass vials (Schott) and closed using Teflon coated injection stoppers (Westpharma). All vials were manually capped (Westpharma).

Stability studies were conducted at $5-8^{\circ} \mathrm{C}, 25^{\circ} \mathrm{C}$ and $40^{\circ} \mathrm{C}$.

\subsection{Rheological characterization}

Rheological characterization was conducted using an Anton Paar Physica MCR 100 (Anton Paar, Graz, Austria) plate-plate rheometer (cone diameter $25 \mathrm{~mm}$ ) at a temperature of $25^{\circ} \mathrm{C}$ and a gap size of $1 \mathrm{~mm}$. Amplitude sweep tests were performed over an amplitude range of 0.01 to $1000 \%$ at an angular frequency of $1 \mathrm{~Hz}$. 


\subsection{Extraction}

In order to analyze long term protein stability, the protein was extracted from the nonaqueous vehicles. The dispersions were transferred into $15 \mathrm{ml}$ centrifuge tubes (Greiner BioOne, Kremsmuenster, Austria), filtered isooctane (PTFE syringe Filter $0.22 \mu \mathrm{m}$, VWR, Radnor, USA) was added to a final volume of $14 \mathrm{ml}$, the tubes were vortexed and were then centrifuged at $1000 \mathrm{rpm}$ for $3 \mathrm{~min}$. The supernatant was then removed. This procedure was repeated 5 times, except for removal of petrolatum (10 times). The tubes were then placed in a VTS-2 vacuum drier (Memmert, Schwabach, Germany) for 2 days at 100 mbar in order to remove remaining isooctane. Obtained powders were subsequently reconstituted in HPW.

\subsection{SEC}

Protein stability was analyzed after reconstitution by HP-SEC using an Agilent 1100 with UV detection at $280 \mathrm{~nm}$ (Agilent Technologies, Santa Clara, USA) equipped with a TSKgel G3000SWXL column (Tosoh, Tokyo, Japan). As an eluent a $100 \mathrm{mM}$ phosphate, $100 \mathrm{mM}$ sulfate buffer at pH 6.8 was used at a flow rate of $0.5 \mathrm{ml} / \mathrm{min}$. The buffer was filtered before use employing a Sartorius pressure vessel equipped with a Sartorius $0.2 \mu \mathrm{m}$ cellulose acetate membrane filter (Sartorius, Goettingen, Germany).

\subsection{ELISA}

An enyzme-linked immunosorbent assay (ELISA) was used to determine etanercept binding activity after storage. For this purpose, an Immunoguide ${ }^{\circledR}$ Enzyme immunoassay for the quantitative determination of free etanercept in serum and plasma was used according to manufacturer's instructions (Tani Medikal, Ankara, Turkey). 


\section{Results and discussion}

\subsection{Corneal drug delivery using protein powder suspensions and the effect of sodium caprate}

Suspensions in $\mathrm{F} 6 \mathrm{H} 8$ and the respective aqueous solution were pipetted on the mounted porcine eyes. While the $\mathrm{F} 6 \mathrm{H} 8$ suspensions spread easily over the cornea, aqueous formulations had to be manually spread using the pipette to cover the whole cornea. Protein concentrations in the cornea were analyzed after $4 \mathrm{~h}$ incubation time.

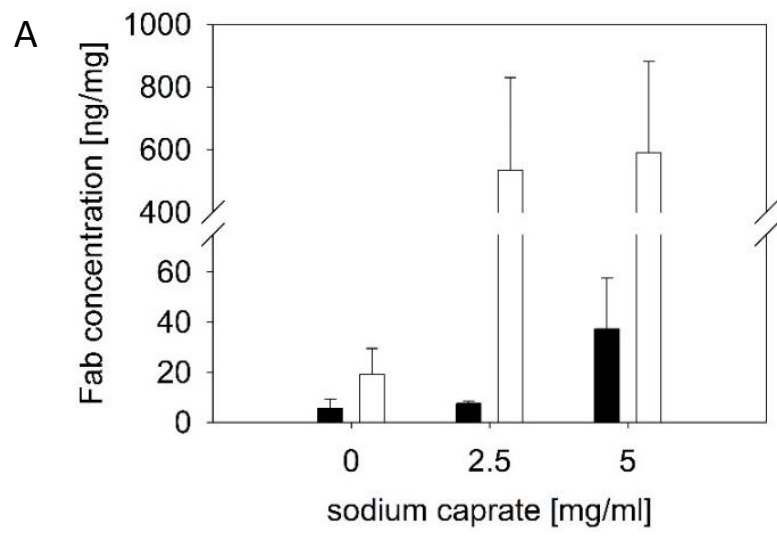

Figure VII-1: Protein concentration in the cornea as a function of sodium caprate concentration after application of aqueous solution ( $\square$ ) or suspension in $\mathrm{F} 6 \mathrm{H} 8(\square)$. Applied formulations contained $5 \mathrm{mg} / \mathrm{ml} \mathrm{Fab} \mathrm{(A)} \mathrm{or} \mathrm{mAb}(\mathrm{B})$.

The amount of Fab and mAb penetrated into the cornea was increased when the protein powder suspensions were used compared to the respective aqueous solutions. Sodium caprate drastically increased the amount of protein that penetrated into the corneal tissue for aqueous formulations as well as suspensions (Figure VII-1). The penetration enhancing effect of sodium caprate is a consequence of its ability to reversibly open tight junctions in the epithelium. ${ }^{34}$ The tight junctions in the corneal epithelium are the main barrier for large molecular weight therapeutic molecules such as proteins. ${ }^{22,23}$ The penetration enhancing effect was more pronounced, when the protein and the penetration enhancer were formulated in a F6H8 suspension. Interestingly, a dose-dependency in the enhancement of protein penetration was seen for the aqueous formulation when comparing formulations containing either 2.5 or $5 \mathrm{mg} / \mathrm{ml}$ sodium caprate. Contrarily, the enhancement effect was the same for both sodium caprate concentrations in the F6H8 suspensions. This suggests, lower 
amounts of potentially cornea damaging penetration enhancer are sufficient for the SFA suspensions approach. ${ }^{35}$ Previous work, using $5 \mathrm{mg} / \mathrm{ml}$ of sodium caprate as a formulation enhancer in an aqueous solution resulted in an increase of corneal thickness of rabbit eyes, which might be related with decreased cell viability. ${ }^{36}$ On the contrary, another study showed no histological effect on pig and human corneal epithelium at the same sodium caprate concentration..$^{25}$ The findings indicate, that the concentration of the penetration enhancer has to be kept as low as possible in order to allow long-term application of the ocular formulation. Besides the vehicle and the penetration enhancer concentration, the size of the protein had a massive influence on the amount penetrated into the cornea (Figure VII-1). This is an interesting finding, as there is a current trend in therapy of ocular diseases towards proteins of smaller size compared to traditional monoclonal antibodies and fusion proteins. Examples include brolucizumab, a single-chain antibody fragment of $26 \mathrm{kDa}$ and cenegermin with 13.3 kDa. Smaller proteins usually show better tissue permeation and are thus more suitable for topical drug delivery. ${ }^{37}$

An eye irritation test was conducted using a model consisting of stratified human keratinocytes. The test indicates a non-irritating formulation, if the viability of the cells after incubation is larger than $60 \%$ referred to tissue treated with the negative control sample. Suspensions containing either 5 or $10 \mathrm{mg} / \mathrm{ml}$ sodium caprate in $\mathrm{F} 6 \mathrm{H} 8$ were tested. Both tested formulations were classified non-irritating confirming the potential of sodium caprate for advanced protein delivery to the cornea (cell viability after incubation ( $c_{\text {sodium caprate }}$ ): $87 \%$ $(5 \mathrm{mg} / \mathrm{ml}) ; 87 \%(10 \mathrm{mg} / \mathrm{ml}))$.

\subsection{Ointments for topical ocular drug delivery}

A big challenge for topical ocular drug delivery is a short residence time of eye drops contributing to a low penetration into the target tissue. ${ }^{27}$ The precorneal residence time can be prolonged with the use of ocular ointments based on hydrocarbon mixtures such as white petrolatum and liquid paraffin decreasing the drainage rate of the formulation. ${ }^{28,29}$

Tumor necrosis factor $\alpha$ (TNF $\alpha$ ) inhibitors such as etanercept and infliximab have been suggested for topical applications due to their improvement of wound healing. ${ }^{9,13} \mathrm{~A}$ study by Ferrari et al. showed the potential of infliximab eye drops in the treatment of corneal surface scarring. ${ }^{13}$ 
MAb and etanercept ointments were prepared by dispersing milled lyophilizates in different non-aqueous vehicles and vehicle mixtures accordingly (see 3.20). The protein powders were cryogenic-milled as described previously (Chapter III) and showed the typical shed like morphology (Figure VII-2). No drastic differences in powder particle sizes were detected between cryogenic milled mAb and etanercept powders (D5/D50/D95 in $\mu \mathrm{m}-\mathrm{mAb}: 3.1 \pm 0.3$ / $9.5 \pm 0.7 / 20.3 \pm 1.7$; etanercept: $3.5 \pm 0.1 / 11.0 \pm 0.5 / 25.7 \pm 1.6)$.
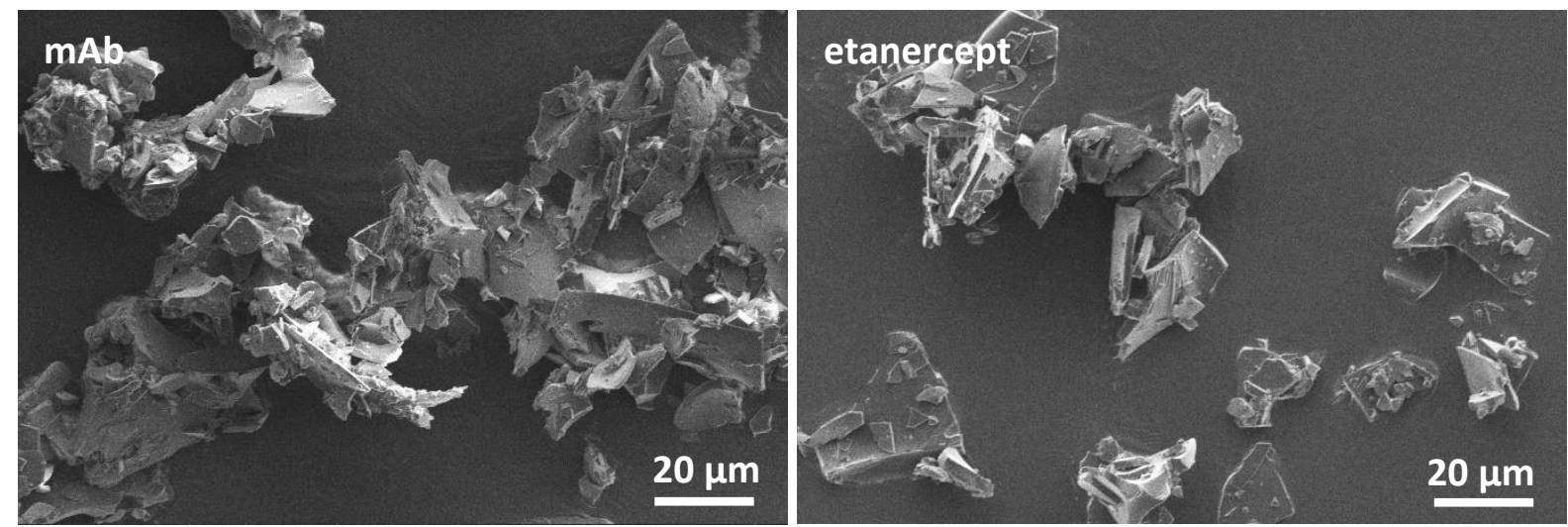

Figure VII-2: SEM images of cryogenic milled mAb and etanercept lyophilizates.

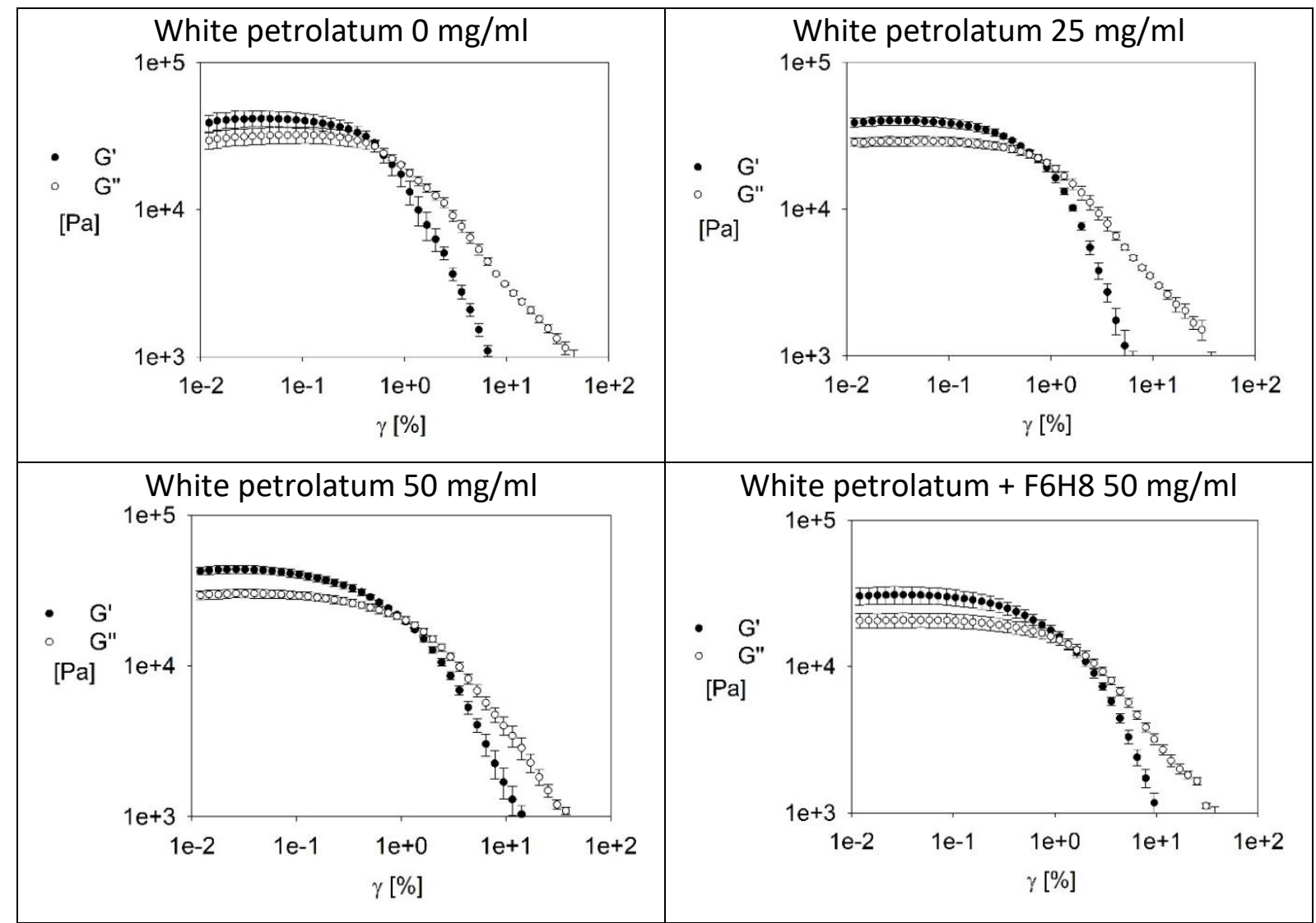

Figure VII-3: Amplitude sweep tests of white petrolatum formulations containing either 0, 25 or $50 \mathrm{mg} / \mathrm{ml}$ protein. 


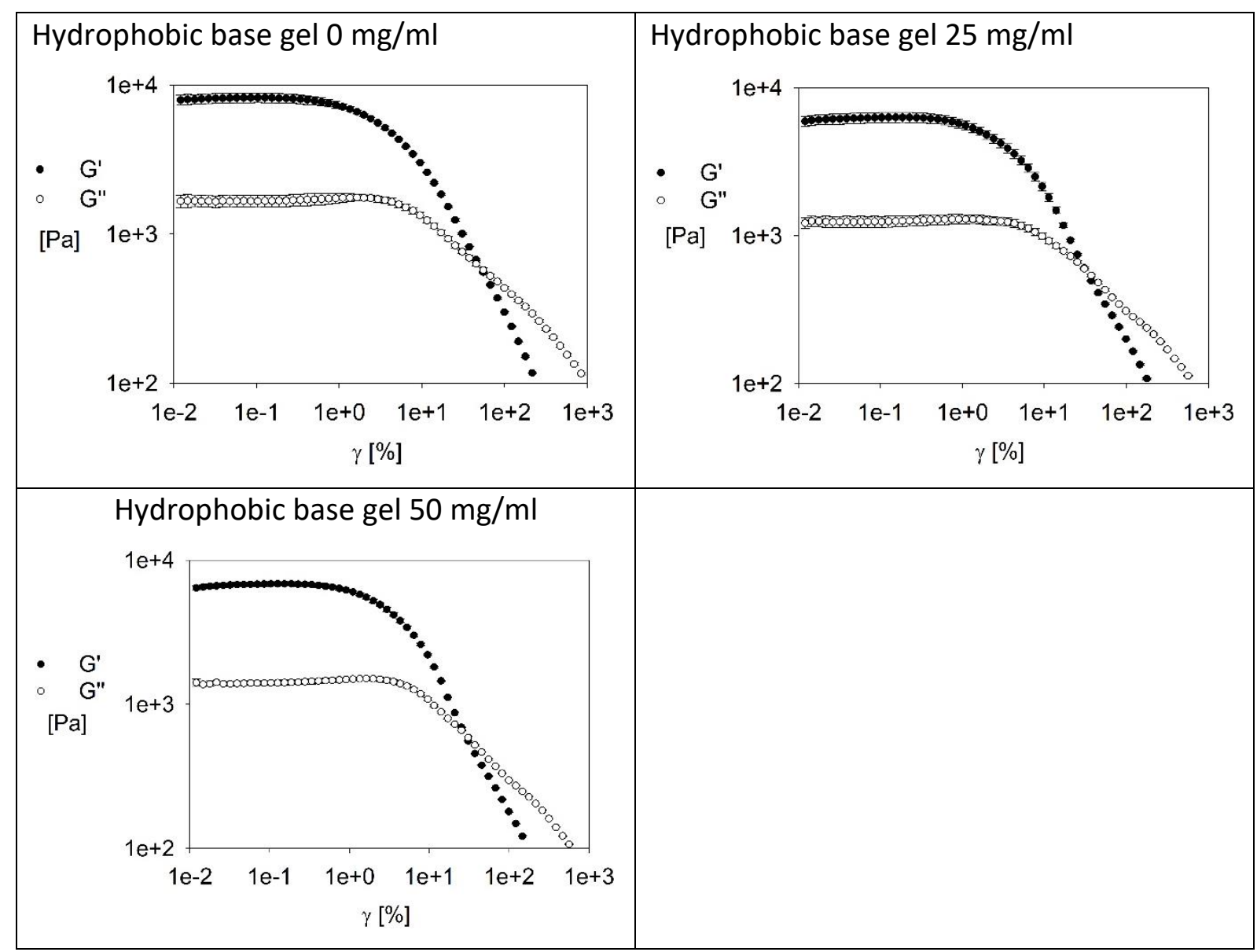

Figure VII-4: Amplitude sweep tests of hydrophobic base gel formulations containing either 0, 25 or $50 \mathrm{mg} / \mathrm{ml}$ protein.

The storage ( $\mathrm{G}^{\prime}$ ) and loss moduli ( $\mathrm{G}^{\prime \prime}$ ) of petrolatum and hydrophobic base gel based ointments were analyzed upon exposure to an increasing shear strain (Figure VII-3/-4). Amplitude sweep tests reveal valuable information about physicochemical characteristics of ointments such as $\mathrm{G}^{\prime}$ in the linear viscoelastic region (LVE region), yield stress $\left(\tau_{\mathrm{y}}\right)$ and cross over modulus (Table VII-3). ${ }^{30,38}$ At low shear strains, all formulations showed a linear viscoelastic behaviour (LVE region), with solid-like properties and G' higher than G" (Figure VII-3/-4). ${ }^{30,38}$ Increasing the strain, lead to loss of the internal structure of the ointments, shear thinning and a rapid decrease of both $G^{\prime}$ and $G^{\prime \prime}$. At higher strains $G^{\prime \prime}$ exceeds $G^{\prime}$ indicating domination of viscous flow. ${ }^{30}$ Thus, all formulations exhibit a typical gel character. ${ }^{38}$ This behaviour is important for ocular ointments, as upon application the elastic nature dominates and the gel does not flow away, whereas blinking of the eye lid with higher shear stress makes the ointment spread easily. ${ }^{29,39}$ 
Table VII-3: Physicochemical characteristics of ointments based on dispersions of mAb powder in white petrolatum and hydrophobic base gel containing 0 to $50 \mathrm{mg} / \mathrm{ml} \mathrm{mAb}$.

\begin{tabular}{|l|c|c|c|}
\hline Formulation & $\begin{array}{c}\text { G' in the LVE } \\
\text { region [Pa] }\end{array}$ & $\begin{array}{c}\text { Cross over } \\
\text { modulus [Pa] }\end{array}$ & $\begin{array}{c}\text { Yield stress }\left(\tau_{\mathrm{y}}\right) \\
{[\mathrm{Pa}]}\end{array}$ \\
\hline White petrolatum $0 \mathrm{mg} / \mathrm{ml}$ & $40550 \pm 6170$ & $24692 \pm 6212$ & $81.9 \pm 3.5$ \\
\hline White petrolatum $25 \mathrm{mg} / \mathrm{ml}$ & $39152 \pm 3472$ & $22457 \pm 3506$ & $66.7 \pm 2.0$ \\
\hline White petrolatum $50 \mathrm{mg} / \mathrm{ml}$ & $42775 \pm 3135$ & $20765 \pm 2490$ & $50.1 \pm 3.3$ \\
\hline $\begin{array}{l}\text { White petrolatum + F6H8 } \\
50 \mathrm{mg} / \mathrm{ml}\end{array}$ & $30339 \pm 5009$ & $13866 \pm 2077$ & $51.1 \pm 0.9$ \\
\hline Hydrophobic base gel $0 \mathrm{mg} / \mathrm{ml}$ & $8114 \pm 732$ & $585 \pm 52$ & $51.1 \pm 2.8$ \\
\hline Hydrophobic base gel $25 \mathrm{mg} / \mathrm{ml}$ & $6183 \pm 597$ & $590 \pm 56$ & $48.8 \pm 8.9$ \\
\hline Hydrophobic base gel $50 \mathrm{mg} / \mathrm{ml}$ & $6703 \pm 288$ & $631 \pm 6$ & $50.8 \pm 4.4$ \\
\hline
\end{tabular}

Adding the mAb powder to the gels did not affect G' in the LVE region (Table VII-3). Addition of $\mathrm{F} 6 \mathrm{H} 8$ to the white petrolatum formulation resulted in a decrease of $\mathrm{G}^{\prime}$. Ointments based on white petrolatum showed higher $G^{\prime}$ values compared to hydrophobic base gel formulations thus exhibiting a higher gel strength. ${ }^{31,38}$

The cross over modulus describes the transition from solid to liquid like physicochemical behaviour $\left(G^{\prime}=G^{\prime \prime}\right)$. A higher cross over modulus has been previously correlated with lower drug release kinetics from ointments. ${ }^{30,31}$ The higher cross over moduli found for white petrolatum formulations, suggest a potentially slower release compared to the hydrophobic base gel formulations. The amount of dispersed mAb powder did not influence the cross over modulus, while the addition of $\mathrm{F} 6 \mathrm{H} 8$ led to a decrease, indicating faster release kinetics.

The yield stress is an important characteristic for ointments and describes the shear stress which has to be applied to initiate the transition from elastic to plastic deformation of the sample. ${ }^{31}$ This is important for the physicochemical behaviour of the formulation including spreadability on the eye, due to eyelid blinking, patient sensation and ease of filling into the primary packaging container. ${ }^{29,31}$ The shear stress, which the ointment is exposed to on the ocular surface, due to eyelid blinking has been estimated to be approximately $3 \mathrm{kPa} .{ }^{40} \mathrm{As}$ all investigated formulations featured a yield stress way below $3 \mathrm{kPa}$, they are considered to spread easy on the ocular surface by blinking of the eye lid (Table VII-3). The yield stresses for white petrolatum ointments decreased with increasing powder concentration from $82 \mathrm{~Pa}$ (no 
powder) to $50 \mathrm{~Pa}(100 \mathrm{mg} / \mathrm{ml}$ lyophilizate). The addition of SFA did not influence the yield stress. Hydrophobic base gel containing ointments featured a yield stress of approximately 50 Pa regardless of the powder concentration.

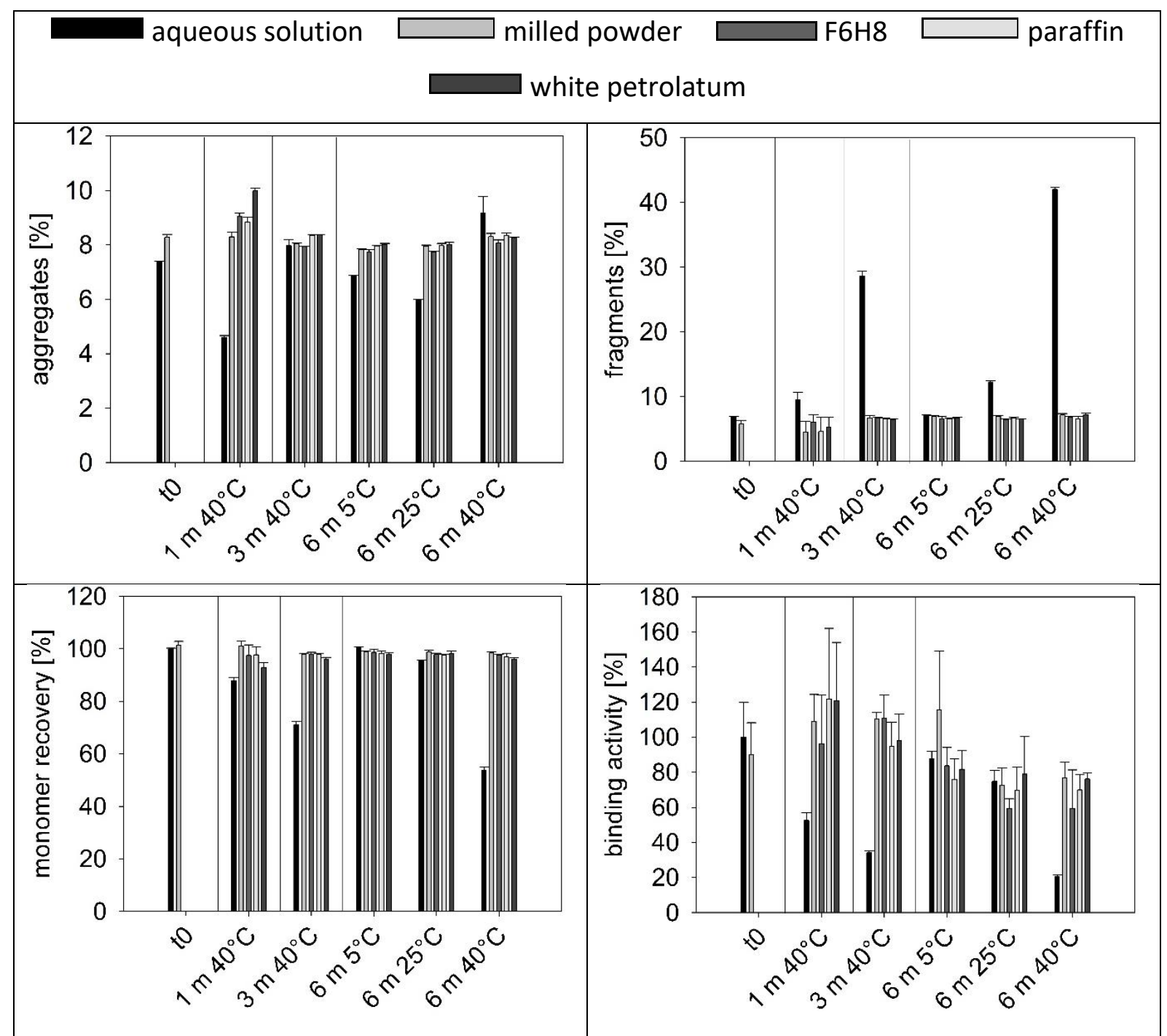

Figure VII-5: Etanercept stability after storage analyzed by SEC and ELISA. Formulations contained $5 \mathrm{mg} / \mathrm{ml}$ etanercept in aqueous solution, powder stored in absence of a vehicle or dispersed in $\mathrm{F} 6 \mathrm{H} 8$, paraffin or white petrolatum.

Ointments did not show signs of soluble aggregate formation after 6 months of storage at 5, 25 or $40^{\circ} \mathrm{C}$ (Figure VII-5). Furthermore no change in the amount of soluble aggregates was detected in the aqueous solution after 6 months of storage at $5^{\circ} \mathrm{C}$. After 1 month at $40^{\circ} \mathrm{C}$ and 6 months at $25^{\circ} \mathrm{C}$ a decrease in the amount of soluble aggregates was detected in the aqueous solution, which might be explained by the formation of larger insoluble protein aggregates. 
The fragment content did not change in the powder upon storage. In the aqueous solution fragmentation was not detected after 6 months at $5^{\circ} \mathrm{C}$, while increased fragment levels were observed after 6 months at $25^{\circ} \mathrm{C}$ and 3 months at $40^{\circ} \mathrm{C}$ (Figure VII-5). Fragmentation as a major instability reaction of etanercept has been described before and is especially pronounced at elevated temperatures. ${ }^{41}$ Only a small monomer loss was found in etanercept powder formulations ( $2-4 \%$ ) after 6 months of storage at $40^{\circ} \mathrm{C}$, while a drastic monomer loss (46\%) was detected in the aqueous solution.

After 6 months of storage minimal loss in binding activity was found for the aqueous solution and the etanercept powder formulations when stored at 5 or $25^{\circ} \mathrm{C}$, while no differences between the formulations were found (Figure VII-5). Already after 1 and 6 months storage at $40^{\circ} \mathrm{C}$, the aqueous etanercept formulation showed a drastic decrease in binding activity to approximately $50 \%$ and $20 \%$, respectively. Contrarily, the powder formulations did not show a change after 1 month and still high binding activity of 60 to $80 \%$ after 6 months storage could be detected. Overall superior etanercept stability in the powder formulations was achieved compared to the aqueous marketed formulation. This confirms previous findings in the field of protein powder suspensions featuring increased protein stability. ${ }^{17,42,43}$ No differences were detected in the various vehicles featuring a comparable stability as the powder stored in absence of a vehicle. These results combined with the ideal rheological characteristics further confirm the high potential of topical protein delivery with dispersions of protein powders in non-aqueous vehicles such as white petrolatum, paraffin and $\mathrm{F} 6 \mathrm{H} 8$. 


\section{Conclusion}

Topical ocular protein formulations based on aqueous solutions face different challenges such as limited protein stability as well as low bioavailability due to poor protein penetration into the target tissue and short residence time. In this study different techniques were investigated to counteract these draw-backs. In the first part protein powder suspensions were prepared in SFAs and the influence of sodium caprate as a penetration enhancer was tested in a porcine ex vivo cornea penetration model. In the second part ointments were prepared to increase ocular residence time and protein stability.

Powder suspensions in $\mathrm{F} 6 \mathrm{H} 8$ effectively delivered $\mathrm{Fab}$ and $\mathrm{mAb}$ to the cornea. The amount of protein penetrated into the porcine cornea was increased for the protein powder suspensions compared to the respective aqueous solutions. The size of protein had a strong influence on permeation resulting in enhanced penetration of the smaller Fab fragment as compared to the mAb. This should be taken into account and single chain antibody fragments or growth factors such as cenegermin may be preferred over larger full mAbs. The addition of the penetration enhancer sodium caprate substantially increased the protein permeation into the cornea. This can be explained by reversible opening of tight junctions by sodium caprate. The effect was more pronounced when the protein was applied in suspensions in F6H8. In future experiments even lower amounts of penetration enhancer in a $\mathrm{F} 6 \mathrm{H} 8$ suspension than the ones tested in this study should be evaluated as the penetration enhancer might have an irritating effect on the corneal epithelium. Nevertheless, no signs of corneal damage were detected when testing relevant sodium caprate suspensions in $\mathrm{F} 6 \mathrm{H} 8$ in an eye irritation test based on stratified human keratinocytes. Besides in vivo testing in animal models, future results should also include a closer examination on penetration behaviour into the corneal tissue for example by applying fluorescent confocal microscopy.

In the second part of the study, ointment formulations were prepared, which offer a potential strategy to counteract short residence times and thus low bioavailability of topically applied protein drugs. The semi-solid preparations consisted of mAb powders dispersed in either hydrophobic base gel, white petrolatum or a mixture of white petrolatum and F6H8. All formulations, with powder concentrations up to $100 \mathrm{mg} / \mathrm{ml}\left(c_{\mathrm{mAb}}=50 \mathrm{mg} / \mathrm{ml}\right)$, showed ideal rheological ointment characteristics. At low strains the ointments featured a viscoelastic solid behaviour and upon increasing the shear stress viscoelastic liquid behaviour was present. These results indicate, that the ointments do not flow out of the container or out of the eye 
after topical application, but spread easily when a shear stress is applied for example by the blinking reflex of the eyelid. ${ }^{31}$ Long term stability of etanercept powder stored in white petrolatum, liquid paraffin and $\mathrm{F} 6 \mathrm{H} 8$ was superior compared to protein stored in the marketed aqueous buffer composition.

Both approaches are applicable as a platform technology for proteins. The investigated dispersions of protein powders in non-aqueous vehicles represent promising formulation strategies to improve topical ocular delivery of proteins by increased penetration, residence time and thus bioavailability as well as increased protein stability. Furthermore, a potential combination of protein eye drops with protein ointments, for application during day or night time, would be interesting, as often seen for antibiotics. Additionally, the described formulation approaches cannot only be used for topical eye delivery, but also for other target tissues such as topical skin or mucosal delivery. 


\section{References}

1. Gervasi, V. et al. Parenteral protein formulations: An overview of approved products within the European Union. Eur. J. Pharm. Biopharm. 131, 8-24 (2018).

2. Hamuro, L. et al. Perspectives on Subcutaneous Route of Administration as an Immunogenicity Risk Factor for Therapeutic Proteins. J. Pharm. Sci. 106, 2946-2954 (2017).

3. Viola, M. et al. Subcutaneous delivery of monoclonal antibodies: How do we get there? J. Control. Release 286, 301-314 (2018).

4. Usmani, S. S. et al. THPdb: Database of FDA-approved peptide and protein therapeutics. PLoS One 12, 1-12 (2017).

5. Vijan, S., Hayward, R. A., Ronis, D. L. \& Hofer, T. Brief report: The burden of diabetes therapy: Implications for the design of effective patient-centered treatment regimens. J. Gen. Intern. Med. 20, 479-482 (2005).

6. Jin, J., Sklar, G. E., Min Sen Oh, V. \& Li, S. C. Factors affecting therapeutic compliance: A review from the patient's perspective. Threrapeutics Clin. Risk Manag. 4, 269-286 (2008).

7. Choonara, B. F. et al. A review of advanced oral drug delivery technologies facilitating the protection and absorption of protein and peptide molecules. Biotechnol. Adv. 32, 1269-1282 (2014).

8. Bruno, B. J., Miller, G. D. \& Lim, C. S. Basics and recent advances in peptide and protein drug delivery. Ther. Deliv. 4, 1443-1467 (2014).

9. Streit, M., Beleznay, Z. \& Braathen, L. R. Topical application of the tumour necrosis factor- $\alpha$ antibody infliximab improves healing of chronic wounds. Int. Wound J. 3, 171179 (2006).

10. Bock, F., König, Y., Kruse, F., Baier, M. \& Cursiefen, C. Bevacizumab (Avastin) eye drops inhibit corneal neovascularization. Graefe's Arch. Clin. Exp. Ophthalmol. 246, 281-284 (2008).

11. Lambiase, A. et al. Nerve growth factor promotes corneal healing: Structural, biochemical, and molecular analyses of rat and human corneas. Investig. Ophthalmol. Vis. Sci. 41, 1063-1069 (2000).

12. Lambiase, A., Rama, P., Bonini, S., Caprioglio, G. \& Aloe, L. Topical Treatment with Nerve Growth Factor for Corneal Neurotrophic Ulcers. N. Engl. J. Med. 338, 1174-1180 (1998).

13. Ferrari, G., Bignami, F., Giacomini, C., Franchini, S. \& Rama, P. Safety and efficacy of topical infliximab in a mouse model of ocular surface scarring. Investig. Ophthalmol. Vis. Sci. 54, 1680-1688 (2013).

14. Vann, R. R. \& Karp, C. L. Perilesional and topical interferon alfa-2b for conjunctival and corneal neoplasia. Ophthalmology 106, 91-97 (1999).

15. Colin, J., Chastel, C., Renard, G. \& Cantell, K. Combination therapy for dendritic keratitis with human leukocyte interferon and acyclovir. Am. J. Ophthalmol. 95, 346-348 (1983). 
16. ANNEX I - SUMMARY OF PRODUCT CHARACTERISTICS for Oxervate, https://ec.europa.eu/health/documents/communityregister/2017/20170706138232/anx_138232_en.pdf, accessed on Dec 14th 2018.

17. Guenther, B. et al. EP2806886B1 - Stabilised protein compositions based on semifluorinated alkanes. (2013).

18. Gesche, G., Bernhard, G., Dieter, S. \& Anthony, P. EP3024484A1 - Stabilized antibody compositions. (2016).

19. Dutescu, R. M., Panfil, C., Merkel, O. M. \& Schrage, N. Semifluorinated alkanes as a liquid drug carrier system for topical ocular drug delivery. Eur. J. Pharm. Biopharm. 88, 123-128 (2014).

20. Agarwal, P., Scherer, D., Günther, B. \& Rupenthal, I. D. Semifluorinated alkane based systems for enhanced corneal penetration of poorly soluble drugs. Int. J. Pharm. 538, 119-129 (2018).

21. Meinert, H. \& Roy, T. Semifluorinated alkanes - A new class of compounds with outstanding properties for use in ophthalmology. Eur. J. Ophthalmol. 10, 189-197 (2000).

22. Mari Hämäläinen, K., Kontturi, K., Auriola, S., Lasse Murtomäki \& Urtti, A. Estimation of pore size and pore density of biomembranes from permeability measurements of polyethylene glycols using an effusion-like approach. J. Control. Release 49, 97-104 (1997).

23. Pescina, S. et al. Permeation of Proteins, Oligonucleotide and Dextrans Across Ocular Tissues: Experimental Studies and a Literature Update. J. Pharm. Sci. 104, 2190-2202 (2015).

24. Williams, K. A. et al. Topically applied antibody fragments penetrate into the back of the rabbit eye. Eye 19, 910-913 (2005).

25. Thiel, M. A. et al. Penetration of engineered antibody fragments into the eye. Clin. Exp. Immunol. 128, 67-74 (2002).

26. Morrison, P. W. J. \& Khutoryanskiy, V. V. Enhancement in corneal permeability of riboflavin using calcium sequestering compounds. Int. J. Pharm. 472, 56-64 (2014).

27. Gaudana, R., Ananthula, H. K., Parenky, A. \& Mitra, A. K. Ocular Drug Delivery. AAPS J. 12, 348-360 (2010).

28. Patel, A., Cholkar, K., Agrahari, V. \& Ashim K, M. Ocular drug delivery systems: An overview. World J Pharmacol 2, 47-64 (2013).

29. Dong, Y. et al. Formulation characteristics and in vitro release testing of cyclosporine ophthalmic ointments. Int. J. Pharm. 544, 254-264 (2018).

30. Bao, Q. et al. Physicochemical attributes and dissolution testing of ophthalmic ointments. Int. J. Pharm. 523, 310-319 (2017).

31. Bao, Q. \& Burgess, D. J. Perspectives on Physicochemical and In Vitro Profiling of Ophthalmic Ointments. Pharm. Res. 35, 1-12 (2018). 
32. Menzen, T. Temperature-Induced Unfolding, Aggregation, and Interaction of Therapeutic Monoclonal Antibodies. (LMU Munich, 2014).

33. Schuele, S. Stabilization of Antibodies in Spray-dried Powders for Inhalation. (LMU Munich, 2005).

34. Soederholm, J. D. et al. Reversible increase in Tight Junction Permeability to Macromolecules in Rat Ileal mucosa In Vitro by Sodium Caprate, a constituent of milk fat. Dig. Dis. Sci. 43, 1547-1552 (1998).

35. Furrer, P., Mayer, J. M., Plazonnet, B. \& Gurny, R. Ocular tolerance of absorption enhancers in ophthalmic preparations. AAPS PharmSci 4, 6-10 (2002).

36. Ottiger, M., Thiel, M. A., Feige, U., Lichtlen, P. \& Urech, D. M. Efficient intraocular penetration of topical anti-TNF- $\alpha$ single-chain antibody (ESBA105) to anterior and posterior segment without penetration enhancer. Investig. Ophthalmol. Vis. Sci. 50, 779-786 (2009).

37. Furrer, E. et al. Pharmacokinetics and posterior segment biodistribution of ESBA105, an anti-TNF- $\alpha$ single-chain antibody, upon topical administration to the rabbit eye. Investig. Ophthalmol. Vis. Sci. 50, 771-778 (2009).

38. Grysko, M. \& Daniels, R. Evaluation of the mechanism of gelation of an oleogel based on a triterpene extract from the outer bark of birch. Pharmazie 68, (2013).

39. Park, E. \& Song, K. Rheological evaluation of petroleum jelly as a base material in ointment and cream formulations with respect to rubbing onto the human body. KoreaAustralia Rheol. J. 22, 279-289 (2010).

40. $\mathrm{Xu}, \mathrm{X}$. et al. Formulation and process factors in $\mathrm{fl}$ uencing product quality and in vitro performance of ophthalmic ointments. Int. J. Pharm. 493, 412-425 (2015).

41. Lim, D. G. et al. Evaluation of etanercept stability as exposed to various sugars with biophysical assessment. Int. J. Pharm. 476, 50-59 (2014).

42. Knepp, V. M., Muchnik, A., Oldmark, S. \& Kalashnikova, L. Stability of nonaqueous suspension formulations of plasma derived factor IX and recombinant human alpha interferon at elevated temperatures. Pharm. Res. 15, 1090-1095 (1998).

43. Weiguo Dai, Beth Hill, Kui Liu, C. M. US 20120076800 - Non-aqueous high concentration reduced viscosity suspension formulations of antibodies. (2012). 



\section{Chapter VIII}

\section{Summary of the thesis}

Protein powder suspensions in non-aqueous vehicles represent an innovative and promising formulation technique. They combine the ready-to-use approach of an aqueous solution with the increased protein stability of lyophilizates. The development and preparation of therapeutic proteins in powder suspensions is a task with various challenges regarding formulation, manufacturing and stability. For manufacturing of the protein powder different techniques are applicable, with spray-drying and freeze-drying with subsequent milling representing the most promising approaches. The vehicle selection is of key importance as it should not negatively impact product stability, ensure biocompatibility and offer appropriate formulation viscosity.

In Chapter III it was tested, if milling can render mAb powders with suitable powder characteristics for the use in non-aqueous suspensions. Three different milling techniques, wet media milling, dry milling and cryogenic milling were compared. Protein powder suspensions obtained by wet media milling were easily injectable through a 25 or a $26 \mathrm{G}$ needle, but substantial protein damage was detected. Dry milling too led to drastic damage to the protein. In contrast, cryogenic ball milling resulted in good preservation of protein integrity during the micronization process. Protein damage was decreased with optimized process parameters including a decreased milling frequency, use of smaller milling balls and applying only minimal milling time. Also, at high mAb to sugar ratios, protein integrity during milling was preserved, which is of importance with regard to high concentration protein formulations. In order to prepare injectable suspensions, an additional sieving step of the milled powders was necessary to prevent needle clogging.

An alternative protein powder preparation technique is spray-drying, which was successfully assessed in Chapter IV. This chapter focussed on studying high concentration protein powder suspensions in non-aqueous vehicles. The two semifluorinated alkanes (SFAs) perfluorobutylpentane (F4H5) and perfluorohexyloctane (F6H8) were identified and tested as vehicles for such preparations and the suspensions were compared to the respective aqueous solutions. The suspensions were injectable through a $27 \mathrm{G}$ needle up to $280 \mathrm{mg} / \mathrm{ml} \mathrm{mAb}$ or 
lysozyme representing a total powder concentration of $400 \mathrm{mg} / \mathrm{ml}$. Especially at high mAb concentrations (above $200 \mathrm{mg} / \mathrm{ml}$ ), suspensions in the two tested SFAs were superior over aqueous solutions in terms of viscosity and glide force. Traditional non-aqueous vehicles for pharmaceutical suspensions such as medium chain triglycerides (MCT) and sesame oil (SO) showed high viscosities and inacceptable glide forces using a $27 \mathrm{G}$ needle. Suspensions prepared with spray-dried powders were superior compared to suspensions prepared with milled lyophilizates. While $210 \mathrm{mg} / \mathrm{ml}$ lysozyme suspensions in $\mathrm{F} 6 \mathrm{H} 8$ based on spray-dried powder were easy injectable through a $26 \mathrm{G}$ needle, the corresponding suspension prepared with milled powder led to needle clogging even though this powder was additionally sieved through a $40 \mu \mathrm{m}$ sieve. It was further possible to predict the viscosity and glide force of the suspensions based on the Krieger-Dougherty equation and the Hagen-Poiseuille law. This is of high importance when it comes to selection or development of a suitable container closure system or application device. Protein powder suspensions were syringeable and could be filled using a peristaltic pump, thus featuring the potential for large-scale manufacturing of protein powder suspension.

An important requirement for pharmaceutical dosage forms is their stability over the shelf life. For protein powder suspensions not only stability of the active pharmaceutical ingredient, but also the physical suspension stability is mandatory. These two features were intensively studied in the provided thesis. While Chapter $\mathbf{V}$ focussed on the suspension physical stability, the goal of Chapter VI was to provide knowledge about protein stability with special focus on mAbs. Optimized formulations of lysozyme, mAb or bevacizumab powder suspensions in nonaqueous vehicles feature essential long-term stability. The suspensions were physically stable with respect to resuspendability, particle size as well as injectability through hypodermic needles even at elevated temperatures of $40^{\circ} \mathrm{C}$ for up to a year. An additional drying step of the spray-dried powder was applied, leading to an improved initial dispersing quality. Furthermore, using suspensions containing the powder with the decreased residual moisture prevented recrystallization of the carbohydrate stabilizer. In contrast, dispersed not additionally dried mAb powders showed recrystallization phenomena. Suspensions based on the model protein lysozyme in $\mathrm{F} 4 \mathrm{H} 5, \mathrm{~F} 6 \mathrm{H} 8, \mathrm{EO}$ and $\mathrm{MCT}$ were stable with respect to powder particle size and were injectable through a $27 \mathrm{G}$ needle after 12 months of storage at $40^{\circ} \mathrm{C}$. This was even possible at an increased protein concentration of $210 \mathrm{mg} / \mathrm{ml}$. MAb suspensions in $\mathrm{F} 4 \mathrm{H} 5, \mathrm{~F} 6 \mathrm{H} 8, \mathrm{EO}$ and $\mathrm{MCT}$ and bevacizumab suspensions in $\mathrm{F} 6 \mathrm{H} 8$ and $\mathrm{EO}$ were stable with 
respect to powder particle size and were injectable after 6 months of storage at $40^{\circ} \mathrm{C}$. Results obtained from resuspendability testing showed improved performance of suspensions in the two tested SFAs compared to suspensions in EO or MCT.

Protein stability was tested in $\mathrm{F} 4 \mathrm{H} 5, \mathrm{~F} 6 \mathrm{H} 8, \mathrm{EO}$ and MCT. Suspensions containing the model $\mathrm{mAb}$ or bevacizumab showed high stability for up to 12 months of storage at $40^{\circ} \mathrm{C}$. Best $\mathrm{mAb}$ stability were obtained for mAb:Tre 70:30 powder suspensions in F4H5, F6H8 and MCT. The stability was comparable to the spray-dried powder stored in absence of a suspension vehicle. When the mAb:Tre 70:30 powder was stored in EO, containing oleic acid moieties, a marked damage to the mAb was detected. Decreasing the protein to stabilizer ratio to $50: 50$ in F6H8 suspensions led to a slight improvement in protein stability with regard to soluble aggregates compared to formulations based on a 70:30 ratio. No influence of the packaging material on protein stability, including oxidation, was detected when suspensions were stored either in glass vials or cyclic olefin polymer prefillable syringes. Protein stability was comparable with sucrose and trehalose as stabilizer. Protein powder suspensions benefited substantially from an additional drying step of the spray-dried powder, especially when EO and MCT were used as a suspension vehicle. Bevacizumab stability was studied, comparing the marketed aqueous solution and spray-dried powder/ suspension formulations with the same composition as the marketed drug product. Especially at high temperatures, the powder and suspension formulations showed markedly higher protein stability.

The last experimental chapter focussed on topical ocular delivery using protein powder suspensions. In Chapter VII protein powder suspensions were investigated to tackle challenges common for topical ocular delivery of proteins, such as limited protein stability as well as low bioavailability due to poor protein penetration into the target tissue and short residence time. First, protein powder suspensions in SFAs were prepared and the influence of sodium caprate as a penetration enhancer was tested in a porcine ex vivo cornea penetration model. Secondly, ointments were prepared to increase ocular residence time and protein stability in such formulations was investigated. Powder suspensions in F6H8 effectively delivered $\mathrm{Fab}$ and $\mathrm{mAb}$ to the cornea. The amount of protein penetrated into the porcine cornea was increased for the protein powder suspensions compared to the respective aqueous solutions. The protein size strongly influenced permeation resulting in penetration of the smaller Fab fragment as clearly enhanced compared to the full mAb. The addition of the penetration enhancer sodium caprate substantially increased the protein permeation into 
the cornea, especially when formulated as suspensions in $\mathrm{F} 6 \mathrm{H} 8$ compared to aqueous solutions. In the second part of the study, ointment formulations were prepared, which offer a potential strategy to counteract short residence times and thus low bioavailability of topically applied protein drugs. The semi-solid preparations consisted of mAb powders dispersed in either hydrophobic base gel, white petrolatum or a mixture of white petrolatum and F6H8. All formulations, with mAb concentrations up to $50 \mathrm{mg} / \mathrm{ml}$, showed ideal rheological ointment characteristics. Long-term stability of etanercept powder stored in ointment bases was superior compared to protein stored in the marketed aqueous buffer solution. The investigated dispersions of protein powders in non-aqueous vehicles represent promising formulation strategies to improve topical ocular delivery of proteins by increased penetration, residence time and thus bioavailability, as well as increased protein stability.

Overall the results highlight the potential of protein powder suspension formulations with various beneficial properties including improved stability due to the solid state and low viscosity. Manufacturing of the powders was established by either milling of lyophilizates or spray-drying. Especially the selection of the suspension vehicle was of high importance. The use of semifluorinated alkanes as suspension vehicles proved to yield suspensions with improved properties including easier resuspendability and high protein stability. Such suspensions are not only a valuable option for parenteral applications but also other routes of drug delivery such as their use as topical ocular formulations are promising. Based on the knowledge established in the present thesis, in vivo studies are required as a next step to establish the formulation approach in improved real-world medicines. Furthermore, highly stable and ready-to-use protein powder suspensions in non-aqueous vehicles could contribute substantially to adequate medical care and vaccination quality in low developed countries, where maintenance of the distribution cold chain is not possible. 

$\mathrm{CV}$

\section{Work experience}

Since 06/2019

Abbvie GmbH \& Co. KG, Ludwigshafen - Laboratory head in manufacturing and container closure science

03/2015 - 10/2018 LMU Munich, Department of Pharmacy, Pharmaceutical Technology and Biopharmaceutics in collaboration with Novaliq GmbH \& Co. KG, Heidelberg

02/2016-08/2018 Stadtapotheke, Bad Tölz - Pharmacist in a public pharmacy

05/2014-11/2014 Obere Apotheke, Schwäbisch Gmünd - Internship in a public pharmacy

10/2013-04/2014 F. Hoffmann-La Roche AG, Basel - Internship in the area of formulation research and development

02/2012-05/2012 UCL School of Pharmacy, London - Research internship in the microbiology research group of Prof. Dr. Peter Taylor

08/2011-01/2012 Max Planck Institute for Medical Research, Heidelberg - Student research assistant in the field of biomolecular optics

09/2012 - 10/2012 Abbott GmbH \& Co. KG (now AbbVie GmbH \& Co. KG), Ludwigshafen

$02 / 2011-04 / 2011-$ Internship in the area of quality assurance and quality control

08/2008-07/2009 German Red Cross, Schwäbisch Gmünd - Civil service as an ambulance driver

\section{Education}

Since 03/2015 PhD student in pharmaceutical technology in the group of Prof. Dr.

Wolfgang Frieß at Ludwig-Maximilians-Universität Munich

01/2015 Official license to practice as a pharmacist

WS 2013/2014 Diploma degree in pharmaceutical technology at Albert-Ludwigs-

Universität Freiburg in collaboration with F. Hoffmann-La Roche AG, Basel

WS 2009/2010 - Pharmacy studies at Ruprecht-Karls-Universität Heidelberg SS 2013 


\section{Presentations and Posters associated with this Thesis}

\begin{tabular}{|c|c|}
\hline $05 / 2019$ & $\begin{array}{l}10^{\text {th }} \text { annual Biologics Formulation Development \& Drug Delivery Forum, } \\
\text { Madrid, Spain - Poster: Protein powder suspensions in non-aqueous vehicles, } \\
\text { Christoph Marschall, Madlen Witt, Bernhard Hauptmeier, Wolfgang Frieß }\end{array}$ \\
\hline $06 / 2018$ & $\begin{array}{l}\text { 3rd PDA Europe Annual Meeting 2018, Berlin, Germany - Oral presentation: } \\
\text { Protein powder suspensions in non-aqueous vehicles - A potential alternative } \\
\text { to conventional formulations? }\end{array}$ \\
\hline $06 / 2018$ & $\begin{array}{l}3^{\text {rd }} \text { PDA Europe Annual Meeting 2018, Berlin, Germany - Poster: Protein } \\
\text { powder suspensions in non-aqueous vehicles, Christoph Marschall, Madlen } \\
\text { Witt, Bernhard Hauptmeier, Wolfgang Frieß }\end{array}$ \\
\hline $02 / 2018$ & $\begin{array}{l}11^{\text {th }} \text { World Meeting on Pharmaceutics, Biopharmaceutics and Pharmaceutical } \\
\text { Technology, Granada, Spain - Poster: Protein powder suspensions in non- } \\
\text { aqueous vehicles, Christoph Marschall, Madlen Witt, Bernhard Hauptmeier, } \\
\text { Wolfgang Frieß }\end{array}$ \\
\hline $10 / 2016$ & $\begin{array}{l}\text { DPhG Annual meeting 2016, Munich, Germany - Poster: Protein powder } \\
\text { suspensions based on perfluorodecalin, Christoph Marschall, Ahmed Yasin, } \\
\text { Madlen Witt, Wolfgang Frieß }\end{array}$ \\
\hline $04 / 2016$ & $\begin{array}{l}10^{\text {th }} \text { World Meeting on Pharmaceutics, Biopharmaceutics and Pharmaceutical } \\
\text { Technology, Glasgow, UK - Poster: Ball milling of mAb lyophilizates, Christoph } \\
\text { Marschall, Gesche Graf, Wolfgang Frieß }\end{array}$ \\
\hline
\end{tabular}

